\title{
Phänotypische und molekulare Analyse einer Maus mit Insertionsmutation und axonaler Reorganisation im Hippocampus
}

\author{
Dissertation \\ zur Erlangung des Doktorgrades \\ der Mathematisch-Naturwissenschaftlichen Fakultäten \\ der Georg-August Universität zu Göttingen
}

vorgelegt von

Detlef Böhm

aus Heinebach

Göttingen 2001 
D7

Referent: Prof. Dr. Wolfgang Engel

Korreferent: Prof. Dr. Ulrich Grossbach

Tag der mündlichen Prüfung: $\quad$ 02. Mai 2001 


\section{Inhaltsverzeichnis}

INHALTSVERZEICHNIS

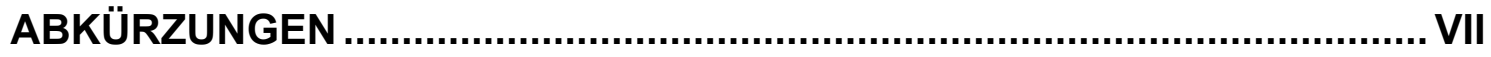

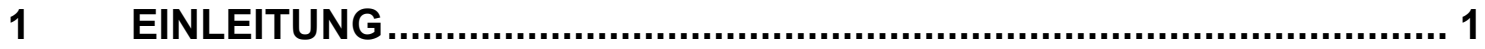

1.1 Ursprung der mutanten TC-Mauslinie und Struktur der verwendeten Konstrukte...............1

1.2 Zur Insertions-Mutagenese bei der Erzeugung transgener Mäuse ..........................................2

1.3 Der Phänotyp der Maus mit Insertionsmutation ...........................................................................3

1.4 Die Hippocampus-Formation: Zytoarchitektur und Konnektivität...........................................4

$1.5 \quad$ Ziele der vorliegenden Arbeit ...................................................................................................

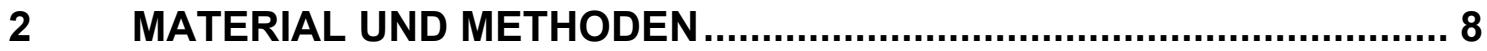

$2.1 \quad$ Chemikalien ..........................................................................................................................

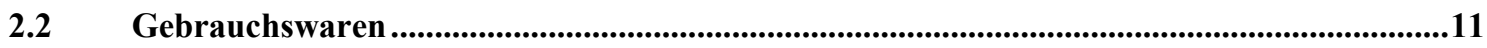

2.3 Stammlösungen, Puffer und Medien............................................................................................11

$2.4 \quad$ Molekulargewichtstandards ...................................................................................................14

2.5 Verwendete Vektoren, Bakterienstämme, Antibiotika und Agarplatten .................................14

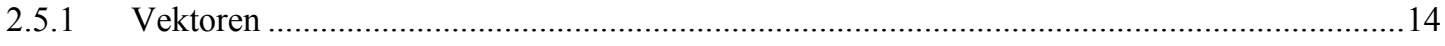

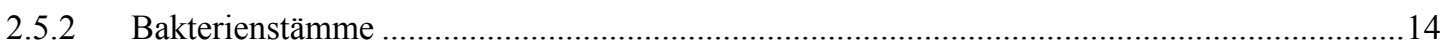

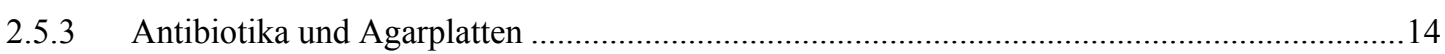

2.6 Gensonden, Oligonukleotide und Antikörper ..........................................................................15

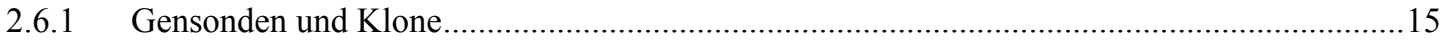

2.6.2 Synthetische Oligonukleotide _.........................................................................................15

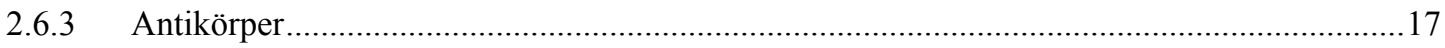

2.7 Eukaryotische Zellinien und Medien ...........................................................................................18

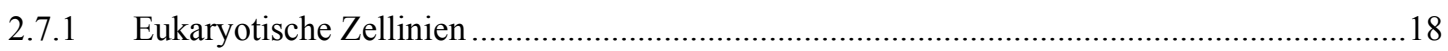

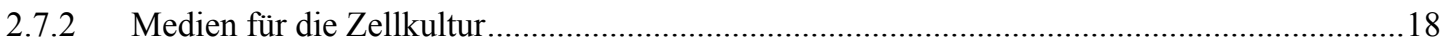


2.10 Methoden zur Isolierung und Konzentrationsbestimmung von Nukleinsäuren 19

2.10.1 Isolierung hochmolekularer genomischer DNA aus Organen ..........................................19

2.10.2 Isolierung von Plasmid-DNA durch Midi- oder Maxipräparation..........................................19

2.10.3 Isolierung von Plasmid-, Cosmid- und PAC-DNA durch Minipräparation .............................20

2.10.4 Isolierung von Cosmid- und PAC-DNA durch Maxipräparation .........................................20

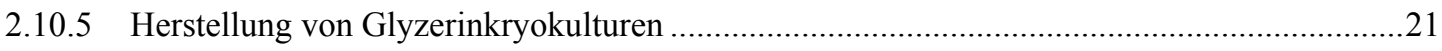

2.10.6 Isolierung von Gesamt-RNA aus Gewebe ....................................................................21

2.10.7 Selektive Anreicherung von mRNA aus Gesamt-RNA Präparationen ..................................22

2.10.8 Konzentrationsbestimmung von Nukleinsäuren ...............................................................22

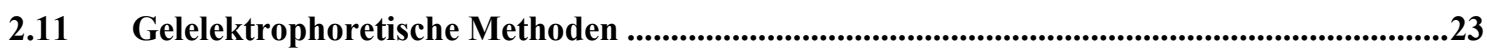

2.11.1 Horizontale Agarose-Gelelektrophorese .........................................................................23

2.11.2 Denaturierende Agarose-Gelelektrophorese ............................................................23

2.11.3 Denaturierende SDS-Polyacrylamid-Gelelektrophorese zur Auftrennung von Proteinen .......24

2.12 Isolierung und Aufreinigung von Nukleinsäurefragmenten

2.12.1 Isolierung und Aufreinigung von DNA-Fragmenten aus Agarosegelen mittels Anionenaustauschersilikat.....

2.13 Techniken der Polymerase-Ketten-Reaktion (PCR) ......................................................26

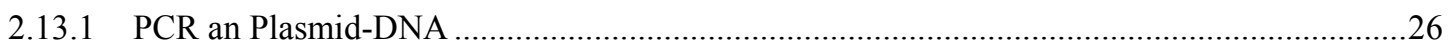

2.13 .2 „Reverse Transkriptions-PCR“ (RT-PCR) ...................................................................27

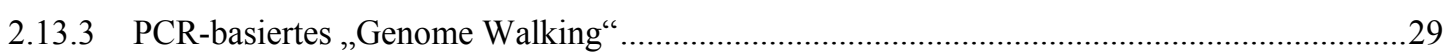

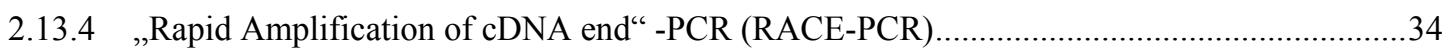

2.14 Subklonierung von DNA-Fragmenten ........................................................................................37

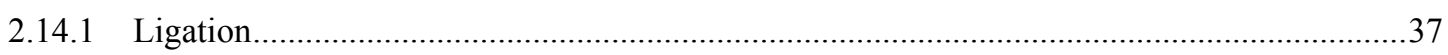

2.14.2 Plasmidtransformation in kompetente Escherichia coli-Zellen .............................................38

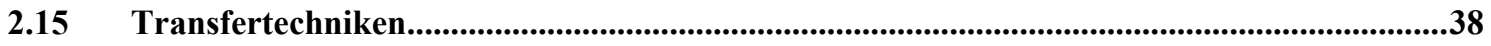

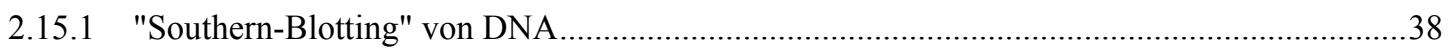

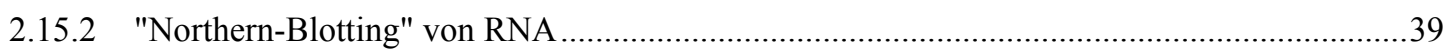

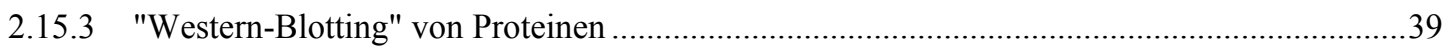

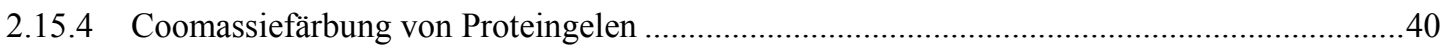


2.16 Enzymatische Modifikationen von Nukleinsäuren ....................................................................40

2.16.1 Spaltung von Plasmid-DNA mit Restriktionsendonukleasen ............................................41

2.16.2 Spaltung von genomischer DNA mit Restriktionsendonukleasen ........................................41

2.16.3 Dephosphorylierungsreaktion mit alkalischer Phosphatase (CIAP) ....................................41

2.16.4 Auffüll- und Glättungsreaktion zur Generierung von „Blunt end”-Fragmenten.....................42

2.16.5 Radioaktive Markierung von DNA-Fragmenten (,random prime labelling") ......................43

2.17 DNA Sequenzanalyse

2.18 Hybridisierungsmethoden ..................................................................................................45

2.18.1 Hybridisierung radioaktiver DNA-Sonden an membrangebundene Nukleinsäuren ................45

2.18.2 Hybridisierung radioaktiver Sonden auf membrangespottete Cosmid- und PAC-Filter der RZPD .46

2.19 Fluoreszenz in situ Hybridisierung (FISH)....................................................................46

2.19.1 Lymphozytenkultur der Maus aus Milzgewebe ..................................................................47

2.19.2 Zellkultur der WMP-1 Zellinie (Zörnig et al. 1995) .........................................................47

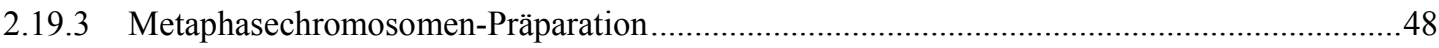

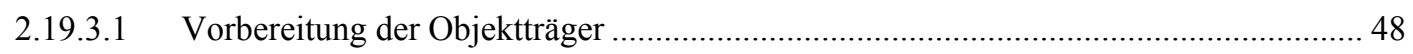

2.19.3.2 Kulturabbruch zur Präparation von Metaphasechromosomen .................................... 48

2.19.4 „Chromosomen-release“ Interphasetechnik nach Senger et al. (1994) .................................49

2.19.5 Vorbehandlung der Chromosomenpräparate .............................................................50

2.19.5.1 RNase A-Behandlung der Chromosomenpräparate …............................................ 50

2.19.5.2 Pepsin-Behandlung der Chromosomenpräparate ..................................................... 51

2.19.5.3 Denaturierung der Chromosomenpräparate ....................................................... 51

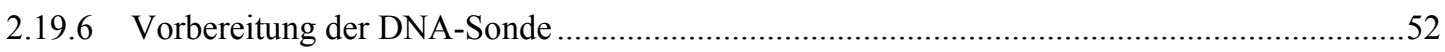

2.19.6.1 Markierung der Sonde über Nicktranslation .............................................................. 52

2.19.6.2 Nachweis des Einbaus von Bio-16-dUTP und Digoxigenin-11-dUTP über Dot-Blot .. 53

2.19.7 Chromosomen-in situ-Supressions-Hybridisierung (CISS) .............................................54

2.19.7.1 Hybridisierungsansatz, Vorhybridisierung und Hybridisierung................................... 54

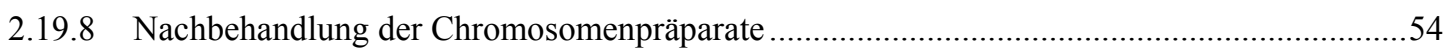

2.19.8.1 Waschen nach der Hybridisierung …................................................................. 55

2.19.8.2 Detektion und Amplifikation der Hybridisierungssignale........................................ 56

2.19.8.3 Gegenfärbung der Chromosomen mit DAPI und Propidiumiodid ................................ 57

2.19.8.4 Auswertung der Chromosomenpräparate ............................................................... 57

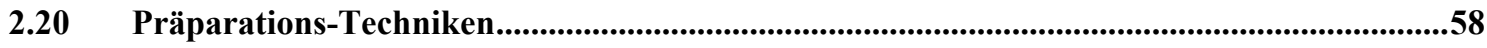

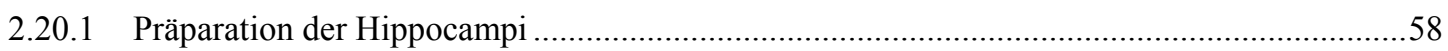


2.21 Extraktion und Konzentrationsbestimmung von Proteinen

2.21.1 Isolierung von Gesamt-Zellysat für Western-Immunoblot .................................................59

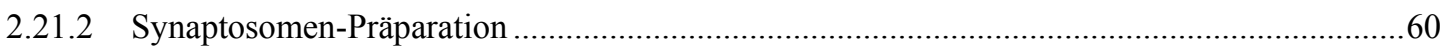

2.21.3 Konzentrationsbestimmung von Proteinen ........................................................................61

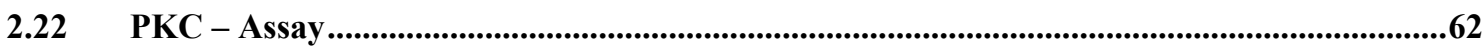

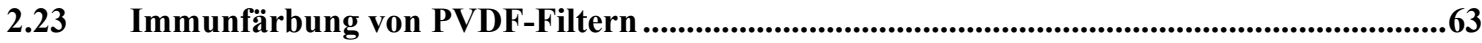

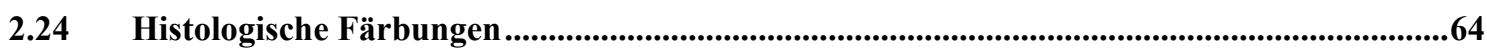

2.24.1 Silber-Sulfid Färbung nach Timm zur Darstellung zinkhaltiger Synapsen in

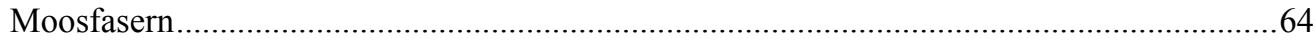

2.24.2 Herstellung Chrom-Kalium-Gelatine beschichteter Objektträger......................................65

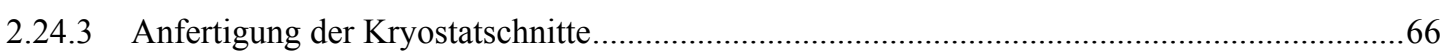

2.24.4 Herstellung von Gummiarabicum .....................................................................................66

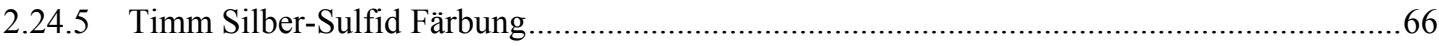

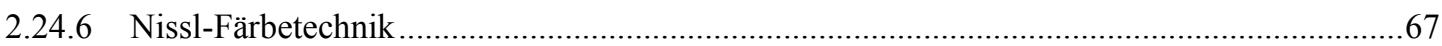

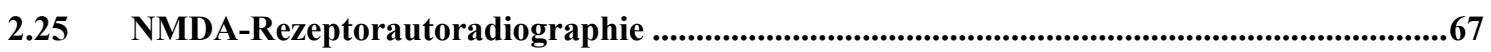

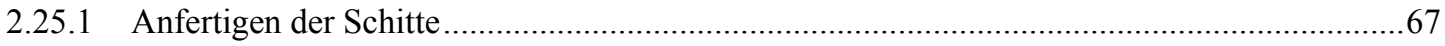

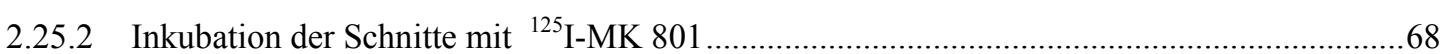

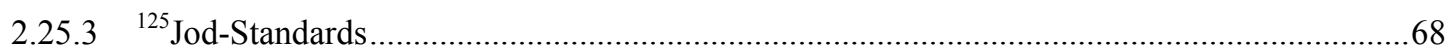

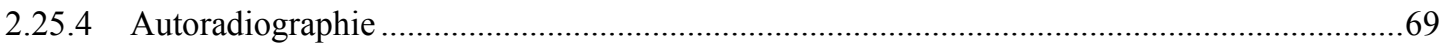

2.25.5 Densitometrische Auswertung der Autoradiogramme ...................................................69

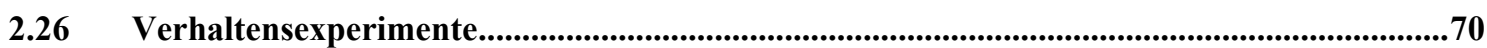

2.26.1 Bewegungsmuster-Aufzeichnung mit Lasermotilimat und „Open-Field““...........................70

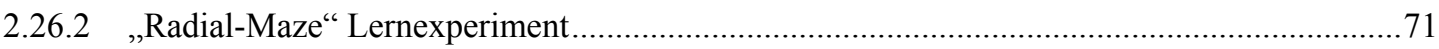

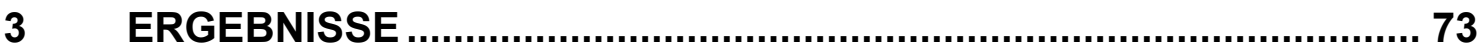

3.1 Die Phänotyp-Analyse der insertionsmutanten TC-Maus ...............................................73

3.1.1 Statistische Analyse der postnatalen Gewichtsentwicklung .................................................73

3.1.2 Statistische Analyse der Wurfgrößen........................................................................... 75

3.1.3 Nachweis von hyperreflektorischem Verhalten nach akustischer Stimulation ......................75

3.1.4 Bewegungsmuster-Analyse der TC-Mausmutante mit Lasermotilimat und „Open-

Field"-Apparatur ..... 
3.1.5 Analyse des Brutpflegeverhaltens der weiblichen homozygoten TC-Maus .80

3.1.6 Untersuchungen zum räumlichen Lernen über die Analyse im Radial-Labyrinth (,Radial Maze“)

3.1.7 Morphologische Untersuchungen der hippocampalen Moosfaser-Entwicklung in der TC-Mauslinie

3.1.8 Immunhistochemische Expressions-Analyse des Calretinin-Proteins im Hippocampus der $\mathrm{TC}^{-/-}$- und Wildtyp-Maus

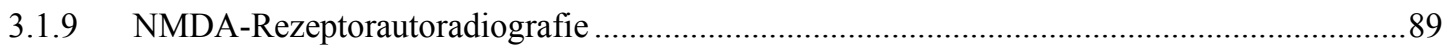

3.1.10 Untersuchungen zur c-fos Expression in der $\mathrm{TC}^{-/-}$-Maus...................................................93

3.1.11 Nachweis pyknotischer Zellkerne und apoptotischer ,,dark neurons“ im Hippocampus der $\mathrm{TC}^{-/-}$-Maus

3.2 Genotypisierung der insertionsmutanten TC-Mauslinie .97

3.2.1 Chromosomale Lokalisierung der transgenen Insertion

3.2.2 Genomische Klonierung der TC-Insertionsregion über „Genome Walking““Experimente 99

3.2.3 Southern-Blot Analyse der TC-Insertionsregion .106

3.2.4 Klonierung und Charakterisierung des Wildtyp-genomischen Bereichs der Insertionsregion. 108

3.2.5 Chromosomale Lokalisierung der isolierten Cosmid- und PAC-Klone. 109

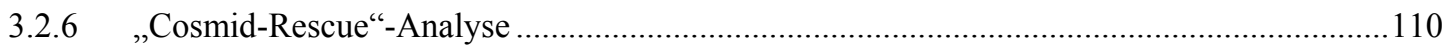

3.2.7 Sequenzanalyse der Cosmid-Endfragmente..................................................................... 112

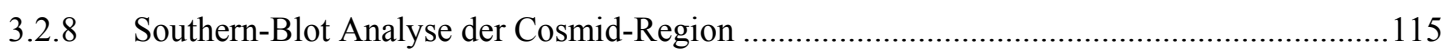

3.2.9 Genomische Klonierung des flankierenden 5'-Bereichs der TC-Insertionsregion über „Genome Walking“-Experiment.

\subsection{Identifizierung, Expressionsanalyse und Klonierung eines SV40-3'UTR}

Fusionstranskripts

3.3.1 Identifizierung und Expressionsanalyse eines Fusionstranskripts mit partieller SV403'UTR-Sonde......

3.3.2 RACE-PCR-Analyse des SV40-3'UTR-Fusionstranskripts

3.3.3 RT-PCR Analyse des SV40-3’UTR-Fusionstranskripts.

3.4 Expressionsanalyse des PLC-ß1 Gens in der TC-Maus ....................................................125

3.4.1 Northern-Blot Analyse der PLC-B1 Expression in der TC-Maus ........................................125

3.4.2 Western-Blot- und immunhistochemische Expressions-Analyse des PLC-ß1-Proteins im Hippocampus der TC-Maus und der Wildtyp-Maus 
3.5 Analyse der Proteinkinase C-Aktivität an hippocampalen Synaptosomen der

PLC-B1 ${ }_{\text {TC }}{ }^{-/}-$Maus

4.1 Zusammenfassende Darstellung der Ergebnisse.................................................................131

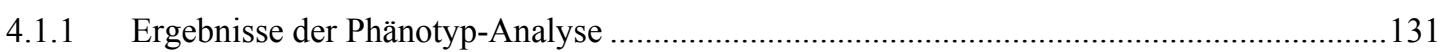

4.1.2 Ergebnisse der morphologischen Hippocampus-Analysen...............................................132

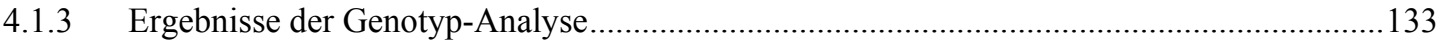

4.2 Die PLC-B1 TC $^{-/-}$-Insertionsmutation in Relation zum existenten PLC-B1 ${ }^{-/-}$-MausModell

4.2.1 Gegenüberstellung der molekulargenetischen Ergebnisse.............................................. 134

4.2.2 Zusammenfassende Gegenüberstellung des PLC-1 ${ }^{-/-}$- und PLC- $\beta 1_{\mathrm{TC}}{ }^{-/-}$- Phänotyps ..............136

4.2.3 Gegenüberstellung der phänotypischen Ergebnisse..........................................................137

4.2.4 Gegenüberstellung der biochemischen Ergebnisse .......................................................138

4.2.5 Gegenüberstellung der morphologischen Ergebnisse ...................................................139

4.3 Molekulare Mechanismen des axonalen Wachstums und der Synaptogenese in epileptischen Tiermodellen und bei der Temporallappen-Epilepsie des Menschen

4.4 Der Hippocampus und die Langzeitpotenzierung

4.5 Die Familie der Phospholipasen C.

4.5.1 Die Struktur, Funktion und Evolution der Phosphoinositol-spezifischen Phospholipasen C beim Säuger

4.5.2 Die Expression der Phospholipase C- $\$$-Isozyme ........................................................... 152

4.5.3 Subzelluläre Lokalisation des PLC-ß1-Proteins ................................................................ 154

4.6 Mögliche ,Downstream“ ${ }^{6 \text { Effekte der PLC-B1 }}$ TC $^{-/-}$-Mutation ..............................................156

Offene Fragen und weiterführende Experimente ................................................................131

$5 \quad$ ZUSAMMENFASSUNG .............................................................. 164

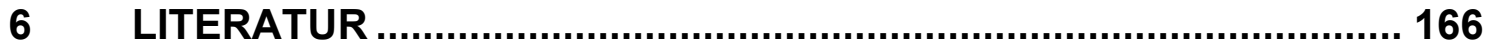

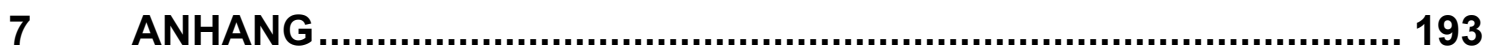




\section{Abkürzungen}

A

AChR

Amp

Abb.

abs.

AHS

AK

AP

APS

$\beta$

BCIP

BLAST

bp

BSA

bzw.

$\mathrm{C}$

${ }^{\circ} \mathrm{C}$

ca.

CAT

$\mathrm{CCD}$

CD

cDNA

$\mathrm{Ci}$

CIAP

$\mathrm{cm}$

cpm

dATP

dCTP

$\mathrm{ddH}_{2} \mathrm{O}$

$\mathrm{dH}_{2} \mathrm{O}$

DAB
Purinbase Adenin

Acetycholin-Rezeptoren

Ampicillin

Abbildung

absolut

Ammonshorn-Sklerose

Antikörper

alkalische Phosphatase

Ammoniumperoxodisulfat

beta

5-Brom-4-Chlor-3-indolylphosphat

Basic Local Alignment Search Tool

Basenpaare

Rinderserumalbumin

beziehungsweise

Pyrimidinbase Cytosin

Grad Celsius

circa

Chloramphenicol-Acetyltransferase

Charge-Coupled Device

Cholinerge Denervierung

komplementäre DNA oder „copy“-DNA

Curie

Calf Intestinal Alkaline Phosphatase

Zentimeter

„,counts per minute“

Desoxyadenosintriphosphat

Desoxycytidintriphosphat

bidestilliertes Wasser

demineralisiertes Wasser

Diaminobenzidintetrahydrochlorid 


\begin{tabular}{|c|c|}
\hline DAG & Diacylglycerol \\
\hline DAPI & $4^{`}, 6$-Diamidino-2-phenylindol \\
\hline DEPC & Diethylpyrocarbonat \\
\hline dGTP & Desoxyguanosintriphosphat \\
\hline dTTP & Desoxythymidintriphosphat \\
\hline d.h. & das heißt \\
\hline DIG & Digoxigenin \\
\hline DMDC & Dimethyldicarbonat \\
\hline DMSO & Dimethylsulfoxid \\
\hline DNA & Desoxyribonukleinsäure \\
\hline DNase & Desoxyribonuklease \\
\hline dNTP & Desoxynukleosidtriphosphat \\
\hline Dpm & „,decays per minute“ \\
\hline ds & Doppelstrang \\
\hline DTT & Dithiotreitol \\
\hline$\varepsilon$ & Absorptionskoeffizient \\
\hline E.coli & Escherichia coli \\
\hline EDTA & Ethylendiamintetraessigsäure \\
\hline EGTA & $\begin{array}{l}\text { Ethylenglycol-bis( } \beta \text {-aminoethylether })-\mathrm{N}, \mathrm{N}, \mathrm{N}^{\circ}, \mathrm{N}^{`} \text { - } \\
\text { tetraessigsäure }\end{array}$ \\
\hline EM & Elektronenmikroskopie \\
\hline EPSP & exzitatorisches postsynaptisches Potential \\
\hline ES-Zellen & Embryonale Stammzellen \\
\hline $\mathrm{EtOH}$ & Ethanol \\
\hline et al. & et alteres \\
\hline FA & Formamid \\
\hline FB & flankierender Bereich \\
\hline FITC & Fluorescein-5-isothiocyanat \\
\hline G & Purinbase Guanin \\
\hline g & Gramm \\
\hline GSP & Genspezifischer Primer \\
\hline $\mathrm{xg}$ & Erdbeschleunigung \\
\hline
\end{tabular}




\begin{tabular}{|c|c|}
\hline HSI & „Hippocampal sympathetic ingrowth“ \\
\hline $\operatorname{IgG}$ & Immunglobulin $\mathrm{G}$ \\
\hline $\mathrm{IP}_{3}$ & Inositol-1,4,5-Trisphosphat \\
\hline IPTG & 1-Isopropyl- $\beta$-D-1-thiogalactopyranosid \\
\hline $\mathrm{kb}$ & Kilobasenpaare \\
\hline $\mathrm{kDa}$ & Kilodalton \\
\hline 1 & Liter \\
\hline Lsg. & Lösung \\
\hline M & Molarität \\
\hline $\mathrm{m}$ & milli \\
\hline $\mathrm{mA}$ & Milliampere \\
\hline mAChR & muscarinische Acetycholin-Rezeptoren \\
\hline $\mathrm{mM}$ & Millimolar \\
\hline MOPS & 3-(N-Morpholino)-propansulfon-Säure \\
\hline mRNA & „messenger“ RNA \\
\hline$\mu$ & micro \\
\hline $\mathrm{nt}$ & Nukleotide \\
\hline $\mathrm{n}$ & nano \\
\hline $\mathrm{NaOAc}$ & Natriumacetat \\
\hline NBT & Nitroblautetrazoliumchlorid \\
\hline $\mathrm{NC}$ & Nitrocellulose \\
\hline NCBI & „National Center for Biotechnology Information” \\
\hline OD & optische Dichte \\
\hline ORF & „open reading frame“ \\
\hline $\mathrm{p}$ & pico \\
\hline p.A. & pro Analysi \\
\hline PAA & Polyacrylamid \\
\hline PAGE & Polyacrylamidgelelektrophorese \\
\hline PBS & „Phosphat Buffered Saline“ \\
\hline PCR & „Polymerase Chain Reaction““ \\
\hline PGK & Phosphoglycerin-Kinase \\
\hline PI & Phosphatidylinositol \\
\hline
\end{tabular}


$\mathrm{PIP}_{2}$

PKC

PLC

PMSF

PVDF

PFA

RNA

RNase

rRNA

RT-PCR

RT

RZPD

$\mathrm{S}$

SDS

s.o.

SPM

SS

s.u.

SV40

$\mathrm{T}$

Tab.

TEMED

TRITC

Tris

TYR

U

UTR

UV

V

$\mathrm{V} / \mathrm{cm}$

Vol.

$\mathrm{v} / \mathrm{v}$
Phosphatidylinositol-4,5-Bisphosphate

Proteinkinase C

Phospholipase C

Phenylmethansulfonylfluorid

Polyvenylidene-difluorid

Paraformaldehyd

Ribonukleinsäure

Ribonuklease

ribosomale RNA

Reverse Transkriptions-PCR

Raumtemperatur

Ressourcen-Zentrum-Primär-Datenbank

Svedberg (Sedimentationskoeffizient)

Natriumdodecylsulfat

siehe oben

synaptische Plasmamembran

„salt saturated“

siehe unten

Simian Virus 40

Pyrimidinbase Thymidin

Tabelle

N,N,N',N'-Tetramethylethylendiamin

Tetramethylrhodamin-5-isothiocyanat

Tris(hydroxyethyl)-aminomethan

Tyrosinase

Unit

„untranslated region“

Ultraviolett

Volt

Volt pro Zentimeter

Volumen

Volumen / Volumen 
WT

$\mathrm{w} / \mathrm{v}$

X-Gal

z.B.
Wildtyp

Gewicht / Volumen

5-Brom-4-chlor-3-indolyl- $\beta$-D-galactopyranosid zum Beispiel 


\section{Einleitung}

\subsection{Ursprung der mutanten TC-Mauslinie und Struktur der verwendeten Konstrukte}

Zur Klärung der Frage, welche Anteile der 5'-flankierenden Region des Proakrosingens dessen testis- und keimzellspezifische Expression regulieren, wurden am Institut für Humangenetik in Göttingen transgene Maus-Linien erzeugt, in denen Teilfragmente der 5'-flankierenden Region auf ihre in vivo-Funktionalität bezüglich der örtlichen und zeitlichen Expression des Chloramphenicol-A Acetyltransferase (=CAT) Reportergens untersucht wurden (Nayernia et al. 1994). Bei der Koinjektion des Fusionskonstruktes ACR-CAT-SV40, bestehend aus $877 \mathrm{bp}$ der 5'-flankierenden Region des Proakrosingens der Ratte, 659 bp der kodierenden Region des CAT-Reportergens und $947 \mathrm{bp}$ der ,3'-untranslated region“ (3'-UTR) des SV40 small-T Antigens (2,4 kb Ava II / Kpn I- Fragment, siehe Abb. 1.1 A) zusammen mit einem Maus-TyrosinaseMinigen TYR-SV40 (siehe Abb. 1.1 B) als Fellmarker zur Überprüfung der Transgenität (Beermann et al. 1990; Beermann et al. 1991) wurde bei homozygoten Tieren einer transgenen Linie eine Wachstumsretardierung in der frühen postnatalen Entwicklung und bei adulten homozygoten Tieren ein auffälliges Verhalten gefunden, die beide nicht ursächlich durch die Funktion des Transgens erklärt werden konnten und somit auf eine Insertionsmutation hinwiesen.

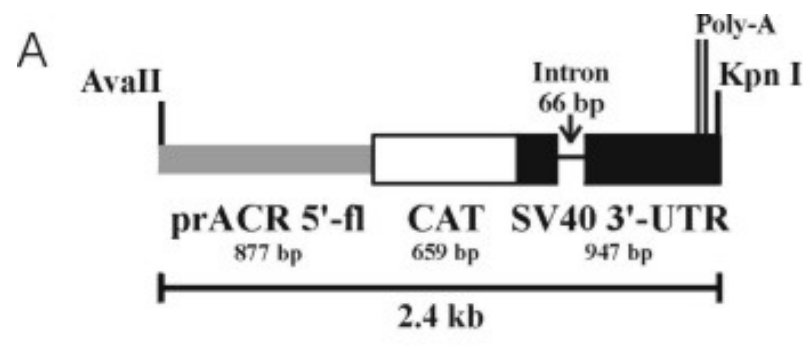

ACR-CAT-SV40

(Ava II / Kpn I)

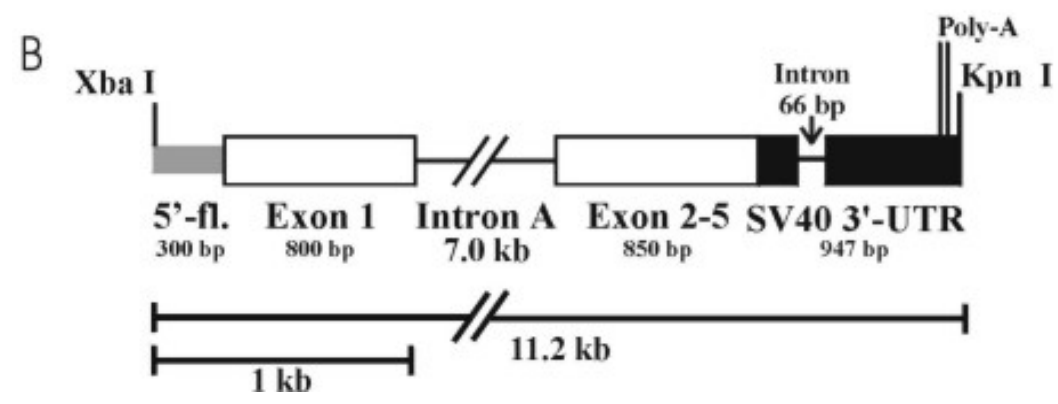

TYR-SV40

(Xba I/ Kpn I)

Abb. 1.1 
Abb. 1.1: Das Konstrukt ACR-CAT-SV40 (A) besteht aus 877 bp der 5'-flankierenden Region des Proakrosin-Gens der Ratte, 659 bp CAT-(Chloramphenicol-Acetyltransferase) ReporterGensequenz und 947 bp der SV40 small-T Antigen 3'-UTR als Poly-A-Signal. Das Konstrukt TYR-SV40 (B) besteht aus 300 bp 5'-flankierender Region, 800 bp Exon 1, $7.0 \mathrm{~kb}$ Intron A und $850 \mathrm{bp}$ der Maus Tyrosinase cDNA für Exon 2-5, gefolgt von ebenfalls 947 bp der SV40 3'-UTR. Die SV40 3'-UTR enthält ein 66 bp Intron an Position 165 nach dem CAT-bzw. Tyrosinase-Stopp-Kodon. Zwei putative Poly-Adenylierungs-Signale (Poly-A-Signale) liegen 83 bp und 111 bp vor der Kpn I-Schnittstelle.

\subsection{Zur Insertions-Mutagenese bei der Erzeugung transgener Mäuse}

Neben der Analyse spontaner Mutationen (z.B. rds, Splotch und Small eye) über Positionsklonierung (Travis et al. 1989; Epstein et al. 1991; Hill et al. 1991) und dem experimentellen „Knock-out“ von Genen mit bekannter Genstruktur (z.B. Insl3 oder NMDA-R1) (Zimmermann et al. 1999; Tsien et al. 1996a) ist die Analyse von Mäusen mit einer Insertionsmutation ein brauchbarer Ansatz zur funktionellen Identifizierung unbekannter Gene, da die mutanten Mauslinien vor der Genotypisierung bezüglich ihres Phänotyps selektiert werden können und die Insertionsstelle im Genom durch die Insertion markiert ist. Die Analyse vom „Phänotyp zum Genotyp“ wird im Gegensatz zur klassischen vorwärts gerichteten Genetik als „Reverse Genetik“ bezeichnet (Broadie 1998) und ermöglicht die Funktionsanalyse von Genen, ohne dass zunächst umfangreiche Informationen über die Genstruktur bekannt sein müssen. Insertionsmutante Mauslinien entstehen durch die genomische Integration exogener „Fremd-DNA“ innerhalb eines endogenen funktionellen Gens, wodurch dessen Genstruktur durch Deletion bzw. exonische oder intronische Insertion verändert wird und die Expression des Gens unterbleibt oder zumindest gestört ist. Methodisch kommen dabei retrovirale- (Jaenisch 1976) oder Mikroinjektions-Techniken (Gordon et al. 1980) mit DNA-Konstrukten oder speziellen „Gene-Trap“-Vektoren (Cecconi und Meyer 2000) zum Einsatz. Zum heutigen Zeitpunkt sind eine Vielzahl insertionsmutanter Mauslinien, und zwar sowohl aus retroviraler Infektion als auch aus transgener- oder „Gene-Trap“-Mikroinjektion, phänotypisch beschrieben, aber nur wenige Mutanten wurden bisher erfolgreich genotypisiert. Die Gründe dafür liegen in dem Auftreten von zum Teil ausgedehnten genomischen Deletionen von bis zu $300 \mathrm{~kb}$ in der Region der Insertion und der möglichen Mutation oder Deletion mehrerer Gene (Lesche et al. 1997). Desweiteren können mehrere Transgen-Integrationen auf dem selben Chromosom (Singh et al. 1991), zusätzlich integrierte Fremd-DNA (Mark et al. 1992) und Effekte der Insertion über weite Distanzen die molekulare Analyse erschweren (Übersichten in: Meisler 1992; Rijkers et al. 1994 und Takahashi et al. 1994). Die größte Zahl insertionmutanter Mauslinien mit detektierbarem pränatalem 
und postnatalem Phänotyp wird nach Mikroinjektion von DNA-Konstrukten beobachtet; solche Insertionsmutationen kommen bei etwa $5 \%$ aller transgenen Tiere vor (Woychik und Alagramam 1998).

\subsection{Der Phänotyp der Maus mit Insertionsmutation}

Bereits bei Tieren der F2-Generation wurde deutlich, dass die homozygoten TC-Mäuse im Vergleich zu ihren Wildtyp- und heterozygoten Geschwistern in der frühen postnatalen Phase signifikant im Wachstum retardiert sind, und dass homozygote Tiere eine hohe Sterblichkeitsrate in der frühen postnatalen Entwicklung aufweisen. Diese frühe postnatale Sterblichkeit ist allerdings nicht vollständig. Homozygote Tiere, die diese frühe postnatale Phase überleben, wachsen zunächst zu unauffälligen Tieren heran und erreichen nahezu das Körpergewicht ihrer Wildtyp- und heterozygoten Geschwister. Adulte homozygote Männchen und Weibchen entwickeln schließlich eine auffällige hypokinetische Bewegungsarmut und eine ausgeprägte Neigung zu hyperreflektorischem Verhalten nach plötzlicher akustischer und taktiler Stimulation.

Hyperreflektorisches Verhalten beobachtet man auch bei einer Reihe experimentell induzierter Epilepsien, z.B. nach intraventrikularer oder intraperitonealer KainatInjektion (Nadler et al. 1980b; Buckmaster und Dudek 1997), durch hippocampale oder entorhinale Läsionen (Laurberg und Zimmer 1981; Guthrie et al. 1997), nach cholinerger Denervierung (CD) durch Fimbria/Fornix-Läsionen (Beck et al. 1994), durch chronische, subkonvulsive elektrische Reizung mesialer Temporallappenabschnitte (= „Kindling“) (Sutula et al. 1988; Represa et al. 1993), durch eine Blockade des inhibitorischen postsynaptischen Potentials von GABA-Rezeptoren mittels Pentylentetrazol (Holmes et al. 1999) und nach Verabreichung des erregenden Cholinergikums Pilocarpin (Clifford et al. 1987; Silva und Mello 2000). Desweiteren kann man auch bei einer epileptischen Mausmutante (Stargazer) mit genetischer Ursache eine ausgeprägte Neigung zu epileptiformer Aktivität nachweisen (Qiao und Noebels 1993; Letts et al. 1998). Die humane Temporallappen-Epilepsie (TLE) ist ebenfalls durch hyperreflektorische Anfälle gekennzeichnet und hat ihren epileptogenen Fokus im Bereich des Temporallappens sowie im Hippocampus. In allen diesen induzierten Epilepsie-Modellen der Maus und der Ratte und bei der TemporallappenEpilepsie des Menschen (Sutula et al. 1989; Houser et al. 1990) lassen sich im Moosfaser-System des Hippocampus axonale Remodellierungs-Prozesse nachweisen, die als ursächlich für die epileptiforme Symptomatik diskutiert werden (Okazaki et al. 1995). 


\subsection{Die Hippocampus-Formation: Zytoarchitektur und Konnektivität}

Die anatomische Terminologie der Hippocampus-Struktur unterscheidet zwischen dem Hippocampus im engeren und der Hippocampus-Formation im weiteren Sinne. Beide sind Teil des limbischen Systems und gehören dem Archicortex an (Duvernoy 1988). Die Hippocampus-Formation umfasst die Regionen Fascia dentata (Gyrus dentatus), den Hippocampus proper, bestehend aus den Regionen des Cornu ammonis (Ammonshorn), und das Subiculum. Das Ammonshorn wird der Nomenklatur von Ramón y Cajal (Cajal 1911; Cajal 1995), Lorente de Nó (1934) und Amaral (1978) folgend aufgrund seiner Neuronendichte und neuronalen Verschaltungen in verschiedene Sektoren eingeteilt, die vom Subiculum ausgehend mit CA1-CA3 (Ćornu Ámmonis) bezeichnet werden (Abb. 1.2). Ramón y Cajal (Cajal 1911) unterteilte die Cornu ammonis in einen Bereich mit großen (,Regio inferior“) und kleinen („Regio superior“) Pyramidenzell-Neuronen und Lorente de Nó (1934) untergliederte die „Regio inferior“ erneut in die Regionen CA3 und CA2, von denen letzterer der Moosfaser-Input fehlt. Die „Regio superior“" wurde in der Nomenklatur von Lorente de Nó (1934) zur Region CA1. Die Hippocampussegmente des Ammonshorns bestehen aus fünf Schichten: dem Stratum lacunosum-moleculare, dem Stratum radiatum, dem Stratum lucidum, dem Stratum pyramidale und dem Stratum oriens (Abb. 1.2). Der Gyrus dentatus besteht aus drei histologischen Schichten: dem Stratum moleculare, dem Stratum granulosum und der polymorphen Schicht im Hilus (Abb. 1.2), die einen hohen Anteil an Pyramiden- und Mooszellen besitzt. Die zytoarchitektonische Struktur der Hippocampus-Formation ist relativ einfach und zwischen verschiedenen Säugetieren gut vergleichbar. Sie ist durch zwei ineinandergreifende C-förmige Strukturen charakterisiert, die zum einen durch die Körnerzellen (Granularzellen) im Stratum granulosum des Gyrus dentatus und zum anderen durch die Pyramidenzellen im Stratum pyramidale des Ammonshorns gebildet werden (Abb. 1.2). Die Dendriten dieser zwei Zelltypen bilden die zellarmen Schichten. Die Pyramidenzellen formen mit ihren apikalen Dendriten die Strata radiatum und lacunosum-moleculare und mit ihren basalen Dendriten das Stratum oriens. Die Dendriten der Körnerzellen bilden das Stratum moleculare des Gyrus dentatus. 


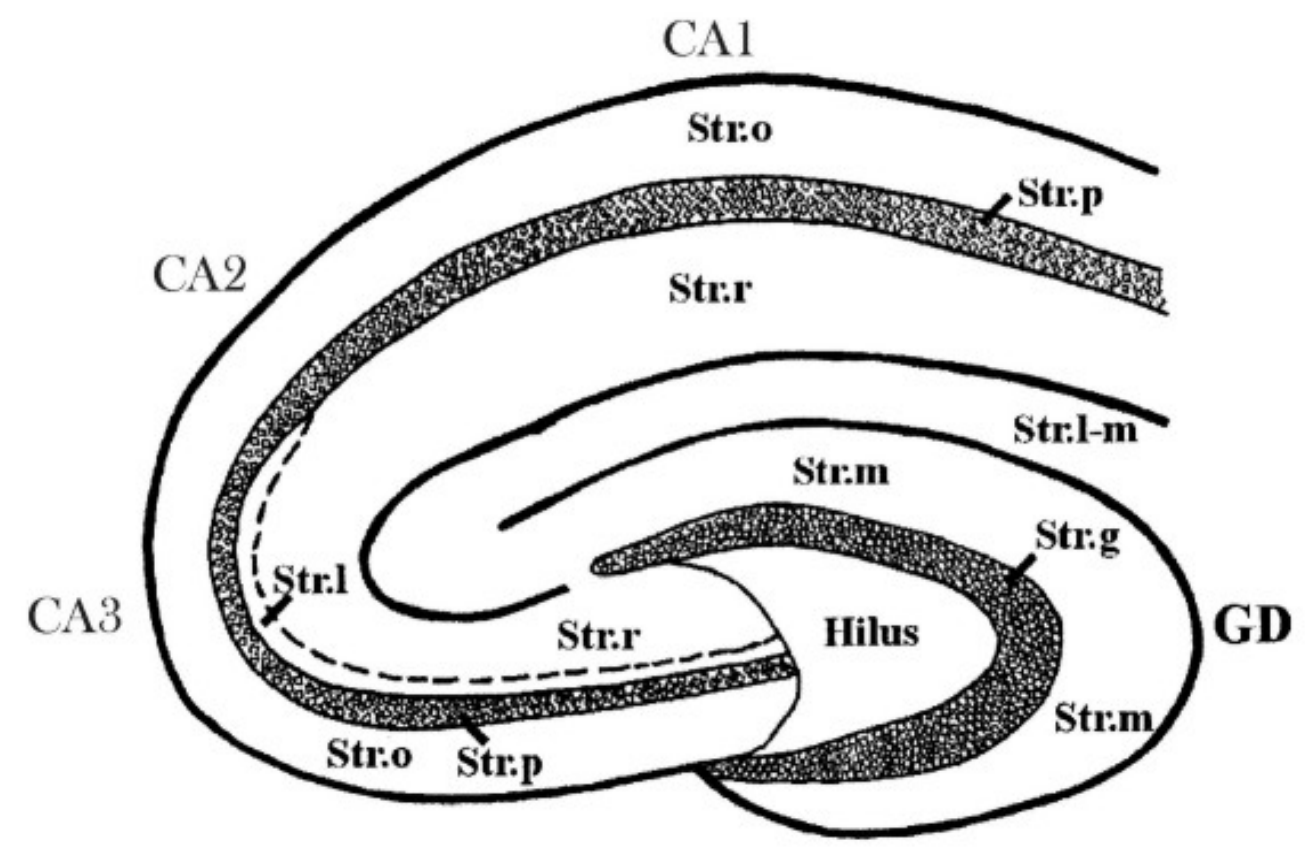

Abb. 1.2: Schematische Darstellung der Hippocampus-Formation der Maus in einem Frontalschnitt durch den mesialen Temporallappen. Die dargestellten Regionen sind: CA1, CA2, CA3 = Regionen des Ammonshorns (Cornu ammonis), GD = Gyrus dentatus, Str.m = Stratum moleculare, Str. $g=$ Stratum granulosum, Str. l-m = Stratum lacunosum-moleculare, Str. $r=$ Stratum radiatum, Str. $p=$ Stratum pyramidale, Str. o $=$ Stratum oriens, Str. $l=$ Stratum lucidum.

Der Hippocampus ist durch verschiedene Faserbahnen mit anderen Hirnregionen über extrinsische Verbindungen und auch zwischen seinen eigenen Regionen über intrinsische Verbindungen synaptisch verknüpft. Diese afferenten Systeme enden in den zellarmen Schichten der Hippocampus-Formation (Deller 1998) und sind in der Abb. 1.3 schematisch dargestellt. Der Tractus perforans (Abb. 1.3 a), der eine besonders wichtige afferente glutamaterge Faserbahn zum Hippocampus darstellt, entspringt im angrenzenden entorhinalen Cortex und endet überwiegend im äußeren Teil des Stratum moleculare im Gyrus dentatus auf den Dendriten der Körnerzellen. Im inneren Teil des Stratum moleculare enden die glutamatergen Projektionen aus dem kontralateralen Hippocampus (Swanson et al. 1981). Die Axone der Körnerzellen bilden glutamaterge Moosfaser-Bündel (Abb. 1.3 b), welche überwiegend im Stratum lucidum der CA3Region auf den apikalen Dendriten der Pyramidenzellen aber auch auf Pyramidenzellen im Hilus des Gyrus dentatus terminieren. Die Axone der Pyramidenzellen in der Region CA3 und im Hilus treten in den Alveus ein und verlassen den Hippocampus über die Fimbria an der ventrikulären Seite (Abb. $1.3 \mathrm{c}$ ). Sie senden jedoch vorher ebenfalls glutamaterge Schaffer-Kollateralen (Abb. 1.3 d) aus, die den CA2-Sektor durchqueren und auf den apikalen Dendriten der CA1-Pyramidenzellen terminieren. Die Axone der 
CA1-Pyramidenzellen verlassen den Hippocampus zum Teil durch den Alveus und die Fimbria (Abb. 1.3 f), andererseits ziehen Kollateralen zu den Pyramidenzellen im Subiculum (Abb. 1.3 e), deren Axone zusammen mit denen der CA1-Pyramidenzellen ein Faserbündel bilden und den Hippocampus über die Fimbria verlassen und zurück zum entorhinalen Cortex ziehen (Abb. $1.3 \mathrm{f}$ ).

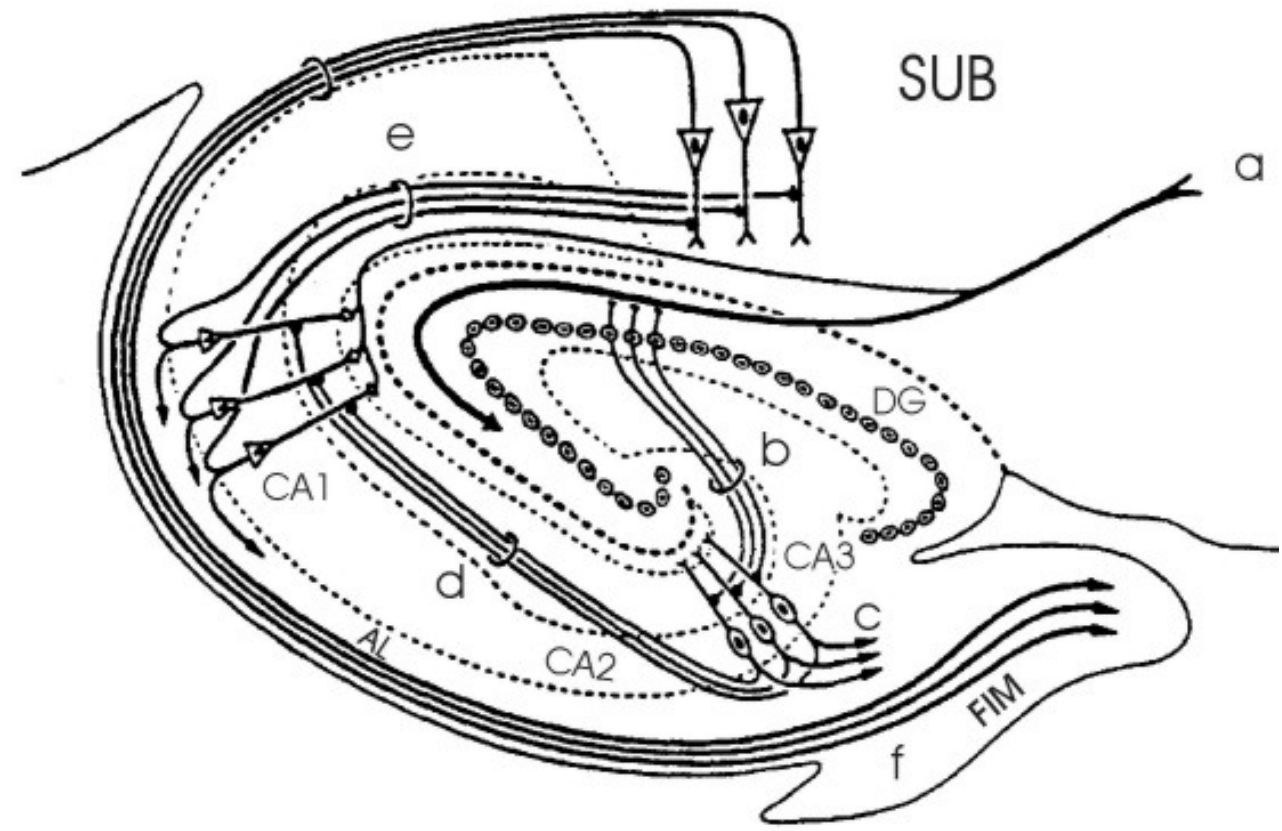

Abb. 1.3: Schematische Darstellung eines hippocampalen Frontalschnittes mit den wichtigsten Afferenzen sowie der trisynaptischen Erregungsleitung. Die Hauptafferenz zum Hippocampus wird von den Fasern des Tractus perforans (a) gebildet. Diese bilden in der Molekularschicht (Stratum moleculare) des Gyrus dentatus (DG) glutamaterge synaptische Kontakte mit den Dendriten der Körnerzellen. Die Axone der Körnerzellen ziehen als Moosfasern (b) zu den Pyramidenzellen im Hilus und der Region CA3, deren Axone (c) den Hippocampus über den Alveus (AL) und die Fimbria (FIM) verlassen. Sie senden jedoch vorher glutamaterge Schaffer-Kollateralen (d) zu den Pyramidenzellen der Region CA1 aus. Deren Axone verlassen den Hippocampus zum Teil (f), senden andererseits aber Kollateralen zu Pyramidenzellen im Subiculum (SUB) (e). Deren Axone bilden ein Faserbündel und verlassen den Hippocampus über die Fimbria und ziehen zurück zum entorhinalen Cortex (f). 


\subsection{Ziele der vorliegenden Arbeit}

Im Rahmen dieser Arbeit sollten im wesentlichen drei Ziele erreicht werden:

1. Der Phänotyp der Maus mit Insertionsmutation sollte bezüglich der beobachteten Verhaltensauffälligkeiten (Hyperreflexie und Hypokinesie) detaillierter analysiert werden. Besonderes Augenmerk galt dabei der postnatalen Entwicklung dieser Merkmale, die sowohl mit Verhaltens- als auch mit Lernexperimenten charakterisiert werden sollten. Das Ziel dieser Untersuchungen bestand darin, zeitlich markante Punkte in der phänotypischen Entwicklung der Maus mit Insertionsmutation zu bestimmen.

2. Durch die Verwendung neuroanatomischer und rezeptorautoradiographischer Methoden sollte versucht werden, ein morphologisches Korrelat für die epileptiformen Verhaltensauffälligkeiten im Gehirn der Insertionsmutanten zu finden und dessen aberrante Funktion zu charakterisieren. Dafür kam in besonderer Weise das hippocampale Moosfasersystem in Frage, dessen Zytoarchitektur und afferente Konnektivität (siehe Abschnitt 1.4) im Rahmen dieser Arbeit detailliert analysiert werden sollte.

3. Die Mutation in dieser Mauslinie sollte mit molekulargenetischen Methoden analysiert werden. Dieses Ziel beinhaltete die Identifizierung und Klonierung des mutierten Gens oder der mutierten Gene, die molekulare Charakterisierung der Mutation, detaillierte Expressionsstudien und funktionelle Analysen. 


\section{Material und Methoden}

\subsection{Chemikalien}

Chemikalien, die nicht gesondert aufgeführt sind, wurden von der Firma Merck (Darmstadt) bezogen.

Acrylamid-Stammlösung (40 \%)

Agarose

Ampicillin

Ampuwa

Aprotinin

AP-konjugiertes Streptavidin-System

AP-konjugierter Digoxigenin-AK

AP-konjugierter anti-Kaninchen IgG

Aqua Polymount

Bacto-Agar

Bacto-Trypton

Bacto-Hefe-Extrakt

Biotin-16-dUTP

Blockierungsreagenz

Bromphenolblau

BSA

Carbachol

${ }^{14} \mathrm{C}$-Chloramphenicol

CIAP

Colcemid

Concanavalin A

Cot-1-DNA

$\alpha-{ }^{32} \mathrm{P}$ dCTP

$\gamma-{ }^{32} \mathrm{P}$ ATP

DAPI

Dextransulfat

Digoxigenin-11-dUTP

Dimethyldicarbonat (Velcorin)

Dithiotreitol (DTT)
Amresco $^{\circledR}$, Ohio, USA

Gibco BRL, Eggenstein

Sigma, Deisenhofen

Fresenius AG, Bad Homburg

Sigma, Deisenhofen

Gibco BRL, Eggenstein

Boehringer, Mannheim

Sigma, Deisenhofen

Polyscience, Warrington

Difco, Detroit, USA

Difco, Detroit, USA

Difco, Detroit, USA

Boehringer, Mannheim

Boehringer, Mannheim

Sigma, Deisenhofen

Biomol, Hamburg

Sigma, Deisenhofen

Amersham, Braunschweig

Gibco BRL, Eggenstein

Boehringer, Mannheim

Boehringer, Mannheim

Gibco BRL, Eggenstein

Amersham, Braunschweig

Amersham, Braunschweig

Serva, Heidelberg

Pharmacia, Freiburg

Boehringer, Mannheim

Bayer AG, Leverkusen

Sigma, Deisenhofen 
DNase I (RNase frei)

dNTP-Set (PCR Grade)

Ethanol

Ethidiumbromid $(1 \mu \mathrm{g} / \mathrm{ml})$

Eukitt

Ficoll 400

FKS

Formamid (99,5\%, deionisiert)

Formaldehyd ( $\geq 37 \%$ )

Freezing-Medium CRYO-BLOCK

Gentamycin

Glutaraldehyd

Glyzerin

Gummiarabicum

${ }^{125}$ I-MK 801

${ }^{125}$ Iod-Standards (Microscales)

IPTG

JETSORB-Insert-Isolierungskit

Kanamycin

$1 \mathrm{~kb}$ DNA - Leiter

Ketamin

Kompetente DH5 $\alpha$ - Zellen

Lachsspermien-DNA

L-Glutamin

Lipopolysaccharide

Leupeptin

Marathon $^{\mathrm{TM}}$ cDNA

Amplifikation System

2-Mercaptoethanol

Membran Hybridisierungs-Puffer

MessageMaker ${ }^{\mathrm{TM}}$ mRNA

Isolationssystem

(+)-MK 801 Hydrogen-Maleat

MicroSpin ${ }^{\mathrm{TM}}$ S-200 HR Säulen

MOPS

Natriumorthovanadat

Natriumdeoxycholat
Sigma, Deisenhofen

Boehringer, Mannheim

ROTH, Karlsruhe

Serva, Heidelberg

Bodo Schmidt, Göttingen

Pharmacia, Freiburg

Gibco BRL, Eggenstein

ROTH, Karlsruhe

Sigma, Deisenhofen

Medizinische Diagnostik Methoden, Gießen

Gibco BRL, Eggenstein

Sigma, Deisenhofen

Gibco BRL, Eggenstein

Merck, Darmstadt

$\mathrm{NEN}^{\mathrm{TM}}$ Life Science, Boston, MA, USA

Amersham, Braunschweig

Biomol, Hamburg

Genomed, Bad Oyenhausen

Sigma, Deisenhofen

Gibco BRL, Eggenstein

cp-pharma, Burgdorf

Gibco BRL, Eggenstein

Sigma, Deisenhofen

Gibco BRL, Eggenstein

Boehringer, Mannheim

Sigma, Deisenhofen

Clontech, Heidelberg

Sigma, Deisenhofen

KPL

Gibco BRL, Eggenstein

RBI, Natick, MA, USA

Amersham Pharmacia Biotech

Biomol, Hamburg

Sigma, Deisenhofen

Sigma, Deisenhofen 
NBT/BCIP-Stocklösung

Nick-Translations-System

Nonidet P-40

Orange-G

PBS

Penicillin

Pepsin

Pepstatin A

PfuTurbo $^{\mathrm{TM}}$ DNA Polymerase

Phenol

100 x Phosphatase Inhibitor Cocktail

Platinum $^{\circledR}$ Taq DNA Polymerase

PMSF

Polyvinylpyrrolidon

Propidiumiodid

Proteinase K

QIAGEN $^{\circledR}$ Plasmid-Midipräpkit

QIAGEN ${ }^{\circledR}$ Large construct Kit

Rapid-Hybridization Puffer

Rediprime $^{\mathrm{TM}}$ II Markierungs-System

Restriktionsenzyme

RNase A

RNase $\mathrm{H}$

RNase-Inhibitor

RNA-Längenstandards

Rompun $^{\circledR}$

Roti ${ }^{\circledR}$-Quant Protein Assays

RPMI-Medium 1640

SDS

Soybean Trypsin Inhibitor

Spermidin

Streptomycin

Sukrose

SUPERSCRIPT $^{\text {TM }}$ II

Szintillationsflüssigkeit

TEMED

TissueTek $^{\circledR}$
Boehringer, Mannheim

Gibco BRL, Eggenstein

Fluka, Deisenhofen

Sigma, Deisenhofen

Biochrom, Berlin

Gibco BRL, Eggenstein

Sigma, Deisenhofen

Sigma, Deisenhofen

Stratagene, Heidelberg

Biomol, Hamburg

Sigma, Deisenhofen

Gibco BRL, Eggenstein

Sigma, Deisenhofen

Pharmacia, Freiburg

Serva, Heidelberg

Boehringer, Mannheim

Qiagen, Hilden

Qiagen, Hilden

Amersham Pharmacia Biotech

Amersham Pharmacia Biotech

Biolabs, Boehringer, BRL

Gibco BRL, Eggenstein

Gibco BRL, Eggenstein

Boehringer, Mannheim

Gibco BRL, Eggenstein

Bayer, Leverkusen

ROTH, Karlsruhe

Gibco BRL, Eggenstein

Serva, Heidelberg

Sigma, Deisenhofen

Sigma, Deisenhofen

Gibco BRL, Eggenstein

Sigma, Deisenhofen

Gibco BRL, Eggenstein

Packard, Groningen

Sigma, Deisenhofen

Sakura, Zoekerwoude, Niederlande 
Total RNA Isolation Reagent

Triton-X-100

Tween-20

Vectashield Antifading

$\mathrm{X}$-Gal

Xylencyanol FF

Xylol

\subsection{Gebrauchswaren}

Agepon $^{\circledR}$

Blotting Papier GB 003

Blotting Papier GB 002

Einmalfilter Minisart NML

(0.45 und $0.2 \mu \mathrm{m})$

Millipore Filter HV, $45 \mu \mathrm{m}$

Fixogum Rubber-Cement (Marabu)

Hybond $^{\mathrm{TM}}$-C extra

Kühlzentrifugenbecher

LX-24-Entwickler

Objektträger/Deckgläschen

Superfrost* Plus Objektträger

Pipettenspitzen

Plastikwaren

Polymax-Fixierer

Reaktionsgefäße

Röntgenfilme Hyperfilm-MP

Röntgenfilme ${ }^{3} \mathrm{H}-\mathrm{Hyperfilm}$

Schlauchfolie

Ultrazentrifugengefäße

Zellkulturflaschen
Biomol, Hamburg

Serva, Heidelberg

Sigma, Deisenhofen

Firma Vector, Firma Camon, Heidelberg

Biomol, Hamburg

Sigma, Deisenhofen

Merck, Darmstadt

AGFA, Leverkusen

Schleicher \& Schüll, Dassel

Schleicher \& Schüll, Dassel

Sartorius, Göttingen

Nihon Millipore, Yonezawa, Japan

Schütt, Göttingen

Amersham Buchler, Braunschweig

Nalge, Rochester, USA

Kodak, Stuttgart

Schütt, Göttingen

Schütt, Göttingen

Eppendorf, Hamburg

Greiner, Nürtingen

Kodak, Stuttgart

Eppendorf, Hamburg

Amersham Buchler, Braunschweig

Amersham-Buchler, Braunschweig

Schütt, Göttingen

Beckmann, München

Greiner, Nunc

\subsection{Stammlösungen, Puffer und Medien}

Die Lösungen für den routinemäßigen Laborbetrieb wurden nach Sambrook et al. (1989) angesetzt. Die Chemikalien wurden den Erfordernissen entsprechend in deionisiertem $\left(\mathrm{dH}_{2} \mathrm{O}\right)$, in vollentsalztem Wasser (Millipore), in bidestilliertem Wasser $\left(\mathrm{ddH}_{2} \mathrm{O}\right)$ oder Ampuwa gelöst. Je nach Bedarf wurden die Lösungen 
dampfdrucksterilisiert ${ }^{1 \mathrm{a}}$, sterilfiltriert ${ }^{1 \mathrm{~b}}$, frisch angesetzt ${ }^{2}$, aliquotiert und bei $-20^{\circ} \mathrm{C}^{3}$ oder bei $4^{\circ} \mathrm{C}^{4}$ aufbewahrt. Für Versuche mit RNA wurden die Chemikalien in mit $0.1 \%$ Dimethyldicarbonat (DEPC-Ersatz) behandeltem und dampfdrucksterilisiertem Wasser gelöst.
AP 1-Puffer ${ }^{1 \mathrm{a}}$
0,1 M Tris / $\mathrm{HCl} \mathrm{pH} 7,5$
$0,1 \mathrm{M} \mathrm{NaCl}$
$2,0 \mathrm{mM} \mathrm{MgCl} 2$
$0,05 \%$ Triton X-100
AP 3-Puffer ${ }^{1 \mathrm{a}}$
$0,1 \mathrm{M}$ Tris / $\mathrm{HCl} \mathrm{pH} 9,5$
$0,1 \mathrm{M} \mathrm{NaCl}$
$50 \mathrm{mM} \mathrm{MgCl}_{2}$
Ampicillin ${ }^{1 b, 3}$
$50 \mathrm{mg} / \mathrm{ml} \mathrm{H}_{2} \mathrm{O}$
Church-Hybridisierungspuffer ${ }^{1 \mathrm{a}}$
$7 \%$ SDS
0,5 M Natriumphosphatpuffer $(\mathrm{pH} 7,2)$
$1 \mathrm{mM}$ EDTA
Church-Waschpuffer ${ }^{1 \mathrm{a}}$
$0,1 \%$ SDS
$40 \mathrm{mM}$ Natriumphosphatpuffer $(\mathrm{pH} 7,2)$
50 x Denhardt's Lösung ${ }^{1 b, 3}$
$1 \%$ Rinderserumalbumin
$1 \%$ Polyvinylpyrrolidon
$1 \%$ Ficoll 400
Entfetter-Lösung ${ }^{2}$
$348 \mathrm{ml}$ Chloroform
$48 \mathrm{ml}$ Ether
$48 \mathrm{ml}$ Methanol
IPTG $^{1 b, 3}$
$100 \mathrm{mM}$ in $\mathrm{H}_{2} \mathrm{O}$
Kanamycin ${ }^{1 b, 3}$
$10 \mathrm{mg} / \mathrm{ml}$ in $\mathrm{H}_{2} \mathrm{O}$
LB-Medium $^{1 \mathrm{a}, 4}$
$1 \%$ Bacto-Trypton
$0.5 \%$ Hefeextrakt
$1 \% \mathrm{NaCl}$
$\mathrm{pH} 7.2$
LB-Agar ${ }^{1 \mathrm{a}, 4}$
LB-Medium mit
$1.5 \%$ Bacto-Agar
$1 \mathrm{M}$ Natriumphosphatpuffer $(\mathrm{pH} 7,2){ }^{1 \mathrm{a}} 342 \mathrm{ml} 1 \mathrm{M} \mathrm{Na}_{2} \mathrm{HPO}_{4}$
$158 \mathrm{ml} 1 \mathrm{M} \mathrm{NaH}_{2} \mathrm{PO}_{4}$ 
NBT/BCIP-Färbelösung ${ }^{2}$

Paraformaldehyd-Lösung $(4 \%)^{2}$

Spermidin $^{1 b, 3}$

$20 \times \operatorname{SSC}^{1 \mathrm{a}}$

Stop-Mix I ${ }^{4}$

Stop-Mix II ${ }^{4}$

$50 \times$ TAE-Puffer ${ }^{1 \mathrm{a}}$

$5 \times$ TBE-Puffer ${ }^{1 \mathrm{a}}$

$10 \times \mathrm{TBS}^{1 \mathrm{a}}$

$1 \times$ TE-Puffer ${ }^{1 \mathrm{a}}$

Thionin-Färbelösung $(0,15 \%)^{2}$

Trisacetat-Puffer ${ }^{1 \mathrm{a}}$

$\mathrm{X}-\mathrm{Ga} 1^{1 \mathrm{~b}, 3}$
$200 \mu \mathrm{l}$ NBT/BCIP-Stocklösung

in $10 \mathrm{ml}$ AP 3-Puffer

$4 \%$ PFA (w/v)

0,1 M Natriumphosphatpuffer $(\mathrm{pH} 7,2)$

auf $60{ }^{\circ} \mathrm{C}$ erhitzen

etwas $\mathrm{NaOH}$ hinzugeben

$200 \mathrm{mM}$

$3 \mathrm{M} \mathrm{NaCl}$

0.3 M Tri-Natrimcitrat

pH 7.0

$15 \%$ Ficoll 400

$1 \mathrm{mM}$ EDTA

$0.01 \%$ Orange $\mathrm{G}$

$0.25 \%$ Bromphenolblau

$0.25 \%$ Xylencyanol

$30 \%$ Glyzerin in Wasser

$2 \mathrm{M}$ Tris $(\mathrm{pH} 8,0)$

$2 \mathrm{M}$ Essigsäure

$50 \mathrm{mM}$ EDTA (pH 8,0)

$450 \mathrm{mM}$ Tris (pH 8.0)

$450 \mathrm{mM}$ Borsäure

$10 \mathrm{mM}$ EDTA

$100 \mathrm{mM}$ Tris $(\mathrm{pH} 8,0)$

$1,5 \mathrm{M} \mathrm{NaCl}$

$10 \mathrm{mM}$ Tris $(\mathrm{pH} 7,5)$

$1 \mathrm{mM}$ EDTA

$0,15 \%$ Thionin $(\mathrm{w} / \mathrm{v})$

0,1 M Essigsäure

3,6 mM Natronlauge

$1 \mathrm{M}$ Tris

pH 7,6 mit Essigsäure einstellen

$2 \%$ in Diemethylformamid 


\subsection{Molekulargewichtstandards}

DNA-Längenstandard $(1 \mu \mathrm{g} / \mu \mathrm{l})$

DNA 1 kb-Leiter (0.12-12.2 kb)

(Gibco BRL, Eggenstein)

RNA-Längenstandard $(1 \mu \mathrm{g} / \mu \mathrm{l})$

RNA-Leiter (0.24 - $9.5 \mathrm{~kb})$

(Gibco BRL, Eggenstein)

SDS-Proteinmarker

Prestained SDS-PAGE Standard

SeeBlue ${ }^{\text {TM }}$ Plus 2

(4 - $500 \mathrm{kDa})$ (Firma NoveX)

\subsection{Verwendete Vektoren, Bakterienstämme, Antibiotika und Agarplatten}

\subsubsection{Vektoren}

\begin{tabular}{|c|c|c|c|}
\hline Plasmid-Vektoren: & pUC 18 & $3,0 \mathrm{~kb}$ & (Norrander et al. 1983) \\
\hline & pBLCAT3 & $4,3 \mathrm{~kb}$ & (Luckow und Schütz 1987) \\
\hline & ptrTYR5 & $14,2 \mathrm{~kb}$ & (Beermann et al. 1991) \\
\hline & pBlueScript II SK +/- & $3,0 \mathrm{~kb}$ & (Stratagene, Heidelberg) \\
\hline & pGEM-T & $3,0 \mathrm{~kb}$ & (Promega, USA) \\
\hline & pT3T7-PAC & $2,9 \mathrm{~kb}$ & RZPD Berlin \\
\hline & pSPORT1 & $4,1 \mathrm{~kb}$ & RZPD Berlin \\
\hline & Lawrist 7 & $5,4 \mathrm{~kb}$ & RZPD Berlin \\
\hline & pPAC4 & $19,5 \mathrm{~kb}$ & RZPD Berlin \\
\hline
\end{tabular}

\subsubsection{Bakterienstämme}

Escherichia coli $\quad$ DH5a

(Gibco BRL, Subcloning efficiency)

\subsubsection{Antibiotika und Agarplatten}

SOC-Medium:

(Gibco BRL, Eggenstein)

LB-Ampicillin-Medium:

$50 \mu \mathrm{g}$ Ampicillin pro ml LB-Medium

LB-Kanamycin-Medium:

$30 \mu \mathrm{g}$ Kanamycin pro ml LB-Medium

LB-Amp-IPTG-X-Gal-Medium:

LB-Ampicillin-Medium

$100 \mu \mathrm{M}$ IPTG

$0,4 \% \mathrm{X}-\mathrm{Gal}(\mathrm{w} / \mathrm{v})$

Den jeweiligen Selektivnährböden wurde vor dem Autoklavieren zusätzlich 1,5 \% (w/v) Bacto-Agar zugesetzt. 


\subsection{Gensonden, Oligonukleotide und Antikörper}

\subsubsection{Gensonden und Klone}

HEF-2

(Rapp et al. 1989; Hanes et al. 1992)

Als Kontrolle für die Integrität und Quantifizierung von RNA wurde ein cDNAFragment für den humanen Elongations-Faktor-2 (HEF-2) benutzt. Das als Gensonde verwendete 1,6 kb Fragment wurde mit Bam HI und $B g l$ II aus der HEF-2-cDNA abgespalten, die dem Institut für Humangenetik freundlicherweise von Prof. Dr. K.H. Scheit, Max-Planck-Institut für Biophysikalische Chemie, Göttingen, zur Verfügung gestellt wurde.

\begin{tabular}{|c|c|c|}
\hline ACR-CAT-SV40 & & (Nayernia et al. 1994) \\
\hline TYR-SV40 & & (Beermann et al. 1991) \\
\hline Maus c-fos & IMAGp998N23999 & RZPD Berlin \\
\hline mPLC- $\beta 1$ & IMAGp998A151771 & RZPD Berlin \\
\hline hPLC- $\beta 1$ & DKFZp434A0814Q2 & RZPD Berlin \\
\hline GAP-43 & IMAGp998H231128 & RZPD Berlin \\
\hline Human SNAP-25 & IMAGp998N23830 & RZPD Berlin \\
\hline Maus ChgB & IMAGp998B19847 & RZPD Berlin \\
\hline Human BDNF & IMAGp998K07736 & RZPD Berlin \\
\hline PAC 473 L8 & Dr. Mariano Rocchi & Instituto di Genetica, Bari, Italien \\
\hline Cosmid A09170 & Bibliothek Nr. 121 & RZPD Berlin \\
\hline PAC L15323 & Bibliothek Nr. 711 & RZPD Berlin \\
\hline
\end{tabular}

\subsubsection{Synthetische Oligonukleotide}

Alle für die Experimente verwendeten Oligonukleotide wurden von der Firma Roth (Karlsruhe) synthetisiert und im lyophilisierten Zustand erworben, mit Ampuwa auf eine Konzentration von $100 \mu \mathrm{M}(100 \mathrm{pmol} / \mu \mathrm{l})$ eingestellt und als Stock bei $-20{ }^{\circ} \mathrm{C}$ gelagert.

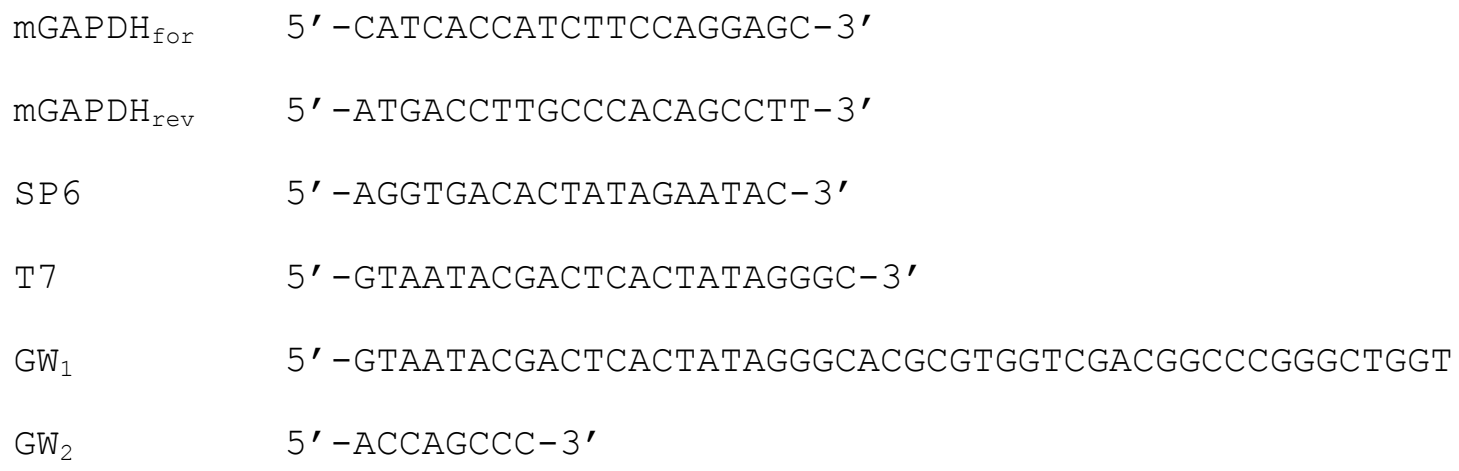




$$
\begin{aligned}
& \mathrm{AP}_{\mathrm{GW}} 1 \quad 5^{\prime}-\mathrm{GTAATACGACTCACTATAGGGC}-3^{\prime} \\
& \mathrm{AP}_{\mathrm{GW}} 2 \quad 5^{\prime}-\mathrm{ACTATAGGGCACGCGTGGT}-3^{\prime}
\end{aligned}
$$

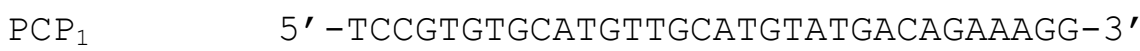

$$
\begin{aligned}
& \mathrm{PCP}_{2} \quad 5^{\prime}-\text { TACCACGGTAGACATATTCTCAGGGCTGCTGG-3' } \\
& \text { CDS 5'-TTCTAGAATTCAGCGGCCGC (T) }{ }_{30} \mathrm{NN}-3^{\prime} \\
& \operatorname{AP}_{\mathrm{RACE}} 1 \quad 5^{\prime} \text {-CCATCCTAATACGACTCACTATAGGGC-3' } \\
& \mathrm{AP}_{\mathrm{RACE}} 2 \quad 5^{\prime} \text {-ACTCACTATAGGGCTCGAGCGGC-3' } \\
& \text { TFR for } \quad 5^{\prime} \text {-ATTTCGGGAATGCTGAGAAAACAGACAGA-3' } \\
& \text { TFR rev 5'-GTCAATGTCCCAAACGTCACCAGA-3' } \\
& \mathrm{PLC}_{147} \quad 5^{\prime}-\mathrm{CAgGCGGCGGCAAGCAGGATCC}-3^{\prime} \\
& \mathrm{PLC}_{177} \quad 5^{\prime}-\text { GCGGCTCGACTGCCGGGCTCTG-3' } \\
& \mathrm{PLC}_{1281 \text { rev }} \quad 5^{\prime} \text {-GGACCTGCTCCTGCTTCAGAGGTGGG-3' } \\
& \text { PLC }_{1245 r e v} \quad 5^{\prime} \text {-CATTGAGCCGGGGATCTCTCTGC-3' } \\
& \text { PLC }_{712 \text { rev }} \quad 5^{\prime} \text {-CTTGGGAGCTTTGGCGTGCTTC-3' } \\
& \mathrm{SV} 40_{\text {for }} 1 \quad 5^{\prime} \text {-GGAACTGATGAATGGGAGCAGTGGTGG-3' } \\
& \text { SV40 for } 1 \mathrm{~N} \quad 5^{\prime} \text {-GGGAGCAGTGGTGGAATGCCTTTAATG-3' } \\
& \text { SV40 for } 2 \quad 5^{\prime} \text {-TGGGTTACAAATAAAGCAATAGCATCAC-3' } \\
& \text { SV4 } 0_{\text {for } 2 \mathrm{~N}} \quad 5^{\prime} \text {-ATAAAGCAATAGCATCACAAATTTCAC-3' } \\
& \text { SV40 rev } 1 \quad 5^{\prime} \text {-ATGTTTCAGGTTCAGGGGGAGGTGTGG-3' } \\
& \text { SV40 rev 1N } 5^{\prime} \text {-GGGGGAGGTGTGGGAGGTTTTTTAAAG-3' } \\
& \mathrm{SV}_{4} 0_{\text {rev }} 2 \quad 5^{\prime} \text {-CATTAAAGGCATTCCACCACTGCTCCC-3' } \\
& \text { SV40 rev } 2 \mathrm{~N} \quad 5^{\prime} \text {-CCACCACTGCTCCCATTCATCAGTTCC-3' } \\
& \mathrm{SV}_{40} 0_{\mathrm{LTR}} 1 \quad 5^{\prime}-\mathrm{TTGAGAGTCAGCAGTAGCCTC}-3^{\prime} \\
& \text { SV } 40_{\text {LTR } 2} \quad 5^{\prime} \text {-CAGCAAGTAGCCTCAATCAATCAAC-3' } \\
& \text { DL2-0, } 8_{\text {rev }} \quad 5^{\prime} \text {-CCCTGTGCTGGAACTTTGAGTATGAG-3' } \\
& \text { DL2-0, } 8_{\text {for }} \quad 5^{\prime} \text {-CCAGAGAGGGAGATAAGAACTGACTCGCA-3' } \\
& \text { DL5-2, } 2_{\text {rev }} \quad 5^{\prime} \text {-ACTGTTTACAAGGAGGCGAC-3' } \\
& \text { DL5-2, } 2_{\text {for }} \quad 5^{\prime} \text {-CTTTGTGATCTCGGAAGCAC-3' }
\end{aligned}
$$




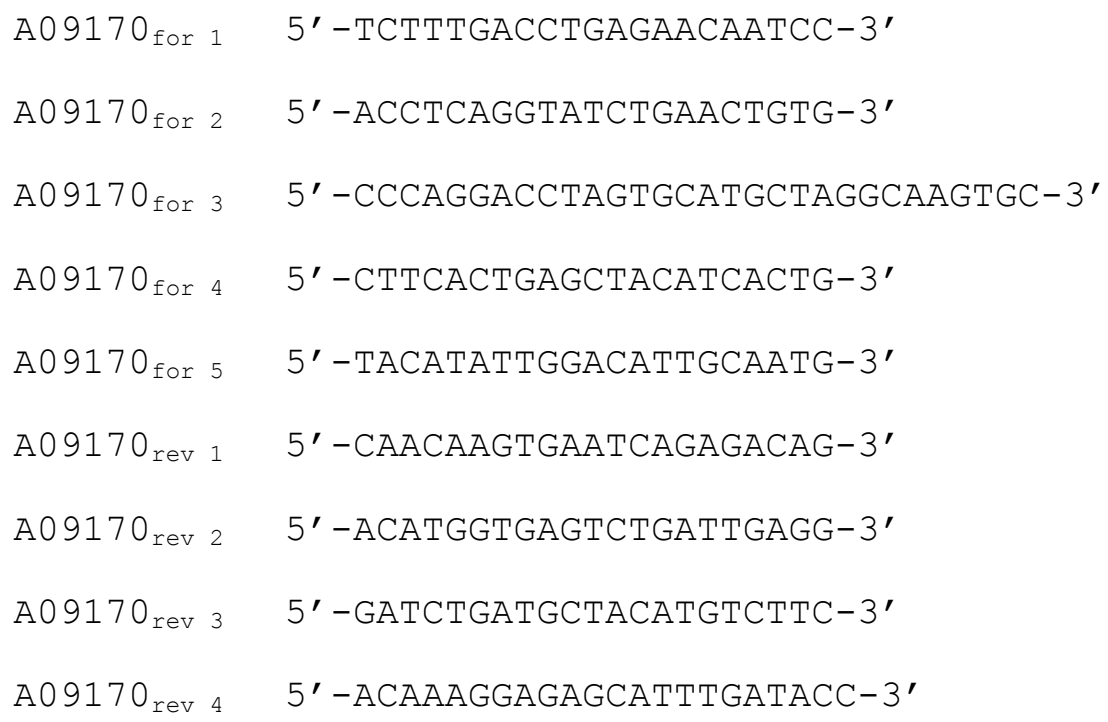

Die thermodynamische Schmelztemperatur $\mathrm{T}_{\mathrm{m}}$ wurde für kurze $(\leq 18 \mathrm{nt})$ Oligonukleotide nach der 2+4 -Formel (Itakura et al. 1984; Thein et al. 1986) („Wallace Temperatur") (2.1) berechnet und für längere Primer ( $\geq 19 \mathrm{nt}$ ) nach der GC-Formel (2.2) (Sambrook et al. 1989) abgeschätzt.

$T_{m}=N_{A+T} \bullet 2{ }^{\circ} \mathrm{C}+N_{G+C} \bullet 4{ }^{\circ} \mathrm{C} \quad(N=$ Anzahl Nukleotide $)$

$T_{m}=61,2{ }^{\circ} \mathrm{C}+0,41(\% G+C)-\frac{600}{l} \quad(l=$ Länge des Oligonukleotids $)$

Die für die jeweilige PCR-Reaktion optimale „Annealing“ -Temperatur kann zwischen $3{ }^{\circ} \mathrm{C}-12{ }^{\circ} \mathrm{C}$ über der $\mathrm{T}_{\mathrm{m}}$ liegen und mußte daher für jede PCR optimiert werden.

\subsubsection{Antikörper}

Anti PLC- $\beta 1$ (Ratte)

Anti GAP-43 (Maus)

Anti c-fos (Maus)

Anti Calretinin (Maus)
Santa Cruz Biotechnology, USA

Dr. Rickmann, Institut für

Neuroanatomie, Universität Göttingen

Dr. Rickmann, Institut für

Neuroanatomie, Universität Göttingen

Prof. Dr. Herbert Schwegler, Institut für

Anatomie, Universität Magdeburg 


\subsection{Eukaryotische Zellinien und Medien}

\subsubsection{Eukaryotische Zellinien}

WMP-1 Zellinie

(Zörnig et al. 1995)

\subsubsection{Medien für die Zellkultur}

RPMI-Gebrauchsmedium-I: $\quad$ RPMI-Medium 1640 mit L-Glutamin $15 \%$ FKS

$2 \%$ Penicillin/Streptomycin

$10 \mu \mathrm{g} / \mathrm{ml}$ Concanavalin A

$45 \mu \mathrm{g} / \mathrm{ml}$ Lipopolysaccharide

RPMI-Gebrauchsmedium-II: $\quad$ RPMI-Medium 1640

$$
\begin{aligned}
& 10 \% \text { FKS } \\
& 1 \% \text { L-Glutamin } \\
& 0,5 \% \text { Gentamycin }
\end{aligned}
$$

\subsection{Genomische Bibliotheken der Maus}

$\begin{array}{lll}\text { Maus Cosmid Bibliothek (129/ola) } & \text { RZPD Berlin } & \text { Bibliothek Nr. } 121 \\ \text { Maus PAC Bibliothek (RPCI21) } & \text { RZPD Berlin } & \text { Bibliothek Nr. } 711\end{array}$

\subsection{Mäuse- und Rattenstämme}

Mäuse des Stammes NMRI wurden von der Firma Charles River Wiga (Sulzfeld) und vom Zentralinstitut für Versuchstierzucht-ZFV (Hannover) bezogen oder in den institutseigenen Tierställen gezüchtet. Die transgene TC-Mauslinie wurde am Institut für Humangenetik in Göttingen von Dr. K. Nayernia auf einem NMRI-Hintergrund erzeugt (Nayernia et al. 1994) und durch Verpaarung von hetero- oder homozygoten Männchen mit heterozygoten Weibchen stabil etabliert. Die Haltungsbedingungen bestanden aus einem zwölfstündigen Hell-Dunkel-Rhythmus (Hellperiode: $6^{00}-18^{00}$ Uhr) bei einer Temperatur von $22{ }^{\circ} \mathrm{C}$. Den Tieren standen eine pelletierte Zuchtdiät (Herilan, Eggersmann, Rinteln) und Wasser ad libitum zur Verfügung. 


\title{
2.10 Methoden zur Isolierung und Konzentrationsbestimmung von Nukleinsäuren
}

\subsubsection{Isolierung hochmolekularer genomischer DNA aus Organen}

Lyse Puffer:

\author{
$50 \mathrm{mM}$ Tris / HCl, $\mathrm{pH} 8.0$ \\ $100 \mathrm{mM}$ EDTA \\ $0.5 \%$ SDS
}

Proteinase K: $\quad 10 \mathrm{mg} / \mathrm{ml} \quad$ in $\mathrm{H}_{2} \mathrm{O}$

Hochmolekulare genomische DNA wurde modifiziert nach Laird et al. (1991) isoliert. Dazu wurde Milzgewebe der Maus oder 1-2 cm des Mauseschwanzes einer lebenden Maus in $10 \mathrm{x}$ Volumen Lyse-Puffer (w/v) zusammen mit Proteinase $\mathrm{K}$ in einer Endkonzentration von $500 \mu \mathrm{g} / \mathrm{ml}$ in einem $50 \mathrm{ml}$ Zentrifugenröhrchen bei $55^{\circ} \mathrm{C}$ über Nacht in einem Schüttelwasserbad inkubiert. Nach Phenol- (1 x Volumen ss-Phenol) und Phenol/Chloroform-Extraktion (1 x Volumen ss-Phenol/Chloroform 1:1) wurde die DNA mit 0,1 x Volumen $3 \mathrm{M} \mathrm{NaOAc}$ und $2 \times$ Volumen $100 \%$ EtOH bei RT ausgefällt, mit $70 \%$ EtOH gewaschen, luftgetrocknet und in $200 \mu$ Ampuwa über mehrere Tage bei RT gelöst und bis zur Analyse bei $4{ }^{\circ} \mathrm{C}$ gelagert. Nach vollständigem Lösen der DNA erfolgte die Konzentrations- und Reinheitsbestimmung im Spektralphotometer (Ultraspec 3000 pro, Amersham Pharmacia) (2.10.8). Die DNA wurde für genomische Southern-Blots (2.15.1) und für Genome-Walking-Experimente (2.13.3) eingesetzt.

\subsubsection{Isolierung von Plasmid-DNA durch Midi- oder Maxipräparation}

Mit Hilfe von Plasmid-Vektoren kann rekombinante DNA (2.14) in Bakterien vermehrt werden. Die Auswahl der Plasmid-Isolierungsmethoden erfolgte nach dem jeweiligen Bedarf und der Kopienzahl der verwendeten Plasmide.

Größere Mengen Plasmid-DNA für Hybridisierungs- und Klonierungsexperimente wurden aus 200-500 ml LB-Übernachtkulturen mit entsprechendem plasmidkodiertem Antibiotikum durch eine modifizierte Form der alkalischen Lyse (Birnboim und Doly 1979; Birnboim 1983) mit den Lösungen des QIAGEN ${ }^{\circledR}$-Plasmid-Systems (QIAGEN $®$, Hilden) präpariert und mit Hilfe der mitgelieferten Anionenaustauschersäulen den Herstellerangaben folgend gereinigt. Die Kulturen wurden aus Minipräparations- oder Glyzerinkryokulturen angeimpft und über Nacht bei $37^{\circ} \mathrm{C}$ im Schüttler inkubiert. 


\subsubsection{Isolierung von Plasmid-, Cosmid- und PAC-DNA durch Minipräparation}

Die Isolierung von Plasmid-, Cosmid- und PAC-DNA im analytischen Maßstab (Minipräparation) wurde mit den Lösungen des QIAGEN $®-P l a s m i d-K i t s ~(Q I A G E N ®$, Hilden) mittels alkalischer Lyse (Birnboim und Doly 1979; Birnboim 1983) aus $5 \mathrm{ml}$ LB-Übernachtkulturen mit entsprechendem plasmidkodiertem Antibiotikum durchgeführt, wobei auf die Reinigung über Anionenaustauschersäulen verzichtet wurde. Die Qualität dieser DNA war hinreichend gut, um sie in Sequenzierungsreaktionen (2.17), in Restriktionen (2.16.1), im Southern-Blot (2.15.1) und für die Insert-Isolierung (2.12) einzusetzen.

\subsubsection{Isolierung von Cosmid- und PAC-DNA durch Maxipräparation}

Zur Isolierung von hochmolekularer Cosmid- und PAC-DNA im Maxipräparationsmaßstab, die frei von bakterieller genomischer DNA ist, wurde der „Large-Construct Kit“ der Firma QIAGEN ${ }^{\circledR}$ verwendet. Die PAC- und Cosmid-DNA wurde für Restriktionskartierungen (2.16.1) und als DNA-Sonde in FISH-Hybridisierungen (2.19.6) eingesetzt.

Vor der Präparation wurde eine LB-Selektivnährplatte durch Ausstreichen eines Teils der Glyzerinkryokulturen (2.10.5) angeimpft und über Nacht bei $37^{\circ} \mathrm{C}$ im Brutschrank inkubiert. Zunächst wurde eine LB-Vorkultur mit dem plasmidkodierten Antibiotikum von dieser Platte angeimpft, nach 8 Stunden 1:1000 in $500 \mathrm{ml}$ LB-Kulturmedium (+ Antibiotikum) verdünnt und diese präparative Kultur 16 Stunden bei $37^{\circ} \mathrm{C} \mathrm{im}$ Schüttelinkubator kultiviert. Die Cosmid- oder PAC-DNA wurde aus der Übernachtkultur durch alkalische Lyse (Birnboim und Doly 1979; Birnboim 1983) mit den Lösungen des „Large-Construct Kits“ (QIAGEN ${ }^{\circledR}$, Hilden) den Herstellerangaben folgend präpariert. Vor der Aufreinigung der DNA mit Hilfe der mitgelieferten Anionenaustauschersäulen wurde die DNA in diesem System den Herstellerangaben folgend ausgefällt, getrocknet, resuspendiert und mit ATP-abhängiger Exonuklease $(0,4 \mu \mathrm{g} / \mu \mathrm{l})$ unter Zugabe von ATP-Lösung für 1 Stunde bei $37^{\circ} \mathrm{C}$ inkubiert. Durch diese Exonuklease-Behandlung wurden Kontaminationen mit bakterieller und unvollständiger Cosmid- und PAC-DNA beseitigt. Nach der Exonuklease Behandlung wurde die DNA über Anionenaustauschersäulen gereinigt, die DNA bei $65^{\circ} \mathrm{C}$ eluiert, mit 2-Propanol gefällt, mit $70 \%$ EtOH gewaschen, getrocknet und in Ampuwa $\left(\mathrm{H}_{2} \mathrm{O}\right)$ gelöst. Die Ausbeute lag für PAC-DNA bei $50 \mu \mathrm{g}$ und für Cosmid-DNA bei $200 \mu \mathrm{g}$. 


\subsubsection{Herstellung von Glyzerinkryokulturen}

Glyzerinkryokulturen wurden aus den LB-Übernachtkulturen der PlasmidMinipräparationen (2.10.3) durch Zugabe von $500 \mu$ sterilem Glyzerin zu $800 \mu \mathrm{l}$ der Bakteriensuspension, anschließender Durchmischung und Lagerung bei $-70{ }^{\circ} \mathrm{C}$ hergestellt.

\subsubsection{Isolierung von Gesamt-RNA aus Gewebe}

Gesamt-RNA für Northern-Analysen wurde aus unterschiedlichen Geweben der Maus und aus verschiedenen Gehirn-Arealen (2.20) isoliert. Da RNA besonders anfällig gegen Abbau durch RNasen endogener und exogener Herkunft ist, wurden alle Lösungen und das Millipore- $\mathrm{H}_{2} \mathrm{O}$ über Nacht mit $0.1 \%$ DMDC inkubiert und autoklaviert, die Benutzung von Glaswaren weitestgehend vermieden oder über Nacht bei $180{ }^{\circ} \mathrm{C}$ erhitzt. Um eine RNase-Kontamination aus exogener Quelle zu vermeiden, wurden alle Glasgeräte und Einmal-Plastikartikel nur mit Handschuhen berührt. Die Arbeitsschritte wurden weiterhin nach Möglichkeit auf Eis oder im Kühlraum durchgeführt.

Die Organe für die RNA-Präparation wurden mit sterilem Präparierbesteck entnommen, kurz in 1 x PBS-Puffer gespült und sofort in einem Reaktionsgefäß in flüssigem Stickstoff schockgefroren. Die Isolierung der RNA wurde mit dem „Total RNA Isolations Reagent" der Firma Biomol (Hamburg) durchgeführt und basiert im wesentlichen auf der Methode von Chomczynski und Sacchi (1987). Bis zu $100 \mathrm{mg}$ Gewebe wurden mit $1 \mathrm{ml}$ „Total RNA Isolations Reagent“ versetzt, mit einem Dispergierwerkzeugs (Ultraturrax T 25, Schütt, Göttingen) homogenisiert und zur vollständigen Dissoziation der Nukleoproteinkomplexe 5 Minuten auf Eis inkubiert. Nach Zugabe von $200 \mu \mathrm{l}$ Chloroform wurde die Suspension vorsichtig "über Kopf" gemischt und erneut 5 Minuten auf Eis inkubiert. Durch Zentrifugation für 10 Minuten bei $4000 \mathrm{x}$ g und $4{ }^{\circ} \mathrm{C}$ wurden die Phasen getrennt. Die obere wässrige Phase wurde in ein neues Reaktionsgefäß überführt und die RNA durch Zugabe von 1 x Volumen 2-Propanol für 10 Minuten auf Eis präzipitiert, durch Zentrifugation für 10 Minuten bei $4000 \mathrm{x} \mathrm{g}$ und $4{ }^{\circ} \mathrm{C}$ sedimentiert, einmal in $75 \%$ Ethanol gewaschen, getrocknet und in 50-100 $\mu$ l DMDC-Wasser gelöst. Die Konzentrationsbestimmung der RNA erfolgte photometrisch (2.10.8), und die Intaktheit der RNA wurde in einem denaturierenden Agarosegel (2.11.2) getestet. Die RNA wurde bis zur weiteten Verwendung bei $-70{ }^{\circ} \mathrm{C}$ aufbewahrt. 


\subsubsection{Selektive Anreicherung von mRNA aus Gesamt-RNA Präparationen}

Die Gesamt-RNA aus der Präparation in Kapitel 2.10.6 wurde für besondere Anwendungen durch Affinitätschromatografie über eine oligo(dT) Zellulose-Matrix, die eine Bindungsaffinität zu polyadenylierter (poly-A ${ }^{+}$) mRNA besitzt, von ribosomaler RNA (rRNA) und anderer nicht polyadenylierter (poly-A') mRNA (z.B Histone) befreit. Dazu wurde in dieser Arbeit das MESSAGEMAKER ${ }^{\mathrm{TM}}$ mRNA Isolationssystem der Firma Gibco BRL (Eggenstein) verwendet. Nach der Konzentrationsbestimmnung der Gesamt-RNA Präparation (2.10.8) wurden bis zu 2 mg Gesamt-RNA mit DMDC- $\mathrm{H}_{2} \mathrm{O}$ auf eine Konzentration von maximal $0,55 \mu \mathrm{g} / \mu$ l eingestellt, für 5 Minuten bei $65^{\circ} \mathrm{C}$ hitzedenaturiert und auf Eis abgekühlt. Anschließend wurde die NaCl-Konzentration der RNA-Lösung durch Zugabe von 0,11 x Volumen $5 \mathrm{M} \mathrm{NaCl}$ auf 0,5 $\mathrm{M}$ eingestellt, die RNA-Lösung mit der oligo(dT) Zellulose-Lösung den Herstellerangeben folgend gemischt, für 10 Minuten bei $37^{\circ} \mathrm{C}$ unter Schütteln die Bindung der poly- $\mathrm{A}^{+}-\mathrm{mRNA}$ an die oligo(dT) Matrix hergestellt und die Suspension in die vom Hersteller gelieferte Säule überführt. Anschließend wurde die Säulenmatrix komprimiert und die Waschschritte (0,5 M NaCl / $20 \mathrm{mM}$ Tris $\mathrm{pH}$ 7,4 und 0,1 M NaCl / $20 \mathrm{mM}$ Tris pH 7,4) nacheinander den Herstellerangaben folgend ausgeführt, wobei die Suspension bei jedem Waschschritte erneut resuspendiert und komprimiert wurde. Die poly- $\mathrm{A}^{+}-\mathrm{mRNA}$ Fraktion konnte anschließend durch Zugabe von auf $65^{\circ} \mathrm{C}$ vorgewärmtem DMDCWasser eluiert werden. Es wurde dann eine zweite Selektion wie beschrieben

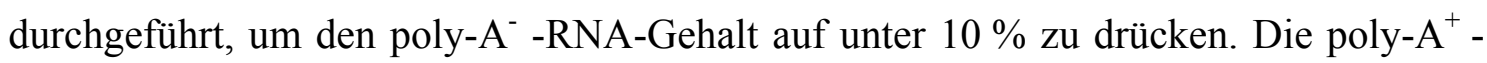
mRNA wurde durch Zugabe von 0,1 x Volumen $3 \mathrm{M} \mathrm{NaOAc}$ und 2,5 x Volumen EtOH über Nacht bei $-20{ }^{\circ} \mathrm{C}$ ausgefällt, zentrifugiert (Minizentrifuge, $12000 \mathrm{x}$ g, 20 Minuten, $4{ }^{\circ} \mathrm{C}$ ), mit $70 \%$ EtOH gewaschen und in DMDC- $\mathrm{H}_{2} \mathrm{O}$ gelöst. Nach zwei Selektionen betrug die Ausbeute etwa $1 \%(w / w)$.

\subsubsection{Konzentrationsbestimmung von Nukleinsäuren}

Die Konzentrationsbestimmung von Nukleinsäuren erfolgte photometrisch durch Bestimmung der Lichtabsorption bei $260 \mathrm{~nm}$ in einem Spektralphotometer (Ultrospec ${ }^{\circledR}$ 3000 pro, Amersham Pharmacia Biotech). Man erhält die Nukleinsäure-Konzentration nach folgender Formel:

$$
c=\left(O D_{260}-O D_{320}\right) \bullet \varepsilon \bullet f \quad \begin{aligned}
& f=\text { Verdünnungsfaktor } \\
& \varepsilon=50 \mu g / \mu l \quad(D N A) \\
& \varepsilon=40 \mu g / \mu l \quad(R N A)
\end{aligned}
$$




\subsection{Gelelektrophoretische Methoden}

\subsubsection{Horizontale Agarose-Gelelektrophorese}

Die horizontale Agarose-Gelelektrophorese (Sambrook et al. 1989) wurde standardmäßig mit einer Agarosekonzentration von $1.0 \%$ (w/v) im 0,5 x TBEPuffersystem durchgeführt und diente der Integritätsprüfung isolierter bzw. synthetisierter Nukleinsäuren (siehe 2.10), der Überprüfung durchgeführter enzymatischer Modifikationen (siehe 2.16) und der „Insert"-Isolierung über Anionenaustauschersilikat (siehe 2.12.1). Die TBE -Gelelektrophorese wurde auch dann benutzt, wenn das Gel nach der Elektrophorese geblottet werden sollte (siehe 2.15.1 und 2.15.2). Die Elektrophorese restringierter genomischer DNA für genomische „SouthernBlots“ (2.15.1) wurde in großen horizontalen Gelkammern $(10$ x $15 \mathrm{~cm}) \mathrm{im} 1 \mathrm{x}$ TAE Puffersystem durchgeführt.

Die Agarose wurde durch Aufkochen in 100-200 ml des entsprechenden Elektrophoresepuffers gelöst, mit $5 \mu$ Ethidiumbromid (Stammlösung $1 \mu \mathrm{g} / \mu \mathrm{l}$ ) versetzt und in die Gelkammer gegossen. Nach Erkalten und Verfestigung der Agarose wurden die Reaktionsansätze nach Zugabe von 0,2 x Volumen Stop-Mix I aufgetragen und in dem entsprechenden Elektrophorese-Puffer bei einer konstanten Spannung von 1.0 - 5.0 $\mathrm{V} / \mathrm{cm}$ elektrophoretisch aufgetrennt. Nach der Elektrophorese wurden die Gele auf einem UV-Transilluminator $(230-360 \mathrm{~nm})$ mit einem Video-Dokumentationssytem (Herolab, Heidelberg) fotografiert und bei Bedarf auf Nitrozellosemembranen transferiert (2.15.1).

\subsubsection{Denaturierende Agarose-Gelelektrophorese}

(Hodge 1994)

10 x MOPS-Puffer:

RNA-Probenpuffer:

RNA-Ladepuffer:

\author{
0,2 M MOPS \\ $50 \mathrm{mM} \mathrm{NaOAc}$ \\ 10 mM EDTA $\quad$ pH 7,0 mit $\mathrm{NaOH}$
}

$60 \%$ Formamid

9,25\% Formaldehyd

1,5 x MOPS-Puffer

$15 \%$ Ficoll 400

$1 \mathrm{mM}$ EDTA

$0.01 \%$ Orange $\mathrm{G}$

$0,05 \%$ Ethidiumbromid (w/v) 
Um eine Rückbildung der Sekundärstruktur der RNA während der Elektrophorese zu vermeiden, wurden RNA-Proben unter denaturierenden Bedingungen in Agarosegelen mit Formaldehyd aufgetrennt. Zur Herstellung dieser Gele wurden $200 \mathrm{ml}$ eines Agarosegels (1,0\%) durch Aufkochen von 2 g Agarose und $20 \mathrm{ml} 10$ x MOPS-Puffer zusammen mit $148 \mathrm{ml}$ DMDC-Wasser hergestellt, nach dem Abkühlen bis auf $60{ }^{\circ} \mathrm{C}$ mit 33,2 ml Formaldehyd bis auf eine Endkonzentration von 6,2 \% (v/v) gemischt und das Gel wie unter 2.11.1 beschrieben in eine horizontale Gelkammer gegossen. Das denaturierende Agarosegel wurde analog zum "Southern-Blot" zum Transfer von gelelektrophoretisch getrennter RNA im „Northern-Blot" (Sambrook et al. 1989) auf eine Nitrozellulosemembran (2.15.2) benutzt.

Die RNA-Proben (15-30 $\mu$ g Gesamt-RNA bzw. 1-2 $\mu \mathrm{g}$ poly-A ${ }^{+}$-mRNA) und $4 \mu \mathrm{l}$ RNA-Längenstandard ( $4 \mu \mathrm{g}$ ) wurden in der Vakuum-Zentrifuge oder durch Zugabe von DMDC-Wasser auf ein Volumen von $6 \mu \mathrm{l}$ gebracht, mit $12 \mu \mathrm{l}$ frisch zubereitetem Proben-Puffer vermischt, für 10 Minuten bei $65{ }^{\circ} \mathrm{C}$ denaturiert und anschließend für 5 Minuten auf Eis gestellt, um eine Renaturierung zu vermeiden. Vor dem Auftragen wurden die Proben mit 0,25 x Volumen RNA-Ladepuffer versetzt und in die Geltaschen pipettiert. Die Elektrophorese erfolgte in 1 x MOPS-Puffer für 8-10 Stunden bei konstanter Spannung von $4.0 \mathrm{~V} / \mathrm{cm}$ bei Raumtemperatur.

\subsubsection{Denaturierende SDS-Polyacrylamid-Gelelektrophorese zur Auftrennung von Proteinen}

(Laemmli 1970)

Acrylamid-Stammlösung:

$40 \%$ (w/v) Acrylamid / Bisacrylamid (29:1)

(Amresco ${ }^{\circledR}$, Ohio)

Laufpuffer (5x):

$25 \mathrm{mM}$ Tris/ $\mathrm{HCl}$ (pH 8.3)

$192 \mathrm{mM}$ Glycin

$0.1 \%$ SDS

Ladepuffer (2x):

$0.5 \mathrm{M}$ Tris/ $\mathrm{HCl}(\mathrm{pH} 6.8)$

$20 \%$ Glyzerin

$0.25 \%$ Bromphenolblau

$4 \%$ SDS (frisch zugesetzt)

$10 \%$ 2-Mercaptoethanol (frisch zugesetzt)

Sammelgelpuffer (4x): $\quad 0.5 \mathrm{M}$ Tris/ $\mathrm{HCl}(\mathrm{pH}$ 6.8)

Trenngelpuffer (4x): $\quad$ 1.5 M Tris/ $\mathrm{HCl}(\mathrm{pH} 8.8)$

APS-Lösung $\quad 10 \%$ APS (w/v) in $\mathrm{H}_{2} \mathrm{O}$ 
Durch die denaturierende SDS-PAGE werden Proteine entsprechend ihren Molekulargewichten aufgetrennt. Durch Aufkochen mit SDS werden die Polypeptidketten entfaltet und dann einheitlich mit einer negativen Ladung abgesättigt, so dass die Eigenladung der Proteine vernachlässigbar wird und deren Wanderungsgeschwindigkeit vorrangig durch das Molekulargewicht bestimmt ist. Durch Verwendung von 2-Mercaptoethanol werden zusätzlich vorhandene Disulfidbrücken reduziert. Mit Hilfe der SDS-PAGE wurden die Gesamt-Proteine aus Gehirn und Hippocampus (2.21.1) aufgetrennt und nach der Elektrophorese durch „Western-Blotting" auf eine Membran (Porablot PVDF, Macherey Nagel, Düren) transferiert (2.15.3).

Die SDS-PAGE zur Auftrennung von Proteinen wurde standardmäßig diskontinuierlich mit einem Konzentrations- und pH-Sprung im Gel durchgeführt. Dadurch wurde die Lauffront gebündelt und die Auflösung der Elektrophorese erhöht. Ein 3,5-20 \%iges Trenngel ( $\mathrm{pH} 8,8)$ wurde dabei in 1,5 mm Schichtdicke zwischen zwei Glasplatten (14 x $16 \mathrm{~cm})$ gegossen und mit einem $4 \%$ igen Sammelgel $(\mathrm{pH} 6,8)$ überschichtet. Die Polyacrylamidstufen wurden aus der 40 \%igen Acrylamid-Stammlösung (Amresco ${ }^{\circledR}$, Ohio) in $1 \mathrm{x}$ Trenn- bzw. Sammelgelpuffer auf die entsprechende Konzentration verdünnt und mit 0,1\% SDS versetzt. Die Polymerisation wurde durch die Zugabe des Radikalbildners APS (0,05\%) und des Radikal-Stabilisators TEMED (0,1\%) gestartet. Die Trenngelstufe wurde bis zur Polymerisation mit $1 \mathrm{x}$ Trenngelpuffer überschichtet. Nach einem Vorlauf von 30 Minuten bei $25 \mathrm{~mA}$ in 1 x Laufpuffer wurden die Proben mit 1 x Volumen 2 x Ladepuffer vermischt, für 3 Minuten bei $95{ }^{\circ} \mathrm{C}$ denaturiert, 1 Minute bei 12000 x g zentrifugiert, in die Geltaschen pipettiert und bei $50 \mathrm{~mA}$ aufgetrennt. Als Standard wurden 7,5 $\mu$ l eines vorgefärbten Protein-ElektrophoreseStandards (,prestained“ SeaBlue ${ }^{\mathrm{TM}}$ Plus2, 4-250 kDa, Firma NOVEX) eingesetzt.

\subsection{Isolierung und Aufreinigung von Nukleinsäurefragmenten}

\subsubsection{Isolierung und Aufreinigung von DNA-Fragmenten aus Agarosegelen mittels Anionenaustauschersilikat}

Diese Methode wurde eingesetzt, um DNA-Fragmente für Hybridisierungs- (2.16.5) und für Klonierungsexperimente (2.14) zu isolieren. Dazu kamen die Fertigsysteme der Firmen Genomed (Bad Oeynhausen, „Jetsorb") und Macherey-Nagel (Düren, NucleoSpin ${ }^{\circledR}$ Extract) zum Einsatz. In beiden System wird die Agarose nach Zugabe einer hochmolaren Lösung des chaotropen Salzes Natriumperchlorat $\left(\mathrm{NaClO}_{4}\right)$ bei $50{ }^{\circ} \mathrm{C}$ irreversibel aufgelöst und die DNA nach dem von Vogelstein und Gillespie (1979) beschriebenen Prinzip in Suspension („Glasmilch“, Jetsorb) oder in „spin- 
Säulen“ an Anionenaustauschersilikat gebunden, mehreren Waschschritten mit Hochsalzpuffer und Niedrigsalzpuffer unterzogen und mit Wasser (Ampuwa) oder TEPuffer eluiert. Die im Macherey Nagel-System durch Zentrifugation optimierten Waschschritte ermöglichen eine salz- und silikatfreie DNA-Präparation und wurden daher zur Aufbereitung von PCR-Produkten vor deren Klonierung (2.14.1) benutzt.

Die entsprechende DNA-Bande wurde nach gelelektrophoretischer Auftrennung (2.11.1) auf einem Transilluminator unter langwelligem UV-Licht (366 nm) mit einem sterilen Skalpell herausgeschnitten und die DNA den Herstellerangaben folgend isoliert.

\subsection{Techniken der Polymerase-Ketten-Reaktion (PCR)}

Die PCR-Technik ist eine enzymatische Methode für die in vitro Amplifikation spezifischer DNA-Fragmente (Saiki et al. 1988). Die Spezifität dieser Amplifikation basiert auf zwei Oligonukleotidprimern, die das zu amplifizierende DNA-Segment flankieren und nach einer Hitzedenaturierung an den komplementären Strängen binden. Die hitzestabile DNA-Polymerase (Taq-Polymerase) des Archeabakteriums Thermus aquaticus (Chien et al. 1976) synthetisiert bei ihrer optimalen Temperatur $\left(72{ }^{\circ} \mathrm{C}\right)$ die DNA entlang der Region zwischen den Primern. Durch sich wiederholende Zyklen von Denaturierung der DNA-Stränge, Anlagerung der Primer ("Annealing") und DNASynthese (Elongation) wird eine exponentielle Vermehrung des jeweiligen DNAFragmentes erreicht. Durch den Einsatz der hitzestabilen Taq-Polymerase wird die Automatisierung der PCR in Thermocyclern ermöglicht.

\subsubsection{PCR an Plasmid-DNA}

Die PCR an Plasmid-DNA wurde durchgeführt, um DNA-Fragmente zu amplifizieren, die nicht durch restriktionsenzymatische Spaltung isoliert werden konnten. Für die PCR wurden folgende Reagenzien aus dem PLATINUM ${ }^{\circledR}$ Taq DNA Polymerase-System (Gibco BRL) in einem dünnwandigen 0,2 ml PCR-Reaktionsgefäß zu einem Gesamtansatz von $50 \mu 1$ zusammenpipettiert:

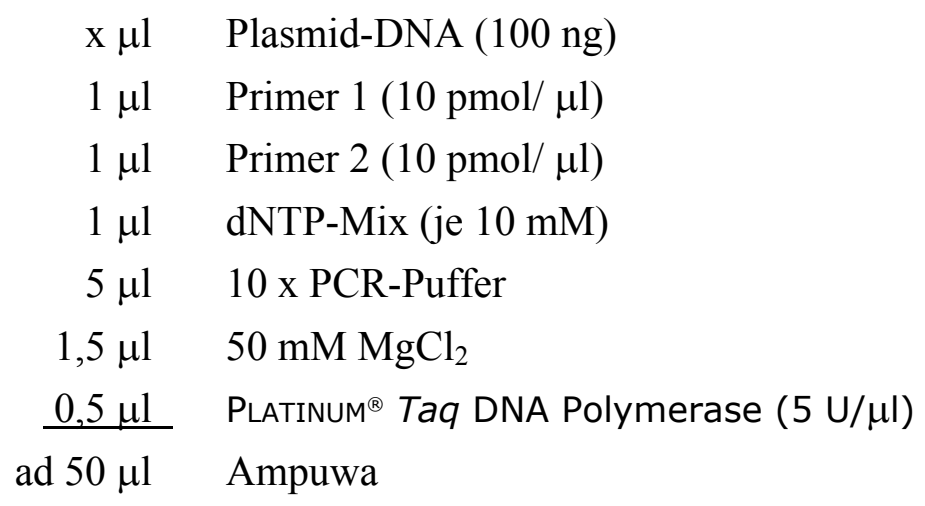


Die Ansätze wurden in einem Thermocycler (Primus 96, MWG Biotech) mit folgendem PCR-Profil für 35 Zyklen inkubiert:

$\left.\begin{array}{lll}5 \text { Min. } & 95{ }^{\circ} \mathrm{C} & \text { Vordenaturierung } \\ 30 \text { Sek. } & 95{ }^{\circ} \mathrm{C} & \text { Denaturierung } \\ 30 \text { Sek. } & 55-65{ }^{\circ} \mathrm{C} & \text { Annealing } \\ 1 \text { Min./ } \mathrm{kb} & 72{ }^{\circ} \mathrm{C} & \text { Elongation } \\ 7 \mathrm{Min} . & 72{ }^{\circ} \mathrm{C} & \text { Auffüllreaktion }\end{array}\right\} x \quad 35$

Die „Annealing"-Temperatur (Anlagerung der Primer) war spezifisch für die einzelnen Primerpaare und wurde für jede Primerkombination optimiert. Die Spezifität des Produktes (Fragmentlänge) wurde nach der Amplifikation in einer horizontalen Agarose-Gelelektrophorese (siehe 2.11.1) überprüft. Dazu wurden $5 \mu$ les Reaktionsansatzes mit 0,2 x Volumen Stop-Mix I vermischt und auf das Gel aufgetragen. In präparativen Ansätzen zur Aufreinigung der PCR-Produkte wurden 20 bis $30 \mu \mathrm{l}$ des PCR-Ansatzes ebenfalls mit 0,2 x Volumen Stop-Mix I auf ein horizontales Agarosegel (1\%) aufgetragen und wie unter 2.12 beschrieben gereinigt.

\subsection{2 „Reverse Transkriptions-PCR“ (RT-PCR)}

(Loh et al. 1989)

Unter der „Reversen Transkriptions-PCR” versteht man die Amplifikation von cDNASequenzen (komplementäre DNA), die zuvor durch reverse in vitro-Transkription der mRNA mit Hilfe des Enzyms Reverse Transkriptase synthetisiert wurden. Mittels der RT-PCR können kleinste Transkriptmengen in Geweben detektiert werden. Die RNA wird dabei in cDNA umgeschrieben (Erststrangsynthese der komplementären DNA). In dieser Arbeit wurde ausschließlich die RT-PCR mit sequenzspezifischer Erststrangsynthese benutzt, um die Expression eines großen Transkriptes zu untersuchen und dessen 5'-cDNA Bereiche zu klonieren. Die Intaktheit und die Integrität der verwendeten RNA wurde über eine Kontroll-RT-PCR mit einem Primerpaar, das ein spezifisches $480 \mathrm{bp}$ Fragment eines ubiquitär exprimierten Stoffwechselgens (GAPDH=Glyzerinaldehyd-3-Phosphat-Dehydrogensase) amplifiziert, dokumentiert (Seipp und Buselmaier 1994).

Es wurden 1 bis $5 \mu \mathrm{g}$ Gesamt-RNA mit 2 pmol genspezifischem Primer (GSP) und 2 pmol des reversen GAPDH-Primers $\left(\mathrm{GAPDH}_{\mathrm{rev}}\right)$ in einem Ansatzvolumen von $11 \mu \mathrm{l}$ für 10 Minuten bei $70^{\circ} \mathrm{C}$ denaturiert und 5 Minuten auf Eis gekühlt. Zu diesem Ansatz wurden folgende Komponenten aus dem SUPERSCRIPT ${ }^{\mathrm{TM}}$ II-System (Gibco BRL) 
gegeben, und anschließend 2 Minuten bei $42^{\circ} \mathrm{C}$ in einem Themocycler (Primus 96, MWG Biotech) vorinkubiert:

$$
\begin{array}{rl}
11 \mu \mathrm{l} & \text { Ansatz (RNA und Primer) } \\
4 \mu \mathrm{l} & 5 \mathrm{x} \text { Reverse Transkriptase-Puffer } \\
2 \mu \mathrm{l} & \text { DTT (0,1 M) } \\
1 \mu \mathrm{l} & \text { dNTP-Mix (je } 10 \mathrm{mM}) \\
1 \mu \mathrm{l} & \text { RNase Inhibitor }
\end{array}
$$

Nach der Vorinkubation wurde $1 \mu \mathrm{l}$ RNase $\mathrm{H}^{-}$Reverse Transkriptase (SUPERSCRIPT $^{\mathrm{TM}}$ II, $200 \mathrm{U}$ ) dazupipettiert, gemischt und 50 Minuten bei $42{ }^{\circ} \mathrm{C}$ inkubiert. Anschließend wurde die zur cDNA komplementäre RNA durch Zugabe von 2 U E. coli RNase H (Gibco BRL) und 20 Minuten Inkubation bei $37^{\circ} \mathrm{C}$ entfernt, da diese RNA die Amplifikation speziell von größeren PCR-Produkten $(>1 \mathrm{~kb})$ inhibieren kann. Die cDNA konnte direkt als Template in die PCR-Reaktion eingesetzt werden oder wurde bei $-20{ }^{\circ} \mathrm{C}$ eingefroren.

Für die PCR wurden folgende Reagenzien aus dem PLATINUm ${ }^{\circledR}$ Taq DNA PolymeraseSystem (Gibco BRL) in einem dünnwandigen 0,2 ml PCR-Reaktionsgefäß zu einem Gesamtansatz von $50 \mu \mathrm{l}$ zusammenpipettiert:

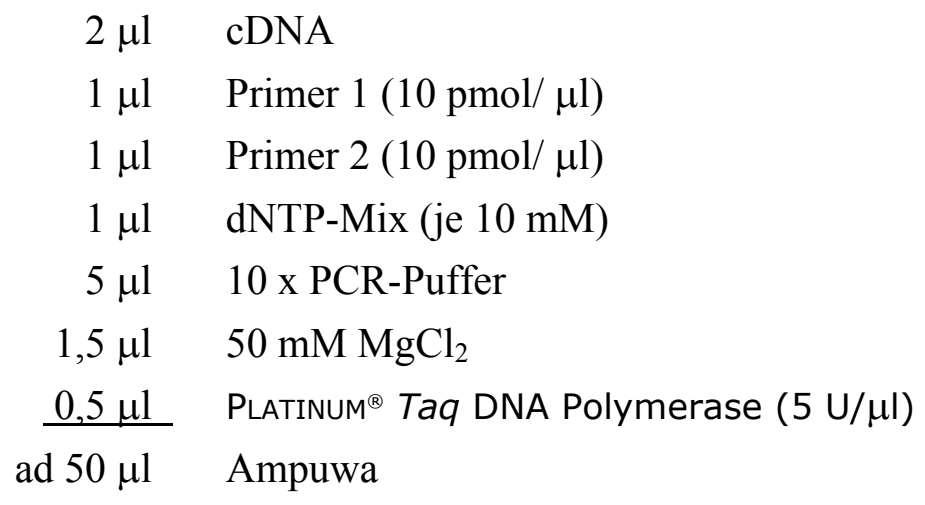

Die Ansätze wurden in einem Thermocycler (Primus 96, MWG Biotech) mit folgendem PCR-Profil für 35 Zyklen inkubiert:

$\begin{array}{lll}5 \text { Min. } & 95^{\circ} \mathrm{C} & \text { Vordenaturierung } \\ 30 \text { Sek. } & 95{ }^{\circ} \mathrm{C} & \text { Denaturierung } \\ 30 \text { Sek. } & 55-65{ }^{\circ} \mathrm{C} & \text { Annealing } \\ 1 \text { Min./ kb } & 72{ }^{\circ} \mathrm{C} & \text { Elongation } \\ 7 \text { Min. } & 72{ }^{\circ} \mathrm{C} & \text { Auffüllreaktion } \\ \infty & 4{ }^{\circ} \mathrm{C} & \text { Kühlung }\end{array}$

Zeitgleich wurde die GAPDH-Kontroll-PCR an den synthetisierten cDNA - Proben mit Hilfe des GAPDH-Primerpaares durchgeführt. Ein Aliquot der PCR-Proben wurde 
anschließend wie unter 2.11.1 auf einem Agarosegel getestet und die PCR-Produkte bei Bedarf über ein präparatives Agarosegel isoliert und subkloniert (2.14). In einigen Fällen war es nötig, eine sogenannte ,nested-PCR“ mit einem zweiten Primerpaar an der DNA der ersten Amplifikation durchzuführen, bevor man spezifische PCR-Produkte erhalten konnte. Dazu wurde die 1. PCR 1:50 mit Ampuwa verdünnt und davon $1 \mu$ in einem weiteren PCR-Ansatz mit einem zweiten Primer-Paar eingesetzt und in einem Thermocycler mit dem oben beschriebenen PCR-Programm amplifiziert.

\subsubsection{PCR-basiertes „Genome Walking“6}

PCR-basiertes „Genome Walking” ist eine Methode zur Amplifikation und Klonierung unbekannter genomischer DNA-Abschnitte in direkter Nachbarschaft bekannter DNASequenzen, wie z.B. cDNA (Siebert et al. 1995). In dieser Arbeit wurde die Methode benutzt, um eine Wildtyp-genomische Region zu amplifizieren und zu klonieren, die in direkter Nachbarschaft zu einer transgenen DNA-Insertion liegt. Zu diesem Zweck wurde hochmolekulare genomische DNA der zu testenden Mäuse isoliert und daraus DNA-Pools Adaptor-ligierter genomischer DNA-Fragmente erzeugt. Aliquots dieser Adaptor-ligierten DNA-Pools wurden dann in zwei aufeinanderfolgenden PCRAmplifikationen mit je einem von zwei genspezifschen Primern $\left(\mathrm{GSP}_{1}\right.$ und $\left.\mathrm{GSP}_{2}\right)$ und einem der zwei Adaptor-Primer $\left(\mathrm{AP}_{\mathrm{GW}} 1\right.$ und $\left.\mathrm{AP}_{\mathrm{GW}}{ }_{2}\right)$ eingesetzt (Abb. 2.1). Die Qualität der DNA-Pools wurde analog in zwei Kontroll-PCRs mit genspezifischen Kontroll-Primern (PCP1 und PCP2) und den beiden Adaptor-Primern ( $\mathrm{AP}_{\mathrm{GW}} 1$ und $\mathrm{AP}_{\mathrm{GW} 2}$ ) überprüft. 

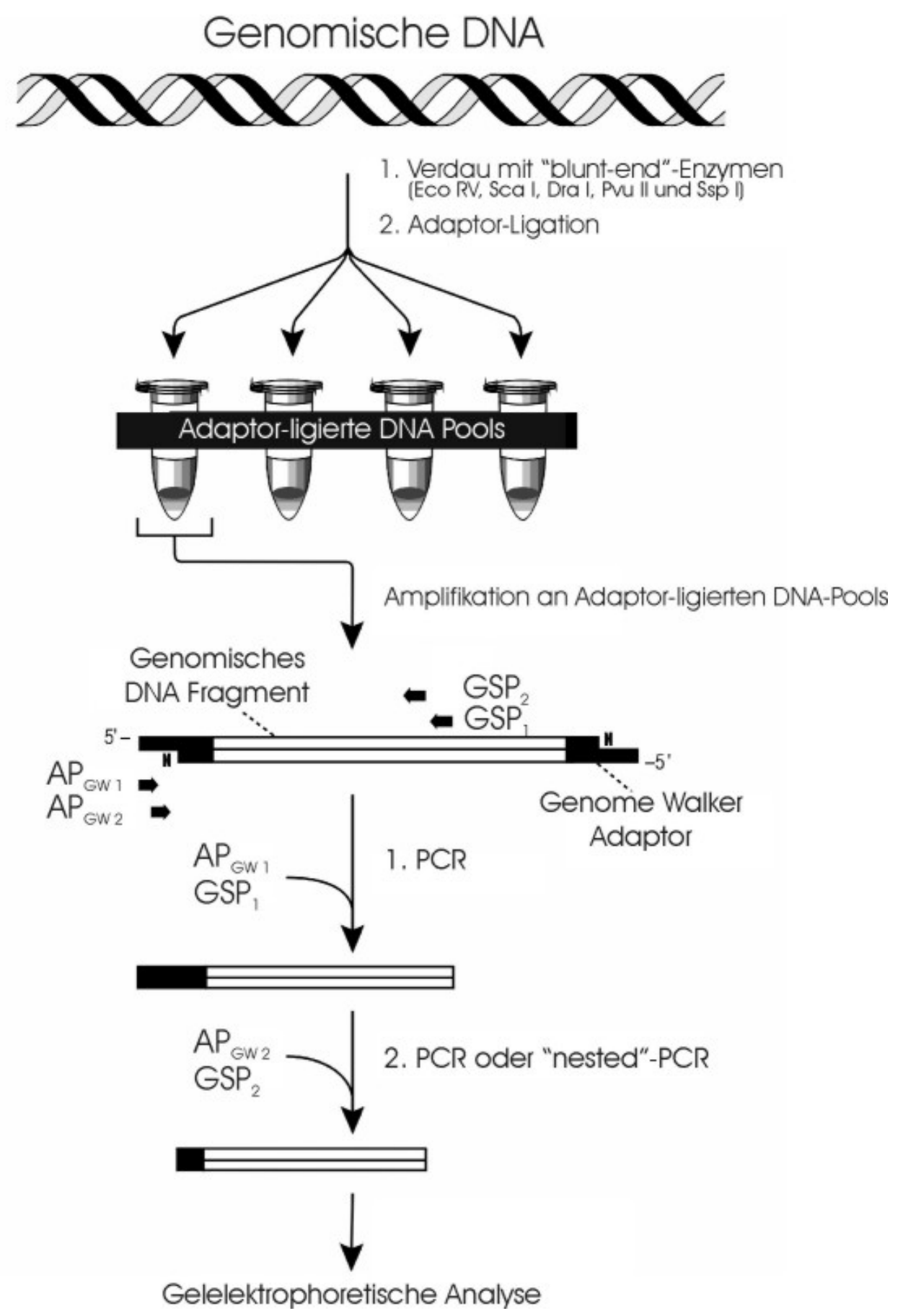

Abb. 2.1: Schematische Darstellung des „Genome-Walking“-Protokolls: Hochmolekulare genomische DNA wird mit „blunt-end“ -Restriktionsenzymen geschnitten und die Fragmente mit dem Genome-Walker - Adaptor ligiert. Aliquots dieser Adaptor-ligierten DNA-Pools werden dann in zwei aufeinanderfolgenden PCR-Amplifikationen mit genspezifschen Primern (GSP $P_{1}$ und $\left.G S P_{2}\right)$ und den Adaptor-Primern $\left(A P_{G W 1}\right.$ und $\left.A P_{G W} 2\right)$ in PCR-Reaktionen eingesetzt und die Amplifikate gelelektrophoretisch analysiert. 
Hochmolekulare genomische DNA wurde wie in Kapitel 2.10.1 beschrieben isoliert und je 2,5 $\mu \mathrm{g}$ Aliquots komplett mit Restriktionsendonukleasen, die glatte Enden („,blunt ends“; EcoR V, Sca I, Dra I, Pvu II, Ssp I) hinterlassen, folgendem Schema folgend über Nacht bei $37^{\circ} \mathrm{C}$ verdaut:

$$
\begin{array}{rll}
\mathrm{x} \mu \mathrm{l} & \text { Genomische DNA } & (2,5 \mu \mathrm{g}) \\
10 \mu \mathrm{l} & 10 \mathrm{x} \text { Reaktions-Puffer } & \\
\underline{8 \mu \mathrm{l}} & \underline{\text { Restriktionsendonuklease }} & (10 \mathrm{U} / \mu \mathrm{l}) \\
\mathrm{H}_{2} \mathrm{O} \text { ad } 100 \mu \mathrm{l} & &
\end{array}
$$

Über ein Agarosegel (2.11.1) wurde ein Aliquot von $5 \mu \mathrm{l}$ auf Vollständigkeit der enzymatischen Reaktion überprüft und gegebenenfalls durch Zugabe von weiterem Enzym, Puffer und entsprechender Erhöhung des Reaktionsvolumens nachverdaut. Erst nach vollständiger Restriktion wurde der Ansatz über Phenol- und ChloroformExtraktion ( $1 \mathrm{x}$ Volumen Phenol, $1 \mathrm{x}$ Volumen Chloroform) von Restriktionsendonuklease befreit und die wässrige Phase nach Zugabe von $20 \mu \mathrm{g}$ Glykogen als „Carrier“, 0,1 x Volumen NaOAc (pH 4,5) und $2 \times$ Volumen EtOH $\left(-20^{\circ} \mathrm{C}\right)$ für 10 Minuten bei $12000 \mathrm{x} \mathrm{g}$ in einer Minizentrifuge präzipitiert, in $80 \% \mathrm{EtOH}\left(-20^{\circ} \mathrm{C}\right)$ gewaschen, getrocknet und in $20 \mu \mathrm{l}$ TE-Puffer $(\mathrm{pH} 7,5)$ gelöst.

Der Adaptor wurde aus den entsprechenden Oligonukleotiden $\left(\mathrm{GW}_{1}\right.$ und $\left.\mathrm{GW}_{2}\right)$ durch Assoziation (,Annealing“) selbst hergestellt. Dazu wurden die Oligonukleotide im äquimolaren Verhältnis (je $25 \mu \mathrm{M}$ ) in einem Schraubdeckelreaktionsgefäß gemischt, für 10 Minuten in einem Becherglas mit $200 \mathrm{ml}$ Wasser durch Aufkochen denaturiert und zusammen mit dem Becherglas in einer Styroporkiste über Nacht bei $4{ }^{\circ} \mathrm{C}$ langsam reassoziiert. Der Adaptor (Endkonzentration: $25 \mu \mathrm{M}$ ) wurde anschließend bei $-20{ }^{\circ} \mathrm{C}$ gelagert.

Die Adaptor-Ligation wurde nach folgendem Pipettierschema angesetzt und über Nacht bei $16{ }^{\circ} \mathrm{C}$ durchgeführt:

$$
\begin{array}{ll}
4,0 \mu \mathrm{l} & \text {,blunt end“"genomische DNA } \\
1,9 \mu \mathrm{l} & \text { Adaptor (25 } \mu \mathrm{M}) \\
1,6 \mu \mathrm{l} & 5 \mathrm{x} \text { Ligation-Puffer (Promega) } \\
\underline{0,5 \mu \mathrm{l}} & \text { T4-Ligase (Promega, 3 U/ } \mu \mathrm{l}) \\
8,0 \mu \mathrm{l} &
\end{array}
$$

Die Ligation wurde dann durch Inkubation für 5 Minuten bei $70{ }^{\circ} \mathrm{C}$ beendet und die DNA-Pools durch Zugabe von $72 \mu 11$ x TE-Puffer (pH 7,4) 1:10 verdünnt. Die DNA konnte direkt als Template in die PCR-Reaktion eingesetzt werden oder wurde bei $-20{ }^{\circ} \mathrm{C}$ eingefroren. 
Für die „Genome Walking“ -PCR wurde das „Advantage ${ }^{\circledR}$ Genomic PCR-System“ der Firma ClONTECH (Heidelberg) verwendet. Dieses PCR-System enthält einen 50 x Polymerase-Mix mit Tth DNA-Polymerase (thermostabile DNA-Polymerase aus Thermus thermophilus) als Hauptkomponente, eine geringe Menge einer weiteren DNA-Polymerase mit 3'-5'-Exonukleaseaktivität zur Fehlerkorrektur $\left(V^{\prime}\right.$ ent $\left._{R}{ }^{\circledR}\right)$ und einen monoklonalen TthStart ${ }^{\mathrm{TM}}$-Antikörper, der die Tth DNA-Polymerase bis zur ersten Denaturierung neutralisert (automatischer „Hot Start"). Durch die Verwendung dieses Polymerase-Systems in Kombination mit dem verwendetenen ,touchdown“-PCR Protokoll (Don et al. 1991; Hecker und Roux 1996) ermöglicht dieses System im „Genome Walking“ - Experiment die Amplifikation von bis zu $6 \mathrm{~kb}$ aus geringen Mengen genomischer DNA bei hoher Sensitivität, Genauigkeit, Effizienz und Ausbeute.

Die Sequenz der genspezifischen Primer (GSP) wurde so gewählt, dass die thermodynamische Schmelztemperatur $\mathrm{T}_{\mathrm{m}}$ zwischen $65-70^{\circ} \mathrm{C}$ lag, was einem G/CGehalt von 40-60 \% entspricht. Die Primerlänge sollte dabei zwischen 27-30 bp liegen. Durch dieses Primer-Design konnte gewährleistet werden, dass die Primer bei der empfohlenen Annealing- und Elongationstemperatur $\left(67^{\circ} \mathrm{C}\right)$ effektiv an ihr Template binden und gleichzeitig eine unspezifische Primer-Bindung unterdrückt wird. Dafür sorgt auch die geringfügig über der $\mathrm{T}_{\mathrm{m}}$ gelegenen Annealing-Temperatur in den ersten 7 PCR-Zyklen der „touchdown“-PCR. Durch diese Prozedur wurde zwar die Effizienz der PCR vermindert, dafür aber die Spezifität erhöht. Für die zweite PCR wurden nach den selben Kriterien sogenannte ,nested“-Primer hergestellt, deren Bindungssequenz innerhalb des mit dem ersten Primerpaar synthetisierten PCR-Produkts lag und die mit den ersten Primern nicht überlappten.

Für die PCR wurden folgende Reagenzien aus dem „Advantage ${ }^{\circledR}$ Genomic PCRSystem“ (Clontech) in einem dünnwandigen 0,2 ml PCR-Reaktionsgefäß zu einem Gesamtansatz von $25 \mu$ zusammenpipettiert:

\begin{tabular}{rl}
$1,0 \mu \mathrm{l}$ & Adaptor-ligierte DNA \\
$0,5 \mu \mathrm{l}$ & $\mathrm{AP}_{\mathrm{GW}}(10 \mathrm{pmol} / \mu \mathrm{l})$ \\
$0,5 \mu \mathrm{l}$ & $\mathrm{GSP}_{1}(10 \mathrm{pmol} / \mu \mathrm{l})$ \\
$0,5 \mu \mathrm{l}$ & $\mathrm{dNTP} \mathrm{Mix}(\mathrm{je} 10 \mathrm{mM})$ \\
$2,5 \mu \mathrm{l}$ & $10 \times$ Tth $-\mathrm{PCR}-\mathrm{Reaktionspuffer}$ \\
$1,1 \mu \mathrm{l}$ & $25 \mathrm{mM} \mathrm{Mg}(\mathrm{OAc})_{2}$ \\
$\underline{0,5 \mu \mathrm{l}}$ & $50 \times$ Advantage ${ }^{\circledR}$ Genomic Polymerase-Mix \\
\hline $\mathrm{d} 25 \mu \mathrm{l}$ & Ampuwa
\end{tabular}

Die Ansätze wurden in einem Thermocycler (Primus 96, MWG Biotech) mit folgendem PCR-Profil inkubiert, wobei zunächst die stringentere Temperatur gewählt wurde: 


$\left.\begin{array}{cll}25 \text { Sek. } & 94^{\circ} \mathrm{C} & \begin{array}{l}\text { Denaturierung } \\ \text { Annealling/Elongation }\end{array}\end{array}\right\} \times 7$

Der PCR-Ansatz wurde anschließend auf Eis gelagert und $5 \mu 1$ auf einem Agarosegel (1,5\%, Kapitel 2.11.1) gelelektrophoretisch aufgetrennt. Bei Vorhandensein von Produkten, sichtbar als Banden oder DNA-Schmier, wurde die Reaktion beendet, bei $-20{ }^{\circ} \mathrm{C}$ eingefroren oder die zweite PCR durchgeführt. Anderenfalls wurde das PCRProgramm (2.6) auf 37 Zyklen verlängert und 5 weitere Zyklen angehängt oder die gesamte PCR mit der niedrig stringenten Temperatur, d.h Reduktion um maximal $2{ }^{\circ} \mathrm{C}$, wiederholt (2.6).

Die ,nested“-PCR wurde dann folgendem Schema folgend zusammenpipettiert und dem PCR Programm (2.7) oder (2.8) unterworfen:

$$
\begin{aligned}
& 1,0 \mu \mathrm{l} \quad \text { DNA aus } 1 . \text { PCR } \\
& 0,5 \mu \mathrm{l} \quad \mathrm{AP}_{\mathrm{GW}_{2}}(10 \mathrm{pmol} / \mu \mathrm{l}) \\
& 0,5 \mu \mathrm{l} \quad \mathrm{GSP}_{2}(10 \mathrm{pmol} / \mu \mathrm{l}) \\
& 0,5 \mu \mathrm{l} \text { dNTP-Mix (je } 10 \mathrm{mM} \text { ) } \\
& 2,5 \mu 1 \quad 10 \times \text { Tth - PCR-Reaktionspuffer } \\
& 1,1 \mu \mathrm{l} \quad 25 \mathrm{mM} \mathrm{Mg}(\mathrm{OAc})_{2} \\
& \underline{0,5 \mu 1} \quad 50 \times \text { Advantage }{ }^{\circledR} \text { Genomic Polymerase-Mix } \\
& \text { ad } 25 \mu \mathrm{l} \quad \text { Ampuwa }
\end{aligned}
$$

\begin{tabular}{|c|c|c|c|}
\hline 25 Sek. & $94^{\circ} \mathrm{C}$ & Denaturierung & $x 7$ \\
\hline 4 Min. & $70-72{ }^{\circ} \mathrm{C}$ & Annealling / Elongation & \\
\hline 25 Sek. & $94^{\circ} \mathrm{C}$ & Denaturierung & 20 \\
\hline 4 Min. & $65-67^{\circ} \mathrm{C}$ & Annealling / Elongation & \\
\hline 7 Min. & $67^{\circ} \mathrm{C}$ & Auffüllreaktion & \\
\hline$\infty$ & $4^{\circ} \mathrm{C}$ & Kühlung & \\
\hline
\end{tabular}




$\begin{array}{cll}25 \text { Sek. } & 94^{\circ} \mathrm{C} & \text { Denaturierung } \\ 30 \text { Sek. } & 60-65^{\circ} \mathrm{C} & \begin{array}{l}\text { Annealing } \\ \text { Elongation }\end{array} \\ 7 \text { Min. } & 72{ }^{\circ} \mathrm{C} & \text { Auffüllreaktion } \\ \infty & 67^{\circ} \mathrm{C} & \text { Kühlung }\end{array} \times 35$

Die PCR-Produkte wurden nach Southern-Blot Hybridisierung (2.18.1) und Isolierung der positiven PCR-Produkte aus Agarosegelen (2.12) mit Hilfe des TA-Klonierungssystems der Firma Promega (2.14.1 Nr. 4) subkloniert und sequenziert (2.17).

\subsection{4 „Rapid Amplification of cDNA end“ -PCR (RACE-PCR)}

Diese Methode wurde benutzt, um das unbekannte 5'-Ende und 3-'Ende einer mRNA ausgehend von einer bekannten internen Sequenz zu amplifizieren und zu klonieren.

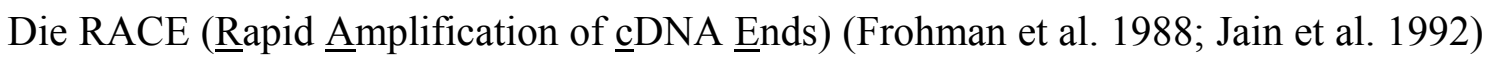
wird mit geringen Modifikationen auch als ,anchored“ PCR (Loh et al. 1989) oder als „one-sided“ PCR (Ohara et al. 1989) bezeichnet. In dieser Arbeit wurde das „Marathon ${ }^{\mathrm{TM}}$ cDNA Amplification“ System der Firma Clontech verwendet. Dieses System zeichnet sich dadurch aus, dass sowohl die 5'- als auch die 3'-RACE an der identischen Adaptor-ligierten cDNA durchgeführt werden können (Chenchik et al. 1996).

Für die cDNA-Synthese wurde $1 \mu \mathrm{g}$ Poly $\mathrm{A}^{+}$-mRNA (2.10.7) aus dem entsprechenden Gewebe zusammen mit $1 \mu \mathrm{l}$ eines oligo-dT Adaptorprimers (CDS-Primer $10 \mu \mathrm{M}$ ) in einem Reaktionsvolumen von $5 \mu$ für 2 Minuten bei $70^{\circ} \mathrm{C}$ denaturiert und für 2 Minuten auf Eis inkubiert. Die Erststrangsynthese wurde mit den Bestandteilen des Systems folgendem Schema folgend zusammenpipettiert:

$$
\begin{array}{rl}
5 \mu \mathrm{l} & \text { mRNA / CDS-Primer-Mix } \\
2 \mu \mathrm{l} & 5 \mathrm{x} \text { Erststrangsynthese-Puffer } \\
1 \mu \mathrm{l} & \text { dNTP-Mix (je 10 mM) } \\
\underline{1 \mu \mathrm{l}} & \text { AMV Reverse Transkriptase (20 U/ } \mu \mathrm{l}) \\
\mathrm{H}_{2} \mathrm{O} \text { ad } 10 \mu \mathrm{l} &
\end{array}
$$

Die Erststrangsynthese wurde bei $42{ }^{\circ} \mathrm{C}$ für 1 Stunde in einem Thermocycler durchgeführt und die Reaktion anschließend auf Eis beendet.

Die Zweitstrangsynthese wurde im direkten Anschluß durchgeführt. Der dabei zum Einsatz kommende Enzymcocktail enthält RNase H, E. coli DNA Polymerase I und E. coli DNA-Ligase. Dieser Enzymcocktail degradiert die eingesetzte mRNA in mRNA/cDNA Hybriden und synthetisiert den zweiten cDNA-Strang (Okayama und 
Berg 1982; Gubler und Hoffman 1983). Die Zweitstrangsynthese wurde mit den Bestandteilen des Systems folgendem Schema folgend zusammenpipettiert:

$$
\begin{array}{rl}
10 \mu \mathrm{l} & \text { Erststrang-Reaktion } \\
16 \mu \mathrm{l} & 5 \times \text { Zweitstrangsynthese-Puffer } \\
1,6 \mu \mathrm{l} & \mathrm{dNTP}-\text { Mix (je } 10 \mathrm{mM}) \\
\underline{4 \mu \mathrm{l}} & 20 \times \text { Zweitstrang-Enzymcocktail } \\
\mathrm{H}_{2} \mathrm{O} \text { auf } 80 \mu \mathrm{l} &
\end{array}
$$

Die Zweitstrangsynthese wurde bei $16{ }^{\circ} \mathrm{C}$ für 1,5 Stunden in einem Wasserbad durchgeführt. Anschließend wurden $2 \mu \mathrm{l}$ (10 U) T4 DNA Polymerase zugefügt und die Reaktion erneut 45 Minuten bei $16^{\circ} \mathrm{C}$ inkubiert. Diese enzymatische Reaktion produziert glatte Enden (,blunt ends“) und ermöglicht die Adaptor-Ligation. Die Reaktion wurde durch Zugabe von EDTA/Glykogen-Mix abgestoppt, je einmal mit $100 \mu \mathrm{l}$ Phenol/Chloroform/Isoamylalkohol (25:24:1) und $100 \mu$ Chloroform/Isoamylalkohol (24:1) extrahiert, die cDNA aus dem wässrigen Überstand durch Zugabe von 0,5 x Volumen $4 \mathrm{M} \mathrm{NH}_{4} \mathrm{OAc}$ (Ammoniumacetat) und 2,5 x Volumen EtOH (95\%) ausgefällt, mit $80 \%$ EtOH gewaschen, luftgetrocknet und in $10 \mu 1 \mathrm{H}_{2} \mathrm{O}$ resuspendiert. Anschließend wurden $2 \mu \mathrm{l}$ der cDNA auf einem 1,2\% Agarosegel analysiert und die DNA-Konzentration abgeschätzt.

Die Adaptor-Ligation wurde mit den Bestandteilen des Systems folgendem Schema folgend zusammenpipettiert:

$$
\begin{array}{rl}
5 \mu \mathrm{l} & \text { ds-cDNA (Doppelstrang-cDNA) } \\
2 \mu \mathrm{l} & \text { Marathon cDNA Adaptor }(10 \mu \mathrm{M}) \\
2 \mu \mathrm{l} & 5 \mathrm{x} \text { Ligations-Puffer } \\
\underline{1 \mu \mathrm{l}} & \text { T4-DNA Ligase }(400 \mathrm{U} / \mu \mathrm{l}) \\
\mathrm{H}_{2} \mathrm{O} \text { auf } 10 \mu \mathrm{l} &
\end{array}
$$

Die Ligation wurde über Nacht bei $16{ }^{\circ} \mathrm{C}$ im Wasserbad durchgeführt. Anschließend wurde die Ligase für 5 Minuten bei $70^{\circ} \mathrm{C}$ inaktiviert und die Adaptor-ligierte cDNA 1:100 mit 1 x TE-Puffer auf eine Konzentration von ungefähr $0,1 \mu \mathrm{g} / \mathrm{ml}$ verdünnt, für 2 Minuten bei $94{ }^{\circ} \mathrm{C}$ denaturiert, 2 Minuten auf Eis abgekühlt und bei $-20{ }^{\circ} \mathrm{C}$ gelagert.

Für die RACE-PCR wurde das „Advantage ${ }^{\circledR} 2$ Polymerase- System“ der Firma CLONTECH (Heidelberg) verwendet, das eine modifizierte Taq-DNA-Polymerase $\left(=\right.$ AdvanTaq $\left.^{\mathrm{TM}}\right)$ mit defizienter Exonukleaseaktivität, eine geringe Menge einer DNAPolymerase mit 3'-5'-Exonukleaseaktivität und einen monoklonalen TaqStart ${ }^{\mathrm{TM}}$ Antikörper enthält. Durch die Kombination mit dem „touchdown“-PCR Protokoll (Don et al. 1991; Hecker und Roux 1996) ermöglicht dieses System im RACE-PCR 
Experiment die Amplifikation von bis zu $18 \mathrm{~kb}$ aus geringen Mengen ds-cDNA bei hoher Sensitivität, Genauigkeit, Effizienz und Ausbeute.

Die Sequenz der genspezifischen Primer (GSP) wurde so gewählt, dass die thermodynamische Schmelztemperatur $\mathrm{T}_{\mathrm{m}}$ zwischen $65-72{ }^{\circ} \mathrm{C}$ lag, was einem G/CGehalt von 50-70 \% entspricht. Die Primerlänge sollte dabei zwischen 23-28 bp liegen.

Für die RACE-PCR wurden folgende Reagenzien aus dem „Advantage ${ }^{\circledR}$ 2-PolymeraseSystem“ (Clontech) mit 3'-gerichtetem GSP for, mit 5'-gerichtetem GSP rev $_{\text {" }}$ und mit den Kontroll-Primern $\mathrm{TFR}_{\text {for }}$ oder $\mathrm{TFR}_{\mathrm{rev}}$ in einem dünnwandigen $0,2 \mathrm{ml}$ PCRReaktionsgefäß zu einem Gesamtansatz von $50 \mu$ zusammenpipettiert:

$$
\begin{aligned}
& 5,0 \mu \mathrm{l} \quad \text { Adaptor-ligierte ds-cDNA } \\
& 1,0 \mu \mathrm{l} \quad \mathrm{AP}_{\mathrm{RACE}} 1(10 \mathrm{pmol} / \mu \mathrm{l}) \\
& 1,0 \mu \mathrm{l} \quad \mathrm{GSP}_{\text {for }}, \mathrm{GSP}_{\text {rev }}, \mathrm{TFR}_{\text {for }} \text { oder } \operatorname{TFR}_{\text {rev }}(10 \mathrm{pmol} / \mu \mathrm{l}) \\
& 1,0 \mu \mathrm{l} \quad \text { dNTP-Mix (je } 10 \mathrm{mM} \text { ) } \\
& 5,0 \mu \mathrm{l} \quad 10 \mathrm{x} \text { cDNA-PCR-Reaktionspuffer } \\
& 1,0 \mu \mathrm{l} \quad 50 \times \text { Advantage }{ }^{\circledR} \text { Genomic-Polymerase-Mix } \\
& \mathrm{H}_{2} \mathrm{O} \text { ad } 50 \mu \mathrm{l}
\end{aligned}
$$

Die Ansätze wurden in einem Thermocycler (Primus 96, MWG Biotech) mit folgendem PCR-Profil inkubiert:

1 Min. $\quad 94{ }^{\circ} \mathrm{C}$

30 Sek. $94{ }^{\circ} \mathrm{C}$

4 Min. $72{ }^{\circ} \mathrm{C}$

30 Sek. $94^{\circ} \mathrm{C}$

4 Min. $70^{\circ} \mathrm{C}$

25 Sek. $94^{\circ} \mathrm{C}$

4 Min. $68^{\circ} \mathrm{C}$

$\infty \quad 4{ }^{\circ} \mathrm{C}$
Vordenaturierung

Denaturierung

Annealling / Elongation $\} x 5$

Denaturierung

Annealling / Elongation $\} x 5$

Denaturierung

Annealling / Elongation

$x 20-25$

$5 \mu \mathrm{l}$ des PCR-Ansatzes wurden anschließend auf einem Agarosegel (1,5\%, Kapitel 2.11.1) gelelektrophoretisch aufgetrennt. Produkte wurden aus dem Gel isoliert (2.12) und in das pGEM-T System der Firma Promega (2.14.1 Nr. 4) subkloniert und sequenziert. Bei negativem Ergebnis wurde die PCR mit einem alternativen PCRProgramm wiederholt (2.10) und/oder eine ,nested-PCR“ mit dem Adaptor-Primer 2 $\left(\mathrm{AP}_{\mathrm{RACE}} 2\right)$ und einem weiteren genspezifischen Primer (GSP $\left.2_{\text {for/rev }}\right)$ durchgeführt. 


$\left.\begin{array}{cll}1 \text { Min. } & 94{ }^{\circ} \mathrm{C} & \text { Vordenaturierung } \\ \text { 25 Sek. } & 94^{\circ} \mathrm{C} & \text { Denaturierung } \\ 4 \text { Min. } & 68^{\circ} \mathrm{C} & \text { Annealling / Elongation }\end{array}\right\} \times 25-30$

\subsection{Subklonierung von DNA-Fragmenten}

\subsubsection{Ligation}

DNA-Fragmente können durch die Bildung von Phosphodiesterbindungen zwischen freien 3'-Hydroxyl- und 5'-Phosphatenden unter Hydrolyse von ATP verbunden werden, wobei diese Reaktion durch eine T4-DNA-Ligase katalysiert wird. Für die Ligasereaktion wurden $50 \mathrm{ng}$ restriktionsenzymatisch linearisierte (2.16.1) und dephosphorylierte (2.16.3) Vektor-DNA und die zu klonierende, restriktionsenzymatisch vorbereitete und eventuell „blunt end“ aufgefüllte (2.16.4) Insert-DNA (2.12) in einem molaren Verhältnis von 1:3 zusammen mit dem vom Hersteller mitgelieferten Ligase-Puffer und $0,1 \mathrm{x}$ Volumen T4-Ligase in einem $10 \mu \mathrm{l}$ Reaktionsansatz gemischt und über Nacht im Wasserbad bei $16^{\circ} \mathrm{C}$ ligiert.

Für die Ligationen kamen in dieser Arbeit unterschiedliche Systeme zum Einsatz:

1. Für Standard-Ligationen wurde das T4-DNA-Ligase-System der Firma Gibco BRL verwendet, deren T4-DNA-Ligase eine Enzymaktivität von $1 \mathrm{U} / \mu 1$ besitzt.

2. Für „blunt-end“ Ligationen wurde das DNA-Ligations-System der Firma Stratagene verwendet, das eine T4-DNA-Ligase mit $4 \mathrm{U} / \mu 1$ und externes ATP verwendet.

3. Für große genomische Fragmente $(>10 \mathrm{~kb})$ wurde das Ligations Express $^{\mathrm{TM}}$ System der Firma Clontech verwendet. Die T4-DNA-Ligase in diesem System besitzt eine Enzymaktivität von $100 \mathrm{U} / \mu 1$ und verwendet externes ATP.

4. Zur Klonierung von PCR-Produkten wurde das pGEM $^{\circledR}$-T Vektorsystem der Firma Promega (Wisconsin, USA) benutzt. Dieses System enthält linearisierten pGEM $^{\circledR}-5 Z f(+)$ Vektor mit einfachen 3'-T-Überhängen, die kompatibel zu den 3'-A-Überhängen von PCR-Produkten sind, die von den meisten thermostabilen DNA-Polymerasen (Taq- und Tth-Polymerasen) aufgrund terminaler Desoxynukleotidyltransferase (TdT) -Aktivität bei der Elongation angehängt werden (Clark 1988; Hu 1993). 
Für die Reaktion benötigtes ATP in dem jeweiligen Ligase-Puffer wurde nach dem ersten Gebrauch in Aliquots eingefroren und jedes Aliquot nur einmal verwendet.

\subsubsection{Plasmidtransformation in kompetente Escherichia coli-Zellen}

(Sambrook et al. 1989)

$50 \mu 1$ kompetente E. coli DH5 $\alpha$ Zellen (Gibco BRL) wurden auf Eis aufgetaut und nach Zugabe von maximal $5 \mu \mathrm{l}$ (1-10 ng) des zu transformierenden Plasmids (2.10.2 bis 2.10.4) oder 1-3 $\mu \mathrm{l}$ des Ligationsansatzes (2.14.1) den Herstellerangaben folgend 30 Minuten auf Eis inkubiert. Nach „Hitzeschock“ bei $37^{\circ} \mathrm{C}$ für 20 Sekunden wurden die Zellen 2 Minuten auf Eis inkubiert und nach Zugabe von $950 \mu$ SOC-Medium (Gibco BRL) 1 Stunde bei $37{ }^{\circ} \mathrm{C}$ inkubiert. Je $50 \mu 1$ und $100 \mu l$ der homogenen Zellsuspension wurden zur Kontrolle auf Selektionsplatten (2.5.3) ausplattiert und über Nacht bei $37{ }^{\circ} \mathrm{C}$ im Brutschrank inkubiert.

Zur Plasmid-Isolierung wurden Einzelkolonien in $5 \mathrm{ml}$ LB-Medium mit dem entsprechendem plasmidkodiertem Antibiotikum überführt, über Nacht bei $37^{\circ} \mathrm{C}$ im Schüttler inkubiert und die Plasmid-DNA wie unter (2.10.3) beschrieben isoliert.

\subsection{Transfertechniken}

\subsection{1 "Southern-Blotting" von DNA}

(Southern 1975)

Denaturierungslösung:

$0.5 \mathrm{M} \mathrm{NaOH}$

$1.5 \mathrm{M} \mathrm{NaCl}$

Neutralisierungslösung:

$1 \mathrm{M}$ Tris ( $\mathrm{pH} 7.5)$

\section{$1.5 \mathrm{M} \mathrm{NaCl}$}

Für den Southern-Blot wurden je $15 \mu \mathrm{g}$ genomische bzw. 1-2 $\mu$ g Plasmid-DNA mit geeigneten Restriktionsendonukleasen verdaut (2.16.2) und elektrophoretisch aufgetrennt (2.11.1). Die DNA im Gel wurde mit Ethidiumbromid angefärbt, fotografiert und anschließend bei RT unter Schütteln mit folgenden Lösungen inkubiert:

30 Minuten in $500 \mathrm{ml}$ Denaturierungslösung

45 Minuten in $500 \mathrm{ml}$ Neutralisierungslösung

Die so behandelte einzelsträngige DNA wurde durch ein modifiziertes KapillarblottingVerfahren mit einem TURBOBLOTTER ${ }^{\mathrm{TM}}$ der Firma Schleicher \& Schüll auf eine Hybond C-Nitrozellulosemembran mit nukleinsäurebindenden Eigenschaften über- 
tragen und durch zweistündige Inkubation bei $80^{\circ} \mathrm{C}$ oder durch „Crosslinken“ mit UVLicht (UV Stratalinker ${ }^{\mathrm{TM}}$ 1800, Stratagene, Heidelberg, 254 nm, $120 \mathrm{~mJ}$ ) auf dem Filter fixiert. Der Southern-Blot wurde den Herstellerangaben folgend mit $20 \mathrm{x}$ SSC als Transferpuffer durchgeführt und erfolgte standardmäßig für 16-18 Stunden bei RT über Nacht. Nach dem Transfer wurde der Filter kurz in 2 x SSC-Puffer gespült, getrocknet und durch „Crosslinken“ oder Inkubation für 2 Stunden bei $80{ }^{\circ} \mathrm{C}$ kovalent auf dem Filter fixiert.

\subsection{2 "Northern-Blotting" von RNA}

Als "Northern-Blotting" wird die Übertragung von RNA auf nukleinsäurebindende Membranen bezeichnet. Die Technik ist der des „Southern-Blottings" äquivalent und wurde wie unter 2.15 .1 beschrieben bei $4{ }^{\circ} \mathrm{C}$ im Kühlraum durchgeführt. Die der Übertragung vorausgehende notwendige Denaturierung der RNA erfolgt schon vor und während der denaturierenden Agarosegelelektrophorese. Das Gel konnte nach der Elektrophorese daher direkt zum Transfer verwendet werden. Nach dem Transfer der RNA aus dem Gel auf den Nitrozellulosefilter wurde der Filter kurz in $2 \mathrm{x}$ SSC gewaschen, getrocknet und die RNA wie unter 2.15.1 beschrieben fixiert.

Die Spur mit dem RNA-Längenstandard wurde vom Filter abgetrennt, die RNA 15 Minuten mit $5 \%$ iger Essigsäure fixiert, für 10 Minuten mit $0,04 \%$ iger Methylenblau-Lösung in 0,5 M NaOAc, pH 5,2, angefärbt und überschüssige Färbelösung unter fließendem Wasser abgespült.

\subsection{3 "Western-Blotting" von Proteinen}

(Towbin et al. 1979; Gershoni und Palade 1982)

Transferpuffer:

$25 \mathrm{mM}$ Tris (pH 8.3)

$192 \mathrm{mM}$ Glycin

$20 \%(\mathrm{v} / \mathrm{v})$ Methanol

Analog zum „Southern-" und „Northern-Blotting" können Proteine nach deren Auftrennung in Polyacrylamidgelen (2.11.3) durch ein Elektroblotting-Verfahren auf Membranen mit Proteinbindungseigenschaften übertragen werden (,Western-Blotting").

Als Membranen wurden verstärkte PVDF-Folien der Firma Macherey und Nagel (Düren) verwendet. Die Übertragung der Proteine erfolgte im sogenannten „Semi-dry“ Blotting-Verfahren, und zwar in einer „Blotting“ -Apparatur (Fastblot B44) der Firma Whatman Biometra (Göttingen). 
Direkt nach der denaturierenden SDS-PAGE (2.11.3) wurde das Gel 15 Minuten in Transferpuffer equilibriert, die zugeschnittene PVDF-Folie $\left(\begin{array}{llll}14 & \mathrm{x} & 8 & \mathrm{~cm}\end{array}\right)$ für zwei Minuten in Methanol aktiviert und 10 Minuten in Transfer-Puffer equilibiert. Auf die Edelstahl-Kathode der Apparatur wurde eine dreifache Lage einzeln in TransferPuffer durchtränktes Blottingpapier (GB004) gelegt, die aktivierte PVDF-Folie, das PAGE-Gel und eine weitere dreifache Lage in Transfer-Puffer getränktes Blottingpapier (GB004) luftblasenfrei darauf plaziert. Diese „Sandwich“ -Kombination“ wurde vorsichtig mit der platinierten Titanium-Anode in Kontakt gebracht und der Transfer für eine Stunde bei einer maximalen Stromstärke von $250 \mathrm{~mA}$ in gekühlter Umgebung $\left(4^{\circ} \mathrm{C}\right.$, Kühlraum) durchgeführt. Anschließend wurden die Folien direkt in der Immunhybridisierung (2.23) eingesetzt oder in Plastikfolie eingeschweißt bei $4{ }^{\circ} \mathrm{C}$ gelagert. Im letzteren Fall wurde die PVDF-Membran nach der Lagerung erneut für 5 Minuten in absolutem Methanol reaktiviert. Die ausgeblotteten Gele wurden durch Coomassie-Färbung (2.15.4) auf ihre Transfereffizienz kontrolliert.

\subsubsection{Coomassiefärbung von Proteingelen}

Färbelösung:

0,025 \% Coomassie Brillant Blue R 250

$10 \%$ Essigsäure

$30 \%$ Methanol

in $\mathrm{H}_{2} \mathrm{O}$

Entfärbelösung: $\quad 10 \%$ Essigsäure

$30 \%$ Methanol

in $\mathrm{H}_{2} \mathrm{O}$

Der blaue Coomassie-Farbstoff bildet mit Proteinen unlösliche Komplexe. Für die Färbung wurden die Polyacrylamidgele für 1 Stunde in der Färbelösung geschwenkt. Anschließend wurden die Gele über Nacht in deionisiertem Wasser grob entfärbt und dann für weitere 10 - 20 Minuten in Entfärbelösung auf einem Taumler so lange equilibriert, bis die Hintergrundfärbung ausgewaschen war. Die Färbe- und Entfärbelösung wurde wiederverwendet.

\subsection{Enzymatische Modifikationen von Nukleinsäuren}

Alle enzymatischen Modifikationen wurden den etablierten molekularbiologischen Standardmethoden folgend durchgeführt, wie sie z.B. in Sambrook et al. (1989) bzw. Ausubel (1995) niedergelegt sind. Reagenzien und Proben für die Durchführung enzymatischer Reaktionen wurden grundsätzlich auf Eis gekühlt und wurden, sofern 
nicht anders angegeben, mit den mitgelieferten Puffersystemen und den Angaben des Herstellers folgend angesetzt.

\subsubsection{Spaltung von Plasmid-DNA mit Restriktionsendonukleasen}

Standardmäßig wurden $10 \mathrm{U}$ Enzym pro $1 \mu \mathrm{g}$ DNA über 1-2 Stunden beim Temperaturoptimum des verwendeten Enzyms eingesetzt. Zur „Insert"- Isolierung wurden entsprechend $10 \mu \mathrm{g}$ Plasmid-DNA mit $100 \mathrm{U}$ Enzym (10 U/ $\mu \mathrm{l})$ in Reaktionsansätzen von 100-200 $\mu 1$ eingesetzt. Doppelrestriktionen wurden in kompatiblen Puffern des Herstellers oder nacheinander nach Hitzeinaktivierung (15 Minuten, $65{ }^{\circ} \mathrm{C}$ ) oder Phenol/Chloroform-Extraktion und EtOH-Fällung durchgeführt. Die Vollständigkeit der Spaltung wurde in einer Agarose-Gelelektrophorese (2.11.1) überprüft. Die Restriktionsenzyme wurden vor Durchführung weiterer enzymatischer Modifikationen (2.16.3 und 2.16.4) hitzeinaktiviert (15 Minuten, $65^{\circ} \mathrm{C}$ ) oder bei hitzeresistenten Restriktionsenzymen über Phenol/Chloroform-Extraktion und EtOH-Fällung entfernt.

\subsubsection{Spaltung von genomischer DNA mit Restriktionsendonukleasen}

Für genomische Southern-Hybridisierungen wurden $15 \mu \mathrm{g}$ genomische DNA in einem $80 \mu \mathrm{l}$ Reaktionsvolumen mit $8 \mu \mathrm{l}$ Restriktionsendonuklease (80 U) durch Zugabe von $10 \mathrm{mM}$ Spermidin für 16 Stunden über Nacht verdaut und tagsüber in einem Reaktionsvolumen von $160 \mu \mathrm{l}$ mit weiteren $8 \mu \mathrm{l}$ Restriktionsendonuklease und Spermidin nachverdaut. Die vollständig restringierte genomische DNA wurde nach Zugabe von 0,2 x Volumen Stop-Mix I über Nacht in einem 1 x TAE -Puffersystem über ein 10 x $15 \mathrm{~cm}$ Agarosegel (2.11.1) aufgetrennt, denaturiert, neutralisiert und auf Nitrozellulose-Folie transferiert (2.15.1).

\subsubsection{Dephosphorylierungsreaktion mit alkalischer Phosphatase (CIAP)}

Bei diesem Verfahren werden Phosphat-Reste am 5'-Ende von DNA-Molekülen, die bei der restriktionsenzymatischen Spaltung (2.16.1) entstehen, durch eine alkalische Phosphatase entfernt. Dadurch wird die Zirkularisierung von Vektor-DNA bei der Ligation verhindert und die Klonierungseffizienz erhöht. Zur Phoshatase-Behandlung wurde die ,calf intestinal alkaline Phosphatase“ (1 U/ $\mu$ l) der Firma Gibco BRL (CIAP) verwendet.

Für 5'-überhängende Enden aus restriktionsenzymatischen Spaltungen von bis zu $20 \mu \mathrm{g}$ Vektor-DNA $(3,0 \mathrm{~kb})$ wurde standardmäßig $1 \mu$ CIAP (1 U) in folgendem Ansatz eingesetzt, und 30 Minuten bei $37^{\circ} \mathrm{C}$ dephosphoryliert: 


$\begin{array}{rl}1 \mu \mathrm{l} & \text { CIAP (Gibco BRL, } 1 \mathrm{U} / \mu \mathrm{l}) \\ 9 \mu \mathrm{l} & \text { Verdünnungs-Puffer }\left(\text { Gibco BRL, }+\mathrm{Zn}^{2+}\right) \\ 10 \mu \mathrm{l} & 10 \mathrm{x} \text { CIAP-Puffer }(\text { Gibco BRL) } \\ \underline{\mathrm{x} \mu \mathrm{l}} & \text { DNA }(\leq 20 \mu \mathrm{g}) \\ \mathrm{H}_{2} \mathrm{O} \text { auf } 100 \mu \mathrm{l} & \end{array}$

Für 3'-überhängende Enden oder „,blunt-ends“ aus restriktionsenzymatischen Spaltungen von bis zu $5 \mu$ g Vektor-DNA wurden $5 \mu$ CIAP ( 5 U) in folgendem Ansatz eingesetzt und für 1 Stunde bei $50{ }^{\circ} \mathrm{C}$ dephosphoryliert:

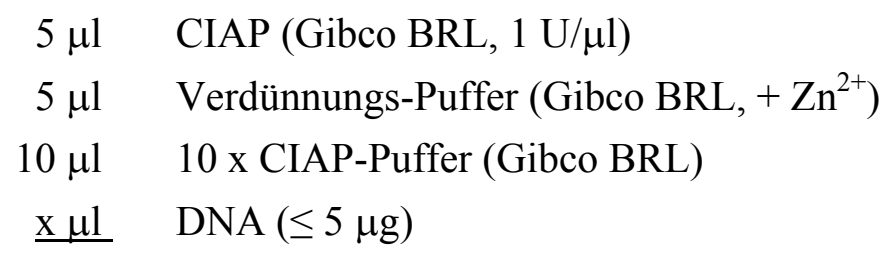

$\mathrm{H}_{2} \mathrm{O}$ auf $100 \mu \mathrm{l}$

Die alkalische Phosphatase wurde nach der Dephosphorylierung bei $75^{\circ} \mathrm{C}$ hitzeinaktiviert und die Vektor-DNA bei $-20{ }^{\circ} \mathrm{C}$ gelagert.

\subsubsection{Auffüll- und Glättungsreaktion zur Generierung von „Blunt end”- Fragmenten}

(Costa und Weiner 1994)

Dieses Verfahren wurde benutzt, um in Klonierungsexperimenten nicht kompatible DNA-Fragmente in „blunt end“ -Fragmente zu überführen und diese dann mit der in 2.14.1 (Nr. 2) beschriebenen Methode in einen entsprechend „blunt end“ vorbereiteten Vektor zu klonieren. Die PfuTurbo ${ }^{\mathrm{TM}}$-DNA-Polymerase (Stratagene, La Jolla, USA) vereint die enzymatischen Aktivitäten zum Auffüllen von 5‘-Überhängen und zum Glätten (,,polishing“) von 3‘-Überhängen.

Für beide Reaktionen wurde $1 \mu \mathrm{g}$ linearisierte und durch EtOH-Fällung gereinigte Insert-DNA folgendem Schema folgend zusammenpipettiert:

$$
\begin{array}{rl}
\mathrm{x} \mu \mathrm{l} & \text { DNA }(1 \mu \mathrm{g}) \\
2,5 \mu \mathrm{l} & \text { dNTP (je 10 mM) } \\
2,5 \mu \mathrm{l} & 10 \mathrm{x} \text { Pfu -DNA-Polymerase-Puffer } \\
\underline{0,5 \mu \mathrm{l}} & \text { PfuTurbo }^{\text {TM }} \text {-DNA-Polymerase }
\end{array}
$$

$\mathrm{H}_{2} \mathrm{O}$ ad $25,0 \mu \mathrm{l}$

Die Reaktion wurde für 2 Stunden bei $70{ }^{\circ} \mathrm{C}$ in einem Thermocycler inkubiert, die DNA mit 1 x Volumen Phenol/Chloroform (1:1) extrahiert, mit 0,1 x Volumen NaOAc 
$(\mathrm{pH} 5,2)$ und $3 \times$ Volumen eiskaltem $\left(-20^{\circ} \mathrm{C}\right)$ EtOH $\left(100 \%\right.$, z.A.) bei $-80{ }^{\circ} \mathrm{C}$ ausgefällt, mit $70 \%$ EtOH gewaschen, getrocknet und in $12 \mu$ Ampuwa- $\mathrm{H}_{2} \mathrm{O}$ gelöst.

\subsubsection{Radioaktive Markierung von DNA-Fragmenten (,random prime labelling")}

Für Hybridisierungsexperimente wurden DNA-Fragmente durch die ,random prime labelling"-Methode radioaktiv markiert (Feinberg und Vogelstein 1983). Für die Markierungsreaktion wurde das „Rediprime ${ }^{\mathrm{TM}}$ II - random prime labelling“ - System der Firma Amersham Pharmacia Biotech verwendet. Dem mitgelieferten Protokoll zur Durchführung der Markierungsreaktion wurde weitgehend gefolgt. Die Dauer der Markierungsreaktion wurde von 10 Minuten auf 1,5 Stunden verlängert und die eingesetzte Aktivität pro Reaktion von $50 \mu \mathrm{Ci}$ auf $40 \mu \mathrm{Ci}$ verringert. Pro Reaktion $(50 \mu \mathrm{l})$ wurden 2,5-25 ng DNA eingesetzt.

Die Reaktion wurde nach der Inkubation durch Zugabe von $2 \mu 1$ 0,5 M EDTA (pH 8.0) gestoppt und das Reaktionsvolumen mit $\mathrm{H}_{2} \mathrm{O}$ auf $100 \mu$ erhöht. Die synthetisierte DNA wurde über ein siebchromatographisches Säulensystem (MicroSin ${ }^{\mathrm{TM}} \mathrm{S}-200 \mathrm{HR}$, Amersham Pharmacia Biotech) von nicht eingebauten Nukleotiden (dNTPs und $\alpha-{ }^{32} \mathrm{P}-$ $\mathrm{dCTP}$ ) befreit und direkt in das Hybridisierungsexperiment (2.18.1) eingesetzt.

\subsection{DNA Sequenzanalyse}

(Sanger et al. 1977)

Die Sequenzierung wurde modifiziert nach dem Kettenabbruchverfahren von Sanger et al. (1977) durchgeführt. Die Methode beruht auf dem Prinzip der durch den Einbau von Didesoxynukleotiden (ddNTP) statistisch unterbrochenen DNA-Neusynthese. Es wurde mit dem DYEnamic ET-Terminator-Mix der Firma Amersham Pharmacia gearbeitet. Dieser Mix enthält dNTPs, mit vier verschiedenen Fluoreszenzfarbstoffen markierte ddNTPs, Taq-DNA-Polymerase sowie Reaktionspuffer.

Die eingesetzte Menge zu sequenzierender Template-DNA wurde nach der Formel (2.11) berechnet. Für ein 2,0 kb Fragment in einem 3,0 kb Vektor wurden demnach $1000 \mathrm{ng}(1 \mu \mathrm{g})$ in die Sequenzreaktion eingesetzt.

$$
m(n g)=\frac{x(b p)}{5}
$$


Der Reaktionsansatz wurde nach folgendem Ansatz in einem dünnwandigen 0,2 ml PCR-Reaktionsgefäß zusammenpipettiert:

$$
\begin{array}{ll}
\mathrm{x} \mu \mathrm{l} \text { DNA } & \mathrm{m}(\mathrm{ng}) \\
1 \mu \mathrm{l} \text { Primer } & (10 \mathrm{pmol} / \mu \mathrm{l}) \\
4 \mu 1 \text { DYEnamic ET-Mix } & \\
\text { ad } 10 \mu \mathrm{l} \text { mit } \mathrm{H}_{2} \mathrm{O} &
\end{array}
$$

Die Kettenabbruchreaktion wurde als PCR in einem automatischen Thermocycler mit Deckelbeheizung (Primus 96, MWG Biotech) standardmäßig mit dem folgendem PCRProgramm durchgeführt:

$\left.\begin{array}{ccl}5 \text { Min. } & 96{ }^{\circ} \mathrm{C} & \text { Vordenaturierung } \\ 30 \text { Sek. } & 98{ }^{\circ} \mathrm{C} & \text { Denaturierung } \\ 15 \text { Sek. } & 50{ }^{\circ} \mathrm{C} & \begin{array}{l}\text { Annealing } \\ \text { Elongation } \\ \text { Min. }\end{array} \\ \infty & 60^{\circ} \mathrm{C} & \text { Kühlung }\end{array}\right\} x \quad 35$

Nach der PCR wurden die Proben mit Wasser auf $20 \mu$ l aufgefüllt und nach Zugabe von $2 \mu \mathrm{NaOAc} /$ EDTA-Puffer mit $80 \mu \mathrm{l}$ eiskaltem $\left(-20^{\circ} \mathrm{C}\right) 95 \% \mathrm{EtOH}$ (z.A.) nach Durchmischung für 15 Minuten auf Eis ausgefällt. Die präzipitierte DNA wurde in einer Mikrozentrifuge für 15 Minuten bei $12000 \mathrm{x}$ g sedimentiert, mit eiskaltem $\left(-20^{\circ} \mathrm{C}\right)$ $75 \% \mathrm{ETOH}$ (z.A.) gewaschen, erneut 5 Minuten zentrifugiert, vollständig vom Überstand befreit und bei Raumtemperatur als Pellet getrocknet. Die DNA wurde schließlich bei $-20{ }^{\circ} \mathrm{C}$ gelagert und vom institutseigenen Sequenzier-Service in geeignetem Probenpuffer aufgenommen, auf ein Sequenziergel aufgetragen und auf einem automatischen Sequenzierer Modell 373A (Applied Biosystems, Weiterstadt) ausgewertet. 


\subsection{Hybridisierungsmethoden}

\subsubsection{Hybridisierung radioaktiver DNA-Sonden an membrangebundene Nukleinsäuren}

(modifiziert nach Denhardt 1966)

$\begin{array}{ll}\text { Hybridisierungslösung I: } & 5 \times \text { Denhardt's Lsg. } \\ & 0.5 \% \text { SDS } \\ & 6 \times \text { SSC } \\ & 10 \% \text { Dextransulfat } \\ & \text { Rapid-Hybridisierungs-Puffer } \\ \text { Hybridisierungslösung II: } & \text { Membran-Hybridisierungs-Puffer } \\ \text { Hybridisierungslösung III: } & 10 \mathrm{mg} / \mathrm{ml} \\ \text { Lachs-Spermien-DNA: } & 2 \times \mathrm{SSC} \\ \text { Waschlösung I: } & 0.1 \% \mathrm{SDS} \\ & 0.2 \times \mathrm{SSC} \\ \text { Waschlösung II: } & 0.1 \% \mathrm{SDS}\end{array}$

Für unterschiedliche Hybridisierungsexperimente haben sich verschiedene Hybridisierungslösungen als optimal erwiesen. Die Hybridisierung von Plasmid-DNA oder PCR-Produkten auf Nitrozellulosemembranen wurde standardmäßig mit Hybridisierungslösung I (Denhardt 1966) durchgeführt. „Northern-Blot“Hybridisierungen (2.15.2) wurden mit Hybridisierungslösung II und genomische „Southern-Blot"“-Hybridisierungen mit Hybridisierungslösung III durchgeführt.

Die Nitrozellulosemembran mit der immobilisierten DNA bzw. RNA wurde für 20 Minuten in $2 \times \mathrm{SSC}$ eingeweicht und für 2-4 Stunden mit 6-10 ml Hybridisierungslösung und $200 \mu \mathrm{g} / \mathrm{ml}$ hitzedenaturierte Lachs-DNA bei $65{ }^{\circ} \mathrm{C}$ im Hybridisierungsofen (Bachofer, Reutlingen) vorhybridisiert. Der Hybridisierungslösung wurde dann die radioaktiv markierte hitzedenaturierte Sonde (2.16.5) zusammen mit $200 \mu \mathrm{g} / \mathrm{ml}$ Lachs-DNA zugesetzt. Die Hybridisierung erfolgte ebenfalls bei $65^{\circ} \mathrm{C}$ über Nacht im Hybridisierungsofen. Am nächsten Tag wurde der Filter wie folgt gewaschen:

$2 \times 10$ Minuten in $2 \times$ SSC bei Raumtemperatur 15 - 20 Minuten in Waschlösung I bei $60-65^{\circ} \mathrm{C}$ 10 - 15 Minuten in Waschlösung II bei $60-65^{\circ} \mathrm{C}$ 
Nach dem Waschen wurden die Filter luftgetrocknet, in Schlauchfolie eingeschweißt und ein Röntgenfilm (Amersham, Braunschweig) vor einer Verstärkerfolie für 1-10 Tage bei $-70{ }^{\circ} \mathrm{C}$ exponiert.

\subsubsection{Hybridisierung radioaktiver Sonden auf membrangespottete Cosmid- und PAC-Filter der RZPD}

Die Hybridisierung radioaktiver Sonden auf Nylonmembran-gespottete DNA-Banken erfolgte unter den von der RZPD empfohlenen Bedingungen. Die Nylon-Filter (22 x 22 $\mathrm{cm}$ ) wurden in einer Hybridisierungswanne in einem Schüttelwasserbad in $250 \mathrm{ml}$ Church-Hybidisierungspuffer für 30 Minuten bei $65^{\circ} \mathrm{C}$ vorhybridisiert und über Nacht zusammen mit $100 \mu \mathrm{g} / \mathrm{ml}$ Lachs-DNA und 2 Hybrisierungssonden $(2.16 .5)$ bei $65^{\circ} \mathrm{C}$ hybridisert. Am nächsten Tag wurde die Hybridisierungslösung verworfen und die Filter wie folgt gewaschen:

2 x 10 Minuten in Church-Waschpuffer bei Raumtemperatur

15 - 30 Minuten in Church-Waschpuffer bei $65^{\circ} \mathrm{C}$

Nach den Waschschritten wurden die Filter mit Doppelnaht feucht in Schlauchfolie eingeschweißt und ein Röntgenfilm (Amersham, Braunschweig) vor einer Verstärkerfolie für einen Tag bei $-70^{\circ} \mathrm{C}$ exponiert.

\subsection{Fluoreszenz in situ Hybridisierung (FISH)}

Die Anwendungsmöglichkeiten der Fluoreszenz in situ Hybridisierung (FISH) auf Metaphasechromosomen-, Interphasekern- oder „chromosome-release“- Präparaten sind breit gefächert. Sie reichen von der Prä- und Postnatal-Diagnostik (Uhrig et al. 1999), der Präimplantations- (Wells und Delhanty 2000) sowie der Tumordiagnostik (Taguchi et al. 1996) bis zum Nachweis von artspezifischen Chromosomen in Hybridzellinien (Tanabe et al. 2000) und zur Lokalisation (Peruzzi et al. 2000) und physikalischen Kartierung (Erdel et al. 1999) von Genen im Rahmen der verschiedensten Genomprojekte. Das Prinzip der FISH auf Chromosomenpräparaten ist die Hybridisierung von Biotin-, Digoxigenin- oder Fluorescein- markierten einzelsträngigen DNA-Fragmenten (Sonden) an komplementäre Sequenzen auf den denaturierten Chromosomen. Fluoreszenzfarbstoff-gekoppelte Antikörpersysteme ermöglichen die Detektion des Hybridisierungsergebnisses bei gleichzeitiger Verstärkung der Signale. 


\subsubsection{Lymphozytenkultur der Maus aus Milzgewebe}

Unter sterilen Bedingungen wurde 4-8 Wochen alten Mäusen nach Betäubung und Tötung die Milz entnommen, diese zusammen mit je 2 ml RPMI-Gebrauchsmedium-I $\left(37^{\circ} \mathrm{C}\right)$ in eine Petrischale gegeben und mit sterilen Scheren etwa 3 Minuten zerkleinert. Das Material wurde dann zusammen mit $10 \mathrm{ml}$ RPMI-Gebrauchsmedium-I (nach Zugabe von $10 \mu \mathrm{g} / \mathrm{ml}$ Concanavalin A und $45 \mu \mathrm{g} / \mathrm{ml}$ Lipopolysaccharide, Abschnitt 2.7.2) in ein Zentrifugenröhrchen überführt und drei Minuten sedimentiert, um grobe Gewebereste abzutrennen. Jeweils $3 \mathrm{ml}$ des Überstandes wurden in kleinen Zellkulturflaschen unter $\mathrm{CO}_{2}$-Begasung $(5 \%)$ im Brutschrank bei $37^{\circ} \mathrm{C}$ für 48 Stunden kultiviert und dabei dreimal pro Tag geschüttelt. Concanavalin A ist ein Lektin oder pflanzliches Hämagglutinin, das aus Canavalia ensiformis (Schwertbohne) gewonnen wird und als Mitogen zur Stimulation von Lymphozyten eingesetzt wird. Für bakterielle Lipopolysaccharide (LPS) wurde in vitro gezeigt, dass es die IgG-, IgA- und IgM-Produktion Immunglobulin-sezernierender Zellen stimuliert, und so ein spezifisches mitogenes Signal mononukleäre Lymphozyten ist (Quintiliani et al. 1984).

\subsubsection{Zellkultur der WMP-1 Zellinie (Zörnig et al. 1995)}

Die kohärent wachsende lymphoblastoide Zellinie WMP-1 der Maus mit stabil fusionierten Robertsonschen Translokationschromosomen wurde von Dr. Christa Dixkens am Institut für Humangenetik in Göttingen etabliert und ist im Haus im entsprechenden Einfriermedium (10\% DMSO) in flüssigem Stickstoff gelagert. Zum Auftauen wurden $1 \mathrm{ml}$ Aliquots bei $37^{\circ} \mathrm{C}$ inkubiert und sofort in Zellkulturflaschen mit $5 \mathrm{ml}$ RPMI-Gebrauchsmedium-II überführt und unter $\mathrm{CO}_{2}-$ Begasung (5\%) im Brutschrank bei $37{ }^{\circ} \mathrm{C}$ kultiviert. Abhängig von der Proliferationsrate wurden die Zellen ein- bis zweimal pro Woche geteilt. Dazu wurde die Zellsuspension in sterilen EinmalZentrifugenröhrchen zentrifugiert $\left(800 \mathrm{xg} / 4^{\circ} \mathrm{C} / 10\right.$ Minuten $)$, der Überstand abgenommen und die Zellen in sterilem 1 x PBS gewaschen. Nach Zentrifugation (s.o.) wurde die entsprechende Menge an frischem RPMI-Gebrauchsmedium-II $\left(37^{\circ} \mathrm{C}\right)$ zugefüttert und die Kultur wie oben beschrieben in Zellkulturflaschen fortgesetzt. Die in dieser Arbeit zur chromosomalen Lokalisierung von PAC-Klonen verwendeten Metaphasepräparate wurden von Frau Dr. C. Dixkens nach dem Protokoll in Kapitel 2.19.3 angefertigt und zur Verfügung gestellt. 


\subsubsection{Metaphasechromosomen-Präparation}

Hanks:

$8 \mathrm{~g} \mathrm{NaCl}$

$400 \mathrm{mg} \mathrm{KCl}$

$60 \mathrm{mg} \mathrm{Na} \mathrm{HPO}_{4}$

$1 \mathrm{~g}$ Glucose

$10 \mathrm{mg}$ Phenolrot

$35 \mathrm{mg} \mathrm{NaHCO} 3$

$\mathrm{H}_{2} \mathrm{O}$ ad $1000 \mathrm{ml}$

Colcemid-Gebrauchslösung: $\quad 1 \mu \mathrm{g} / \mathrm{ml}$ Hanks

Hypotone Lösung: $\quad 0,563 \% \mathrm{KCl}$

Fixativ: $\quad$ Methanol / Essigsäure (3+1, frisch angesetzt)

\subsubsection{Vorbereitung der Objektträger}

Zur Entfettung und zur Entfernung von Staubpartikeln wurden die Objektträger über Nacht in einem Diethylether / Ethanol-Gemisch (1:1) in Küvetten gelagert. Im Anschluss wurden sie dann unter fließendem demineralisiertem Wasser gespült und bis zur Verwendung in Milli-Q-Wasser bei $4{ }^{\circ} \mathrm{C}$ in Küvetten gelagert.

\subsubsection{Kulturabbruch zur Präparation von Metaphasechromosomen}

Der Zellkultur aus Kapitel 2.19.1 und 2.19.2 wurde eine Stunde vor der Aufarbeitung $0,1 \mu \mathrm{g}$ Colcemid pro $1 \mathrm{ml}$ Medium zur Arretierung der Zellen in der Mitose zugefügt (100 $\mu$ l Colcemid-Gebrauchslösung pro $1 \mathrm{ml}$ Medium). Nach Ablauf der Kulturzeit wurden die Zellen 10 Minuten durch Zentrifugation bei $800 \mathrm{x}$ g sedimentiert und langsam in $10 \mathrm{ml}$ temperierte hypotone Lösung $\left(37^{\circ} \mathrm{C}\right)$ resuspendiert. Die hypotone Behandlung wurde für 11 Minuten im Wasserbad bei $37^{\circ} \mathrm{C}$ durchgeführt. Nach der Hypotonie erfolgte eine Vorfixierung durch Zugabe von $2 \mathrm{ml}$ frisch angesetztes und eiskaltes $\left(-20^{\circ} \mathrm{C}\right)$ Fixativ und vorsichtige Durchmischung der Suspension. Die Essigsäure oxidiert bei dieser Fixierung das Häm $\left(\mathrm{Fe}^{2+}\right)$ des Hämoglobins zu Hämin $\left(\mathrm{Fe}^{3+}\right)$, was zu einem Farbumschlag der Suspension von rot nach rotbraun führt. Die so vorfixierten Zellen wurden erneut durch Zentrifugation für 10 Minuten bei 800 x g sedimentiert und der Überstand so weit wie möglich abgesaugt. Durch Zugabe von eiskaltem Fixativ unter gleichzeitiger Durchmischung erfolgte die vollständige Fixierung der Zellen. Die so fixierten Zellen wurden erneut 10 Minuten bei $800 \mathrm{xg}$ zentrifugiert und der Überstand bis auf $1 \mathrm{~cm}$ abgenommen. Nach dreimaliger Wiederholung der Fixierung wurde der Überstand nach der Zentrifugation (s.o.) bis auf 
$1 \mathrm{~cm}$ abgenommen und die Zellen vorsichtig resuspendiert. Drei Tropfen der Suspension wurden dann aus einer Höhe von etwa $1 \mathrm{~m}$ auf einen vorbehandelten (Abschnitt 2.19.3.1), kalten $\left(4^{\circ} \mathrm{C}\right)$ und mit Wasser benetzten Objektträger aufgetropft und zur besseren Spreitung auf diesem verblasen. Bei 160facher Vergrößerung wurden dann die Zell- und Metaphasendichte sowie die Spreitungsqualität der Chromosomen im Phasenkontrastmikroskop kontrolliert. Bei Bedarf konnte die Zellsuspension auch im Fixativ und verschlossen bei $-20^{\circ} \mathrm{C}$ gelagert werden. Die Chromosomenpräparate wurden bei Raumtemperatur für 2 Wochen getrocknet und darüber hinaus bei $-20{ }^{\circ} \mathrm{C}$ gelagert. Vor der Lagerung wurden die Metaphasepräparate erneut unter einem Phasenkontrastmikroskop begutachtet und die für die FISH (2.19.5) geeigneten „Felder“ (ca. 22 x $22 \mathrm{~mm}$ ) mit einem Diamantschreiber auf der Objektträgerunterseite markiert.

\subsection{4 „Chromosomen-release“ Interphasetechnik nach Senger et al. (1994)}

$\begin{array}{lll}10 \times \text { PBS } & 80 \mathrm{~g} \mathrm{NaCl} & (1,37 \mathrm{M}) \\ 2 \mathrm{~g} \mathrm{KCl} & (26,8 \mathrm{mM}) \\ 2,4 \mathrm{~g} \mathrm{KH}_{2} \mathrm{PO}_{4} & (17,6 \mathrm{mM}) \\ 14,4 \mathrm{~g} \mathrm{Na}_{2} \mathrm{HPO}_{4} & (80,9 \mathrm{mM}) \\ & \mathrm{H}_{2} \mathrm{O} \text { auf } 11 & (\mathrm{pH} 7,4) \\ & 0,05 \mathrm{M} \mathrm{NaOH} & \\ \mathrm{NaOH} / \mathrm{EtOH}-\text { Lösung } & 30 \% \mathrm{EtOH} & \end{array}$

Die im folgenden beschriebene Interphasetechnik geht auf das „released chromatin“ Protokoll für hochauflösende Fluoreszenz-in-situ-Hybridisierung von Senger et al. (1994) und Fidlerova et al. (1994) zurück und wurde in der Arbeitsgruppe von Prof. Dr. W. Schempp im Institut für Humangenetik und Anthropologie der Universität Freiburg erlernt und durchgeführt.

Eine unter Standardbedingungen (2.19.3) ohne Colcemid-Behandlung fixierte Lymphozytenkultur aus Milzgewebe der Maus (2.19.1) wurde bei $800 \mathrm{x}$ g für 10 Minuten zentrifugiert, der Überstand abgesaugt und je nach Größe des Pellets mit 10-30 Tropfen frisch angesetztem Fixativ (Methanol/Essigsäure) resuspendiert. Zwei Tropfen der Suspension wurden gleichmäßig auf einen trockenen, beschichteten Objektträger (Superfrost* Plus) aufgetropft, durch leichtes Blasen verteilt und 1 Minute in einer Küvette mit 1 x PBS inkubiert, um das Chromatin zu rehydrieren. Anschließend wurde überschüssiges PBS mit einem trockenen Papiertuch an den Rändern des Objektträgers entfernt und $80 \mu \mathrm{l}$ der $\mathrm{NaOH} / \mathrm{EtOH}$-Lösung auf das Ende des Objektträgers aufgetragen und mit der kurzen Kante eines großen Deckglases (60 x $24 \mathrm{~mm}$ ) gleichmäßig unter einem Winkel von $30^{\circ}$ ausgestrichen. Bei Kontakt mit Natronlauge werden die 
Zellkerne unmittelbar zerstört, das Chromatin tritt aus und wird mit der Lösung beim Ausstreichen über den Objektträger verteilt. Das Resultat dieser Prozedur kann unter einem Phasenkontrastmikroskop nach der Fixierung (siehe unten) direkt als irreguläres Netzwerk aus Chromatinfäden sichtbar gemacht und überprüft werden. Die Fixierung des Chromatins sollte sehr vorsichtig mit 1-2 Tropfen Methanol $\left(4{ }^{\circ} \mathrm{C}\right)$ durchgeführt werden, die auf dem horizontal liegenden Objektträger verteilt werden. Bei diesem Arbeitsschritt ist darauf zu achten, dass die Methanol-Menge möglichst gering gehalten wird, da zuviel Flüssigkeit das Chromatin abspülen kann, was an einer viskösen Konsistenz der abtropfenden Flüssigkeit deutlich wird.

Anschließend wurden die Präparate über Nacht luftgetrocknet und direkt verwendet (2.19.5) oder in einer aufsteigenden EtOH-Reihe $(70 \%, 85 \%, 99 \%)$ je 3 Minuten dehydriert und bei $-80{ }^{\circ} \mathrm{C}$ eingefroren. Vor der Lagerung wurden die Präparate erneut unter einem Phasenkontrastmikroskop begutachtet und die für die FISH (2.19.5) geeigneten „Felder“ (ca. 22 x 22 mm) mit einem Diamantschreiber auf der Objektträgerunterseite markiert.

\subsubsection{Vorbehandlung der Chromosomenpräparate}

Eine Vorbehandlung der Objektträger vor Einsatz in der FISH hat sich für die Qualität des Fluoreszenzpräparates als günstig erwiesen. Durch die RNase A-Behandlung werden auf dem Objektträger fixierte RNAs und durch die Pepsin-Behandlung proteinhaltige Zellbestandteile entfernt. Hiermit wird die Möglichkeit der unspezifischen Bindung der Sonde an endogener RNA sowie von zur Fluoreszenzverstärkung und -detektion genutzten Antikörpern stark vermindert. Diese Prozedur erhöht die Spezifität der Hybridisierung in bezug auf Signal und Hintergrund.

\subsubsection{RNase A-Behandlung der Chromosomenpräparate}

RNase A-Lösung:

$10 \mu \mathrm{RNase} \mathrm{A}(10 \mathrm{mg} / \mathrm{ml}$ in $2 \times \mathrm{SSC})$

$100 \mu 120 \times \mathrm{SSC}$

$900 \mu \mathrm{l}$ Aqua dest.

Um diese garantiert Dnase-frei einzusetzen, wurde die RNase A-Lösung vor dem Gebrauch 15 Minuten im Wasserbad gekocht. Nach Abkühlung der Lösung bei Raumtemperatur wurden jeweils $200 \mu$ pro Präparat aufgetragen, mit einem Deckglas (60 x $24 \mathrm{~mm}$ ) luftblasenfrei abgedeckt und 60 Minuten bei $37^{\circ} \mathrm{C}$ in einer feuchten Kammer ( 2 x SSC) im Brutschrank inkubiert. Anschließend wurde das Deckglas durch Inkubation in einer Küvette mit 2 x SSC entfernt, dreimal 5 Minuten in einer Küvette mit 2 x SSC bei Raumtemperatur gewaschen und anschließend mit Pepsin behandelt. 


\subsubsection{Pepsin-Behandlung der Chromosomenpräparate}

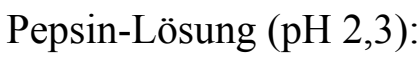

Formaldehyd-Lösung:
$99 \mathrm{ml}$ Aqua dest.

$1 \mathrm{ml} 0,1 \mathrm{~N} \mathrm{HCl}$

$30 \mu \mathrm{Pepsin}\left(100 \mathrm{mg} / \mathrm{ml}\right.$ in $\left.\mathrm{H}_{2} \mathrm{O}\right)$

$1 \%$ Formaldehyd in $1 \times \mathrm{PBS} / 50 \mathrm{mM} \mathrm{MgCl} 2(\mathrm{v} / \mathrm{v})$

Die Pepsin-Behandlung kann in ihrer Dauer variiert werden, je nachdem, ob bei der Begutachtung der Chromosomenpräparate im Phasenkontrastmikroskop viele Metaphasen mit Resten an Kernhüllen- und Cytosol-Bestandteilen sichtbar sind. Standardmäßig wurde die Inkubation für 7,5 Minuten bei $37^{\circ} \mathrm{C}$ im Wasserbad durchgeführt. Anschließend wurden die Präparate zweimal für 5 Minuten in $1 \mathrm{x}$ PBS und einmal für 5 Minuten in $1 \times \mathrm{PBS} / 50 \mathrm{mM} \mathrm{MgCl}_{2}$ gewaschen, dann in $1 \%$ Formaldehyd-Lösung für 15 Minuten bei Raumtemperatur fixiert, erneut für 5 Minuten in $1 \times$ PBS gewaschen, über eine aufsteigende EtOH-Reihe (70 \%, $85 \%, 99 \%)$ für jeweils 3 Minuten bei $-20{ }^{\circ} \mathrm{C}$ dehydriert und bei Raumtemperatur luftgetrocknet.

\subsubsection{Denaturierung der Chromosomenpräparate}

Denaturierungslösung:

$70 \%$ Formamid

$$
2 \times \mathrm{SSC} \quad(\mathrm{pH} 7,0)
$$

Die frisch angesetzte Denaturierungslösung wurde in einer Küvette im Wasserbad auf $70{ }^{\circ} \mathrm{C}$ erwärmt und die Objektträger darin exakt 1,5 Minuten denaturiert. Anschließend wurden die Objektträger kurz in eisgekühltem $2 \times \mathrm{SSC}\left(4^{\circ} \mathrm{C}\right)$ gespült, in eiskaltem $70 \% \mathrm{EtOH}\left(-80^{\circ} \mathrm{C}\right)$ gesammelt und durch eine eisgekühlte $\left(-80^{\circ} \mathrm{C}\right)$ aufsteigende EtOH-Reihe $(70 \%, 85 \%, 99 \%)$ geführt, dehydriert und für mindestens 20 Minuten aufrecht an der Luft getrocknet. 


\subsubsection{Vorbereitung der DNA-Sonde}

\subsubsection{Markierung der Sonde über Nicktranslation}

(Rigby et al. 1977)

10 x NT -Puffer:

$$
\begin{aligned}
& 0,5 \mathrm{M} \text { Tris / } \mathrm{HCl} \mathrm{pH} 8,0 \\
& 50 \mathrm{mM} \mathrm{MgCl}_{2} \\
& 0,5 \mathrm{mg} / \mathrm{ml} \mathrm{BSA}
\end{aligned}
$$

Für die Markierung großer genomischer Fragmente, wie z.B. Cosmid- ( 40 kb) oder PAC-DNA-Inserts $(\sim 120 \mathrm{~kb})$, mit Digoxigenin- oder Biotin- markierten Desoxyribonukleotiden für die FISH hat sich die Methode der Nicktranslation durchgesetzt. Hierbei setzt eine Desoxyribonuklease I (DNase I) Einzelstrangbrüche (nicks) in die doppelsträngige DNA, die durch die 5'-3'-DNA-Polymerase I - Aktivität einer KlenowPolymerase unter Einbau von im Überschuss zugesetztem Biotin-16-dUTP oder Digoxigenin-11-dUTP wieder komplettiert wird. Zeitgleich kommt es durch die DNase I zur Fragmentierung des DNA-Templates, so dass markierte Fragmente mit einer Länge zwischen 200 bp und 600 bp entstehen. Diese Länge gewährleistet eine gute Diffusionsfähigkeit durch die Zell- und Chromosomenmatrix zu den Zielsequenzen und eine spezifische Hybridisierung. Für die Markierung wurde der Nick-TranslationsKit der Firma Gibco BRL (Life Technologies) verwendet. Für jeweils 1,5 $\mu$ g DNA-

\begin{tabular}{|c|c|}
\hline $1,5 \mu \mathrm{g}$ DNA-Sonde & $\mathrm{x}$ \\
\hline dNTP-Mix (dATP/dGTP/dCTP je 0,2 mM) & 5,0 \\
\hline Biotin-16-dUTP (1 mM) & 1,5 \\
\hline Pol I $(0,5 \mathrm{U} / \mu \mathrm{l}) /$ DNase I $(0,4 \mathrm{mU} / \mu \mathrm{l})$ - Mix & $\underline{5,0}$ \\
\hline
\end{tabular}
Sonde wurden folgende Markierungsansätze pipettiert:

$\underline{\text { Biotin }}$

$\mathrm{H}_{2} \mathrm{O}$ auf $50,0 \mu \mathrm{l}$

Digoxigenin

1,5 $\mu \mathrm{g}$ DNA-Sonde

x $\quad \mu 1$

0,1 M 2-Mercaptoethanol

$5,0 \mu 1$

10 x DIG DNA Labeling Mix

$2,5 \mu \mathrm{l}$

(je $1 \mathrm{mM} \mathrm{dATP/dGTP/dCTP,} \mathrm{0,65} \mathrm{mM} \mathrm{dTTP,}$

0,35 mM DIG-11-dUTP

10 x NT-Puffer

$5,0 \quad \mu 1$

Pol I (0,5 U/ $\mu \mathrm{l}) /$ DNase I $(0,4 \mathrm{mU} / \mu \mathrm{l})$ - Mix

$\underline{5,0 \quad \mu 1}$

$\mathrm{H}_{2} \mathrm{O}$ ad $50,0 \mu \mathrm{l}$ 
Die Ansätze wurden für 90 bis 120 Minuten bei $16{ }^{\circ} \mathrm{C}$ im Wasserbad inkubiert. Anschließend wurde ein Aliquot von $8 \mu \mathrm{l}$ auf ein 1,6\% horizontales Agarosegel (2.11.1) aufgetragen und der Fragmentlängenbereich bestimmt. Bei einer mittleren Fragmentlänge von $200 \mathrm{bp}$ bis $600 \mathrm{bp}$ wurde der Reaktionsansatz durch Zugabe von $5 \mu$ Stop-Puffer (0,5 M EDTA, pH 8,0) abgestoppt und sogleich ausgefällt oder bei $-20^{\circ} \mathrm{C}$ gelagert. Bei einer deutlich größeren mittleren Fragmentlänge wurde die Inkubationszeit bei $16^{\circ} \mathrm{C}$ verlängert oder erneut $50 \mu \mathrm{l}$ Markierungsansatz ohne DNA zugegeben, weitere 30 Minuten inkubiert und der Fragmentlängentest wiederholt.

\subsubsection{Nachweis des Einbaus von Bio-16-dUTP und Digoxigenin-11-dUTP über Dot-Blot}

Blockierungspuffer:

$$
0,3 \% \text { BSA in AP1-Puffer }
$$

Der Filternachweis diente der Kontrolle des Bio-16-dUTP- bzw. Dig-11-dUTP-Einbaus der über Nicktranslation (2.19.6.1) erzeugten Sonden-DNA. Zur Detektion von biotinylierter Sonden-DNA wurde ein mit alkalischer Phosphatase (AP) konjugiertes Streptavidin-System in einer Verdünnung von $10^{-3}$ in Blockierungspuffer verwendet. Bei Streptavidin handelt es sich um ein Biotin-bindendes Protein aus Streptomyces avidinii, dessen natürliche Bindungsaffinität zu Biotin $\mathrm{zu}$ dessen Detektion benutzt wird. Zur Detektion von Digoxigenin-markierter Sonden-DNA wurde ein AP-

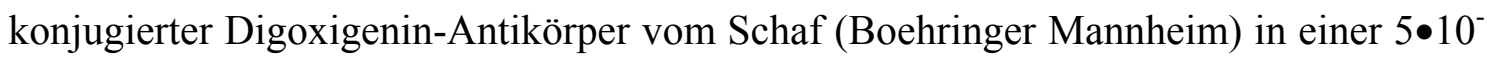

${ }^{3}$ Verdünnung in Blockierungspuffer benutzt. Die lokale enzymatische Aktivität der konjugierten alkalischen Phosphatase (AP) katalysiert die Oxidation des NBT/BCIP Färbesystem zu einem blauen Indigofarbstoff. Zum Filternachweis wurden je $1 \mu \mathrm{lder}$ markierten DNA in verschiedenen Verdünnungen $\left(10^{0}, 10^{-1}, 10^{-2}\right.$ und $\left.10^{-3}\right)$ auf eine mit $2 \times$ SSC befeuchtete Nitrozellulosemembran aufgetragen, getrocknet und für 30 Minuten im Ofen bei $80{ }^{\circ} \mathrm{C}$ fixiert. Anschließend wurde der Filter 30 Minuten in $10 \mathrm{ml}$ Blockierungspuffer bei $37^{\circ} \mathrm{C}$,geblockt“. Die Filter wurden 10 Minuten bei Raumtemperatur mit dem entsprechenden Detektionssystem (Biotin: AP-Streptavidin, 1:1000; Digoxigenin: Anti-Digoxigenin-AP, 1:5000) in Blockierungspuffer inkubiert und dann für $2 \times 3$ Minuten in AP 1-Puffer und $3 \times 3$ Minuten in AP 3-Puffer gewaschen. Zur Farbreaktion wurde NBT/BCIP-Stocklösung (Boehringer Mannheim, Kat.-Nr. 1681451) verwendet. Zur Farbreaktion wurden die Filter für 2 Stunden im Dunkeln in der NBT/BCIP-Färbelösung inkubiert. Anschließend wurden die Filter in $\mathrm{H}_{2} \mathrm{O}$ gespült und getrocknet. Eine deutliche Blaufärbung der $10^{-1}$ - und eine erkennbare Blaufärbung der $10^{-2}$-Verdünnung wurden als ausreichende Markierung der DNA für die folgende FISH gewertet. 


\subsubsection{Chromosomen-in situ-Supressions-Hybridisierung (CISS)}

Eukaryotische DNA enthält genomische repetitive Sequenzen wie z.B. Alu- und alphoide Sequenzen, SINEs und LINEs. Eine in situ-Hybridisierung auf Chromosomen des Menschen oder der Maus mit einer DNA-Sonde, die solche repetitiven Sequenzen enthält, würde zu einer uniformen Markierung der Chromosomen führen und spezifische Hybridisierungssignale überdecken. Durch die Methode der CISSHybridisierung ist es möglich, solche genomischen DNA-Fragmente spezifisch in der FISH einzusetzen. Dabei werden die repetitiven Anteile der DNA-Sonde durch Vorhybridisierung mit unmarkierter genomischer DNA oder Cot-1-DNA abgesättigt und so deren Hybridisierung auf den repetitiven chromosomalen Sequenzen supprimiert (Lichter et al. 1988; Pinkel et al. 1988). Zur Absättigung und Verminderung von unspezifischen Hybridierungssignalen dient die Zugabe gescherter Lachs-SpermienDNA (Sigma, Kat.-Nr. D956).

\subsubsection{Hybridisierungsansatz, Vorhybridisierung und Hybridisierung}

CISS-Mastermix

$$
\begin{aligned}
& 20 \% \text { Dextransulfat } \\
& 4 \text { x SSC pH 7,0 }
\end{aligned}
$$

Für die Hybridisierung wurden jeweils $300 \mathrm{ng}$ biotinylierte und/oder digoxigenierte Sonde aus 2.19.6.1 eingesetzt und zusammen mit $200 \mu \mathrm{g}$ Cot-1-DNA und $60 \mu \mathrm{g}$ gescherter Lachs-Spermien-DNA bei $-20{ }^{\circ} \mathrm{C}$ mit dem 2,5-fachen Volumen EtOH und dem 0,1-fachen Volumen $3 \mathrm{M}$ Natriumacetat (pH 5,5) über Nacht ausgefällt. Nach der Fällung wurde die Proben-DNA durch Zentrifugation bei $12000 \mathrm{xg}$ und $4{ }^{\circ} \mathrm{C}$ für 10 Minuten präzipitiert, in eiskaltem $70 \% \mathrm{EtOH}\left(-20^{\circ} \mathrm{C}\right)$ gewaschen, getrocknet und in $6 \mu$ Formamid (FA, pH 7,0) und $6 \mu$ CISS-Mastermix für 10 Minuten bei $37^{\circ} \mathrm{C}$ gelöst. Anschließend wurde die Proben-DNA für 10 Minuten bei $75^{\circ} \mathrm{C}$ im Heizblock denaturiert und anschließend zur Absättigung der repetitiven DNA-Sequenzen für 30 Minuten bei $37^{\circ} \mathrm{C}$ vorhybridisiert. Nach der Vorhybridisierung wurde die gesamte Proben-DNA sofort auf den vorbereiteten Objektträger (2.19.5) luftblasenfrei unter einem $22 \times 22 \mathrm{~mm}$ Deckglas aufgetragen, mit Fixogum Rubber-Cement (Marabu) luftdicht umrandet und in einer feuchten Kammer mit 2 x SSC $1-2$ Tage bei $37^{\circ} \mathrm{C}$ hybridisiert.

\subsubsection{Nachbehandlung der Chromosomenpräparate}

Durch die Bindung von Avidin (an Biotin) oder Antikörper (an Digoxigenin), an die ein Fluorochrom gekoppelt ist, können biotin- und digoxigeninmarkierte Sonden nach der Hybridisierung unter dem Fluoreszenzmikroskop sichtbar gemacht werden. Als 
Fluorochrome wurden FITC (Fluorescein-5-isothiocyanat) und TRITC (Tetramethylrhodamin-5-isothiocyanat) verwendet. FITC besitzt sein Absorptionsmaximum bei $495 \mathrm{~nm}$ und sein Emissionsmaximum bei $515 \mathrm{~nm}$ (hellgrüne Emission). TRITC hat ein Absorptionsmaximum von $575 \mathrm{~nm}$ und ein Emissionsmaximum von $600 \mathrm{~nm}$ (rote Emission). Für beide Systeme fand ein etabliertes Verstärkungssystem Anwendung. Das Biotin-Signal wurde im ersten Detektionsschritt zunächst mit einer Avidin-FITC-Lösung (Firma Atlanta Vector, Vertrieb Firma Serva, Kat.-Nr. A-2011) und im zweiten und dritten Detektionsschritt mit einem biotinylierten Ziegen-antiAvidin-Antikörper (BAAD, Firma Atlanta Vector, Vertrieb Firma Serva, Kat.-Nr. BA0300) markiert und dann erneut mit Avidin-FITC-Lösung verstärkt. Das DigoxigeninSignal wurde im ersten Detektionsschritt mit einem Anti-Digoxigenin-Antikörper der Maus (Firma Sigma, Kat.-Nr. D-8156) markiert und im zweiten Detektionsschritt mit einem TRITC-gekoppelten Anti-Maus-Antikörper der Ziege (Firma Sigma, Kat.-Nr. T-5393) verstärkt.

\subsubsection{Waschen nach der Hybridisierung}

Waschlösung 1

$\left(42{ }^{\circ} \mathrm{C}\right)$

$50 \%$ Formamid

$$
2 \times \mathrm{SSC}
$$

$2 \times \mathrm{SSC}$

$0,1 \times \mathrm{SSC}$

$4 \times \mathrm{SSC}$

0,1\% Tween-20

Waschlösung 4

$$
\left(42{ }^{\circ} \mathrm{C}\right)
$$

$\mathrm{pH} 7,0$

$\mathrm{pH} \mathrm{7,0}$

$\mathrm{pH} 7,0$

pH 7,0

Mit den anschließenden Waschschritten wurden nicht oder nur schwach und damit unspezifisch gebundene Sondenmoleküle vom Objektträger entfernt. Alle Waschschritte erfolgten unter Schütteln in der bei der angegebenen Temperatur vorgewärmten Waschlösung. Nach dem Entfernen des Fixogum wurde zunächst das Deckglas in der Waschlösung 1 abgespült und die Objektträger dem folgenden Schema entsprechend gewaschen:

$\begin{array}{ll}3 \times 10 \text { Minuten } & \text { Waschlösung } 1 \\ 3 \times 5 \text { Minuten } & \text { Waschlösung } 2 \\ 2 \times 5 \text { Minuten } & \text { Waschlösung } 3 \\ 1 \times 5 \text { Minuten } & \text { Waschlösung } 4\end{array}$




\subsubsection{Detektion und Amplifikation der Hybridisierungssignale}

Blocking-Lösung:

Waschlösung $4\left(45^{\circ} \mathrm{C}\right)$

$$
\begin{aligned}
& 5 \% \text { BSA } \\
& 4 \text { x SSC } \\
& 0,1 \% \text { Tween-20 }
\end{aligned}
$$

$$
\begin{array}{ll}
4 \times \mathrm{SSC} & \mathrm{pH} \mathrm{7,0} \\
0,1 \% \text { Tween-20 } &
\end{array}
$$

Alle Inkubationsschritte wurden in einer mit 2 x SSC befeuchteten Kammer und im Dunkeln durchgeführt. Die Detektion der Hybridisierungssignale auf Metaphasechromosomen (2.19.3) erfolgte auf dem Objektträger unter einem $24 \times 60 \mathrm{~mm}$ Deckglas. Die Detektion der Hybridisierungssignale auf dem „released chromatin“ (2.19.4) wurde mit umgedrehtem Objektträger unter einem durch Adhäsion frei hängenden $24 \times 60 \mathrm{~mm}$ Deckglas durchgeführt. Zur simultanen Detektion und Verstärkung sowohl biotinylierter als auch digoxigenierter Signale wurden nacheinander drei Detektionsreaktionen mit folgender Zusammensetzung der Antikörper durchgeführt:

1. Avidin-FITC

2. BAAD-Lösung (Biotinyliertes Anti-Avidin) + Maus-Anti-Digoxigenin-Antikörper

3. Avidin-FITC + TRITC-gekoppelter Ziege-Anti-Maus-IgG
$1: 200 \quad$ in Blocking-Lösung $1: 100 \quad$ in Blocking-Lösung $1: 100$ in Blocking-Lösung $1: 200 \quad$ in Blocking-Lösung $1: 200 \quad$ in Blocking-Lösung

Alle Antikörper- bzw. Avidin-Lösungen wurden vor Gebrauch 3 Minuten bei 10000 x g zentrifugiert, um Antikörperkonglumerate $\mathrm{zu}$ sedimentieren und aus dem Überstand zu entfernen.

Nach Durchführung der Waschschritte (2.19.8.1) wurden die Objektträger in $80 \mathrm{ml}$ Blocking-Lösung in einer Küvette für 30 Minuten bei $37{ }^{\circ} \mathrm{C}$ inkubiert. Nach dem „Blocking“ wurden $200 \mu \mathrm{l}$ der Detektionslösung 1 auf den Objektträger aufgebracht und wie oben beschrieben für 45 Minuten in einer feuchten Kammer bei $37^{\circ} \mathrm{C}$ inkubiert. Nach der Inkubation wurde das Deckglas in einer Küvette mit Waschlösung $4\left(45^{\circ} \mathrm{C}\right)$ abgespült und für $3 \times 5$ Minuten bei $45^{\circ} \mathrm{C}$ in Waschlösung 4 gewaschen. Ebenso wurde nacheinander mit der Detektionslösung 2 und 3 verfahren, wobei zwischendurch immer 3 x 5 Minuten bei $45^{\circ} \mathrm{C}$ in Waschlösung 4 gewaschen wurde. 


\subsubsection{Gegenfärbung der Chromosomen mit DAPI und Propidiumiodid}

DAPI - Stammlösung

DAPI - Färbelösung

Propidiumiodid - Stammlösung

Propidiumiodid - Färbelösung
$1 \mathrm{mg}$ DAPI in $5 \mathrm{ml} \mathrm{H}_{2} \mathrm{O}$

$7 \mu \mathrm{DAPI}$ - Stammlösung in $10 \mathrm{ml} 2 \times \mathrm{SSC}$ pH 7,0

$10 \mathrm{mg}$ Propidiumiodid in $10 \mathrm{ml} \mathrm{H}_{2} \mathrm{O}$

$7 \mu 1$ Propidiumiodid - Stammlösung in $10 \mathrm{ml}$

2 x SSC pH 7,0

Zur Chromosomengegenfärbung wurden die Fluoreszenzfarbstoffe DAPI (4‘,6-Diamidino-2-phenylindol) (Lin et al. 1977) und Propidiumiodid verwendet, die ausschließlich an DNA binden und stark fluoreszierende Farbkomplexe bilden. Nach dem letzten Waschschritt wurde das Präparat für 7 Minuten im Dunkeln mit 1 ml DAPIoder Propidiumiodid - Färbelösung überschichtet und anschließend mit Leitungswasser gespült. Anschließend wurden die Präparate im Dunkeln bei Raumtemperatur getrocknet und mit $25 \mu \mathrm{l}$ Antifading-Lösung (Vectashield, Firma Vector, Vertrieb Firma Camon, Heidelberg) (Johnson und Nogueira Araujo 1981) luftblasenfrei eingedeckelt und lichtgeschützt bei $4{ }^{\circ} \mathrm{C}$ gelagert.

\subsubsection{Auswertung der Chromosomenpräparate}

Die Präparate wurden mit einem Zeiss Axiophot-Fluoreszenz-Lichtmikroskop (ausgestattet mit einer HBO-100 Watt Quecksilberdampflampe) im Auflichtfluoreszenzverfahren ausgewertet.

Digitale Schwarzweiß-Aufnahmen der Metaphasepräparate wurden mit dem jeweiligen Filtersystem im Hause mit einer CCD-Kamera (Charge-Coupled Device, COHU High performance CCD camera) aufgenommen. Die Kamera wurde mit einem Macintosh Computer und dem Programm MacProbe gesteuert und das Bild direkt auf den Monitor übertragen. Die erstellten Graustufenbilder wurden in dem Programm MacProbe geöffnet und nachträglich die drei Fluoreszenzfarbsignale (blau, rot, grün) mit einer der realen Farbe entsprechenden Farbe belegt, übereinandergelegt und der durch die Filter bedingte Pixelversatz korrigiert.

Die digitalen Schwarzweiß-Aufnahmen der „chromosome release“ -Präparate wurden mit dem jeweiligen Filtersystem mit einer hochauflösenden, gekühlten CCD-Kamera (Chip KAF 1400) aufgenommen und von Frau S. Röttger in der Arbeitsgruppe von Prof. Dr. W. Schempp (Institut für Humangenetik und Anthropologie Freiburg) ausgewertet. 


\subsection{Präparations-Techniken}

\subsubsection{Präparation der Hippocampi}

(Gispen et al. 1972)

Die Mäuse wurden abgetötet und dekapitiert. Das Fell wurde vom Nacken her über die Schädeldecke gezogen, der Schädel durch einen Mittelschnitt in der Schädeldecke geöffnet und das Gehirn mit einem Löffelspatel aus der Schädelhöhle herauspräpariert. Das Gehirn wurde anschließend kurz in kaltem 1 x PBS gespült und auf ein mit 1 x PBS getränktes Filterpapier (Whatman GB003), das über eine Metallplatte in Kontakt mit einem Eisreservoir stand, gelegt. Zunächst wurde das Cerebellum abgetrennt und anschließend die beiden Großhirnhemisphären mit einem Skalpell entlang der fissura longitudinalis voneinander getrennt. Die Seitenventrikel wurden geöffnet und die Hippocampi mit einem kleinen Spatellöffel vom übrigen Gewebe separiert und zur Isolierung von Synaptosomen (2.21.2) oder Gesamtprotein (2.21.1) in das entsprechende Puffermedium überführt oder zur Isolierung von Gesamt-RNA (2.10.5) in flüssigem Stickstoff eingefroren.

\subsubsection{Gehirn-Entnahme zur Rezeptorautoradiografie}

Das Gehirn wurde freipräpariert und dem Schädel entnommen, mit Gewebeeinbettungsmittel (TissueTek ${ }^{\circledR}$ ) auf ein Aluminiumplättchen gelegt und in einem Aluminiumgefäß über flüssigem Stickstoff $\left(-195,8{ }^{\circ} \mathrm{C}\right)$ eingefroren. Die Lagerung erfolgte bis zur weiteren Verarbeitung in Kunststofftüten eingeschweißt bei $-80{ }^{\circ} \mathrm{C}$ im Gefrierschrank. 


\subsection{Extraktion und Konzentrationsbestimmung von Proteinen}

\subsubsection{Isolierung von Gesamt-Zellysat für Western-Immunoblot}

(nach dem Protokoll der Firma Santa Cruz Biotechnology, Inc.)

PMSF

Aprotinin

Pepstatin A

Leupeptin

Natriumorthovanadat

RIPA-Stammlösung

RIPA-Gebrauchslösung:

(frisch zubereitet und

auf Eis gekühlt)
$10 \mathrm{mg} / \mathrm{ml} \mathrm{PMSF} \mathrm{(w/v)} \mathrm{in} \mathrm{Isopropanol}$

$10 \mathrm{mg} / \mathrm{ml}(\mathrm{w} / \mathrm{v})$ in $\mathrm{H}_{2} \mathrm{O}$

$1 \mathrm{mg} / \mathrm{ml}(\mathrm{w} / \mathrm{v})$ in Methanol

$10 \mathrm{mg} / \mathrm{ml}(\mathrm{w} / \mathrm{v})$ in $\mathrm{H}_{2} \mathrm{O}$

$100 \mathrm{mM}$ in $\mathrm{H}_{2} \mathrm{O}$

9,1 $\mathrm{mM} \mathrm{Na}_{2} \mathrm{HPO}_{4}$

$1,7 \mathrm{mM} \mathrm{NaH}_{2} \mathrm{PO}_{4}$

$150 \mathrm{mM} \mathrm{NaCl} \quad \mathrm{pH} \mathrm{7,4}$

$1 \%$ Nonidet P-40

$0,5 \%$ Natriumdeoxycholat $\left(\mathrm{C}_{24} \mathrm{H}_{39} \mathrm{NaO}_{4}\right)$

$0,1 \%$ SDS

RIPA-Stammlösung

$100 \mu \mathrm{g} / \mathrm{ml}$ PMSF

$25 \mu \mathrm{g} / \mathrm{ml} \quad$ Aprotinin

$10 \mu \mathrm{g} / \mathrm{ml} \quad$ Pepstatin A

$25 \mu \mathrm{g} / \mathrm{ml} \quad$ Leupeptin

$1 \mathrm{mM} \quad$ Natriumorthovanadat

Das Gewebe wurde wie unter 2.20 beschrieben präpariert und im Verhältnis $0,3 \mathrm{ml}$ RIPA-Gebrauchslösung pro $100 \mathrm{mg}$ Gewebe gemischt und mit einem Homogenisator auf Eis aufgeschlossen. Nach erneuter Zugabe von $3 \mu \mathrm{l}$ PMSF pro $100 \mathrm{mg}$ Gewebe wurde das Zell-Lysat 30 Minuten auf Eis inkubiert und anschließend die Zelltrümmer durch zweimalige Zentrifugation für 10 Minuten bei $4{ }^{\circ} \mathrm{C}$ und $1000 \mathrm{xg}$ sedimentiert. Die Proteinkonzentration des Überstandes wurde wie unter 2.21 .3 bestimmt und Aliquots des Gesamt-Zellysats bei $4{ }^{\circ} \mathrm{C}$ und $-20^{\circ} \mathrm{C}$ gelagert oder direkt in die denaturierende SDS-Polyacrylamidelektrophorese (2.11.3) eingesetzt. 


\subsubsection{Synaptosomen-Präparation}

(Marchi und Raiteri 1989)

\begin{tabular}{|c|c|c|c|}
\hline Homogenisierungs-Puffer & $10 \mathrm{mM}$ & Tris- $\mathrm{HCl} \mathrm{pH} 7,4$ & \\
\hline & $0,32 \mathrm{M}$ & Sukrose & \\
\hline & $5 \mathrm{mM}$ & EDTA & \\
\hline & $1 \mathrm{mM}$ & EGTA & \\
\hline & $0,1 \mathrm{mM}$ & PMSF & \\
\hline & $10 \mu \mathrm{g} / \mathrm{ml}$ & Aprotinin & \\
\hline & $10 \mu \mathrm{g} / \mathrm{ml}$ & Leupeptin & \\
\hline & $10 \mu \mathrm{g} / \mathrm{ml}$ & Pepstatin A & \\
\hline & & Ammoniummolybdat & \\
\hline & $1 \times$ Phosphatase & Natriumorthovanadat & \\
\hline & Inhibitor Cocktail & Natriumtartrat & \\
\hline & & Imidazol & \\
\hline & $25 \mu \mathrm{g} / \mathrm{ml}$ & Soybean Trypsin Inhibitor & \\
\hline & $1 \mathrm{mM}$ & $\mathrm{NaF}$ & \\
\hline 1 x Ringer-Lösung & $125 \mathrm{mM}$ & $\mathrm{NaCl}$ & \\
\hline$\left(+\mathrm{Ca}^{2+}, \mathrm{Mg}^{2+}\right.$ und Glukose $)$ & $3 \mathrm{mM}$ & $\mathrm{KCl}$ & \\
\hline & $1 \mathrm{mM}$ & $\mathrm{NaH}_{2} \mathrm{PO}_{4}$ & \\
\hline & $22 \mathrm{mM}$ & $\mathrm{NaHCO}_{3}$ & $(\mathrm{pH} \mathrm{7,4)}$ \\
\hline & $+1,2 \mathrm{mM}$ & $\mathrm{CaCl}_{2}$ & \\
\hline & $+1,2 \mathrm{mM}$ & $\mathrm{MgSO}_{4}$ & \\
\hline & $+10 \mathrm{mM}$ & Glukose & \\
\hline Extraktionspuffer: & $20 \mathrm{mM}$ & Tris-HCl pH 7,5 & \\
\hline & $0,5 \mathrm{mM}$ & EDTA & \\
\hline & $0,5 \mathrm{mM}$ & EGTA & \\
\hline & $10 \mathrm{mM}$ & 2-Mercaptoethanol & \\
\hline & $0,5 \%$ & Triton X-100 & \\
\hline & $25 \mu \mathrm{g} / \mathrm{ml}$ & Aprotinin & \\
\hline & $25 \mu \mathrm{g} / \mathrm{ml}$ & Leupeptin & \\
\hline
\end{tabular}

Die Präparation von Synaptosomen oder synaptischer Plasmamembranen (SPM) geht auf die Arbeiten von De Robertis et al. (1961) sowie Gray und Whittaker (1962) zurück, in denen mit elektronenmikroskopischen Aufnahmen gezeigt werden konnte, dass schwach homogenisiertes Gehirnmaterial, das zur Isolation von Mitochondrien über 
einen Sukrosegradienten fraktioniert wurde, zahlreiche intakte synaptische Endigungen mit funktionalen synaptischen Vesikeln enthält, die zum Teil mit ihrer postsynaptischen Komponente assoziiert sind. Die Isolationsmethode wurde in der Folgezeit bezüglich der Abtrennung der mitochondrialen Fraktion und der Größe, Komplexität und in-vitro Funktionalität der Synaptosomen optimiert und für unterschiedlichste Arbeiten über neurophysiologische Fragestellungen eingesetzt (Kristjansson et al. 1982; Malva et al. 1994; Cammarota et al. 1997; Lonart und Sudhof 1998). In der vorliegenden Arbeit wurden hippocampale Synaptosomen dem Protokoll von Marchi und Raiteri (1989) folgend isoliert und nach Konzentrationsbestimmung (2.21.3) in den Proteinkinase C Assay (2.22) eingesetzt.

Die Hippocampi von zwei Mäusen oder das Gehirn einer Maus wurden wie unter 2.20 beschrieben präpariert, auf Eis gesammelt, zweimal mit je $3 \mathrm{ml}$ HomogenisierungsPuffer gewaschen, gewogen und in einen Glas-Homogenisator mit Teflon Pistell $(0,25 \mathrm{~mm}$ Freiraum) zusammen mit 10 Volumen (w/v) kaltem HomogenisierungsPuffer durch 10 Hübe bei $900 \mathrm{rpm}$ aufgeschlossen. Durch Zentrifugation bei $1000 \mathrm{x} \mathrm{g}$ für 10 Minuten wurden die intakten Zellkerne und die Zelltrümmer sedimentiert und der sogenannte postnukleäre Überstand gesammelt. Anschließend wurde die Synaptosomen-Fraktion durch Zentrifugation des Überstandes für 20 Minuten bei $13000 \mathrm{xg}$ und $4{ }^{\circ} \mathrm{C}$ sedimentiert, das Pellet in $100 \mu$ l Ringer-Lösung $\left(+\mathrm{Ca}^{2+}, \mathrm{Mg}^{2+}\right.$, Glukose, + Inhibitoren) resuspendiert und am selben Tag noch nach der Proteinkonzentrationsbestimmung (2.21.3) im PKC-Assay (2.22) eingesetzt.

\subsubsection{Konzentrationsbestimmung von Proteinen}

(Bradford 1976)

BSA-Stammlösung: $\quad 100 \mu \mathrm{g} / \mathrm{ml}$

Die Proteinkonzentration wurde nach der Methode von Bradford (1976) mit Hilfe des Roti $^{\circledR}$-Quant Protein Assays (Firma ROTH, Karlsruhe) bestimmt. Der im Protein-Assay enthaltene Farbstoff ändert sein Absorptionsverhalten bei $595 \mathrm{~nm}$ linear zur Proteinkonzentration im Reaktionsansatz. Durch Mitführen einer BSA-Eichreihe (0/ 1,0/ 1,5/ 2,0/ 2,5/ 3,0/ 4,0/ 5,0 $\mu \mathrm{g}$ BSA) bei jeder Messung kann die Proteinkonzentration aus der Eichgeraden interpoliert werden. Das $\mathrm{zu}$ messende Zellysat (Abschnitt 2.21.1) oder die Synaptosomen-Präparation (Abschnitt 2.21.2) wurden verdünnt (1:20 bis 1:40) und $50 \mu 1$ der Verdünnung in eine flachbödige 96Loch-Mikrotiterplatte (Greiner, Nürtingen) pipettiert. Ebenso wurde mit der BSAEichreihe verfahren. Der Roti ${ }^{\circledR}$-Quant - Farbstoff wurde 1:1,75 (z.B. 2 ml Roti ${ }^{\circledR}$-Quant $\left.+3,5 \mathrm{ml} \mathrm{H} \mathrm{H}_{2} \mathrm{O}\right)$ mit $\mathrm{H}_{2} \mathrm{O}$ verdünnt und jeweils $200 \mu \mathrm{l}$ mit der Proteinlösung vermischt. 
Die Messung der Extinktion erfolgte nach mindestens 5 Minuten Inkubation bei Raumtemperatur in einem „Microplate Reader 450“ (Biorad Laboratories, München) bei $595 \mathrm{~nm}$. Es wurden je Probe zwei Messungen durchgeführt und die Werte gemittelt.

\subsection{PKC - Assay}

(Yasuda et al. 1990)

5 x PKC-Substratlösung

$\begin{array}{ll}250 \mu \mathrm{M} & \text { Ac-MBP }_{4-14} \\ 100 \mathrm{mM} & \text { ATP } \\ 5 \mathrm{mM} & \mathrm{CaCl}_{2} \\ 100 \mathrm{mM} & \mathrm{MgCl}_{2} \\ 20 \mathrm{mM} & \text { Tris, pH 7,5 }\end{array}$

Zur Messung der Proteinkinase-C Aktivität wurden $250 \mu \mathrm{g}$ der SynaptosomenPräparation (2.21.2) in 1 x Ringer-Lösung $\left(+\mathrm{Ca}^{2+}, \mathrm{Mg}^{2+}\right.$, Glukose, + Inhibitoren) und Zugabe von $1 \mathrm{mM}$ Carbachol, einem Agonisten nikotinischer und muscarinischer Acetylcholin-Rezeptoren, in $40 \mu \mathrm{l} \mathrm{Gesamtvolumen} \mathrm{für} 40$ Minuten bei $30^{\circ} \mathrm{C}$ inkubiert und so der cholinerge Signaltranduktionsweg induziert. Nach 40 Minuten wurden die synaptosomalen Membranen durch Zugabe von Triton X-100 (0,5\%) und 2Mercaptoethanol $(10 \mathrm{mM})$ solubilisiert, das Volumen auf $50 \mu \mathrm{l}$ erhöht und ein $10 \mu \mathrm{g}$ Aliquot $(2 \mu \mathrm{l})$ in das PKC-Assay-System der Firma Gibco BRL eingesetzt. Dieses PKC-Assay-System basiert auf einem N-terminal acetylierten und damit stabilisierten, synthetischen Polypeptid des basischen Myelin-Proteins Ac-MBP ${ }_{4-14}$ (Yasuda et al. 1990), das in dem benutzten Protein Kinase C Assay System enthalten ist. Das Substrat Ac-MBP ${ }_{4-14}$ wird spezifisch und hochsensitiv von aktivierter, d.h. Membran-assoziierter PKC unter Zugabe von $\gamma-{ }^{32} \mathrm{P}$-ATP phosphoryliert, anschließend an PhosphozellulosePapier (P-81) gebunden und gewaschen. Die ${ }^{32} \mathrm{P}$ - Aktivität der PhosphozellulosePapiere wurde in $5 \mathrm{ml}$ Szintillationsflüssigkeit im Szintillationsmessgerät detektiert und quantifiziert.

Der PKC-Assay wurde folgendem Schema folgend in je drei Ansätzen pro Synaptosomenpräparation zusammenpipettiert:

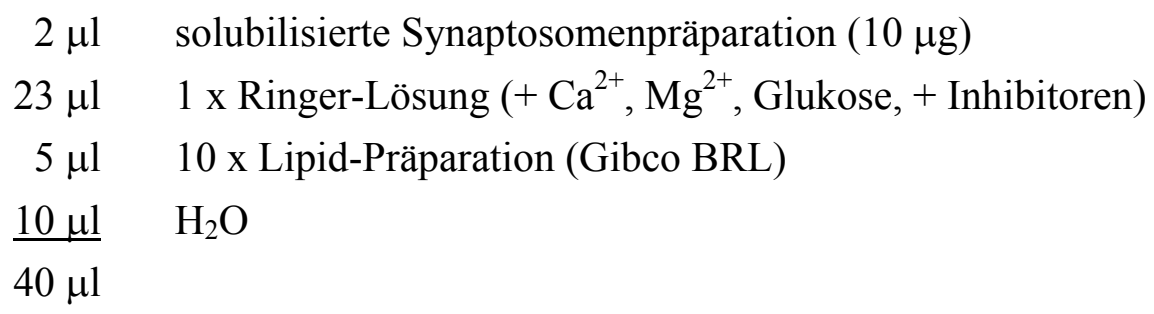


In je einem Ansatz wurde statt Lipid-Präparation ein spezifischer PKC-Inhibitor hinzugegeben, und zwar um die PKC-Spezifität des detektierten Signals nachzuweisen:

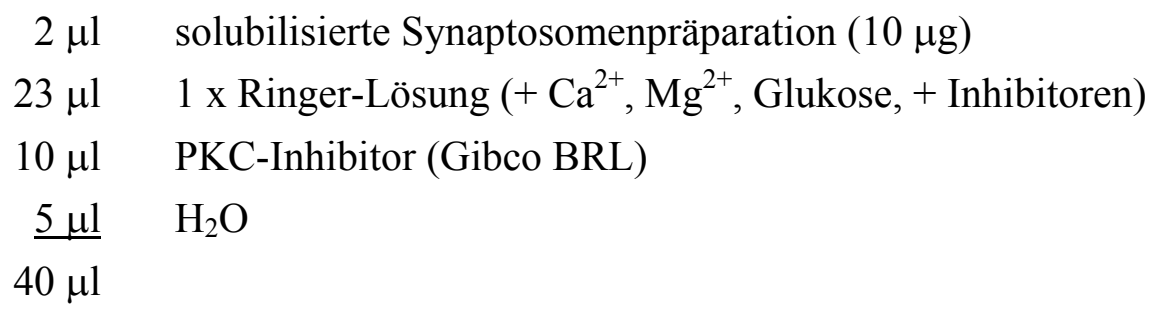

Um die Bindung des PKC-Inhibitors zu ermöglichen, wurden die Ansätze für 20 Minuten bei Raumtemperatur inkubiert. Pro Reaktionsansatz wurden $10 \mu 15$ x PKCSubstratlösung mit $\gamma^{32} \mathrm{P}$-ATP $(3000 \mathrm{Ci} / \mathrm{mmol}, 10 \mu \mathrm{Ci} / \mu \mathrm{l})$ gemischt, und zwar in einer Konzentration von 20-25 $\mu \mathrm{Ci} / \mathrm{ml}$. Die PKC-Substratlösung $(10 \mu \mathrm{l})$ wurde $\mathrm{zu}$ den Reaktionsansätzen pipettiert und exakt 5 Minuten bei $30^{\circ} \mathrm{C}$ inkubiert. Anschließend wurden $25 \mu \mathrm{l}$ des Reaktionsansatzes auf ein rundes Phosphozellulose-Papier (P-81, $2 \mathrm{~cm}$ Durchmesser) pipettiert, getrocknet, zweimal in $500 \mathrm{ml} 1 \%$ (v/v) Phosphorsäure und zweimal in $500 \mathrm{ml} \mathrm{H}_{2} \mathrm{O}$ für jeweils 5 Minuten gewaschen und in einem Szintillationsröhrchen zusammen mit $5 \mathrm{ml}$ Szintillationsflüssigkeit in einem Szintillationsmessgerät die ${ }^{32} \mathrm{P}$ - Aktivität detektiert und quantifiziert.

\subsection{Immunfärbung von PVDF-Filtern}

Blockierungspuffer:

$1 \times$ TBS

$0,05 \%$ Tween-20

$5 \%$ Bockierungsreagenz (Milchpulver)

Waschpuffer:

$1 \times$ TBS

$0,05 \%$ Tween-20

Die Protein-beladenen PVDF-Filter aus Kapitel 2.11.3 und 2.15.3 wurden direkt verwendet oder nach Lagerung bei $4{ }^{\circ} \mathrm{C}$ zunächst 3 Minuten in Methanol reaktiviert und gründlich in Waschpuffer gespült. Nach einstündiger Inkubation unter Schütteln in Blockierungspuffer wurden die Filter für 1 Stunde bei Raumtemperatur in $5 \mathrm{ml}$ einer verdünnten Lösung des primären Antikörpers (1:200 in Blockierungspuffer), und zwar eingeschweißt in einer Schlauchfolie, inkubiert. Danach wurde die Membran dreimal für 5 Minuten unter Schütteln in Waschpuffer inkubiert und anschließend in $5 \mathrm{ml}$ Blockierungspuffer mit dem sekundären Antikörper, einem mit alkalischer Phosphatasekonjugierten anti-Kaninchen IgG (AP-anti-rabbit-IgG, Firma Sigma), in einer 1:10000 Verdünnung für 45 Minuten bei Raumtemperatur unter Schütteln inkubiert. Nach dieser Inkubation wurde der Filter erneut dreimal für 5 Minuten in Waschpuffer gewaschen. 
Zur Detektion wurde das bereits in Kapitel 2.19.6.2 beschriebene NBT/BCIPFärbesystem als Substrat für die alkalische Phosphatase benutzt. Dazu wurde der Filter zunächst dreimal für 5 Minuten in AP 1-Puffer gewaschen, zweimal für 3 Minuten in AP 3-Puffer auf pH 9,5 umgepuffert, eingeschweißt in Schlauchfolie im Dunkeln ohne Schütteln 1-2 Stunden in $10 \mathrm{ml}$ NBT/BCIP-Färbelösung gefärbt, in $\mathrm{H}_{2} \mathrm{O}$ gewaschen, luftgetrocknet und fotodokumentiert.

\subsection{Histologische Färbungen}

\subsubsection{Silber-Sulfid Färbung nach Timm zur Darstellung zinkhaltiger Synapsen in Moosfasern}

(Timm 1958; Danscher und Zimmer 1978; Schwegler und Crusio 1995)

Perfusions-Lösung I

Perfusions-Lösung II

Lösung III

Betäubungsmittel

$$
\begin{aligned}
& 1,17 \%(\mathrm{w} / \mathrm{v}) \mathrm{Na}_{2} \mathrm{~S} \\
& 1,19 \%(\mathrm{w} / \mathrm{v}) \mathrm{NaH}_{2} \mathrm{PO}_{4}
\end{aligned}
$$

$3 \%$ Glutaraldehyd (v/v)

in $1 \times$ PBS $(\mathrm{pH} 7,35)$

20 \% Sukrose in Lösung II

$0,2 \%$ Rompun $^{\circledR}$ (Bayer)

1,0\% Ketamin (cp-pharma D31303 Burgdorf)

in $\mathrm{H}_{2} \mathrm{O}$

Die von Timm (1958) beschriebene Silber-Sulfid Färbetechnik ermöglicht es, den Ort und den differentiellen Gehalt von Schwermetall-Ionen in Geweben zu bestimmen. Im Hippocampus kann diese Methode aufgrund des hohen Gehaltes an Zink-Ionen in den präsynaptischen Vesikeln der hippocampalen Moosfaser - Terminalien dazu benutzt werden, das Terminationsgebiet der Moosfasern im Hilus und in der CA3-Region auf Gehirnschnitten anzufärben. Dazu ist es notwendig, das Material vor der Färbung geeignet zu fixieren, wobei man nach transkardieller in vivo Perfusion mit sulfidischer Lösung das synaptische $\mathrm{Zn}^{2+}$ als wasserunlösliches Zinksulfid präzipitiert und das Gewebe mit 3 \% wässeriger Glutaraldehyd - Lösung fixiert. Bei der Perfusion gelangt die Perfusions-Lösung in den linken Ventrikel und über das Arterien-System in den Körperkreislauf und durchspült die inneren Organe einschließlich des Gehirns bis in die feinsten Blutkapillaren, so dass eine optimale Durchdringung des Gewebes mit dem Fixativ gewährleistet ist.

Beide Perfusions-Lösungen wurden in $500 \mathrm{ml}$ Injektionsflaschen gefüllt, über Kopf aufgehängt und mit Injektions-Tropfvorrichtungen bestückt. Die Schläuche beider 
Lösungen wurden im unteren Bereich über einen Dreiwegehahn zusammengeführt und in einem abführenden Schlauch vereint, an dessen Ende eine „stumpf“-geschliffene Injektionskanüle angebracht war. Das System wurde anschließend mit den PerfusionsLösungen befüllt, wobei der abführende Schlauch zunächst mit der Perfusions-Lösung I gespült wurde.

Nach der Narkose der Maus mittels intraperitonealer Injektion von $100 \mu 1$ Betäubungsmittel $\left(0,2 \%\right.$ Rompun $^{\circledR}, 1,0 \%$ Ketamin in $\left.\mathrm{H}_{2} \mathrm{O}\right)$ pro 10 g Körpergewicht (KG) wurde die Maus mit Präpariernadeln an den Extremitäten auf der Unterlage fixiert und nach Ausbleiben der Reflexe der Brustkorb mit einer Schere geöffnet. Damit die Perfusions-Lösung den Körperkreislauf nach der Passage verlassen kann, wurde das rechte Atrium geöffnet. Die Injektionskanüle wurde in den linken Ventrikel des Herzens gestochen und befestigt. Über den Dreiwegehahn wurde dann die Perfusions-Lösung I in den Ventrikel geleitet, wobei an der Tropfvorrichtung eine Tropfgeschwindigkeit von etwa 1 Tropfen pro Sekunde eingestellt wurde. Mit diesem ersten Perfusionsschritt wurde das hippocampale Moosfaser-System bereits kurz mit sulfidischer Lösung gespült und Zinksulfid an den Moosfaser Synapsen präzipitiert. Zusätzlich wurde damit das Blut aus den Gefäßen entfernt, was an der Farbänderung der Leber von rot nach braun zu erkennen war. Anschließend wurde der Dreiwegehahn umgestellt und die Perfusions-Lösung II für 5 Minuten durch den Körperkreislauf geleitet. Mit diesem zweiten Perfusionschritt wurde das Gewebe fixiert, wobei die Muskulatur des Tieres erstarrte. Nach erfolgter Fixierung wurde erneut die sulfidische Perfusion-Lösung I für 5 Minuten durch den Körperkreislauf geleitet und die Zinksulfid-Präzipitation abgeschlossen. Anschließend wurde das Tier dekapitiert, die Schädeldecke geöffnet, das Gehirn herauspräpariert und über Nacht in Lösung III bei Raumtemperatur kryoprotektiert und anschließend am Kryotom geschnitten.

\subsubsection{Herstellung Chrom-Kalium-Gelatine beschichteter Objektträger}

Gelatine-Lösung

$$
\begin{aligned}
& 1 \% \text { Blattgelatine } \\
& 0,1 \% \mathrm{CrK}\left(\mathrm{SO}_{4}\right)_{2} \\
& 0,002 \% \text { Thymol }
\end{aligned}
$$

Für die Timm-Färbetechnik wurden Objektträger ohne Schliff (76 x 26 mm) verwendet. Diese wurden eine Stunde in konzentrierter Chromschwefelsäure von MetallVerunreinigungen befreit, da geringste Mengen als sogenannte Belichtungskeime wirken und die Bildung unspezifischer Silberpräzipitate in der anschließenden TimmFärbung katalysieren. Anschließend wurden die Objektträger gründlich in Millipore$\mathrm{H}_{2} \mathrm{O}$ gewaschen. Für die Gelatine-Lösung wurde die Blattgelatine in Streifen 
geschnitten, zusammen mit Thymol und $\mathrm{CrK}\left(\mathrm{SO}_{4}\right)_{2}$ in $\mathrm{H}_{2} \mathrm{O}$ bei $80{ }^{\circ} \mathrm{C}$ aufgelöst und auf Raumtemperatur abgekühlt. Die Objektträger wurden bei Raumtemperatur in der Lösung gelatinisiert und anschließend über Nacht im Brutschrank bei $55^{\circ} \mathrm{C}$ getrocknet.

\subsubsection{Anfertigung der Kryostatschnitte}

Zur Anfertigung der Kryostatschnitte wurde das institutseigene Kryostat-Mikrotom (2700 Frigocut, Reichert-Jung) verwendet. Zum Schneiden wurden die Gehirne auf dem Objekttisch mit dem Freezing-Medium (CRYO-BLOCK) befestigt und die Objektkühlung und der Innenraum des Kryostat-Mikrotoms auf $-20{ }^{\circ} \mathrm{C}$ temperiert. Es wurden $40 \mu \mathrm{m}$ dicke horizontale Schnittserien beginnend in der midseptotemporalen Ebene angefertigt. Die Schnitte wurden mit einem vorgekühlten Pinsel gewendet, auf ebenfalls vorgekühlte, Chrom-Kalium-Gelatine beschichtete Objektträger aufgeschmolzen und über Nacht bei Raumtemperatur getrocknet.

\subsubsection{Herstellung von Gummiarabicum}

Gummiarabicum

$50 \%(\mathrm{w} / \mathrm{v})$

$500 \mathrm{~g}$ Gummiarabicum wurden bei $70{ }^{\circ} \mathrm{C}$ unter Rühren portionsweise zu $1000 \mathrm{ml} \mathrm{H}_{2} \mathrm{O}$ gegeben und einen Tag bei $70{ }^{\circ} \mathrm{C}$ gerührt. Nach Erkalten über Nacht wurde das flüssige Gummiarabicum bei $-20{ }^{\circ} \mathrm{C}$ gelagert.

\subsubsection{Timm Silber-Sulfid Färbung}

Timm-Lösung

5,1 g Zitronensäure

$4,7 \mathrm{~g}$ Natriumcitrat

3,4 g Hydrochinon (Reduktionsmittel)

$120 \mathrm{ml} 50 \%(\mathrm{w} / \mathrm{v})$ Gummiarabicum

$80 \mathrm{ml} \mathrm{H}_{2} \mathrm{O}$

Das Silbernitrat $(170 \mathrm{mg})$ wurde abgedunkelt in $2 \mathrm{ml}$ Timm-Lösung gelöst und zu $198 \mathrm{ml}$ Timm-Lösung in eine mit Chromschwefelsäure gereinigte und mit $\mathrm{H}_{2} \mathrm{O}$ gespülte abgedunkelte Küvette gegeben. Die Objektträger wurden in der Küvette in einem abgedunkelten Brutschrank bei $35^{\circ} \mathrm{C}$ für 45 Minuten gefärbt, dann 10 Minuten unter Leitungswasser gewässert und 10 Minuten in destilliertem $\mathrm{H}_{2} \mathrm{O}$ gewaschen. Anschließend wurde das Silber-Präzipitat in $1 \%$ wässriger Natriumthiosulfat-Lösung fixiert, erneut zweimal für 5 Minuten in destilliertem $\mathrm{H}_{2} \mathrm{O}$ gespült, die Schnitte in einer aufsteigenden Ethanolreihe $(70 \% / 95 \% / 100 \% / 100 \%)$ für jeweils 5 Minuten entwässert, zweimal für 5 Minuten in Xylol gewaschen und mit Eukitt ${ }^{\circledR}$ als Dauer-Präparat konserviert. 


\subsubsection{Nissl-Färbetechnik}

Um die exakten Schnittebenen darzustellen, wurde von den Objektträgern pro Tier jeder zehnte mit Thionin angefärbt. Hierzu wurden die ausgewählten Objektträger über Nacht bei $37^{\circ} \mathrm{C}$ im Wärmeschrank getrocknet und mit Thionin angefärbt. Hierbei handelt es sich um eine Kernfärbung für Neurone (Nissl-Färbung).

Die Objektträger wurden 5 Minuten in Entfetter-Lösung getaucht und in einer absteigenden Ethanolreihe $\left(2 \times 100 \%, 90 \%, 80 \%, 70 \%, 50 \% \mathrm{EtOH}, 1 \times \mathrm{H}_{2} \mathrm{O}\right.$ je 1 Minute) hydriert. Danach wurde für 2 Minuten in $4 \%$-igem Paraformaldehyd (PFA, $\mathrm{pH} 7,2$ ) nachfixiert, anschließend erneut für 10 Sekunden in $\mathrm{H}_{2} \mathrm{O}$ gespült und die Färbung für 2-3 Minuten in 0,15\% Thionin-Färbelösung durchgeführt. Anschließend wurden die Objektträger zweimal kurz in $\mathrm{H}_{2} \mathrm{O}$ gewaschen und die Färbung 2-3 Minuten in 2,5\% Ammoniummolybdat-Lösung stabilisiert. Nach erneutem Spülen in $\mathrm{H}_{2} \mathrm{O}$ wurden die Schnitte in einer aufsteigenden Ethanolreihe $(50 \%, 70 \%, 80 \%$ und $90 \%$ EtOH, je 1 Minute) vordehydriert, 1 Minute in $90 \% \mathrm{EtOH} / 0,4 \%$ Essigsäure (v/v) differenziert, vollständig dehydriert ( $90 \%, 2$ x $100 \%$ EtOH, je 1 Minute), 4 x jeweils eine Minute in Xylol gespült und die Schnitte mit Eukitt ${ }^{\circledR}$ eingedeckt.

\subsection{NMDA-Rezeptorautoradiographie}

\subsubsection{Anfertigen der Schitte}

Von den gefrorenen Gehirnen (2.20.2) wurden wie in Kapitel 2.24.3 beschrieben Gefrierschnitte angefertigt. Dazu wurde eine Schnittdicke von $10 \mu \mathrm{m}$ eingestellt. Die ersten Schnitte bis zum Auftreten des Hippocampus wurden verworfen. Um die anatomische Schnittebene erkennen zu können, wurden einzelne Schnitte auf Objektträger aufgezogen und eine Thionin-Schnellfärbung durchgeführt. Dazu wurde der frische Schnitt kurz in $\mathrm{H}_{2} \mathrm{O}_{\text {bidest }}$ getaucht, für 2 Minuten in $0,15 \%$ Thionin gefärbt und anschließend in $\mathrm{H}_{2} \mathrm{O}_{\text {bidest }}$ abgespült. Die Schnittebene konnte dann durch Vergleich mit einem Gehirnatlas (Franklin und Paxinos 1997) der Maus verglichen werden. Der Hippocampus wurde vollständig geschnitten und fortlaufend auf 40 mit 0,5\% Gelatine beschichtete vorgekühlte Objektträger aufgezogen, wobei zunächst nur ein Schnitt auf jeden Objektträger überführt wurde. Anschließend wurde wieder mit dem ersten Objektträger begonnen, so dass jeder Objektträger zum Abschluss mit sieben Schnitten bestückt war und einen Querschnitt durch den gesamten Hippocampus repräsentierte. Die Objektträger wurden bis zur weiteren Verwendung bei $-80^{\circ} \mathrm{C}$ im Gefrierschrank gelagert. Von den 40 Objektträgern pro Tier wurde jeder zehnte histologisch mit Thionin (2.24.6) angefärbt, um damit die exakten Schnittebenen darzustellen. 


\subsubsection{Inkubation der Schnitte mit ${ }^{125}$ I-MK 801}

(Herkenham und Sokoloff 1984)

Für die Rezeptorbindung wurde der Ligand ${ }^{125}$ I-MK 801 (spez. Aktivität 2200 $\mathrm{mCi} / \mathrm{mmol}$ ) gewählt, der antagonistisch an NMDA-Rezeptoren bindet. ${ }^{125} \mathrm{I}$ ist ein Gamma-Strahler mit einer Halbwertszeit von 60 Tagen und der Ligand ${ }^{125} \mathrm{I}$-MK 801 besitzt mit $2200 \mathrm{Ci} / \mathrm{mmol}$ eine sehr hohe spezifische Aktivität, die für den Nachweis der NMDA-Rezeptoren im Verhältnis zu der größeren Menge an unspezifischen Bindungsstellen nötig ist.

Am Tag vor der Inkubation wurden je Tier zwei Objektträger, die einen möglichst breiten Querschnitt durch den Hippocampus repräsentieren, ausgewählt und über Nacht bei $4{ }^{\circ} \mathrm{C}$ im Exsikkator getrocknet. Am nächsten Tag wurden die Objektträger für 90 Minuten bei Raumtemperatur in Trisacetat-Puffer vorinkubiert. Während dieser Zeit wurden $0,4 \mathrm{nmol}{ }^{125} \mathrm{I}-\mathrm{MK} 801$ pro Gefäß zu $12 \mathrm{ml}$ Trisacetat-Puffer gegeben. Aus jedem Inkubationsgefäß wurden $50 \mu$ entnommen und in einem Szintillationsmessgerät gemessen, um die tatsächliche Konzentration des Radioliganden in der Pufferlösung zu kontrollieren. Anschließend wurden die Objektträger in die Inkubationsgefäße gegeben und für 90 Minuten bei Raumtemperatur und absoluter Dunkelheit inkubiert. Ungebundener Radioligand wurde nach der Inkubation durch Waschen für 90 Minuten in Trisacetat-Puffer und zweimal für eine Minute in kaltem $\mathrm{H}_{2} \mathrm{O}\left({ }^{\circ} \mathrm{C}\right)$ entfernt. Zum Abschluss wurden die Objektträger unter einem kalten Luftstrom über Nacht getrocknet.

Zur Ermittlung der unspezifischen Bindung wurde jeweils ein Objektträger pro Tier unter identischen Inkubationsbedingungen in den Inkubationsgefäßen inkubiert, denen zusätzlich unmarkiertes (+)-MK 801 Hydrogen-Maleat in 10 000-fachem Überschuss (4 $\mu \mathrm{mol}$ pro Gefäß) hinzugegeben wurde.

\subsection{3 $\quad{ }^{125}$ Jod-Standards}

Um die zu messenden Bindungsstärken quantifizieren zu können, wurden industriell gefertigte Standards verwendet (Microscales, Amersham). Dabei handelt es sich um Kunststoffblöcke mit unterschiedlichen Bereichen, die bestimmte Mengen an ${ }^{125} \mathrm{I}-$ Radioaktivität enthalten.

Von einem derartigen Standardblock wurden mit einem Rotationsmikrotom (Typ 2218, LKB) $10 \mu \mathrm{m}$ dicke Schnitte angefertigt und diese Schnitte mit Gelatinelösung auf die Objektträger fixiert. Für die Filmexposition wurden jeweils drei dieser Standards mit in die Kassette gegeben. 


\subsubsection{Autoradiographie}

Nach dem Trocknen der inkubierten Schnitte (2.25.2) wurden diese in Autoradiographiekassetten zusammen mit drei ${ }^{125}$ I-Standards (2.25.3) eingelegt und ein photosensitiver Film ( ${ }^{3} \mathrm{H}$-Hyperfilm, Amersham-Buchler, Braunschweig) aufgelegt. Die Kassetten wurden so für 20 Stunden bei $4{ }^{\circ} \mathrm{C}$ exponiert. Zur Entwicklung wurden die Filme für zwei Minuten in eisgekühltem Entwickler (5\%) inkubiert (LX-24, Kodak, Stuttgart) und die Entwicklung in einem Stopbad unterbrochen (0,5\%-ige Essigsäure für 30 Sekunden). Die Fixierung wurde für 20 Minuten in Polymax-Fixierer (Kodak, Stuttgart) durchgeführt. Die Filter wurden schließlich unter Leitungswasser gewaschen, dem zum Ende des Waschvorgangs ein Netzmittel (Agepon ${ }^{\circledR}$, AGFA, Leverkusen) zugesetzt wurde. Die Expositionszeit wurde so bemessen, dass eine Sättigung auf dem Film vermieden und eine Quantifizierung der Signale ermöglicht wurde.

\subsubsection{Densitometrische Auswertung der Autoradiogramme}

Die quantitative densitometrische Auswertung der Autoradiogramme erfolgte mit Hilfe eines computergestützten Bildanalysesystems (Imaging Inc., St. Catharines, Kanada) gesteuert von der Software MCID 4.2 (Imaging Inc.).

Der zu messende Film wurde auf einen Leuchttisch mit stufenlos regelbarer Helligkeit gelegt und das Bild mit Hilfe einer Kamera über einen elektronischen Vorverstärker auf einem Computer digitalisiert. Der gewünschte Bildausschnitt wurde auf den Monitor projiziert und die zu quantifizierende Region mit der „Computer-Maus“ umfahren. Die durchschnittliche Schwärzung der markierten Region wurde von dem Bildanalysesystem über die Messung der Absorption quantifiziert. Um eine Bezugsgröße für die Messwerte zu erhalten, wurden die exponierten Flächen der ${ }^{125} \mathrm{I}$-Standards auf diese Weise gemessen und ihren jeweiligen Radioaktivitäten zugewiesen. Aus dem Verhältnis von Radioaktivität und Absorption der Standardfelder erstellte die Software eine Eichkurve, die bei den nachfolgenden Messungen die absolute Quantifizierung der am Hirnschnitt gebundenen Radioaktivität ermöglichte. Die Standards besitzen als „Gewebeersatz“ die Einheit „dpm/mg Gewebeäquivalent“ (dpm = Zerfälle pro Minute) und können über die spezifische Aktivität des ${ }^{125} \mathrm{I}-\mathrm{MK} 801$ in die Stoffmengenkonzentration (fmol/mg Gewebeäquivalent) umgerechnet werden. 


\subsection{Verhaltensexperimente}

\subsubsection{Bewegungsmuster-Aufzeichnung mit Lasermotilimat und „Open-Field““}

(Crusio und Schwegler 1987)

Das „Offen-Feld“-Experiment („Open-Field“) ist ein einfaches Experiment, um die motorische Aktivität und Exploration von Mäusen zu messen. Es besteht aus einer einfachen, umrandeten Fläche mit einem Netzwerk von rechtwinklig angeordneten Linien im Abstand von $10 \mathrm{~cm}$. Das Versuchstier wird in diese Kammer gesetzt und das Verhalten wird über einen Zeitraum von 15 Minuten ( 3 x 5 Minuten) beobachtet. Das Tier befindet sich dabei in einer neuen Umgebung, die es zu erkunden gilt. Während dieser Exploration können eine Reihe von Verhaltensvariablen gemessen werden:

1. Motorische Aktivität (Anzahl der Linienüberquerungen)

2. Anzahl: Aufrichten an der Seitenwand (,Leaning“)

3. Anzahl: Aufrichten im freien Feld (,Rearing“)

4. Anzahl und Zeit: Schreckhaftes, unbewegliches Verharren („Freezing“)

5. Anzahl und Zeit: Putzen

6. Abgabe von Kot (Defäkation)

7. Abgabe von Urin (Urination)

Mit diesem Experiment erhält man auf eine einfache und schnelle Weise Verhaltensdaten, die sich aufgrund des komplexen Verhaltens allerdings aus den unterschiedlichsten Komponenten wie Motivation, Exploration, Stress, Furcht und räumlichem Lernen zusammensetzten können.

Eine automatisierte Version des „Open-Field“ ist das in Kooperation mit Frau Dr. Harvemann-Reinicke benutzte „Opto-Varimex-3 Activity Meter“ (Magnus-Ellenbroek und Havemann-Reinecke, 1993). Dieses automatische Aufnahmesystem zerlegt die Motilität des Versuchstieres über ein aufwendiges Laserdetektionssystem in zwei vertikale Komponenten $(\mathrm{X}, \mathrm{Y})$ und eine horizontale Komponente $(\mathrm{Z})$. Zusätzlich ist das Computerprogramm in der Lage die Gesamtdistanz $\mathrm{zu}$ berechnen und das Bewegungsmuster über einen XY-Plotter auszudrucken. Die Versuchszeit in dieser Apparatur betrug fünf Minuten. 


\subsection{2 „Radial-Maze“ Lernexperiment}

(Schwegler et al. 1990)

Räumliches Erinnerungsvermögen von Mäusen kann in einem sogenannten LabyrinthExperiment („Maze-experiment“") untersucht werden. In dieser Arbeit wurde ein 8-Arm„Radial Maze“ (Eigenbau des Instituts für Neuroanatomie, Magdeburg) benutzt. Im Gegensatz zum „Morris Water Maze“ (Morris 1984) zeigen die Tiere in dieser „trockenen“ Version des für Lernexperimente etablierten „Maze-Experiments“ ein reduziertes Stressverhalten, so dass Stressartefakte ausgeschlossen werden können.

Das „Radial Maze“ besteht aus einem zentralen Raum und 8 geschlossenen PlexiglasArmen, die radial in identischem Abstand von dem zentralen Raum wegführen. Die zentrale Plattform besitzt einen Durchmesser von $22 \mathrm{~cm}$ und die Arme sind $25 \mathrm{~cm}$ lang, $6 \mathrm{~cm}$ hoch und $6 \mathrm{~cm}$ breit. Am Ende jedes Arms wurden hinter einer perforierten Wand frische Futterpellets positioniert, um die Apparatur gleichmäßig mit Futtergeruch zu „durchfluten“ und den Tieren die Geruchsorientierung zu erschweren. Vor der perforierten Wand wurde jeder Arm mit einem kleinen Futterpellet $(10 \mathrm{mg})$ zur Belohnung bestückt, das von den Tieren gefressen werden sollte. Das „Radial Maze“ wurde in einem ruhigen Versuchsraum auf dem Boden plaziert und räumliche Orientierungspunkte zwischen den Armen und um das „Radial Maze“ herum positioniert. Diese räumlichen Marker und die Position des „Radial Maze“ im Raum wurde über den gesamten Zeitraum des Experimentes (7 d) nicht mehr verändert.

Die Tiere wurden zunächst an zwei aufeinanderfolgenden Tagen an das Gerät gewöhnt, indem sie über einen Zeitraum von 10 Minuten die gesamte Apparatur ohne Belohnungspellet frei explorieren konnten. Zeitgleich wurden die Tiere über eine Reduktionsdiät auf 85 \% ihres Körpergewichtes gebracht und dort gehalten. Nach dieser Gewöhnungsphase wurde am dritten Tag mit dem Lernexperiment begonnen, wobei an fünf aufeinander folgenden Tagen jedes Tier einmal getestet wurde. Dazu wurde die Apparatur mit Belohnungspellets bestückt und die Maus in den zentralen Raum gesetzt, wobei die Eingänge der Arme zunächst noch durch transparente „Guillotinen“-Türen verschlossen waren. Nach fünf Sekunden wurden die Türen geöffnet und dem Tier die freie Auswahl der Arme ermöglicht. Während des Tests wurden folgende Parameter notiert: 
1. Gewicht des Tieres

2. Reihenfolge der betretenen Arme

3. Laufzeit

4. Putzzeit

5. Putzhäufigkeit

Als Kriterium für das Betreten eines Armes galt die Überschreitung der Grenze zwischen zentralem Raum und Arm mit allen 4 Pfoten. Das Betreten eines Armes wurde als Laufstrecke von $50 \mathrm{~cm}(2 \times 25 \mathrm{~cm})$ gewertet. Der Test wurde beendet, nachdem alle 8 Arme erfolgreich besucht und alle Futterpellets gefressen wurden, oder nach einer Gesamtdauer von 15 Minuten. Aus den notierten Parametern wurden anschließend folgende Werte abgeleitet:

„Working Memory“-Fehler: Die Anzahl der fehlerhaft doppelt besuchten Arme bis zum Ende des Tests.

„New Entries“:

Die Anzahl neu besuchter Arme innerhalb der ersten 8 Eintritte.

Aktivität: $\quad$ Gesamtlaufstrecke (in $\mathrm{cm}$ ) pro Zeit (in Sekunden) 


\section{Ergebnisse}

\subsection{Die Phänotyp-Analyse der insertionsmutanten TC-Maus}

\subsubsection{Statistische Analyse der postnatalen Gewichtsentwicklung}

Durch Verpaarung des männlichen heterozygoten TC-,,Founder“-Tieres der F0Generation (Nayernia 1993) mit weiblichen Albino-Tieren (NMRI) wurden in der F1-Generation heterozygote und Wildtyp-Nachkommen generiert. Heterozygote Tiere waren aufgrund zelltypspezifisch exprimierter transgener Tyrosinase (Abb. 1.1, B) in den Melanozyten der Augen und der Haut grau pigmentiert und daher von den nichttransgenen Albino-Tieren äußerlich zu unterscheiden. Die Kopplung beider TransgenInsertionen der Konstrukte ACR-CAT-SV40 und TYR-SV40 (Abb. 1.1 A, B) und die gemeinsame Integration an einem chromosomalen Ort wurde durch genomische DotBlot-Analysen an genomischer DNA der F1-Generation gezeigt. Alle pigmentierten Tiere waren in diesen Analysen auch transgen für das Konstrukt ACR-CAT-SV40 (Nayernia 1993). Von transgenen und pigmentierten Tieren der F1-Generation und F2Generation wurden weitere Verpaarungen angesetzt, um homozygote Tiere zu erhalten. Diese waren äußerlich leicht anhand der Fellfarbe von den heterozygoten Tieren zu unterscheiden, da die TYR-SV40-Transgen-Expression in homozygoten Tieren in genotyp-spezifischer Weise zu einer verstärkten Pigmentierung des Felles führt (Abb. $3.1, \mathrm{~A})$.

Im Vergleich zu Wildtyp- und heterozygoten Geschwistern der F2-Generation und zu heterozygoten Tieren der F3-Generation waren die homozygoten TC-Mäuse in der frühen postnatalen Phase signifikant im Wachstum retardiert (Abb. $3.1 \mathrm{~A}, \mathrm{~B}$ ) und zeigten in den ersten 40 Tagen der postnatalen Entwicklung eine Sterblichkeitsrate von $73 \%$ (Abb. 3.1, B), was durch eine quantitative Analyse des Körpergewichtes und der Sterblichkeitsrate über einen Zeitraum von 75 Tagen an zwei Würfen einer F2- $(+/-\widehat{\delta} \mathbf{x}$ $+/-$ ) und vier Würfen einer F3-Generation (-/- $\hat{\sigma} \mathbf{x}+/-$ + $)$ ermittelt werden konnte. Die Messwerte wurden mit dem Programm STATISTICA (Version 5.5) innerhalb der Gruppen gemittelt und die Standardabweichung für Stichproben und die Signifikanz der Messwerte zu diskreten Zeitpunkten über eine einfaktorielle ANOVA-Analyse ermittelt (Abb. 3.1 B). Die Wachstumsretardierung bildete sich postnatal zwischen dem zweiten und dritten Tag aus. Am dritten Tag wurde mit der ANOVA-Analyse bereits eine Signifikanz der Messwerte von $\mathrm{p}=0,02(\mathrm{~F}=6,8)$ berechnet, wohingegen die Messwerte 
am ersten und zweiten Tag keine signifikanten Unterschiede aufweisen. Beginnend am vierten Tag war auch die erste Phase der erhöhten Sterblichkeit zu beobachten (Abb. 3.1 B). Die Sterblichkeitsrate blieb daraufhin bis zum 20. Tag relativ konstant. Nach dem „Absetzen“ der Tiere von der Mutter am postnatalen Tag 22 kam es mit etwas zeitlicher Verzögerung erneut zu einem signifikanten Anstieg der Sterblichkeit, die dann auf null zurückging. Zeitgleich kam es ab dem Tag 30 bei den überlebenden Tieren zu einer Beschleunigung der Gewichtszunahme. Die frühe Sterblichkeit zeigte sich unabhängig von exogenen Faktoren, wie der Wurfgröße, und von endogenen Faktoren, wie dem Zeitpunkt des Öffnens von Augen und Ohren am Tag 12 der postnatalen Entwicklung.
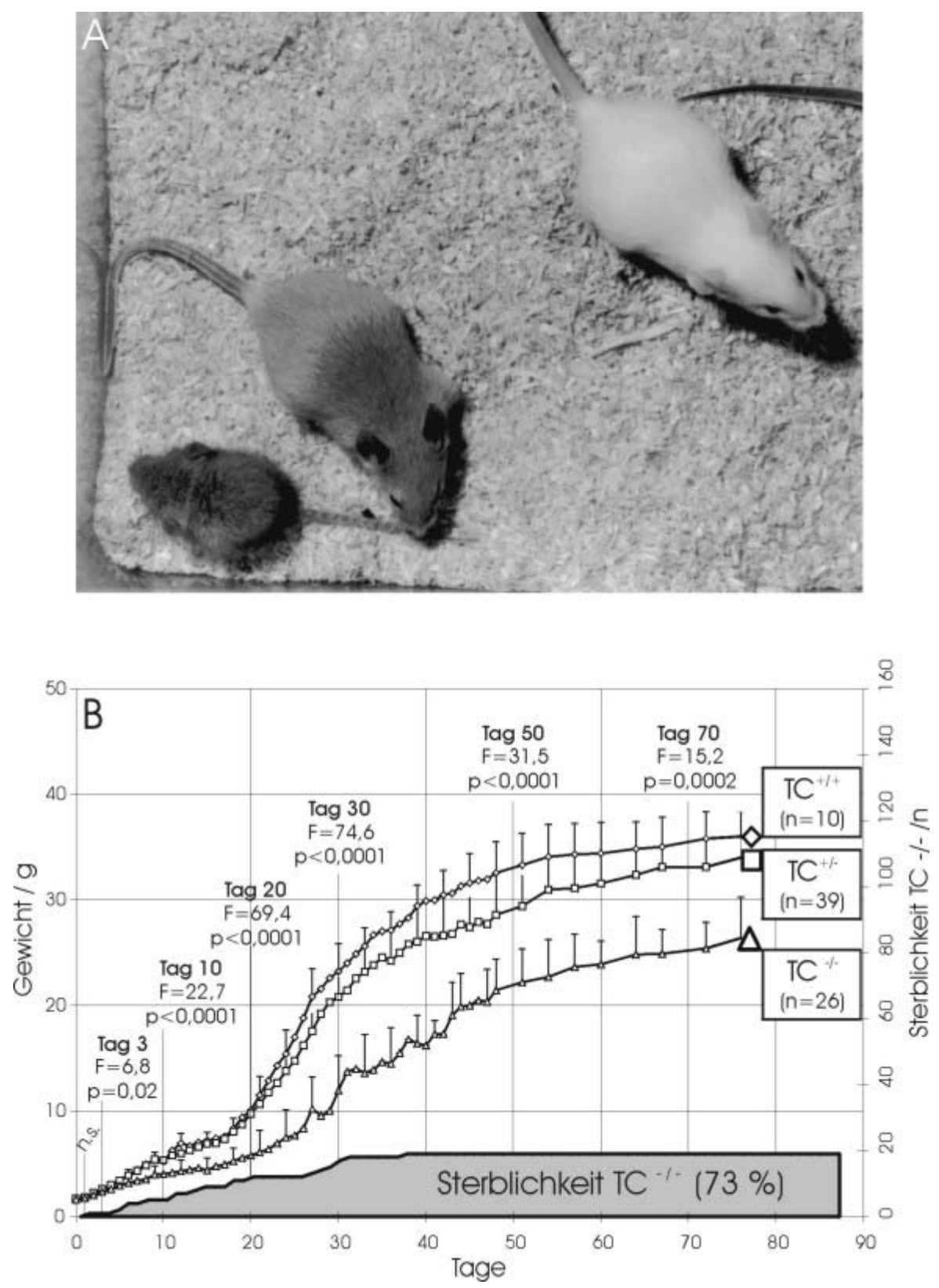

Abb. 3.1 
Abb. 3.1: (S. 74) Postnatale Wachstumsretardierung bei einem 22 Tage alten Tier der F2-Generation aus einer Verpaarung: +/- $\delta \boldsymbol{x}+/-q(\boldsymbol{A})$ und quantitative Analyse der Wachstumsretardierung

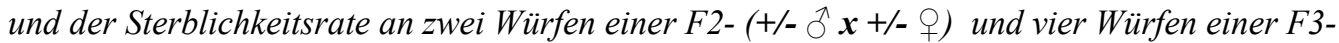
Generation (-/- $\hat{0} \boldsymbol{x}+/-$ +) (B). Das Gewicht der Tiere in (B) wurde jeden Tag zur selben Zeit bestimmt, die Messwerte mit dem Programm STATISTICA (Version 5.5) innerhalb der Gruppen statistisch gemittelt und die Signifikanz der Messwerte zu diskreten Zeitpunkten über eine einfaktorielle ANOVA-Analyse ermittelt. Die Standardabweichung für Stichproben wurde als Fehlerbalken eingezeichnet $(n=75)$.

\subsubsection{Statistische Analyse der Wurfgrößen}

Die Tabelle 3.1 gibt die quantifizierte Verteilung der Nachkommen aus der F2- und F3Generation wieder. Die Zahl der homozygoten Tiere aus 7 Würfen der F2-Generation betrug 22, und zwar bei einer Gesamtzahl von 90 Tieren. Der Anteil der homozygoten Nachkommen in der F3-Generation belief sich bei 12 Würfen und einer Gesamtzahl von 137 Tieren auf 64 Tiere (46,7 \%). Dies entspricht nach den Mendel'schen Vererbungsgesetzen etwa den zu erwartenden $25 \%$ (F2-Generation) bzw. $50 \%$ (F3Generation). Die prozentuale Verteilung der Genotypen in der F2- und in der F3Generation ist in der Tabelle 3.1 wiedergegeben.

\begin{tabular}{|c|c|c|c|c|c|}
\hline Generation & $\begin{array}{l}\text { Anzahl der } \\
\text { Würfe }\end{array}$ & $\begin{array}{c}\text { Gesamtzahl } \\
\text { der Tiere }\end{array}$ & $\begin{array}{c}\text { Wildtyp } \\
(+/+)\end{array}$ & $\begin{array}{c}\text { Heterozygot } \\
(+/-)\end{array}$ & $\begin{array}{c}\text { Homozygot } \\
(-/-)\end{array}$ \\
\hline $\begin{array}{c}\mathbf{F 2} \\
\left(+/-\oslash^{\Uparrow} \mathbf{x}+/-\varnothing\right)\end{array}$ & 7 & 90 & $\begin{array}{c}25 \\
(27,8 \%)\end{array}$ & $\begin{array}{c}43 \\
(47,8 \%)\end{array}$ & $\begin{array}{c}22 \\
(24,4 \%)\end{array}$ \\
\hline $\begin{array}{c}\mathbf{F 3} \\
(-/-\diamond \mathbf{x}+/-\uparrow)\end{array}$ & 12 & 137 & - & $\begin{array}{c}73 \\
(53,3 \%)\end{array}$ & $\begin{array}{c}64 \\
(46,7 \%)\end{array}$ \\
\hline
\end{tabular}

Tabelle 3.1: Quantitative Verteilung von Wildtyp-, heterozygoten und homozygoten TC-Mäusen in der F2-(+/- $\widehat{0} \boldsymbol{x}+/-$ q) und F3- (-/- ô $\boldsymbol{x}+/-$ q) Generation.

\subsubsection{Nachweis von hyperreflektorischem Verhalten nach akustischer Stimulation}

$\mathrm{Ab}$ einem Alter von 6-7 Monaten zeigten sowohl weibliche als auch männliche homozygote TC-Mäuse $\left(\mathrm{TC}^{-/-}\right)$, die die frühe Wachstumsretardierungsphase und postnatale Sterblichkeit überlebten (siehe Abschnitt 3.1.1), eine auffällige und ausgeprägte Neigung zu hyperreflektorischem Verhalten bei plötzlicher akustischer und taktiler Stimulation. Diese Hyperreflexie äußerte sich durch eine übertriebene motorische Reaktion der Extremitäten-Muskulatur und steigerte sich bis zum 
schreckhaften Sprung-Verhalten, wie es in der Abb. 3.2 abgebildet ist. Charakteristisch für diese Reaktion war der in der Abb. 3.2 sichtbare abgeknickte Schwanz während und nach der Schreckreaktion, der meist eine ausgeprägte Bewegungsstarre folgte, die eine erneute Induktion des Sprung-Verhaltens erschwerte. Wildtyp-Tiere und heterozygote TC-Mäuse zeigten in keiner Alterstufe dieses auffällige Verhalten. Das Auftreten dieser Hyperreflexie ab dem 6.-7. Monat der postnatalen Entwicklung geht zeitgleich mit einer zu diesem Zeitpunkt beginnenden Infertilität homozygoter Männchen bei nachweislich intakter Testis-Morphologie und Spermien-Motilität einher, was auf eine Beeinträchtigung des Sexualverhaltens und der sexuellen Orientierung hindeutet.

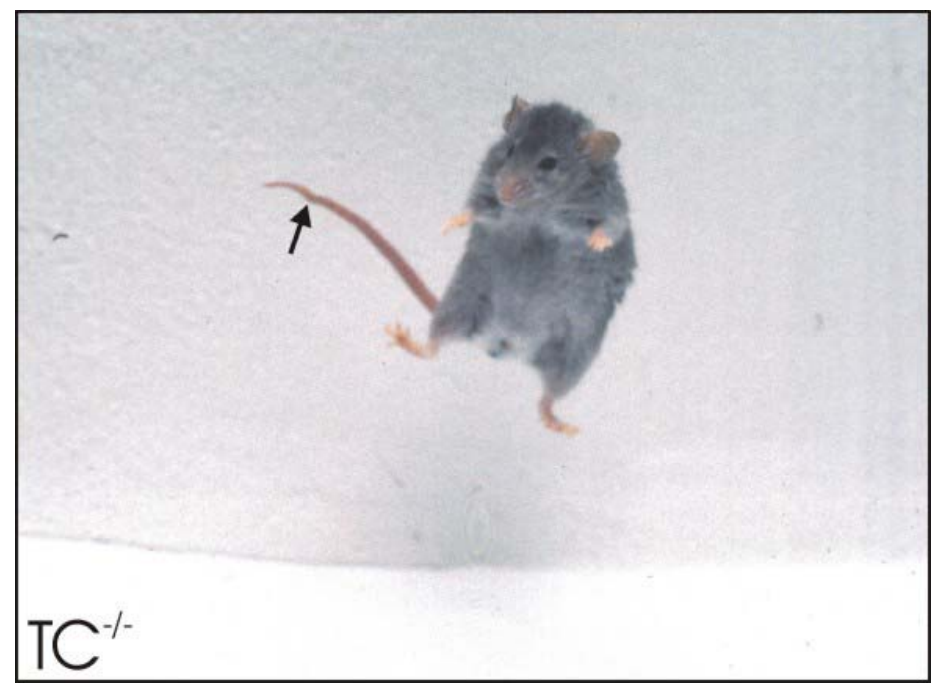

Abb. 3.2: Hyperreflektorisches Verhalten einer 6 Monate alten männlichen homozygoten TC ${ }^{-/}$- Maus nach Exposition eines plötzlichen akustischen Stimulus. Der Pfeil deutet auf den abgeknickten Schwanz hin.

\subsubsection{Bewegungsmuster-Analyse der TC-Mausmutante mit Lasermotilimat und „Open-Field"-Apparatur}

Durch den Lasermotilimat, einer automatisierten Version des „Open-Field“Experiments, wurde eine stark verminderte motorische Aktivität bei adulten homozygoten TC-Mäusen im Vergleich zu Wildtyp-Mäusen (NMRI) gleichen Alters nachgewiesen (Abb. 3.3, A und B). Acht Monate alte männliche und weibliche Mäuse wurden über einen Zeitraum von 5 Minuten in der Apparatur experimentell analysiert und die erfassten Bewegungskoordinaten mit einem XY-Plotter dokumentiert. In der Abb. 3.3 sind die Bewegungsmuster der in Tabelle 3.2 aufgeführten männlichen Mäuse dargestellt. Die Tabelle 3.2 gibt die aus den Parametern berechnete gesamt zurückgelegte Distanz wieder. 


\begin{tabular}{|c|c|}
\hline & Gesamtdistanz / cm \\
\hline $\mathbf{W T}^{+/+} \lesssim$ & 1942 \\
\hline $\mathbf{W T}^{+/+} q$ & 1588 \\
\hline $\mathbf{T C}^{-/-}$ & 91 \\
\hline $\mathbf{T} \mathbf{C}^{-/-} q$ & 121 \\
\hline
\end{tabular}

Tabelle 3.2: Quantifizierung der mittels Lasermotilimat berechneten Gesamtdistanz von acht Monate alten weiblichen (P) und männlichen $(\hat{O})$ Wildtyp- $\left(W T^{+/+}\right)$und homozygoten TC-Mäusen $\left(T C^{+-}\right)$.

In einer „Open-Field“-Apparatur wurden in einer postnatalen Entwicklungsstudie auf manuelle Weise Parameter erfasst, die den im Lasermotilimat gemessenen Daten äquivalent sind (Abb. 3.3 und Abb. 3.4). In der Entwicklungsstudie wurden je vier Tiere jedes Genotyps $\left(\mathrm{WT}^{+/+}, \mathrm{TC}^{+/-}\right.$und $\mathrm{TC}^{-/}$) aus vier Altersgruppen $(4,12,24$ und 36 Wochen) im „Open-Field“ analysiert und über 15 Minuten die Parameter „Anzahl der Linienüberquerungen“ (Lokomotion, Abb. 3.3, C), „Aufrichten an der Seitenwand“ („Leaning“, Abb. 3.4, A) und „Aufrichten im freien Feld“ („Rearing“, Abb. 3.4, B) gezählt, die Werte mit dem Programm STATISTICA (Version: 5.5) gemittelt und die Standardabweichung für Stichproben, die Signifikanz der Messwerte über eine ZweiWeg-ANOVA (Genotyp * Alter) und über einen t-Test für unabhängige Stichproben berechnet. Die grafische Darstellung zeigt einen deutlichen Alterseffekt bei der Ausbildung des hypokinetischen Verhaltens der TC-Maus. Die Abb. 3.3 (C) stellt die zum Lasermotilimat äquivalenten Lokomotionsparameter in der postnatalen Entwicklung grafisch dar und zeigt eine signifikante Reduktion $(\mathrm{p}<0,0001 ; \mathrm{t}=13,3)$ der Motilität bei 36 Wochen ( 9 Monate) alten homozygoten $\mathrm{TC}^{-/-}$-Mäusen im Vergleich zu gleichaltrigen Wildtyp- und heterozygoten TC-Mäusen und im Vergleich zu den jüngeren homozygoten TC-Mäusen.

Die Analyse der Parameter „Leaning“ und „Rearing“ in der Abb. 3.4 zeigt auch für diese in die dritte Dimension gerichteten Parameter einen deutlichen Alterseffekt. Die Anzahl der „Leaning“-Ereignisse ist bereits in vier Wochen $(p=0,09 ; t=2,0)$, 12 Wochen $(\mathrm{p}=0,02 ; \mathrm{t}=2,5)$ und 24 Wochen alten $\mathrm{TC}^{-/-}$-Tieren $(\mathrm{p}=0,03 ; \mathrm{t}=2,3)$ gegenüber den Wildtyp-Tieren und noch mehr gegenüber den heterozygoten Tieren vermindert. In 36 Wochen alten $\mathrm{TC}^{-/-}$-Tieren detektierte dieses Experiment erneut eine signifikante Reduktion der „Leaning“-Aktivität $(\mathrm{p}<0,0001 ; \mathrm{t}=11,6)$ gegenüber den gleichaltrigen Vergleichstieren und gegenüber den jüngeren Tieren gleichen Genotyps (Abb. 3.4, A). Die „Rearing“-Ereignisse sind in der homozygoten Situation ( $\mathrm{TC}^{-/}$) 
bereits deutlich in 12 Wochen alten Mäusen signifikant gegenüber den entsprechenden Wildtyp- $(\mathrm{p}<0,0001 ; \mathrm{t}=7,4)$ und heterozygoten Tieren $(\mathrm{p}<0,0001 ; \mathrm{t}=6,4)$ und gegenüber den vier Wochen alten Tieren gleichen Genotyps reduziert $(p=0,06 ; t=2,0)$.

Diese Reduktion der „Rearing“-Ereignisse bleibt in 24 Wochen $(\mathrm{p}=0,008 ; \mathrm{t}=4,2)$ und 36 Wochen $(\mathrm{p}=0,003 ; \mathrm{t}=5,1)$ alten $\mathrm{TC}^{-/-}$-Tieren erhalten (Abb. 3.4, B).
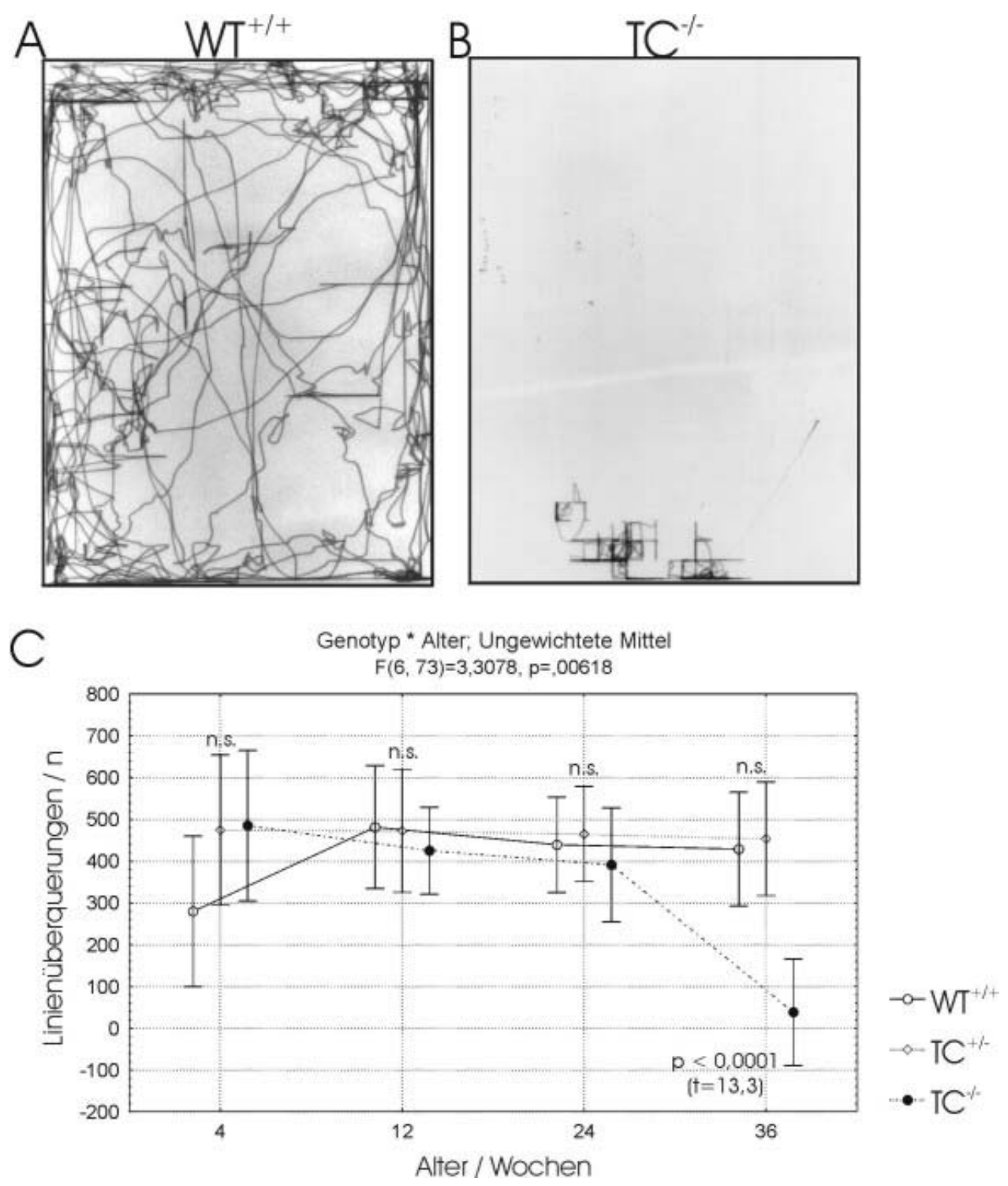

Abb. 3.3: Grafische Darstellung der mit dem Lasermotilimat (A, B) und der „Open-Field“-Apparatur (C) erfassten Bewegungskoordinaten. In (A) ist das Bewegungsmuster einer acht Monate alten Wildtyp-Maus (WT ${ }^{++}$) über fünf Minuten im Vergleich zum äquivalenten Bewegungsmuster einer homozygoten $T^{\text {/- }}$-Maus gleichen Alters (B) dargestellt. In (C) sind die zum Lasermotilimat äquivalenten Lokomotionsparameter über 15 Minuten in der postnatalen Entwicklung der verschiedenen Versuchsgruppen $(n=4)$ grafisch dargestellt. Die Mittelwerte, die Standardabweichung für Stichproben und die Signifikanz der Messwerte sind mit dem Programm STATISTICA (Version: 5.5) über eine Zwei-Weg-ANOVA (Genotyp * Alter) und über einen t-Test für unabhängige Stichproben berechnet (n.s. $=$ nicht signifikant, $W T^{+^{+}}=$ Wildtyp, $T C^{+/}=$TC heterozygot, $T C^{+-}=T C$ homozygot). 

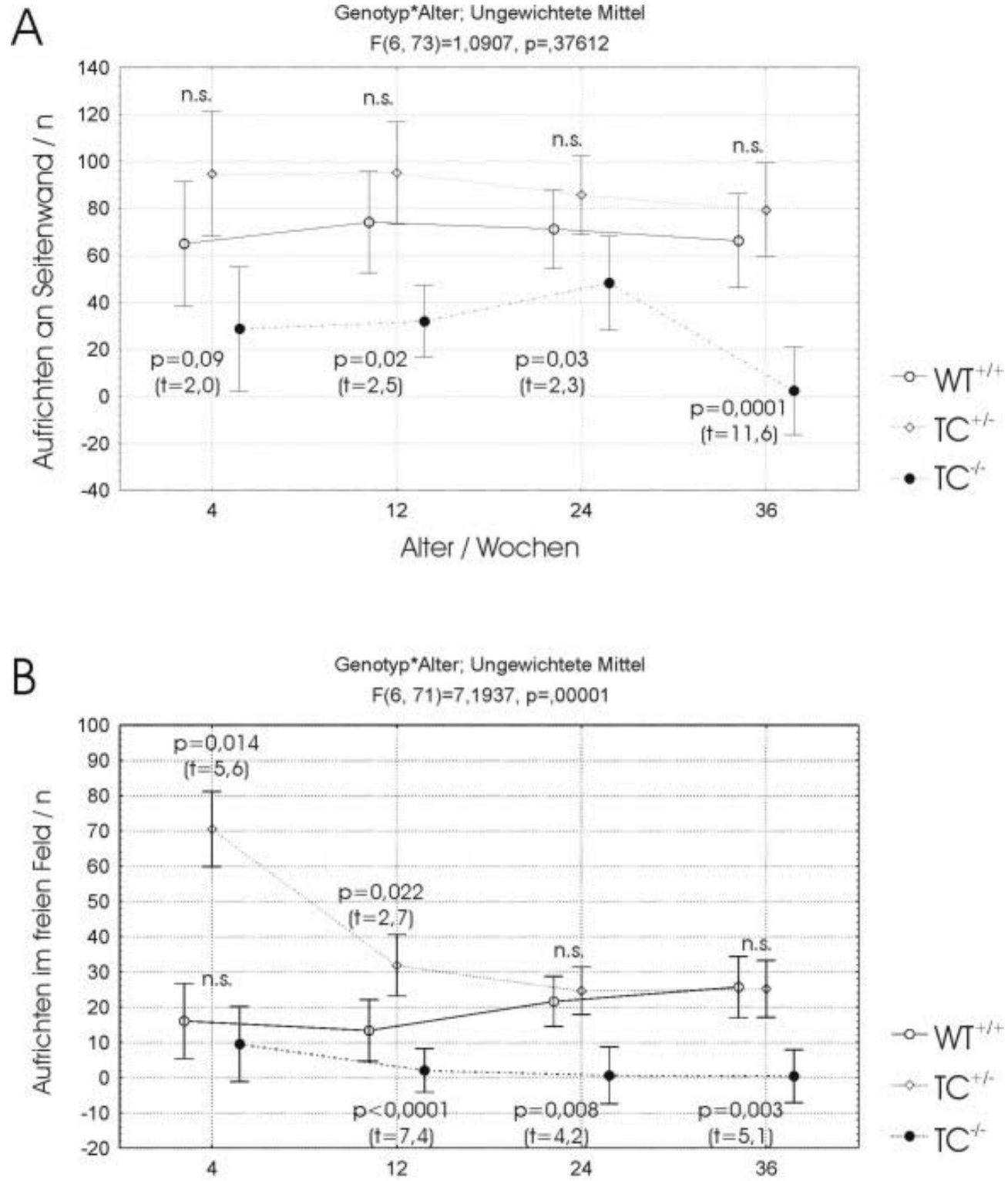

Abb. 3.4: Grafische Darstellung der mit der „Open-Field“-Apparatur erfassten Bewegungskoordinaten über 15 Minuten bezüglich der Parameter „Aufrichten an der Seitenwand = Leaning “ (A) und „Aufrichten im freien Feld = Rearing“ (B) in der postnatalen Entwicklung der verschiedenen Versuchsgruppen $(n=4)$. Die Mittelwerte, die Standardabweichung für Stichproben und die Signifikanz der Messwerte sind mit dem Programm STATISTICA (Version: 5.5) über eine Zwei-Weg-ANOVA (Genotyp * Alter) und über einen t-Test für unabhängige Stichproben berechnet. (n.s. $=$ nicht signifikant, $W T^{++}=$Wildtyp, $T C^{+/}=T C$ heterozygot, $T C^{+/}=T C$ homozygot). 


\subsubsection{Analyse des Brutpflegeverhaltens der weiblichen homozygoten TC-Maus}

In Verpaarungen der F3-Generation zeigte sich unabhängig vom Genotyp des Männchens $\left(\mathrm{WT}^{+/+}, \mathrm{TC}^{-/-}\right.$oder $\mathrm{TC}^{-/-}$) bei homozygoten $\mathrm{TC}^{-/-}$-Weibchen ein abnormes Brutpflegeverhalten, das ein Absterben des gesamten Wurfes zur Folge hatte (Abb. 3.5, A). Heterozygote $\mathrm{TC}^{+/-}$-Weibchen (Abb. 3.5, B) und Wildtyp-Weibchen zeigten ein normales Brutpflegeverhalten, das Nestbau, das Zurückbringen von Nachwuchs („Retrieving“) sowie Wärmen und Säugen der Nachkommen umfasst. Das abnorme Brutpflegeverhalten ist unabhängig vom Alter der homozygoten $\mathrm{TC}^{-/-}$-Weibchen und ist bereits bei acht Wochen alten Tieren zu beobachten. Aufgrund des abnormen Brutpflegeverhaltens weiblicher $\mathrm{TC}^{-/-}$-Tiere und der späteren Infertilität männlicher $\mathrm{TC}^{-/-}$-Tiere (>6 Monate) (siehe Abschnitt 3.1.3) wurde die Zucht mit $\mathrm{TC}^{+/-}$-Weibchen und mit jungen $\mathrm{TC}^{-/-}$-Männchen $(<6$ Monate) etabliert.
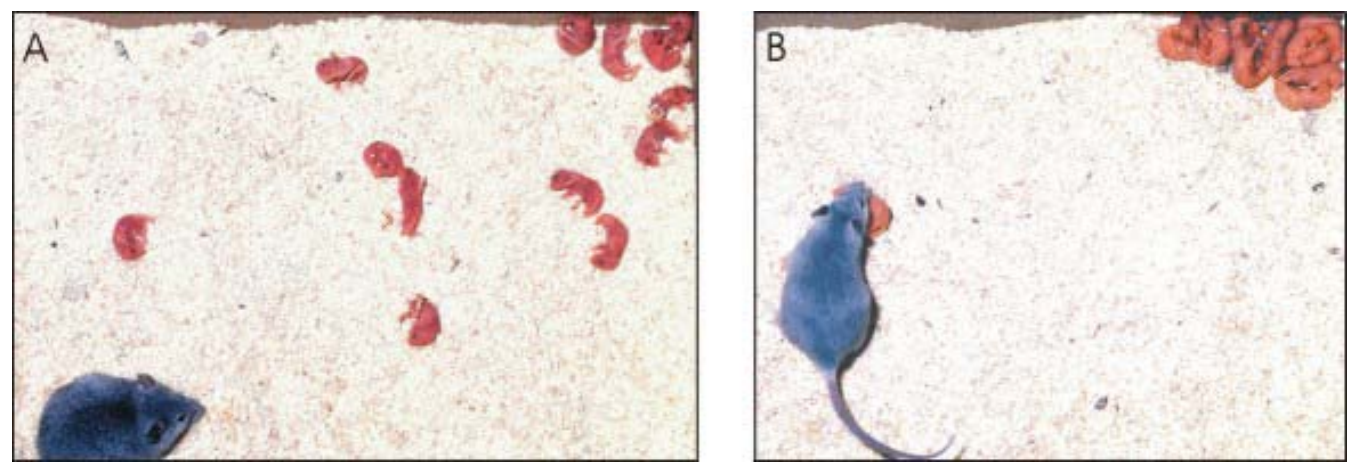

Abb. 3.5: Darstellung des abnormen Brutpflegeverhaltens eines homozygoten drei Monate alten $\mathrm{TC}^{-/-}$Weibchens mit komplett verstorbenem Wurf (A). In (B) ist das Brutpflegeverhalten (, Retrieving“) eines heterozygoten $T^{+/-}-$Weibchens gezeigt.

\subsubsection{Untersuchungen zum räumlichen Lernen über die Analyse im Radial- Labyrinth (,Radial Maze ${ }^{6)}$}

Je sechs Wildtyp- $\left(\mathrm{WT}^{+/+}\right)$, heterozygote $\left(\mathrm{TC}^{+/-}\right)$und acht homozygote $\left(\mathrm{TC}^{-/-}\right)$männliche TC-Mäuse im Alter von drei Monaten wurden in einem Radial-Labyrinth (,RadialMaze“) wie in Abschnitt 2.26.2 beschrieben an fünf aufeinanderfolgenden Tagen mit einer Lernaufgabe konfrontiert, die das sogenannte Arbeitsgedächtnis („Working Memory") der Mäuse bezüglich ihres räumlichen Lernvermögens testet. Die Reihenfolge der betretenen Arme sowie die Laufzeit wurden notiert und daraus die Aktivität, die Neueintritte („New Entries“) und die Fehlerzahl des Arbeitsgedächtnisses innerhalb der Messgruppe und über die Versuchstage drei bis fünf gemittelt (siehe Abschnitt 2.26.2). Die gemittelten Werte sind zusammen mit der Standardabweichung 
für Stichproben als Fehlerbalken in der Abb. 3.6 grafisch dargestellt und wurden einer Kruskal-Wallis- Rangvarianzanalyse unterzogen.

A

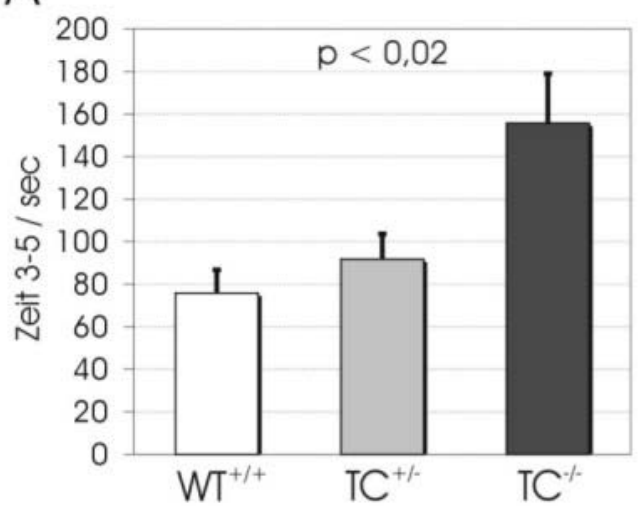

C

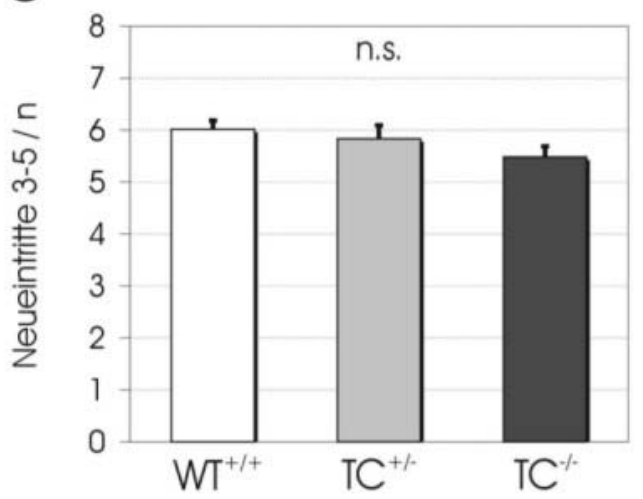

$E$

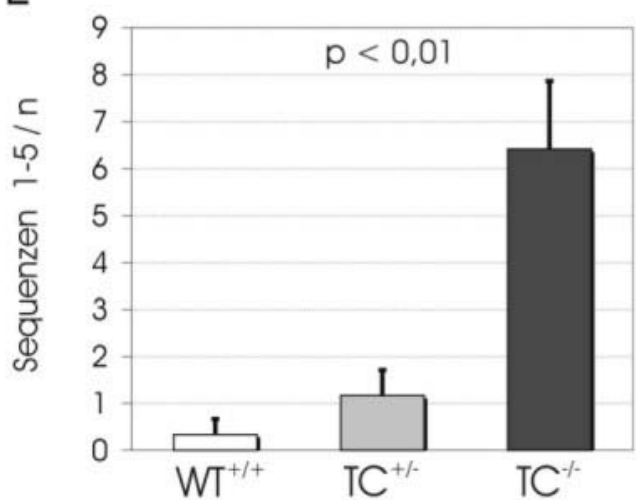

B

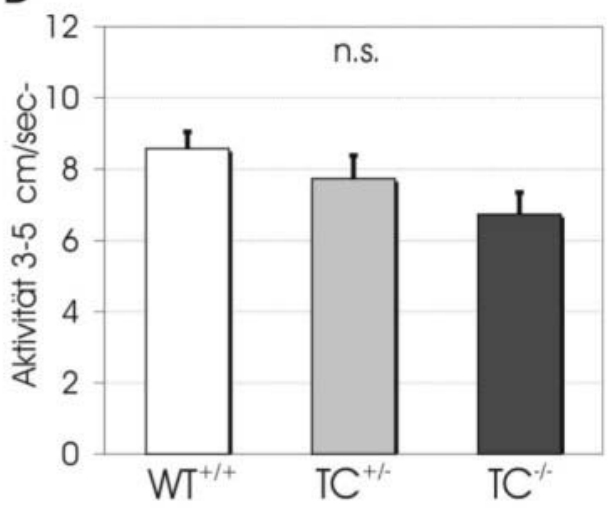

$\mathrm{D}$

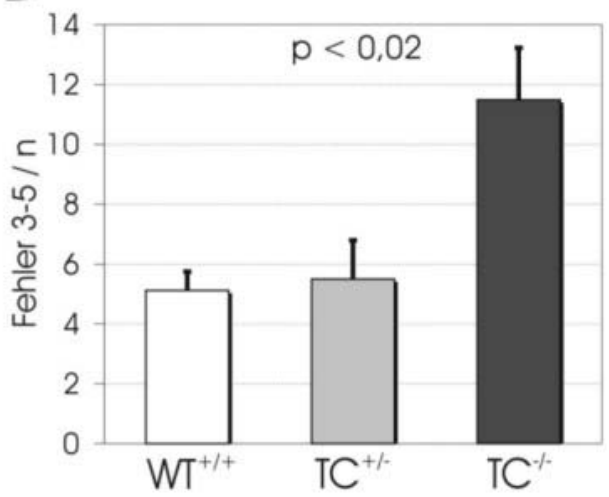

Abb. 3.6: Grafische Darstellung der mit der „Radial-Maze“-Apparatur erfassten, abgeleiteten und innerhalb der Messgruppen und über die Versuchstage 3-5 gemittelten Parameter: Zeit 3-5 (A), Aktivität 3-5 (B), Neueintritte 3-5 (C), ,Working-Memory"-Fehler 3-5 (D) und die innerhalb der Messgruppen gemittelte und über die Versuchstage 1-5 addierte Anzahl der Sequenzen $(E)\left(W T^{++}=\right.$Wildtyp, $T C^{+/}=T C$ heterozygot, $T C^{-/}=T C$ homozygot, n.s. $=$ nicht signifikant). 
Die Rangvarianzanalyse ergab, dass die in der Gruppe der homozygoten Tiere benötigte Zeit zur Bewältigung der Aufgabe signifikant erhöht ist (Abb. 3.6, A, p<0,02), die Aktivität, d.h. die zurückgelegte Strecke pro Zeit, aber nicht signifikant verringert ist (Abb. 3.6, B). Die Anzahl der Neueintritte („New Entries“, siehe Abschnitt 2.26.2), die die Anzahl der betretenen Arme bis zum Auftreten des ersten Fehlers angibt, ist zwischen den untersuchten Gruppen ebenfalls nicht signifikant verändert (Abb. 3.6, C), obwohl die mittlere Fehlerzahl (Fehler 3-5) bis zum Ende des Tests (Abb. 3.6, D) mit $\mathrm{p}<0,02$ in der homozygoten Gruppe $\left(\mathrm{TC}^{-/}\right)$signifikant erhöht ist. Die Analyse der Reihenfolge, in der die Arme betreten wurden, ergab eine signifikant hohe Anzahl an Fehlern in der $\mathrm{TC}^{-/-}$-Testgruppe, die in Wiederholungssequenzen angeordnet waren. Dieses waren zum Teil zweifach, dreifach aber auch vierfach Wiederholungssequenzen. Eine Zweifach-Wiederholungssequenz wurde mit dem Grundwert 1, eine DreifachWiederholung mit dem Grundwert 2 und eine Vierfach-Wiederholung mit dem Grundwert 3 gewichtet, mit der entsprechenden Anzahl an Wiederholungen multipliziert, aufsummiert und innerhalb der Testgruppen gemittelt in der Abb. 3.6 (E) gegenübergestellt. Die Signifikanz der dargestellten Erhöhung der Anzahl Wiederholungs-Sequenzen wurde über Kruskal-Wallis-Analyse auf $\mathrm{p}<0,01$ berechnet.

\subsubsection{Morphologische Untersuchungen der hippocampalen Moosfaser- Entwicklung in der TC-Mauslinie}

Aufgrund der beobachteten Verhaltensauffälligkeiten (Abschnitte 3.1.3 bis 3.1.5) und der detektierten Lerndefizite (3.1.6) der TC-Mausmutanten, die auf Veränderungen in der Hippocampus-Morphologie hindeuten (Qiao und Noebels 1993; Schwegler und Crusio 1995; Holmes et al. 1999), wurden neuroanatomische Studien an horizontalen Gehirnschnitten durch den Hippocampus durchgeführt. Dazu wurde die TimmFärbetechnik gewählt, da sie spezifisch die in der CA3-Region des Hippocampus prominenten Moosfasern anfärbt und glutamaterge exzitatorische synaptische Kontakte detektiert. Diese Untersuchungen zeigen bei 12 Monate alten $\mathrm{TC}^{-/}$- Mäusen eine massive Vergrößerung der suprapyramidalen Moosfaserprojektion (SP-MF) in der CA3- Region des Hippocampus (Suprapyramidale Moosfaser-Hyperplasie, Abb. 3.7, C) und ein starkes Auswachsen (,Sprouting“) von supragranulären Moosfasern (SG-MF) auf die Dendritenbäume der Granularzellen (Abb. 3.7, C, D), wie man sie auch in induzierten und genetisch bedingten Tiermodellen für Epilepsie findet. Diese morphologischen Veränderungen sind in 12 Monate alten $\mathrm{WT}^{+/+}$- und $\mathrm{TC}^{+/-}$-Mäusen nicht nachweisbar (Abb. 3.7, A, B). Die suprapyramidale Moosfaser-Hyperplasie ist auf den apikal dendritischen Bereich der Pyramidenzellen in der Region des Stratum lucidum (Str. 1.) beschränkt, dehnt sich in die Region des Stratum radiatum (Str. r.) aus 
und wird dort durch eine diskrete Grenzschicht markiert. In der basal zum Stratum pyramidale (Str. p., Pyramidenzellschicht) gelegenen Region des Stratum oriens (Str. o.) zeigt sich kein aberrantes Moosfaserwachstum. Die in dieser Region liegenden intraund infrapyramidalen Moosfasern (IIP-MF) finden sich in allen drei Genotypen in konstanter Ausprägung (Abb. 3.7, A, B, C). Die Grenze zwischen dem CA3- und CA1Sektor, die durch das Ende der Timm-positiven Zone markiert ist, wird ebenfalls nicht durch aberrantes Moosfaserwachstum ,überschritten“. Die Ausschnittvergrößerung des Hilus der 12 Monate alten $\mathrm{TC}^{-/-}$-Maus in (D) zeigt eine Schichtung der supragranulärer Moosfaser-Terminationszonen innerhalb der Molekularschicht des Gyrus Dentatus, die aufgrund ihres differentiellen Gehaltes an Zink unterschiedlich intensiv angefärbt sind.
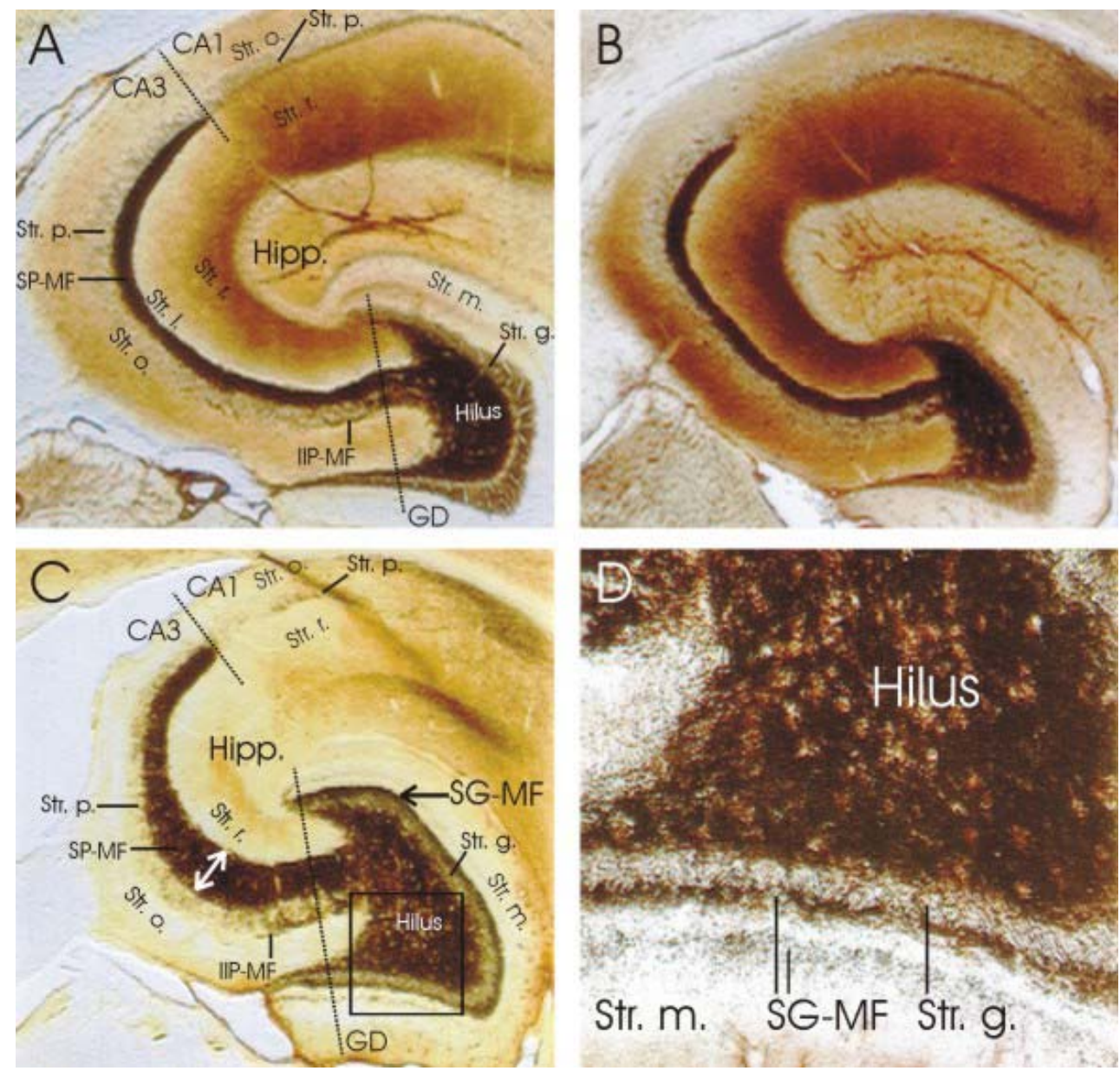

Abb. 3.7: Timm-Silbersulfid gefärbte Hippocampusschnitte einer 12 Monate alten $W T^{+/+}$- (A, Wildtyp), $T^{+/-}$- (B) und einer $T C^{+-}$-Maus $(C, D)$. Die suprapyramidale Moosfaser-Hyperplasie ist durch einen weißen Doppelpfeil $(\leftarrow \rightarrow)$ und die supragranuläre Moosfaserprojektion durch einen einfachen Pfeil $(\rightarrow)$ markiert. CA1/CA3 = Regionen des Cornu Ammonis, GD = Gyrus dentatus, Hipp. = Hippocampus, IIP-MF = Intra- und Infrapyramidale Moosfasern, SG-MF= Supragranuläre Moosfasern, SP-MF = Suprapyramidale Moosfasern, Str.o .= Stratum oriens, Str.r. = Stratum radiatum, Str.p. = Stratum pyramidale, Str.m. = Stratum moleculare, Str.g. $=$ Stratum granulosum, Str. l. = Stratum lucidum (Vergrößerung A-C: 40 x, D: 200 x). 

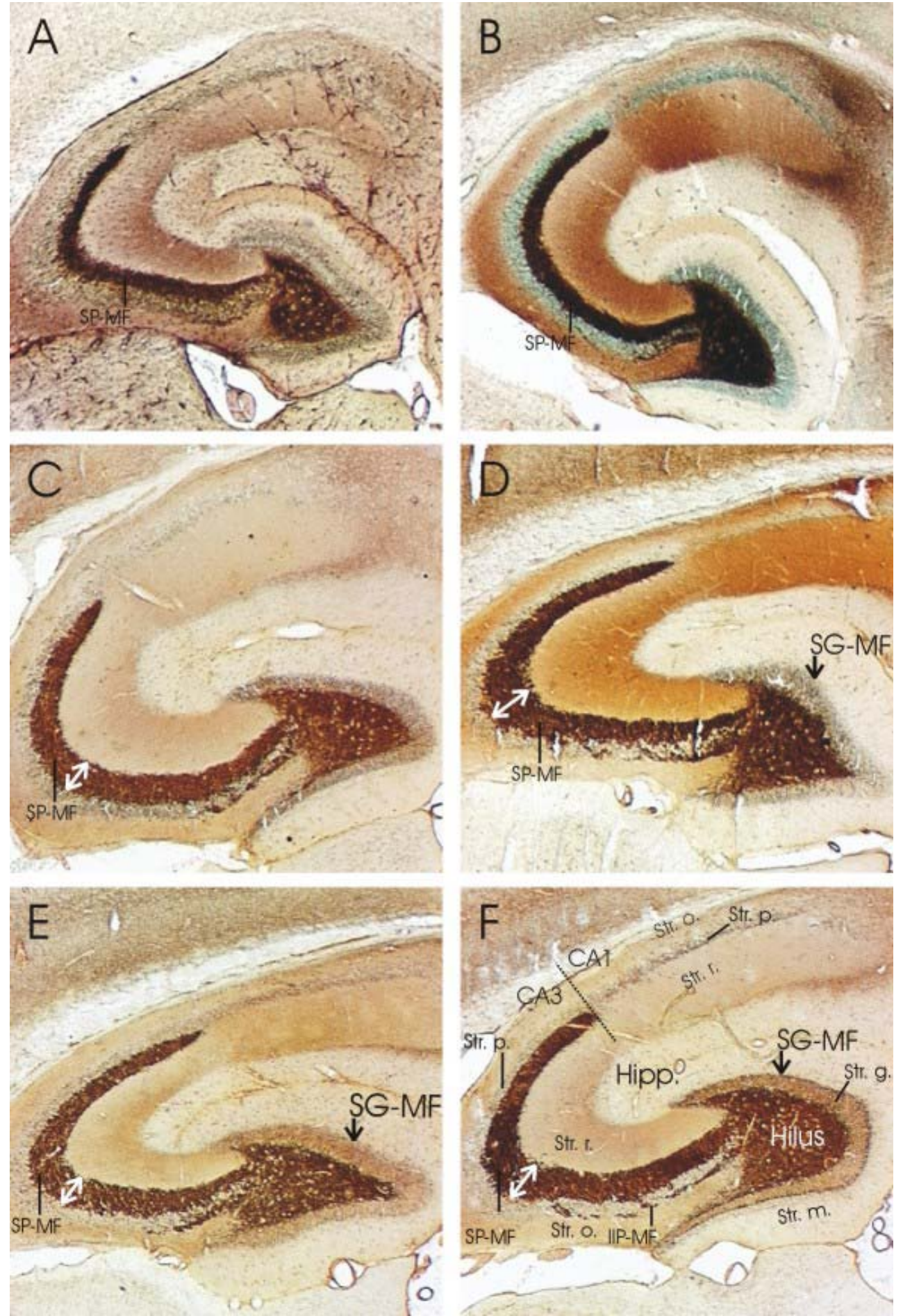

Abb. 3.8: Timm-Silbersulfid gefärbte Hippocampusschnitte von TC ${ }^{+-}$-Mäusen unterschiedlicher Altersstufen: (A) 2 Wochen, (B) 4 Wochen, (C) 3 Monate, (D) 4 Monate, (E) 5 Monate und (F) 7 Monate. Die suprapyramidale Moosfaser-Hyperplasie ist durch einen weißen Doppelpfeil $(\leftrightarrow \rightarrow)$ und die supragranuläre Moosfaserprojektion durch einen einfachen Pfeil $(\rightarrow)$ markiert. CA1/CA3 = Regionen des Cornu Ammonis, Hipp. = Hippocampus, IIP-MF = Intra- und Infrapyramidale Moosfasern, $S G-M F=$ Supragranuläre Moosfasern, $S P-M F=$ Suprapyramidale Moosfasern, Str.o .= Stratum oriens, Str.r. = Stratum radiatum,, Str.p. = Stratum pyramidale, Str.m. = Stratum moleculare, Str.g. = Stratum granulosum (Vergrößerung A-F: $40 x$ ). 
In einer postnatalen Entwicklungsstudie an Timm-gefärbten Hippocampusschnitten mutanter $\mathrm{TC}^{-/-}$-Mäuse wurde die Frage analysiert, $\mathrm{zu}$ welchem Zeitpunkt der postnatalen Entwicklung sich die in der $\mathrm{TC}^{-/-}$-Mutante beschriebenen Veränderungen der Hippocampus-Morphologie ausbilden. Dazu wurden aus jeder Altersgruppe (2 Wochen, 4 Wochen, 3 Monate, 4 Monate, 5 Monate und 7 Monate) jeweils sechs Tiere mit der Timm-Färbetechnik analysiert. Die Abb. 3.8 zeigt jeweils einen der Timm-gefärbten Hippocampusschnitte der jeweiligen Altersstufe und die Abb. 3.9 stellt die Ergebnisse dieser Analyse bezüglich der untersuchten Fragestellung grafisch dar.
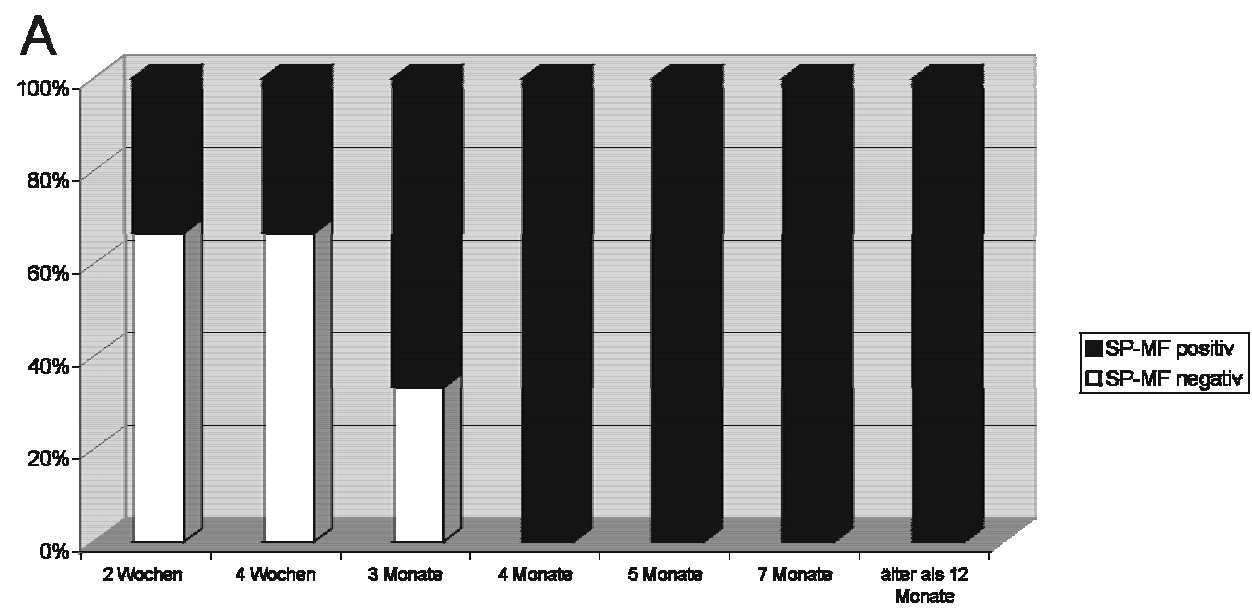

口SP-MF negativ

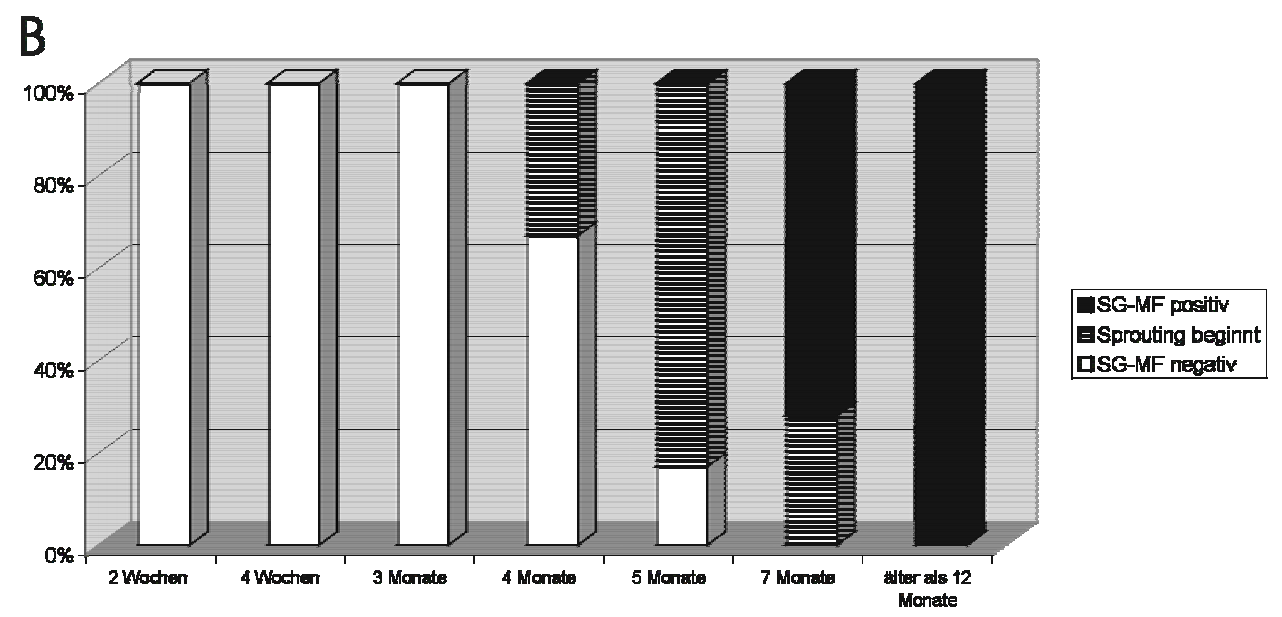

Abb.3.9: Ergebnisse der auf Timm-Silbersulfid Färbung basierten Entwicklungsstudien der hippocampalen Moosfaserprojektionen von $T C^{\text {- }}$-Mäusen unterschiedlicher Altersstufen $(n=6)$. In (A) ist die postnatale Entwicklung der suprapyramidalen Moosfaser-Hyperplasie und in (B) die postnatale Entwicklung der aberranten supragranulären Moosfaserprojektion in der $T C^{+-}$-Maus schematisch dargestellt. SG-MF = Supragranuläre Moosfasern, SP-MF = Suprapyramidale Moosfasern. 
Die Ausbildung der aberranten supragranulären Moosfaserprojektion in der $\mathrm{TC}^{-/}$Situation beginnt ab einem postnatalen Alter von 4 Monaten (Abb. 3.8, D, E, F und Abb. 3.9, B). In diesem Alter zeigen bereits zwei von sechs Tieren (33\%) eine beginnende Timm-Färbung in dem Bereich der Körnerzellschicht. In der Gruppe der fünf Monate alten Tiere sind bereits $83 \%$ und in der Gruppe der 7 Monate alten Tiere $100 \%$ der Tiere in der Timm-Färbung positiv bezüglich der aberranten supragranulären Moosfaserprojektion, deren Intensität mit zunehmendem Alter zunimmt (Abb. 3.8, F und Abb. 3.7, C). Die Ausbildung zwischen dem fünften und siebten postnatalen Monat korreliert zeitlich mit der Ausbildung des hyperreflektorischen und hypokinetischen Phänotyps (Abschnitt 3.1.3 und 3.1.4). Eine suprapyramidale Moosfaser-Hyperplasie ist bereits in $33 \%$ der zwei und vier Wochen alten, in $67 \%$ der drei Monate alten und in $100 \%$ aller älteren $\mathrm{TC}^{-/-}$-Tiere zu beobachten (Abb. 3.8 und Abb. 3.9, A).

\subsubsection{Immunhistochemische Expressions-Analyse des Calretinin-Proteins im Hippocampus der TC $^{-/-}$- und Wildtyp-Maus}

Sowohl in genetisch bedingten (Qiao und Noebels 1993) als auch in experimentell induzierten Tiermodellen mit Epilepsie und aberrantem supragranulärem Moosfaserwachstum (Holmes et al. 1999), als auch bei der Temporallappen-Epilepsie des Menschen (Sutula et al. 1989; Houser et al. 1990) wird der Verlust von Calretininpositiven Mooszellen im Hilus des Gyrus dentatus als ursächlich diskutiert (Silva und Mello 2000). Aus diesem Grund wurde in einer immunhistochemischen Studie an einer acht Monate alten $\mathrm{TC}^{-/-}$-Maus mit einem polyklonalen Antikörper gegen das CalretininProtein der Maus die Expression dieses Calcium-Bindungsproteins untersucht. In der Wildtyp-Situation ( $\mathrm{WT}^{+/+}, 8$ Monate) ist mit diesem Antikörper eine flächige und eine punktuell starke Immunfärbung im Hilus und in der inneren Molekularschicht (i.m.L) des Stratum moleculare im Gyrus dentatus zu detektieren (Abb. 3.10. A) Die Immunfärbung im Hilus detektiert Mooszellen, die in Clustern zusammengelagert sind, sowie deren Dendriten, und die Immunfärbung in der inneren Molekularschicht (i.m.L.) des Stratum moleculare detektiert Calretinin-positive asymmetrische Synapsen der Mooszellen-Axone auf den Dendriten der Granularzellen. Daneben existiert eine Subpopulation von GABAergen Interneuronen in geringer Anzahl über den gesamten Hippocampus verteilt, dessen symmetrische Synapsen ebenfalls Calretinin-positiv sind, und in der Immunfärbung der Abb. 3.10 (A) nicht detektiert werden. Daher ist die Calretinin-positive Immunfärbung in der Abb. 3.10 (A) auf die Regionen des Hilus und des Stratum granulosum begrenzt. 

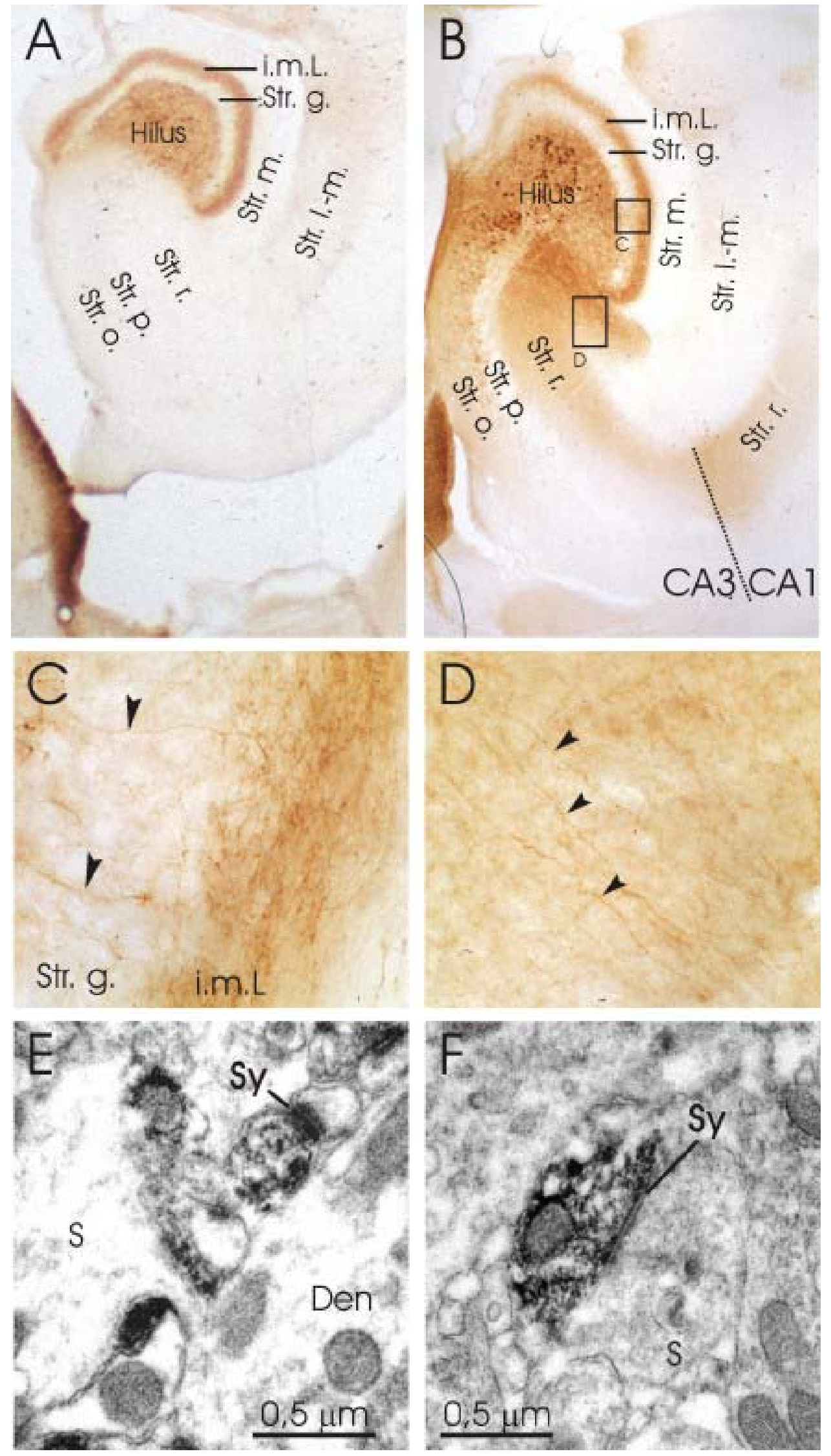

Abb. 3.10 
Abb. 3.10:(Seite. 87) Immunhistologische Expressionsanalyse mit einem polyklonalen Antikörper gegen das Calretinin-Protein der Maus an 40 um dicken Gefrierschnitten des Gehirns einer acht Monate alten Wildtyp- $\left(W T^{+/+} A\right)$ und einer $T C^{+-}-\operatorname{Maus}(B, C, D)$. In $(E)$ und $(F)$ sind elektronenmikroskopische Aufnahmen einer asymmetrischen Calretinin-positiven Synapse eines Mooszell-Axons (E) und einer symmetrischen Calretinin-positiven Synapse eines GABAergen Interneurons $(F)$ in der CA3-Region einer $T C^{+-}$-Maus dargestellt. (\$) = Axone, CA1/CA3 = Regionen des Cornu Ammonis, Den. = Dendrit, i.m.L. = innere Molekularschicht, $S=$ Dendritischer Fortsatz (,,Spine“), Str.o .= Stratum oriens, Str.r. = Stratum radiatum,, Str.p. = Stratum pyramidale, Str.g. = Stratum granulosum, Str.-l.-m. = Stratum lacunosummoleculare, Str. $m$. = Stratum moleculare, Sy $=$ Synapse.

In der $\mathrm{TC}^{-/-}$-Situation konnte primär kein Verlust der Mooszellen detektiert werden. Diese sind als Zell-Cluster in großer Zahl im Hilus des Gyrus dentatus und im Stratum oriens der Region CA3 vorhanden (Abb. 3.10 B). Die Expression von Calretinin ist allerdings durch aberrantes axonales Wachstum in den Regionen CA3 (D) und CA1 (B) und im Stratum granulosum (C) und durch immunpositive Mooszell-Cluster in der Region CA3 (B) ausgedehnt, wobei das Stratum pyramidale immunnegativ bleibt. Die aberranten Axone bilden in der Region CA3 asymmetrische (Abb. $3.10 \mathrm{E}$ ) und symmetrische (Abb. 3.10 F) Calretinin-positive Synapsen, so dass sowohl glutamaterge Mooszell-Axone (asymmetrische Synapsen) als auch Axone von GABAergen Interneuronen (symmetrische Synapsen) in der CA3- Region aberrant auswachsen. Die Untersuchungen zur Calretinin-Immunhistochemie und zur Immun-Elektronenmikroskopie wurden in Kooperation mit Herrn Prof. Schwegler am Institut für Anatomie der Universität in Magdeburg durchgeführt. 


\subsubsection{NMDA-Rezeptorautoradiografie}

Der NMDA-Rezeptor ist ein im Hippocampus besonders stark exprimierter ionotroper und exzitatorischer Glutamat-Rezeptor, der als glutamat-aktivierter Calcium-Kanal vor allem für die Langzeitpotenzierung im Hippocampus verantwortlich ist und daher in Lernvorgänge involviert ist. Mit Hilfe von rezeptorautoradiografischen Untersuchungen mit ${ }^{125}$ I -markiertem NMDA-Rezeptor-Antagonisten (MK 801) an Hirnschnitten von $\mathrm{WT}^{+/+}$-, $\mathrm{TC}^{+/-}$- und $\mathrm{TC}^{-/-}$-Mäusen wurde das Expressionsmuster des funktionalen, aus diversen Untereinheiten bestehenden und an der Zelloberfläche exponierten Rezeptors untersucht. Die Rezeptordichte wurde über die durch ${ }^{125}$ I induzierte Schwärzung auf dem Autoradiografiefilm in der entsprechenden Region densitometrisch quantifiziert und unterschiedliche Bindungsstärken in „Falschfarben-Abbildungen“ dargestellt. In diesen Abbildungen nimmt die Bindungsintensität und damit die NMDARezeptordichte mit der Farbabstufung von rot, über gelb und grün nach blau ab (Abb. 3.11 A, C, E, Abb. 3.12 A, C, E, G). Mit Hilfe einer Computeranalyse wurde die NMDA-Rezeptorverteilung entlang einer Messgeraden beginnend im Stratum oriens, über das Stratum pyramidale bis ins Stratum radiatum quantifiziert und in der Abb. 3.11 (B, D, F) und Abb. 3.12 (B, D, F, H) dargestellt. In einer weiteren Computeranalyse wurde die MK 801-Bindungsstärke im Stratum oriens der CA1-Region des Hippocampus flächig ausgewählt und in fmol/mg quantifiziert (Abb. 3.13).

Mit Hilfe dieser Untersuchungen an Hirnschnitten von jeweils sechs 12 Monate alten $\mathrm{WT}^{+/+}$-, $\mathrm{TC}^{+/-}$- und $\mathrm{TC}^{-/-}$-Mäusen konnte gezeigt werden, dass in der $\mathrm{TC}^{-/-}$-Situation eine $35 \%$ Reduktion der NMDA-Rezeptordichte im Stratum oriens der CA1-Region vorliegt (Abb. 3.11, E, F und Abb. 3.13, A, B). Die NMDA-Rezeptordichte auf der apikal dendritischen Seite der Pyramidenzellen in der CA1-Region (Stratum radiatum) ist in der $\mathrm{TC}^{-/-}$-Situation gegenüber den äquivalenten Kontrolltieren (Abb. 3.11, A-B: $\mathrm{WT}^{+/+}, \mathrm{C}-\mathrm{D}: \mathrm{TC}^{+/}$) unverändert. Die NMDA-Rezeptordichte im Stratum radiatum und Stratum oriens der CA3-Region und im Stratum moleculare des Gyrus dentatus ist im Hippocampus der $\mathrm{TC}^{-/-}$-Mäuse gegenüber den entsprechenden Kontrolltieren ebenfalls unverändert. Die NMDA-Rezeptordichte im Stratum pyramidale und im Hilus des Gyrus dentatus ist in allen drei Genotypen minimal. 

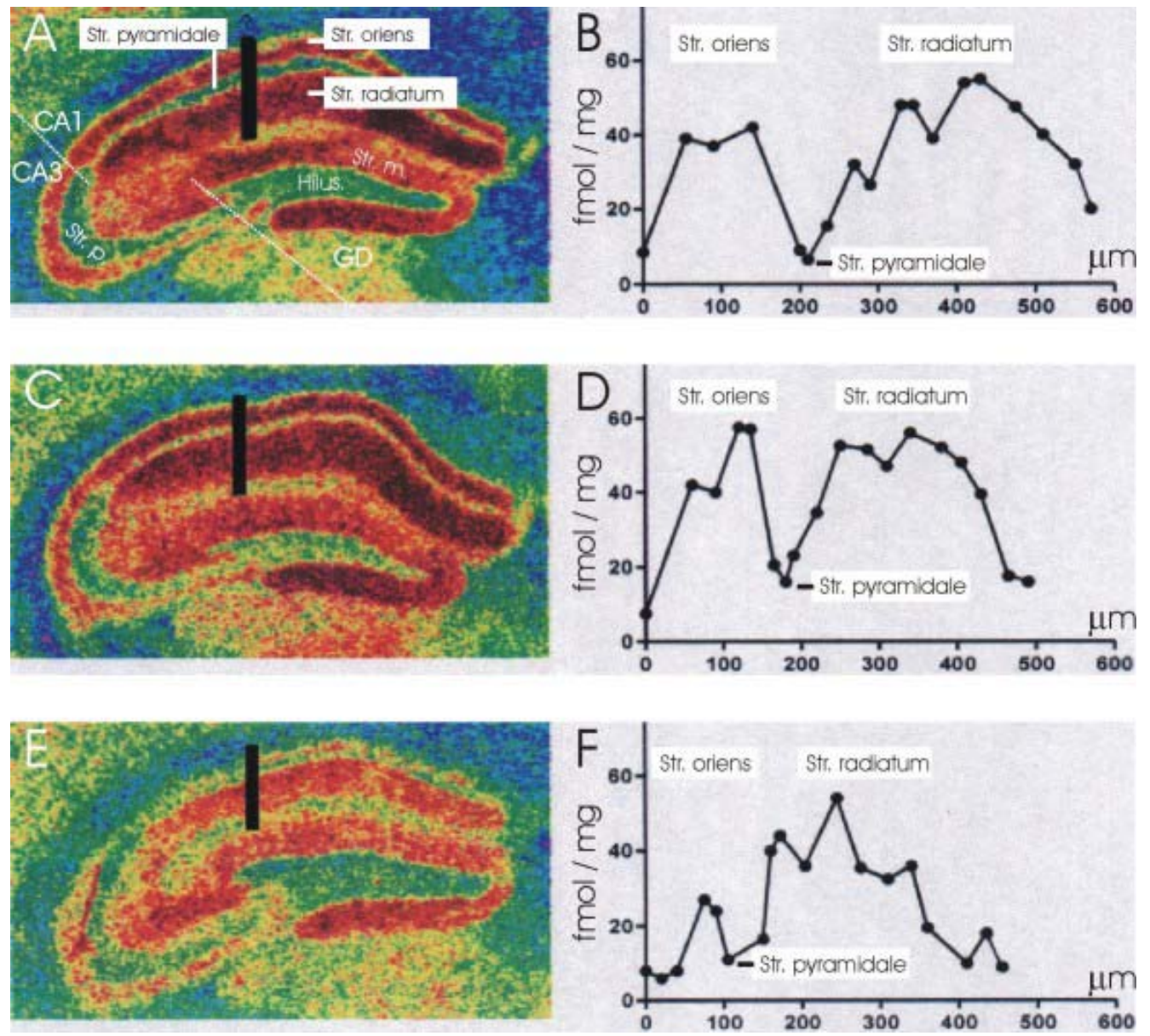

Abb. 3.11:,Falschfarben-Darstellungen“ (A, C, E) der ${ }^{125}$ I-MK 801-Rezeptorautoradiografie an Hippocampusschnitten einer 12 Monate alten $W^{+/+}-(A, B), T C^{+/}-(C, D)$ sowie $T C^{+-}$-Maus $(E, F)$ und quantitative Darstellung der äquivalenten NMDA-Rezeptorverteilung entlang der eingezeichneten Messgeraden in $(A, C, E)$ beginnend im Stratum oriens, über das Stratum pyramidale bis ins Stratum radiatum in der Region CA1 (B, D, F). Die MK 801-Bindungsintensität nimmt mit der Farbabstufung von rot über gelb und grün nach blau ab. Die Rezeptordichte ist in $(B, D, F)$ in der Einheit fmol/mg angegeben. CA1/CA3 = Regionen des Cornu Ammonis, $G D=$ Gyrus dentatus, Str.p. = Stratum pyramidale, Str.m. = Stratum moleculare (Vergrößerung A, C, E: 40x).

In einer postnatalen Entwicklungsstudie an ${ }^{125} \mathrm{I}-\mathrm{MK} 801$ inkubierten Hippocampusschnitten von $\mathrm{WT}^{+/+}$-Wildtyp-Mäusen und mutanten $\mathrm{TC}^{-/-}$-Mäusen wurde die Frage analysiert, zu welchem Zeitpunkt der postnatalen Entwicklung sich die in der $\mathrm{TC}^{-/-}$Mutanten beschriebenen Veränderungen der NMDA-Rezeptordichte ausbilden. Dazu wurden jeweils sechs Tiere aus den Altergruppen drei und neun Monate gewählt, da die Ergebnisse aus dem Abschnitt 3.1 .7 bereits gezeigt haben, dass morphologische Veränderungen im Hippocampus von $\mathrm{TC}^{-/-}$-Tieren im Alter von sechs bis sieben Monaten auftreten und eine Gruppe deutlich vor und eine weitere deutlich nach diesem Ereignis analysiert werden sollte. Zusätzlich wurde in dieser Entwicklungsstudie auf die Analyse heterozygoter $\mathrm{TC}^{+/-}$-Mäuse verzichtet, da in 12 Monate alten Tieren keine 
signifikanten Unterschiede $\mathrm{zu}$ den $\mathrm{WT}^{+/+}$-Kontrolltieren detektiert werden konnten (Abb. 3.11, C, D und Abb. 3.13, A, B).
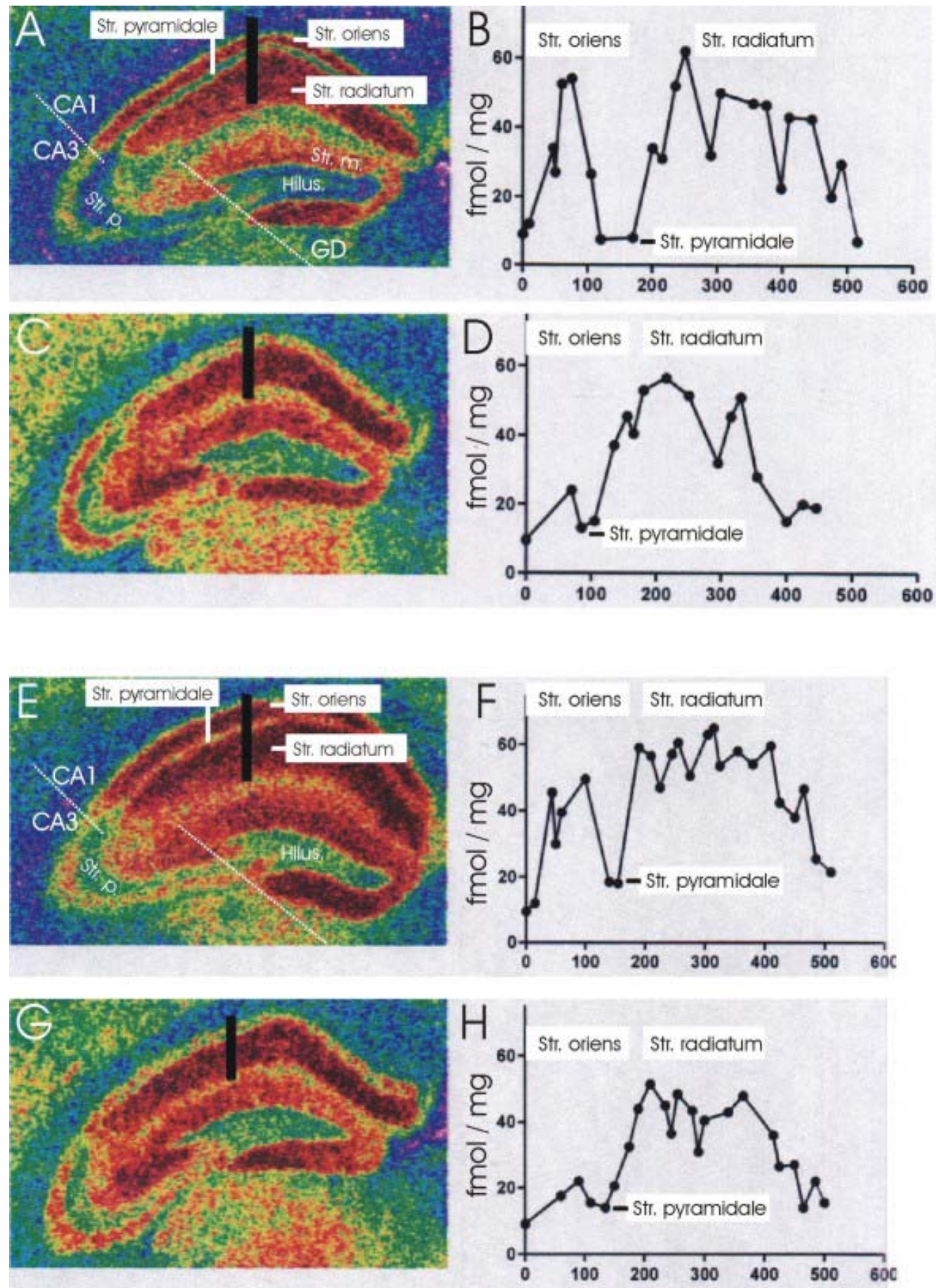

Abb. 3.12 
Abb. 3.12:(S. 91) „Falschfarben-Darstellungen“ (A, C, E, G) der ${ }^{125}$ I-MK 801-Rezeptorautoradiografie an Hippocampusschnitten einer drei Monate alten $W T^{+/+}-(A, B)$ und $T C^{+-}-\operatorname{Maus}(C, D)$ sowie einer neun Monate alten $W T^{t_{+}^{+}}-(E, F)$ und $T C^{--}-$Maus $(G, H)$ und quantitative Darstellung der äquivalenten NMDA-Rezeptorverteilung entlang der eingezeichneten Messgeraden in $(A, C, E, G)$, beginnend im Stratum oriens über das Stratum pyramidale bis ins Stratum radiatum in der Region $C A 1$ ( $B, D, E, H)$. Die MK 801-Bindungsintensität nimmt mit der Farbabstufung von rot über gelb und grün nach blau ab. Die Rezeptordichte ist in $(B, D, F$, $H$ ) in der Einheit fmol/mg angegeben. CA1/CA3 = Regionen des Cornu Ammonis, GD = Gyrus dentatus, Str.p. = Stratum pyramidale, Str.m. = Stratum moleculare, (Vergrößerung A, C, E, $G: 40 x$ ).
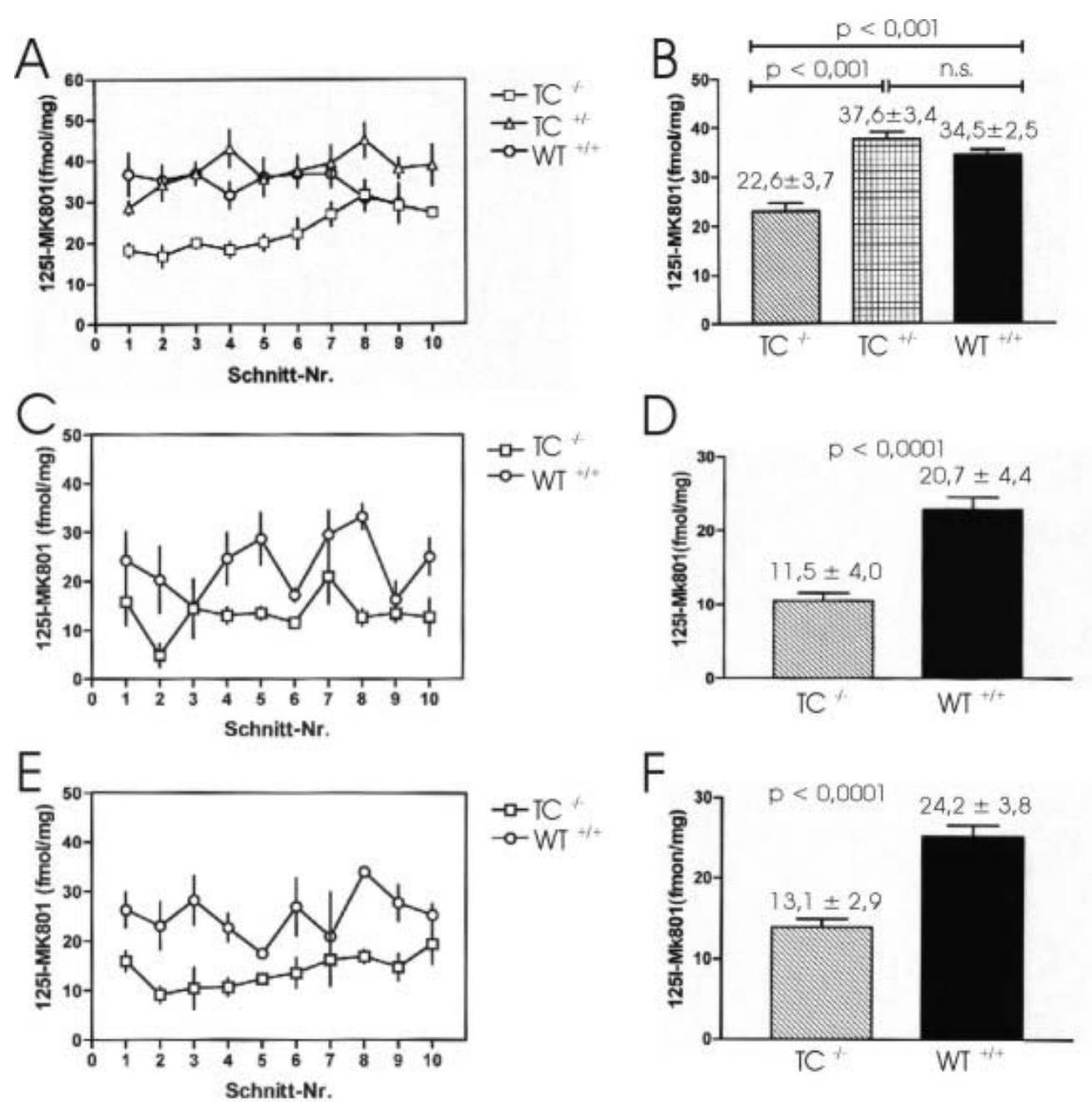

Abb. 3.13: Schematische Darstellung der gemittelten NMDA-Rezeptordichte innerhalb des Stratum oriens der CA1-Region ( $n=6)$ bezüglich der Schnittebene von rostral (1) nach caudal (10) in $(A, C, E)$ und der über die Schnittebenen des Hippocampus gemittelten NMDA-Rezeptordichte in (B, D, F). In (A, B) ist die Rezeptordichte an Hippocampusschnitten der 12 Monaten alten $\mathrm{WT}^{+/+}$(०), $T C^{+/-}-(\Delta)$ und $T C^{+-}-$Maus ( $\left.\square\right)$ dargestellt. Die Teilabbildungen $(C-F)$ stellen entsprechend die Rezeptordichte der neun Monate alten $(C, D)$ und drei Monate alten Versuchsgruppen (E, F) dar. Die der NMDA-Rezeptordichte äquivalente ${ }^{125}{ }^{2}$ MK 801Bindungsintensität ist in der Einheit fmol/mg angegeben. Die gemittelten Werte der jeweiligen Versuchgruppe sind in (B, D, F) zusammen mit der berechneten Standardabweichung dargestellt. (n.s. = nicht signifikant) 
Die Abb. 3.12 stellt jeweils einen der ${ }^{125}$ I-MK 801 inkubierten Hippocampusschnitte der Altersstufe 3 Monate (A, C) und 9 Monate (E, G) in einer „Falschfarben-Abbildung“ zusammen mit der dazugehörigen Rezeptorverteilung entlang der Messgeraden (B, D, F, H) grafisch dar. Die Analyse dieser Abbildungen, die quantitative Analyse der Rezeptorverteilung und die statistische Auswertung der Daten (Abb. 3.13) zeigen, dass die in der 12 Monate alten $\mathrm{TC}^{-/-}$-Maus beschriebene Reduktion der NMDARezeptordichte im Stratum oriens der CA1-Region in neun Monate alten und auch bereits in drei Monate alten $\mathrm{TC}^{-/-}$-Tieren detektiert werden kann. Die zwischen den Tieren der jeweiligen Gruppe und über die Schnittebenen des Hippocampus gemittelten Werte ergeben eine Reduktion an MK 801-Bindung von $45 \%$ (3 Monate), $45 \%$ (9 Monate) und $35 \%$ (12 Monate) (Abb. 3.13 B, D, F).

\subsubsection{Untersuchungen zur c-fos Expression in der TC $^{-/-}$-Maus}

Die Expression des ,immediate-early“ Gens c-fos wurde analysiert, da die c-fos Expression unter anderem auch durch die Aktivität von NMDA-Rezeptoren aktiviert wird (Lerea et al. 1992; Bading et al. 1993) und c-fos Expression in axonale Wachstumsprozesse von Neuronen im Hippocampus involviert ist (Watanabe et al. 1996).

Über einen Northern-Blot mit einer c-fos cDNA als Sonde an hippocampaler GesamtRNA einer 12 Monate alten $\mathrm{WT}^{+/+}$- und einer $\mathrm{TC}^{-/-}$-Maus konnte eine differentiell stark verminderte c-fos mRNA-Expression im Hippocampus der $\mathrm{TC}^{-/-}$-Maus nachgewiesen werden (Abb. 3.14 G). Die Intaktheit der verwendeten RNA wurde durch Rehybridisierung der Membran mit der cDNA für den ubiquitär exprimierten humanen Elongationsfaktor überprüft. In der Abb. 3.14 (A-F) ist die c-fos Expression durch Immunhybridisierung an $40 \mu \mathrm{m}$ dicken horizontalen Gefrierschnitten einer drei Monate alten $\mathrm{WT}^{+/+}(\mathrm{A}, \mathrm{C}, \mathrm{E})$ und einer äquivalenten $\mathrm{TC}^{-/-}$-Maus $(\mathrm{B}, \mathrm{D}, \mathrm{F})$ mit einem polyklonalen Antikörper gegen das c-fos Protein der Maus dargestellt. Die Teilabbildungen (A) und (B) zeigen Immunfärbungen aus der Region des Gyrus dentatus. Die Abbildungen (C) und (D) bzw. (E) und (F) bilden die entsprechende Immunhybridisierung in der CA3-, bzw. CA1-Region des Hippocampus ab. In der Wildtypsituation $\left(\mathrm{WT}^{+/+}, \mathrm{A}, \mathrm{C}, \mathrm{E}\right)$ detektiert der Antikörper c-fos positive Pyramidenzellen im Stratum pyramidale der Region CA3 (C) und CA1 (E) und c-fos positive Granularzellen (Körnerzellen) im Stratum granulosum des Gyrus dentatus (A). Zusätzlich hybridisieren weitere c-fos positive Neurone im Stratum oriens und vereinzelt im Stratum radiatum der Region CA3 und CA1 und im Hilus des Gyrus dentatus mit dem c-fos Antikörper. Diese c-fos positiven Neurone im Hilus (A), im Stratum oriens sowie im Stratum radiatum der Region CA3 und CA1 (C und E) fehlen 
in den äquivalenten Immunhybridisierungen an Schnitten einer $\mathrm{TC}^{-/-}$-Maus (Abb. 3.14 B, D, F). Die c-fos Immunhistochemie wurde in Kooperation mit der Arbeitsgruppe von Herrn Dr. Rickmann am Institut für Neuroanatomie der Universität Göttingen durchgeführt.
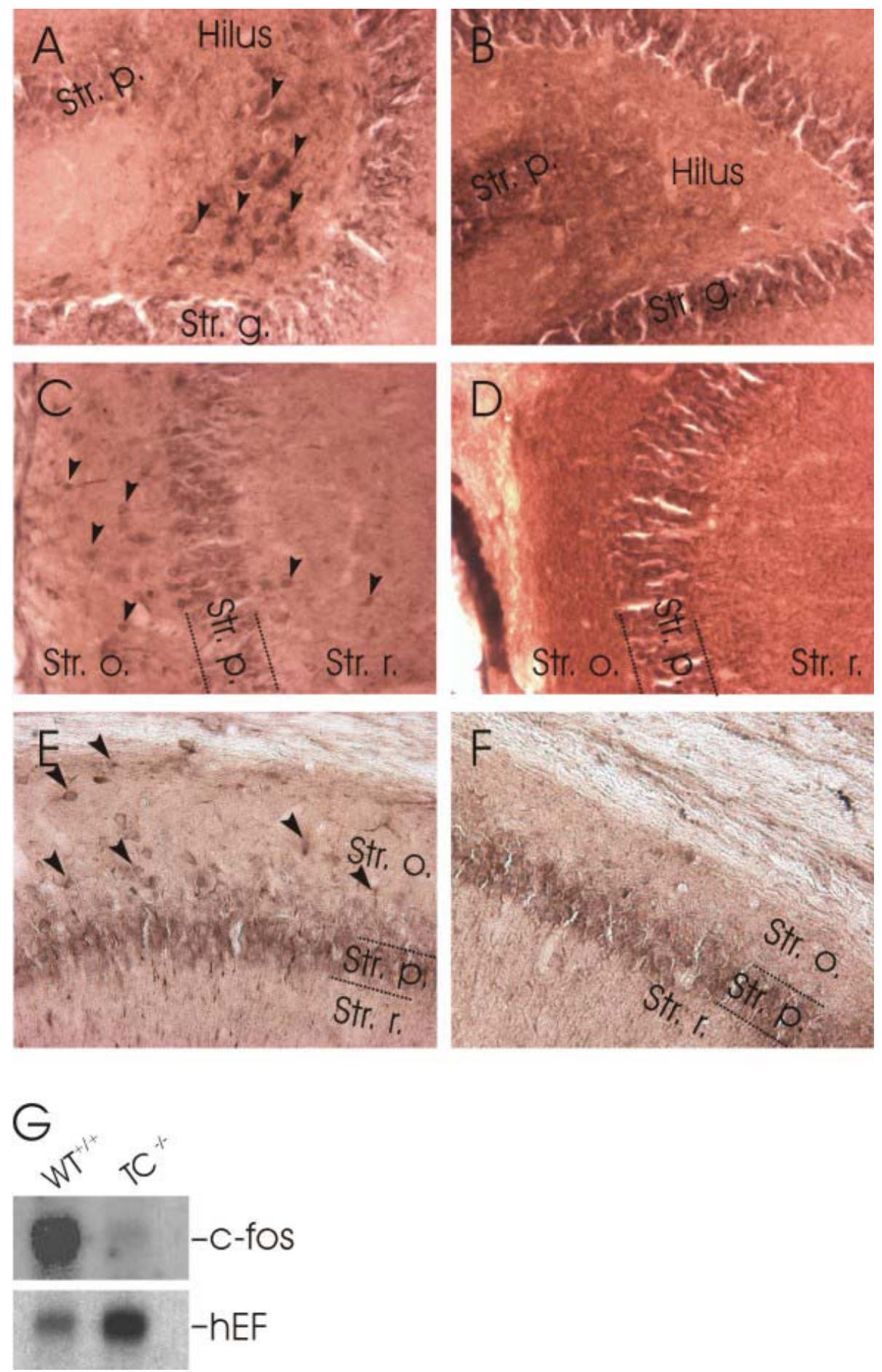

Abb. 3.14 
Abb. 3.14:(Seite 94) Immunhistologische Expressionsanalyse mit einem polyklonalen Antikörper gegen das c-fos-Protein der Maus an $40 \mu$ m dicken horizontalen Gefrierschnitten des Gehirns einer drei Monate alten Wildtyp- $\left(W T^{+/+} A, C, E\right)$ und einer homozygoten $\left(T C^{+-}\right)$TC-Maus $(B, D, F)$ und Northern-Blot mit c-fos cDNA an hippocampaler Gesamt-RNA einer 12 Monate alten $W T^{+/+}$- und einer $T C^{+/}$-Maus $(G) . h E F=$ humaner Elongationsfaktor, Str.o .= Stratum oriens, Str.r. = Stratum radiatum, Str.p. = Stratum pyramidale, Str.g. = Stratum granulosum (Vergrößerung A-F: 200 x).

\subsubsection{Nachweis pyknotischer Zellkerne und apoptotischer „dark neurons“ im Hippocampus der TC $^{-/-}$-Maus}

Der Verlust der c-fos positiven Neurone im Hilus und im Stratum oriens, sowie im Stratum radiatum der Region CA3 und CA1 (siehe Abschnitt 3.1.10) und die massiven histologischen Veränderungen im Hippocampus der $\mathrm{TC}^{-/-}$-Maus (siehe Abschnitt 3.1.7 bis 3.1.10) könnten zum Teil durch apoptotische Prozesse ausgelöst werden oder diese zur Folge haben. Aus diesem Grund wurde mit einer Methylenblau / Azur II Zellkörperfärbung an 1,5 $\mu \mathrm{m}$ dicken Semidünnschnitten des Gehirns einer acht Monate alten $\mathrm{TC}^{-/-}$-Maus im Hippocampus die Kompaktheit der Zellkerne analysiert, um so einen Hinweis auf DNA-Fragmentierung und apoptotische Prozesse zu erhalten. Die Übersichtsfärbung in Abb. 3.15 (A) zeigt den Übergang zwischen der CA1-Region und dem Subiculum. Die lichtmikroskopische Auswertung der Präparate ergab, dass im Subiculum pyknotische Zellkerne $(B, C)$ und im Übergangsbereich zwischen Stratum pyramidale und Stratum oriens der Region CA1 neben normalen Neuronen apoptotische sogenannte „dark neurons“ (D) zu sehen sind. Im Gyrus dentatus und in der Region CA3 sind diese Veränderungen nicht zu detektieren. Diese Ergebnisse weisen auf apoptotische oder neurodegenerative Prozesse im Subiculum und im Stratum pyramidale der Region CA1 hin. 


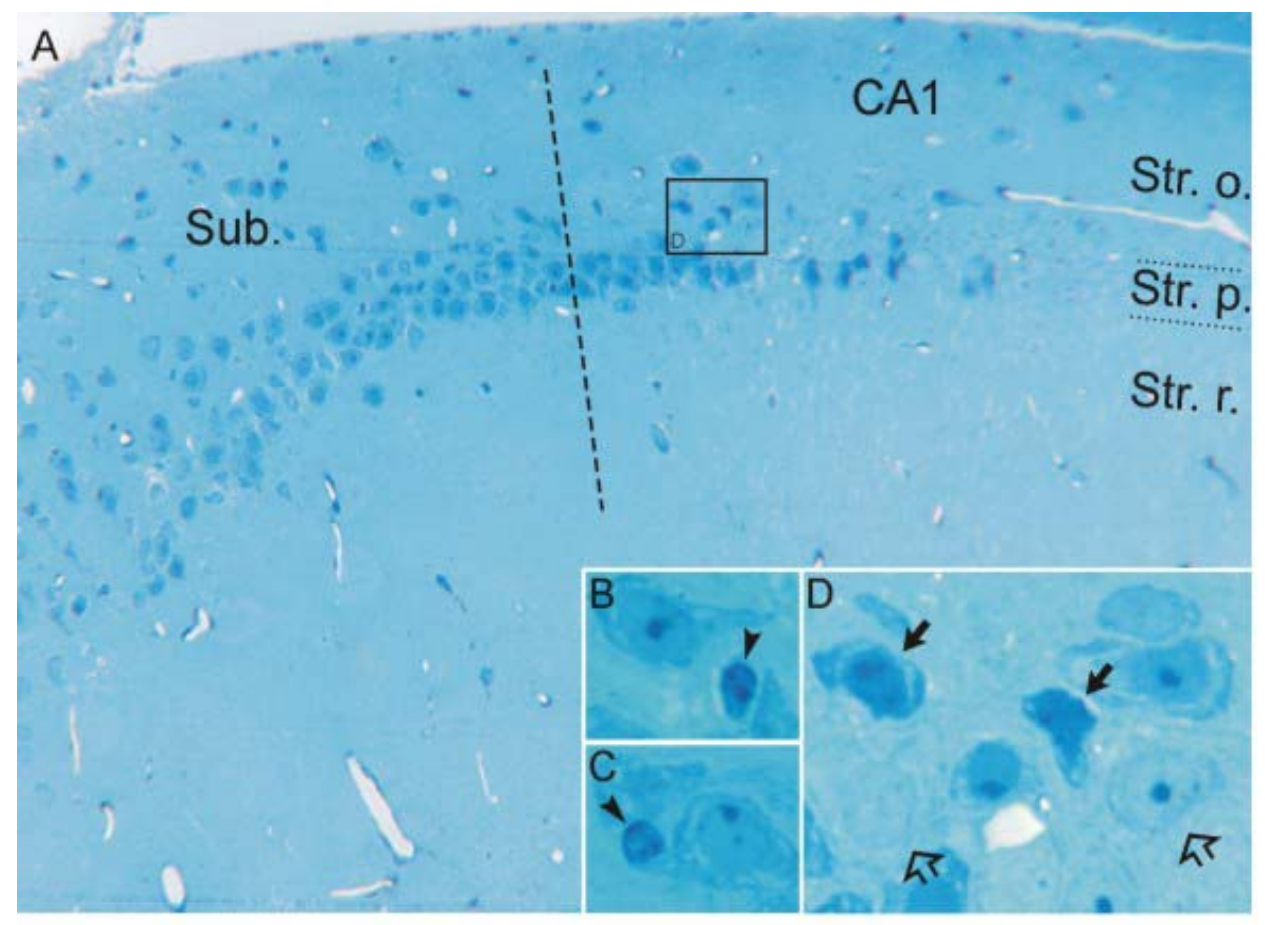

Abb. 3.15:Methylenblau / Azur II -Übersichtsfärbung (A) an einem 1,5 $\mu$ m horizontalen Semidünnschnitt durch den Hippocampus einer acht Monate alten TC ${ }^{+-}$-Maus. Der Übergang zwischen CA1Region und Subiculum ist durch die gestrichelte Linie markiert. Die Ausschnittvergrößerungen zeigen pyknotische Zellkerne (\$) im Subiculum (B, C) und apoptotische „,dark neurons “ (\$) und normale Neurone (†) im Übergangsbereich zwischen Stratum pyramidale und Stratum oriens $(D) . C A 1=$ Region des Cornu Ammonis, Str.o $=$ Stratum oriens, Str.r. $=$ Stratum radiatum, Str.p. $=$ Stratum pyramidale, Sub. $=$ Subiculum . 


\subsection{Genotypisierung der insertionsmutanten TC-Mauslinie}

\subsubsection{Chromosomale Lokalisierung der transgenen Insertion}

Durch Fluoreszenz in-situ Hybridisierung (FISH) mit FITC markierter CAT-SV40(Abb. 3.16, a) und TYR-SV40-Sonde (Abb. 3.16, c) an Propidiumjodid- gegengefärbten Metaphase-Chromosomen und durch Simultan-Doppelhybridisierung mit FITCmarkierter CAT-SV40- und TRITC- markierter TYR-SV40-Sonde an DAPIgegengefärbten Metaphase-Chromosomen (Abb. 3.16, b) einer männlichen homozygoten TC-Maus konnte gezeigt werden, dass die Integration der transgenen Konstrukte an einem chromosomalen Ort oder zumindest in einem so geringen Abstand erfolgt ist, dass das Signal durch die konventionelle in-situ Hybridisierung nicht aufgelöst werden kann. Durch eine Simultan-Doppelhybridisierung mit FITCmarkierter TYR-SV40- und TRITC-markierter CAT-SV40-Sonde an dem ,gestreckten“ Chromatin einer männlichen homozygoten TC-Maus (Abb. 3.16, f) konnte die Kointegration beider Konstrukte an einem chromosomalen Ort hochauflösend bestätigt werden. Ferner konnte die Größe der Insertion durch den internen TYR-SV40 Standard (11 kb) auf ungefähr $200 \mathrm{~kb}$ abgeschätzt werden.

Nach der in-situ Hybridisierung wurde eine G-Banden Färbung der Metaphasen aus Abb. 3.16 (c) durchgeführt und das markierte Chromosom durch den auffälligen Giemsa-negativen Block im perizentromerischen Bereich und durch die zwei starken Giemsa-positiven Banden im langen Arm, und zwar in der Mitte und in der distalen Region, als Chromosom 2 der Maus identifiziert (Abb. 3.16, d). In dem Ideogramm des Chromosoms 2 der Maus in Abb. 3.16 (e) ist die Lokalisation der Transgeninsertion schematisch dargestellt.

Abb. 3.16:(Seite 98) FISH-Hybridisierungen mit FITC-markierter CAT-SV40- (A) und TYR-SV40-Sonde (C) an Propidiumjodid-gegengefärbten Metaphase-Chromosomen und Simultan-Doppelhybridisierung mit FITC-markierter CAT-SV40- und TRITC-markierter TYR-SV40-Sonde an DAPIgegengefärbten Metaphase-Chromosomen (B) einer männlichen homozygoten TC-Maus belegen die Integration (\$) der transgenen Konstrukte an einem chromosomalen Ort. Die G-Bänderung (D) der Metaphase in (C) ermöglichte die Lokalisation der Insertion auf Chromosom 2 der Maus in der Region F3-G. In (E) ist das entsprechende Ideogramm des Chromosoms 2 der Maus dargestellt und die Region der Insertion markiert. In $(F)$ ist eine Simultan-Doppelhybridisierung mit FITC-markierter TYR-SV40- und TRITC-markierter CATSV40-Sonde an dem, gestreckten" Chromatin einer männlichen homozygoten TC-Maus gezeigt. Die Pfeile (9) markieren zwei SV40-3'UTR Signale und damit den Anfang und das Ende einer TYR-SV40 Insertion. 

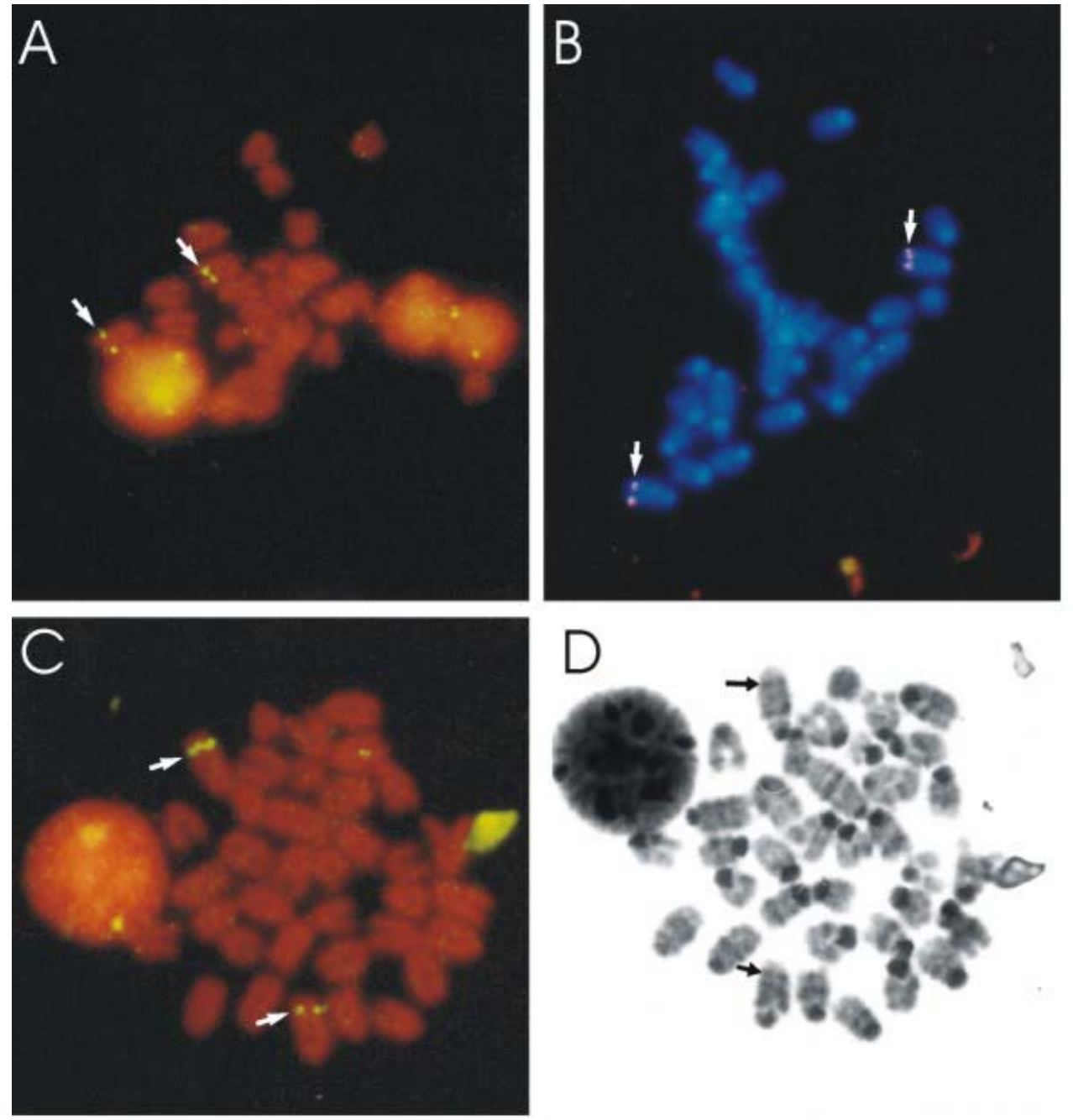

E

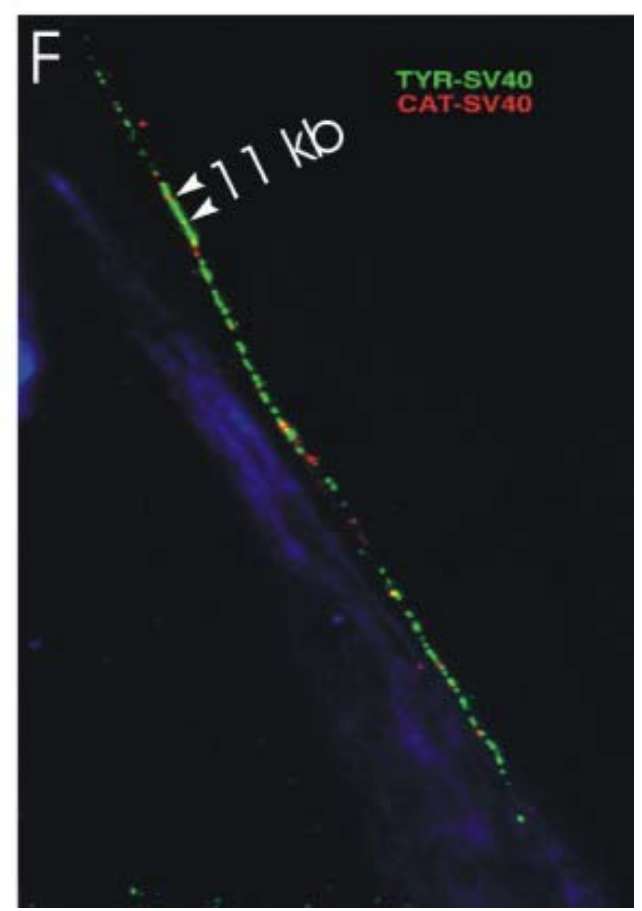

Abb. 3.16 


\subsubsection{Genomische Klonierung der TC-Insertionsregion über „Genome Walking"'-Experimente}

Für die Klonierung des Wildtyp-genomischen Anteils der Insertionsregion auf Chromosom 2 der Maus (Abb. 3.16) wurde das modifizierte „Genome-Walking“Verfahren der Firma Clontech eingesetzt. Dieses PCR-basierte „Genome Walking” System ermöglicht die Amplifizierung und Klonierung unbekannter genomischer DNABereiche in direkter Nachbarschaft zu bekannten DNA-Sequenzen, wie z.B. cDNA (Siebert et al. 1995), oder wie in diesem Fall der genomisch inserierten Konstrukt-DNA. Für das Experiment wurden endständige Oligonukleotide aus der SV40-3'UTR Region beider Konstrukte $\left(\mathrm{SV}_{40} 0_{\text {for2 }}\right.$ und $\left.\mathrm{SV} 40_{\text {for } 2 \mathrm{~N}}, \mathrm{Abb}, 3.17 \mathrm{~A}, \mathrm{~B}\right)$ zusammen mit den Adaptor-kodierten Gegen-Primern $\left(\mathrm{AP}_{\mathrm{GW} 1}\right.$ und $\left.\mathrm{AP}_{\mathrm{GW}}\right)$ an selbst generierten genomischen Adaptor-ligierten DNA-Pools einer homozygoten TC-Maus (DL1-DL5) eingesetzt.

A

ACR-CAT-SV40

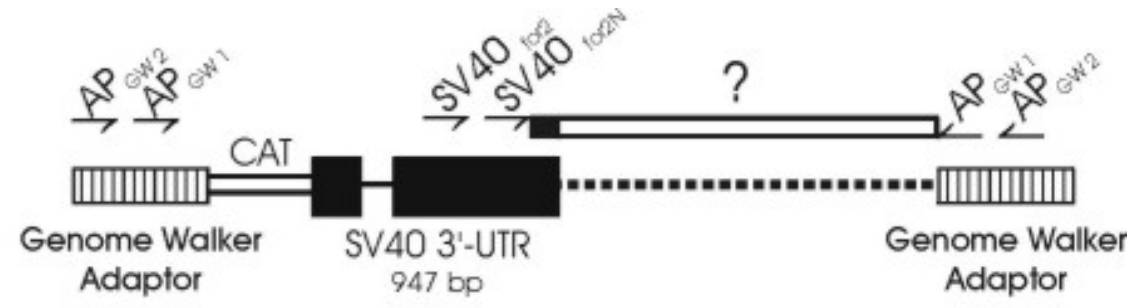

B

TYR-SV40

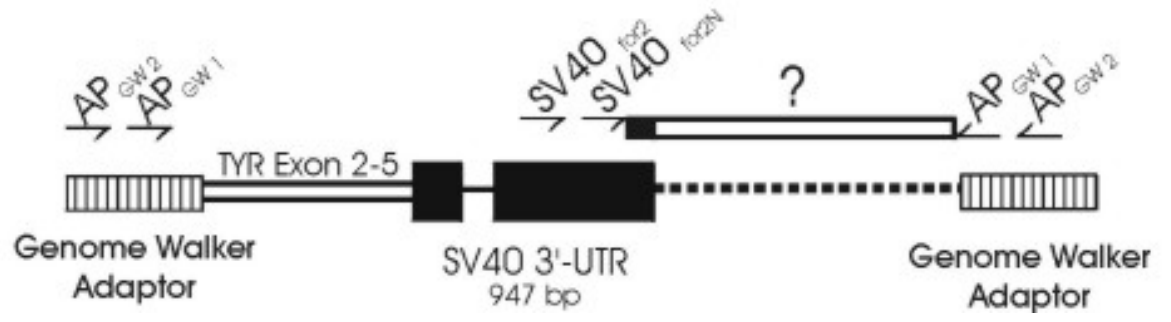

Abb. 3.17:Schematische Darstellung der „Genome Walking“-Strategie mit endständigen Oligonukleotiden $\left(S V 40_{\text {for } 2}\right.$ und SV40 for $2 N$ ) aus der SV40 3'-UTR Region der Konstrukte ACR-CATSV40 (A) und TYR-SV4O (B) zusammen mit Adaptor-kodierten Gegen-Primern (AP $P_{G W 1}$ und $\left.A P_{G W 2}\right)$ an selbst generierten genomischen Adaptor-ligierten DNA-Pools einer homozygoten TC-Maus. Die Positionen der im „Genome Walking“ - Experiment verwendeten SV40 3'UTR- und Adaptor-kodierten Oligonukleotiden sind schematisch ( $<$ und $\longrightarrow$ ) dargestellt und die Positionen der „Genome Walker-Adaptoren“ (schraffierte Boxen) sind hypothetisch gewählt. $C A T=$ Chloramphenicol-Acetyltransferase, 3'-UTR $=$,3'-Untranslated Region “, SV40 = Simian Virus 40, TYR = Tyrosinase.

Die Qualität der Adaptor-ligierten DNA-Pools der homozygoten TC-Maus (DL1-DL5) wurde im Vorfeld über zwei PCR-Kontrollreaktionen mit genspezifischen KontrollPrimern (PCP1 und PCP2) und den Adaptor-Primern $\left(\mathrm{AP}_{\mathrm{GW} 1}\right.$ und $\left.\mathrm{AP}_{\mathrm{GW}}\right)$ verifiziert. Mit diesen Kontrollprimern (PCP1 und PCP2) aus dem Intron 6 des murinen Gens für Interleukin $1 \beta$ (IL 1ß) konnten an den verschiedenen DNA-Pools reproduzierbare 
Fragmente amplifiziert werden (Abb. 3.18), so dass die erzeugten DNA-Pools als qualitativ hochwertig angesehen werden konnten.

\begin{tabular}{|c|c|c|c|}
\hline & Enzym & Fragmentgröße & 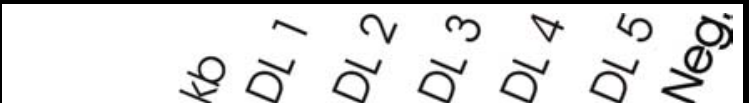 \\
\hline DL1 & EcoRV & $1,4 \mathrm{~kb}$ & $12 \mathrm{~kb}-\mathrm{C}$ \\
\hline DL2 & Sca I & $0,7 \mathrm{~kb}$ & $2 \mathrm{~kb}-$ \\
\hline DL3 & Dra I & $2,5 \mathrm{~kb}$ & \\
\hline DL4 & Pvu II & $3,5 \mathrm{~kb}$ & \\
\hline DL5 & Ssp I & $1,6 \mathrm{~kb}$ & $0,5 \mathrm{~kb}-\ldots$ \\
\hline
\end{tabular}

Abb. 3.18:Rechts: Ethidiumbromid gefärbtes 1,2\% Agarosegel der Amplifikate aus den PCR-Reaktionen mit murinen Kontrollprimern PCP1 und PCP2 aus dem Intron 6 des IL 1及 Gens der Maus an Adaptor-ligierten DNA-Pools einer homozygoten TC-Maus. Die Tabelle links listet die zur Generierung der DNA-Pools verwendeten „blunt end"- Enzyme und die entsprechenden Fragmentlängen der Kontrollamplifikate auf. Neg. $=$ Negativkontrolle, $k b=$ Längenstandard (1 kb DNA-Leiter, Gibco BRL)

Die PCR-Ansätze mit den endständigen Oligonukleotiden aus der SV40-3'UTR Region $\left(\mathrm{SV}_{40} 0_{\text {for2 }}\right.$ und $\mathrm{SV} 40_{\text {for2N }}$, Abb. 3.17) zusammen mit den Adaptor-kodierten GegenPrimern $\left(\mathrm{AP}_{\mathrm{GW} 1}\right.$ und $\left.\mathrm{AP}_{\mathrm{GW} 2}\right)$ wurden nach der Amplifikation über ein 1,2\% Agarosegel aufgetrennt. Die Abb. 3.19 zeigt das Ergebnis dieser gelelektrophoretischen Auftrennung mit dieser Primer-Kombination. Aufgrund der endständigen Lage der Oligonukleotide (114 bp vor der Kpn I -Schittstelle) wurde auf einen Southern-Blot verzichtet und die Produkte direkt über Sequenzierung identifiziert. Alle Fragmente, die groß genug waren, um prinzipiell über das Konstrukt hinausgehende Bereiche zu beinhalten, wurden isoliert, in den $p G E M-T$ Vektor kloniert und sequenziert.

Die mit der Primerkombination $\mathrm{SV}_{40} 0_{\text {for2N }} / \mathrm{AP}_{\mathrm{GW}}$ erzeugten Amplifikate besitzen eine Größe von 0,8 $\mathrm{kb}$ und 1,5 kb (DL2), 0,5 kb und 0,6 kb (DL4), 1,6 kb und 2,0 kb (DL5) im Agarosegel (Abb. 3.19). Die Klonierung der Fragmente aus DL5 misslang zunächst aufgrund geringer DNA-Ausbeute und wurde nach erfolgreicher Klonierung und Sequenzierung der Fragmente aus DL2 und DL4 eingestellt. 


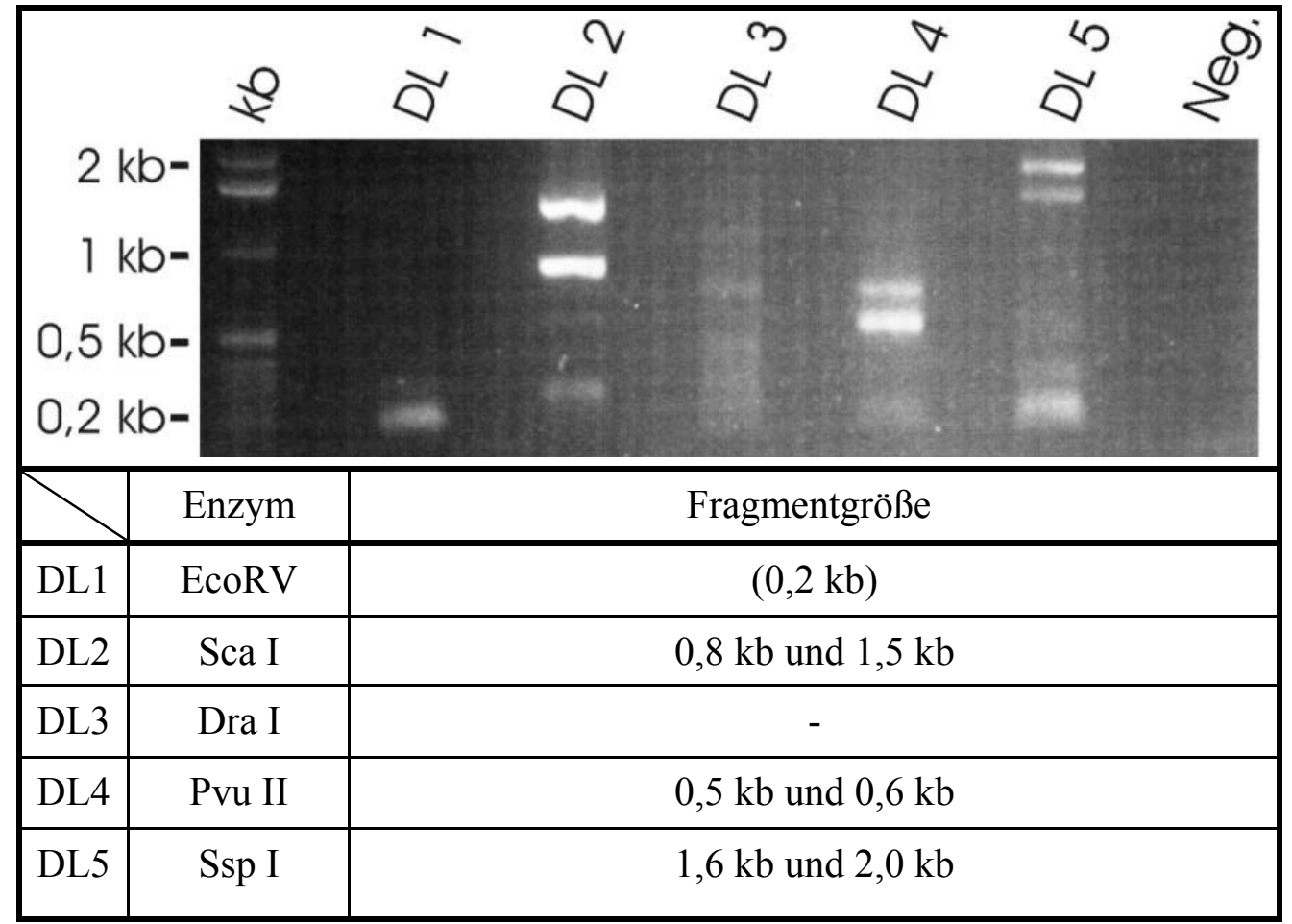

Abb. 3.19:Rechts: Ethidiumbromid gefärbtes 1,2\% Agarosegel der Amplifikate nach der zweiten PCRReaktion mit der Primerkombination $S V 40_{\text {for } 2} / A P_{G W 1}$ und $S V 40_{\text {for } 2 N} / A P_{G W 2}$ aus der SV40 3'UTR Konstrukt-DNA an Adaptor-ligierten DNA-Pools einer homozygoten TC-Maus. Die DNAPools DL1-DL5 sind mit „,blunt end“- Enzymen generiert und anschließend Adaptor-ligiert. Die Tabelle unten listet die zur Generierung der DNA-Pools verwendeten „,blunt end“Enzyme und die entsprechenden Fragmentlängen der Amplifikate auf. Neg. = Negativkontrolle, $k b=$ Längenstandard (1 kb DNA-Leiter, Gibco BRL).

Die Sequenzanalyse der Fragmente aus DL2 und DL4 ergab das in Abb. 3.20 schematisch dargestellte Bild: Die Fragmente $0,8 \mathrm{~kb}$ und $0,6 \mathrm{~kb}$ zeigten untereinander Homologie in dem über den SV40-3'UTR hinausgehenden Bereich (Abb. 3.20 A). Dieser Bereich ließ sich nicht den Sequenzen für die verwendete Konstrukt-DNA zuordnen und wurde daher als putativ Wildtyp-genomische Sequenz, die der SV403'UTR Insertion angrenzt, interpretiert. Ein BLAST-Sequenzabgleich dieser Sequenz gegen die Datenbanken des NCBI (www.ncbi.nlm.nih.gov/BLAST/) erbrachte keine Homologie mit genomischen-, STS- und EST-Datenbanken von Maus, Mensch und Ratte. Die Fragmente 0,5 kb (Abb. 3.20 B) und 1,5 kb (Abb. 3.20 C) zeigten in dem über den SV40-3'UTR hinausgehenden Bereich Homologie zu Teilen der verwendeten Konstrukte. Das 0,5 kb Fragment beinhaltet angrenzend an die SV40-3'UTR ein Fragment aus der 5'-flankierenden Region des Ratten-Proakrosin-Gens in 5'-3' Orientierung beginnend an Position 1 (Abb. 3.20 B, Abb. 1.1 A), und das 1,5 kb Fragment besteht zu einem überwiegenden Teil aus der 5'-flankierenden Region und Exon 1 des Maus Tyrosinase-Gens ebenfalls in 5'-3'-Orientierung und beginnend an 
Position 1 wie es im Konstrukt TYR-SV40 (Abb. 3.20 C, Abb. 1.1 B) enthalten ist. Die pGEM-T klonierten 1,5 kb und 0,5 kb Fragmente wurden daher nicht weiter bearbeitet. Die Struktur dieser analysierten Fragmente spiegelt jedoch eindeutig die Tandem-artige „Kopf an Kopf“- Kointegration beider Konstrukte wider, wie bereits mit FISHHybridisierung (Abb. 3.16 f) gezeigt werden konnte.

Ausschließlich die klonierten 0,8 kb- und 0,6 kb-Fragmente wurden weiter bearbeitet und im folgenden mit DL2-0,8 $\mathrm{kb}$ und DL4-0,6 kb bezeichnet.

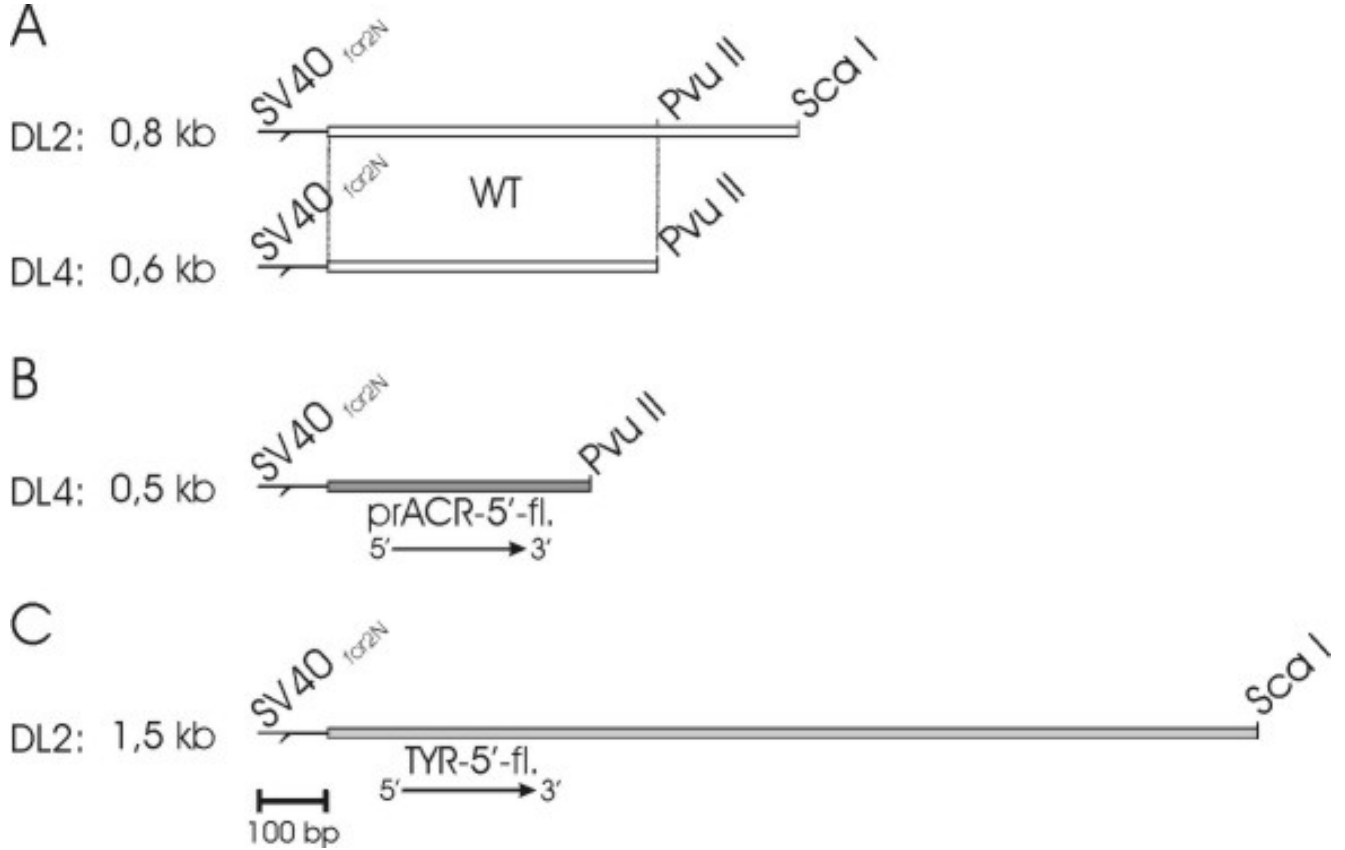

Abb. 3.20:Schematische Darstellung der Sequenzanalyse der amplifizierten Produkte aus Abb. 3.19. Die Fragmente in (A) zeigen untereinander Homologie in dem über die SV40-3'UTR hinausgehenden Bereich. Dieser Bereich wurde als putative Wildtyp-genomische Sequenz (WT), die der SV40-3'UTR Insertion angrenzt, interpretiert. Das Fragment in (B) zeigt über die SV40-3'UTR -Sequenz hinaus Homologie zu der 5 '-flankierenden Region des ProakrosinGens der Ratte in 5'-3'-Orientierung, wie es in dem Konstrukt ACR-CAT-SV40 (Abb. 1.1 A) enthalten ist. Das Fragment in (C) besteht zu einem überwiegenden Teil aus der 5'flankierenden Region und Exon 1 des Tyrosinase-Gens der Maus in 5'-3'-Orientierung, wie es im Konstrukt TYR-SV40 (Abb. 1.1 B) enthalten ist ( WT = Wildtyp-genomischer Bereich).

Zur Erzeugung geeigneter Sonden aus den Klonen DL2-0,8 kb und DL4-0,6 kb für genomische Southern-Blots (3.2.3), für „Screening“-Experimente genomischer Bibliotheken (3.2.4) und zur Generierung von sequenzspezifischen Oligonukleotiden für nachfolgende „Genome-Walking“-Experimente wurde eine Restriktionskarte aus der Konsensus-Sequenz der klonierten Region erstellt. Die Klone DL2-0,8 kb und DL4$0,6 \mathrm{~kb}$ (3.2.2) wurden mit Vektor-Primern (SP6 und T7) mehrfach von beiden Seiten sequenziert und aus den erhaltenen Sequenzen mit dem Programm DNASIS ${ }^{\circledR}$ (Version: 2.50) die Konsensus-Sequenz und eine Restriktionskarte erzeugt, die schematisch in 
Abb. 3.22 (A) dargestellt ist. Die Konsensus-Sequenz aus den Sequenzen von Klon DL2-0,8 kb und DL4-0,6 kb umfasst eine Länge von 777 bp, bestehend aus $113 \mathrm{bp}$ SV40-3'UTR, gefolgt von 664 bp putativer Wildtyp-genomischer Sequenz. Die Positionen der gängigsten Enzyme wurden überprüft und in Abb. 3.22 (A) dargestellt.

Für die weitere Klonierung und Sequenzierung des Wildtyp-genomischen Anteils der Insertionsregion ausgehend von der in Abb. 3.22 gezeigten putativen Wildtypgenomischen Sequenz, sowohl in Richtung der Insertion als auch in der entgegengesetzten Richtung, wurde das „Genome-Walking“- Experiment an Adaptorligierten DNA-Pools aus genomischer DNA einer männlichen Wildtyp-Maus wiederholt. Die Positionen der für dieses Experiment benutzten Oligonukleotide DL2$0,8_{\text {rev }}$ und DL2- $0,8_{\text {for }}$ sind in Abb. 3.22 dargestellt. Die PCR wurde halb-,,nested“ durchgeführt, d.h. die zweite PCR wurde erneut mit dem ersten genspezifischen Primer zusammen mit dem „nested“ gelegenen Adaptor-Primer durchgeführt. Das Ziel dieses Experimentes war es, in direkter Nachbarschaft zur Insertion sowohl ,aufwärts“ als auch „abwärts“ nach exonischen, bzw. kodierenden Regionen zu suchen und dort funktionale Elemente des mutierten Gens zu finden. Die Abb. 3.21 zeigt das Ergebnis der gelelektrophoretischen Auftrennung der Amplifikate aus diesem „GenomeWalking“"Experiment.

Die mit der Primerkombination DL2-0, $8_{\text {rev }} / \mathrm{AP}_{\mathrm{GW}}$ erzeugten Amplifikate besitzen eine Größe von 0,6 kb (DL2) und 1,2 kb (DL5) (Abb. 3.21, A) und die mit der Primerkombination DL2- $0,8_{\text {for }} / \mathrm{AP}_{\mathrm{GW} 2}$ amplifizierten Produkte migrierten im Agarosegel bei 0,5 kb (DL2) und 2,2 kb (DL5) (Abb. 3.21, B). Die Produkte wurden isoliert, in $p G E M-T$-Vektor kloniert und über Sequenzierung identifiziert. Die Klone DL2-0,5 kb und DL5-2,2 kb aus der revers gerichteten Amplifikation und die Klone DL2-0,6 kb und DL5-1,2 kb wurden zunächst mit $p G E M-T$-Vektor-Primern (SP6 und T7) mehrfach von beiden Seiten sequenziert. Der Klon DL5-2,2 kb wurde auch mit Hilfe der genspezifischen Oligonukleotide DL5-2,2 $2_{\text {rev }}$ und DL5-2,2 $2_{\text {for }}$ sequenziert. Aus den Sequenzen wurde mit dem Programm DNASIS ${ }^{\circledR}$ die Konsensus-Sequenz und eine Restriktionskarte der gängigsten Restriktionsenzyme erzeugt, die schematisch in Abb. 3.22 (B) dargestellt ist. 


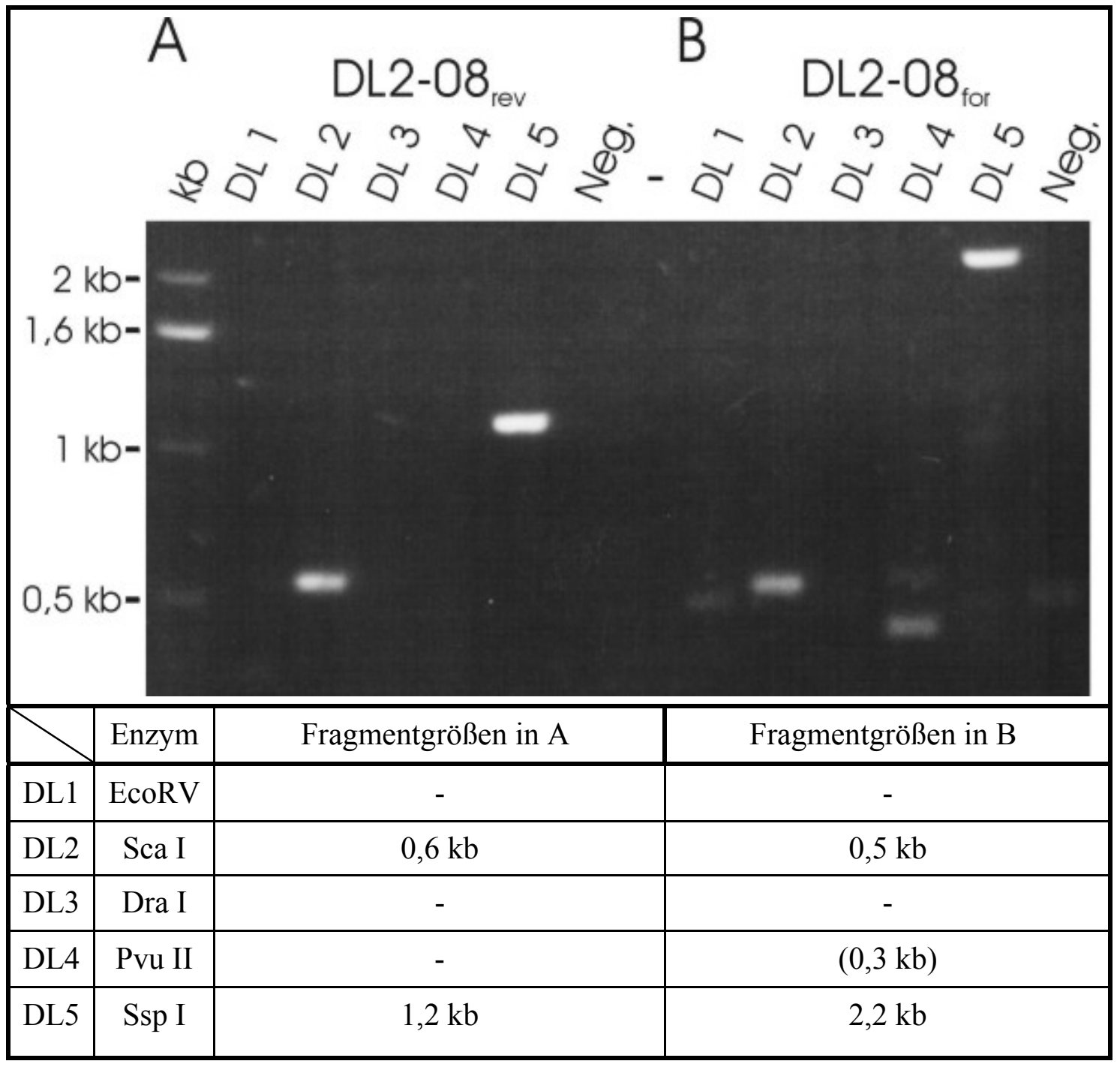

Abb. 3.21:Ethidiumbromid gefärbtes 1,2\% Agarosegel der Amplifikate nach der zweiten, halb-,,nested“" durchgeführten PCR-Reaktion mit den Primerkombinationen (A) DL2-08 $8_{\text {rev }} / A P_{G W 1}$ und DL2$08_{\text {rev }} / A P_{G W 2}$ und (B) DL2-08 for $/ A P_{G W 1}$ und DL2-08 for $/ A P_{G W 2}$ an Adaptor-ligierten DNA-Pools einer Wildtyp-Maus. Die DNA-Pools DL1-DL5 wurden mit „,blunt end“- Enzymen generiert und anschließend Adaptor-ligiert. Die Tabelle unten listet die zur Generierung der DNA-Pools verwendeten ,, blunt end"- Enzyme und die entsprechenden Fragmentlängen der Amplifikate in (A) und (B) auf. Neg. = Negativkontrolle, $k b=$ Längenstandard (1 kb DNA-Leiter, Gibco $B R L)$.

Die Konsensus-Sequenz aus den Sequenzen von Klon DL2-0,6 , DL5-1,2 ,DL2-0,5 und DL5-2,2 umfasst 2918 bp und enthält 633 bp über die Insertion hinausgehende WildtypSequenz. Ein BLAST-Sequenzabgleich mit diesen Sequenzen gegen die SequenzDatenbanken des NCBI (www.ncbi.nlm.nih.gov/BLAST/) erbrachte auch hier keine Homologie mit genomischen-, STS- und EST-Datenbanken von Maus, Mensch und Ratte und die Suche nach einem offenen Leserahmen (ORF), dessen Existenz einen Hinweis auf translatierte Bereiche gibt, blieb ohne Ergebnis. 


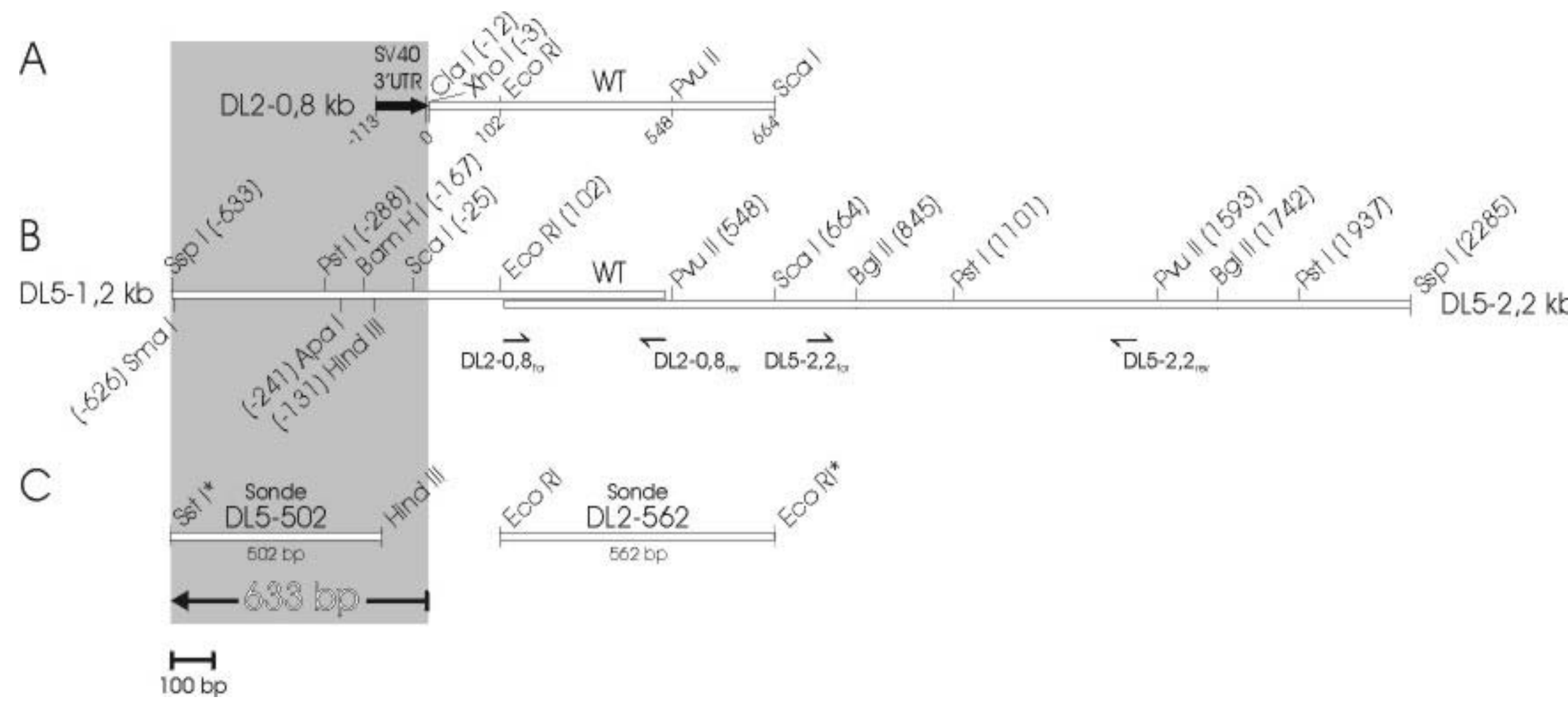

Abb. 3.22 (A) Schematische Darstellung der Restriktionskarte des Klons DL2-0,8 kb. Im 5'-Bereich sind 113 bp der SV40-3'UTR dargestellt, gefolgt von 664 bp putativer genomischer Sequenz. (B) Schematische Darstellung der durch Sequenzierung der Klone DL5-1,2 kb und DL5-2,2 kb erweiterten KonsensusSequenz. Im 5'-Bereich sind 663 bp über die SV40-3'UTR -Insertion hinausgehende Sequenz schattiert unterlegt. Die Restriktionskarte ist für die angegebenen Restriktionsenzyme vollständig. Die Nukleotid-Positionen der Restriktionsenzyme sind numerisch bezüglich der Insertionsstelle (0) angeben. Die Positionen der für das „,Genome-Walking“ -Experiment verwendeten Oligonukleotide DL-0,8 for und DL-0,8 rev und der für die Sequenzierung verwendeten Primer DL5-2,2 $2_{\text {rev }}$ und DL5-2,2 for sind schematisch dargestellt. In (C) ist die Erzeugung und die Lage der Sonden DL2-562 und DL5-502 durch EcoRI bzw. Sst I- und Hind III-restriktionsenzymatische Spaltung der DL2-0,8 kb DNA bzw. DL5-1,2 kb DNA gezeigt. Mit* markierte Restriktionsenzyme stellen Vektorschnittstellen dar. 


\subsubsection{Southern-Blot Analyse der TC-Insertionsregion}

Die in Kapitel 3.2.2 beschriebenen PCR-Produkte mit putativ anteiliger Wildtypgenomischer Sequenz (Abb. 3.20, A und Abb. 3.22) wurden in Hybridisierungen auf genomische Southern-Blots auf ihre tatsächliche Nähe zur TC-Insertionsregion überprüft. Da die klonierte SV40-3'UTR Sequenz sowohl aus einer endständigen ACRCAT-SV40- als auch aus einer TYR-SV40-Insertion stammen kann, wurden die Enzyme für die Restriktion der genomischen DNA aus denen ausgewählt, die nachweislich in beiden Konstrukten schneiden. Dadurch sollte garantiert werden, dass Fragmente unterschiedliche Größe entstehen und ein Fragment-,,Shift" detektiert werden kann. Es wurden die Restriktionsenzyme Hind III, Bgl II, Xba I und Bam HI gewählt. Als Sonden für die genomischen Southern-Blots wurden die in Abb. 3.22 dargestellten Fragmente DL2-562 und DL5-502 verwendet, die aus den entsprechenden Klonen DL2-0,8 kb und DL5-1,2 kb restriktionsenzymatisch isoliert wurden.

Das Ergebnis der genomischen Southern-Blots mit der Sonde DL2-562 ist in der Abb. 3.23 dargestellt und zeigt an dem Insertionsort mit allen vier verwendeten Restriktionsenzymen einen deutlichen Fragment-,,Shift" von einem Wildtyp-Allel $(+/+)$ zu einem mutanten Allel (-/-). Heterozygote Tiere (+/-) sind bi-allelisch und besitzen am Insertionsort sowohl das Wildtyp- als auch das mutante Allel.

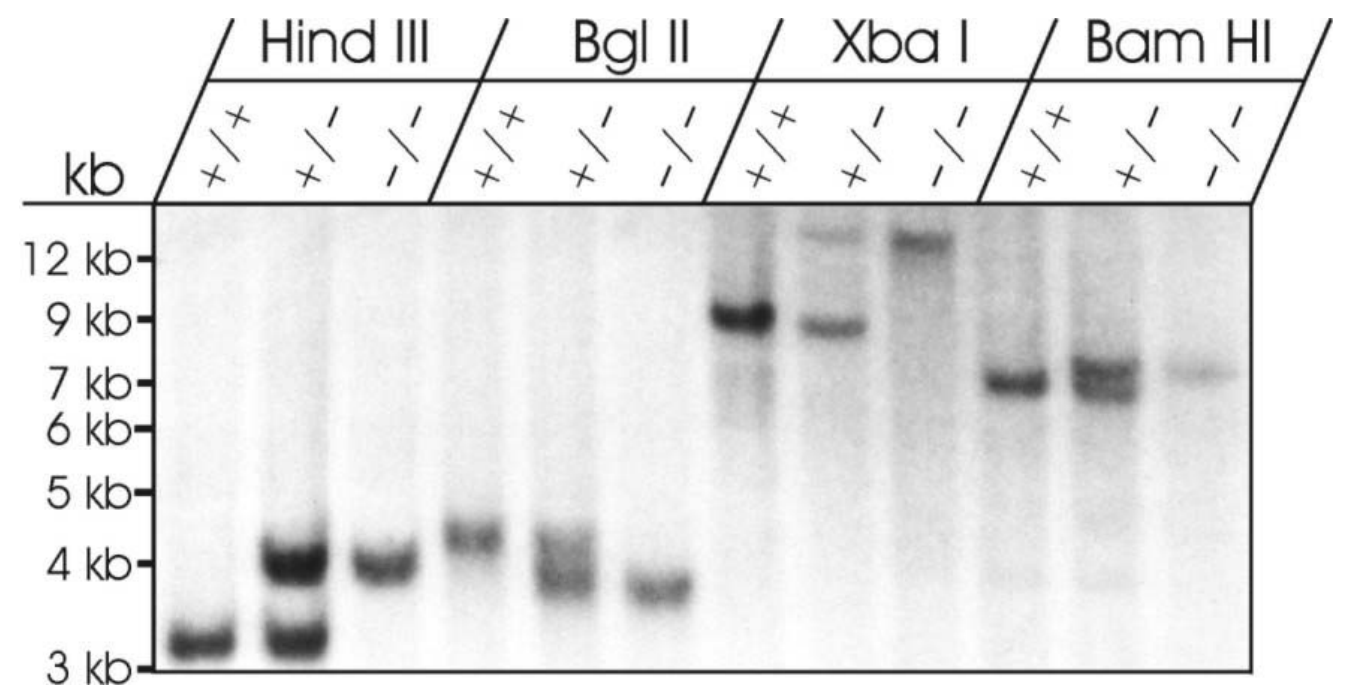

Abb. 3.23: Genomischer Southern-Blot an DNA von Wildtyp (+/+), heterozygoten (+/-) und homozygoten (-/-) TC-Mäusen mit der putativ genomischen Wildtyp-Sonde DL2-562. Die genomische DNA wurde mit den Restriktionsenzymen Hind III, Bgl II, Xba I und Bam HI restringiert $(k b=k b$ Leiter, $+/+=$ Wildtyp, $+/-=$ heterozygot, $-/-=$ homozygot)

Die Abb. 3.24 zeigt das Ergebnis des genomischen Southern-Blots mit der Sonde DL5-502, die aus der über die Insertion hinausgehenden Wildtyp-Region (Abb. 3.22, B) 
isoliert wurde. Die Sonde DL5-502 detektiert das $B g l$ II- $(4,2 \mathrm{~kb})$ und $X b a$ I- generierte Wildtyp-Fragment (9 kb) aus der Hybridisierung mit der Sonde DL2-562 (Abb. 3.23), je ein weiteres Hind III- $(0,6 \mathrm{~kb})$ und Bam HI -Fragment $(9 \mathrm{~kb})$ und die Deletion aller Fragmente im Genom der TC-Maus. Die Deletion umfasst mindestens eine Größe von 502 bp, zeigt keine Homologie zu bekannten Sequenzen der Datenbanken und enthält keinen offenen Leserahmen (ORF) bzw. exonische oder translatierte Bereiche. Die Sonde DL5-502 hat in der bekannten Konsensus-Sequenz eine endständige Lage (Abb. $3.22, \mathrm{C})$, so dass von einer weiteren Ausdehnung der Deletion ausgegangen werden kann.

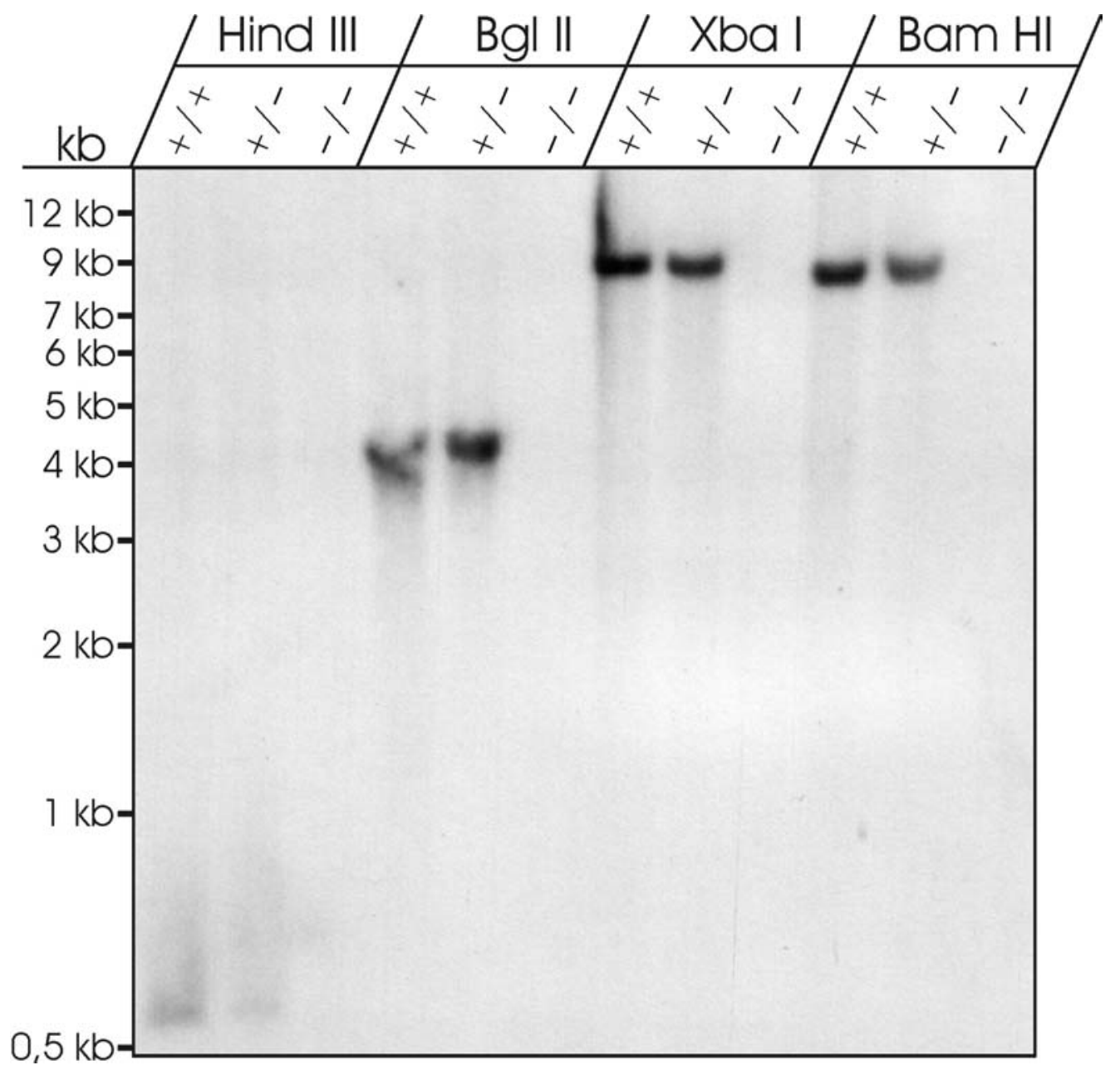

Abb. 3.24:Genomischer Southern-Blot an DNA von Wildtyp (+/+), heterozygoten (+/-) und homozygoten (-/-) TC-Mäusen mit der putativ genomischen Wildtyp-Sonde DL5-502. Die genomische DNA wurde mit den Restriktionsenzymen Hind III, Bgl II, Xba I und Bam HI restringiert $(k b=k b$ Leiter, $+/+=$ Wildtyp, $+/-=$ heterozygot, $-/-=$ homozygot) 


\subsubsection{Klonierung und Charakterisierung des Wildtyp-genomischen Bereichs der Insertionsregion}

Zur Isolierung genomischer Klone aus der Insertionsregion wurden im Duplett auf Nylonmembran gespottete genomische PAC- und Cosmid-Bibliotheken von der RZPD in Berlin bezogen und mit der Sonde DL2-562 (Abb. 3.22, C) hybridisiert. Die genomische DNA auf den Filtern stammte von weiblichen Tieren (PAC-Bibliothek) bzw. von männlichen Mäusen (Cosmid-Bibliothek) des Stammes 129Sv, also von Mäusen mit hinreichender genetischer Nähe zum Hintergrund-Stamm der TransgenInsertion (NMRI). Anfänglich hybridisierten zwei Cosmid-Klone und sechs PAC-Klone mit der Sonde DL2-562. Die PAC-Klone wurden mit I 24, K 12, E 18, L 15, L 24 und C 10 bezeichnet, und die Cosmid-Klone erhielten die Bezeichnungen A09170 und A09182. Die DNA dieser Klone wurde mit dem Restriktionsenzym Bam HI verdaut, da dieses Enzym nicht in den Vektoren pPAC4 (19,5 kb) und Lawrist7 (5,4 kb) schneidet, und gelelektrophoretisch aufgetrennt (Abb. 3.25, A,E). Es zeigte sich, dass alle sechs PAC-Klone ein ähnliches Restriktionsmuster aufwiesen, aber nicht identisch waren. Die Hybridisierung mit der Sonde DL2-562 auf dem Southern-Blot des Gels in Abb. 3.25 (A) detektierte in allen sechs PAC-Klonen das $7 \mathrm{~kb}$ Wildtyp-Fragment (B), wie es auch im genomischen Southern-Blot mit dieser Sonde detektiert wurde (Abb. 3.23). Für die Restriktionskartierung und für die chromosomale Lokalisierung wurde der PAC Klon L 15 ausgewählt, weil dessen Insert-Größe am größten erschien. Die detaillierte Restriktionsanalyse mit diversen Enzymen (Abb. 3.25, C) bestätigte diese Vermutung und ließ eine Abschätzung der Insert-Größe, bei einer $p P A C 4$-Vektorgröße von 19,5 kb, auf ca. $100 \mathrm{~kb}$ zu. Die Hybridisierung dieses Southern-Blots (Abb. 3.25, C) mit der Deletions-Sonde DL5-502 (Abb. 3.22, B) detektierte in dem PAC-Klon die WildtypFragmente, wie sie auch im genomischen Southern-Blot mit dieser Sonde detektiert wurden (Abb. 3.24). Die restriktionsenzymatische Analyse der putativ positiven Cosmid-Klone A09170 und A09182 ergab keine Übereinstimmung im Restriktionsmuster (Abb. 3.25, E). Im Klon A09170 ließ sich jedoch bereits restriktionsenzymatisch ein $7 \mathrm{~kb}$ Fragment identifizieren, dass mit der Sonde DL2-562 auf dem Southern-Blot dieses Gels (E) ebenfalls hybridisierte (Abb. 3.25, F). Der Cosmid-Klon A09170 wurde im folgenden für Klonierungs-Experimente benutzt. 


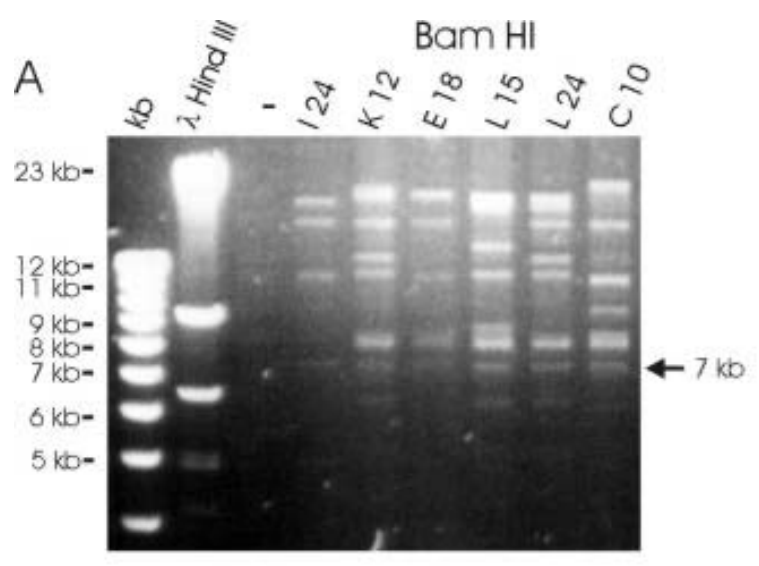

B

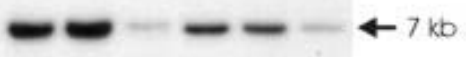

C
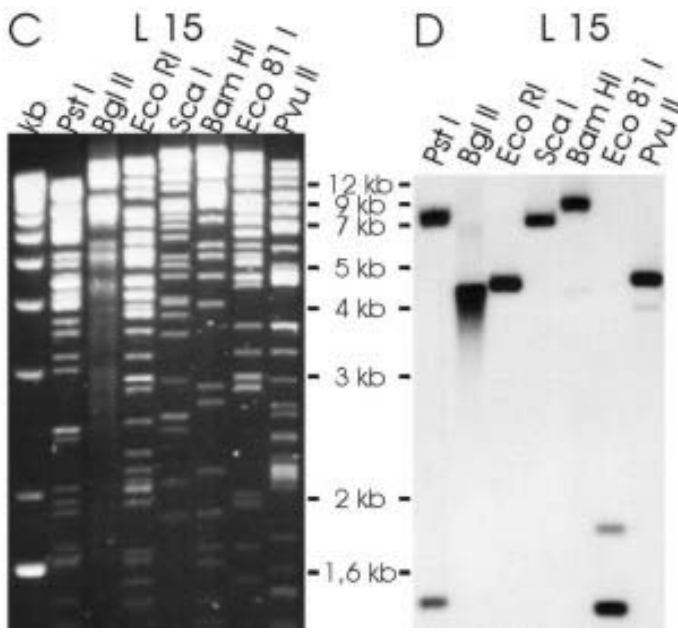

E

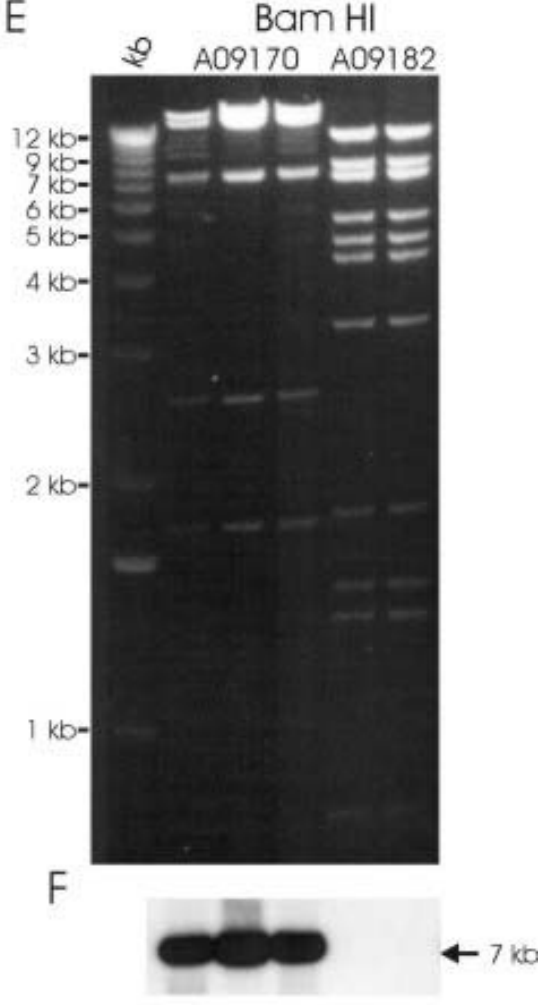

Abb. 3.25:Restriktionsenzymatische Analyse der PAC- (A) und Cosmid-DNA (E) mit Bam HI und das Hybridisierungsergebnis der Southern-Blots mit der Sonde DL02-565 (B,F). In (C) ist die detaillierte Restriktionsanalyse des PAC-Klons L 15 und das Hybridisierungsergebnis dieses Southern-Blots mit der Deletions-Sonde DL5-502 dargestellt

\subsubsection{Chromosomale Lokalisierung der isolierten Cosmid- und PAC-Klone}

Durch Doppel-Fluoreszenz in-situ Hybridisierung (FISH) an DAPI-gegengefärbten Metaphase-Chromosomen der Zellinie WMP-1 (Zörnig et al. 1995) konnten die genomischen Klone A09170 und L15 auf Chromosom 2 in der Region der Insertion (Abb. 3.16) lokalisiert werden (Abb. 3.26). Dazu wurde FITC-markierte A09170 Cosmid-DNA (A) bzw. FITC-markierte L15-PAC-DNA (B) zusammen mit TRITCmarkierter DNA des bereits auf Chromosom 2 der Maus in Region H in Telomer-Nähe lokalisierten PAC 473 L8 (www.biologia.uniba.it/rmc/9-MOUSE/-MOUSE.html) in einer Simultan-Doppelhybridisierung eingesetzt und die Hybridisierungssignale relativ 
zur kohybridisierten TRITC-markierten PAC 473 L8-DNA auf Chromosom 2 in der Region F3-G in Telomer-Nähe (qtel) lokalisiert.
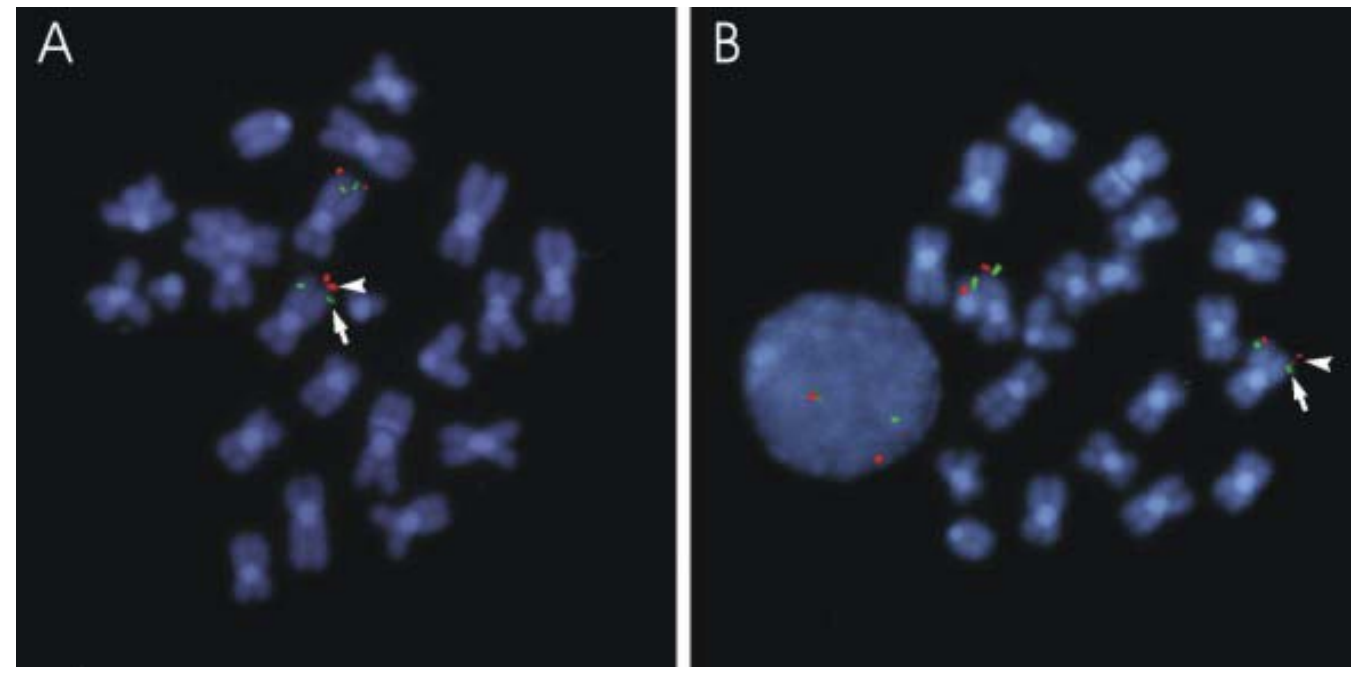

Abb. 3.26:Doppel-FISH-Hybridisierung mit FITC-markierter A09170 Cosmid-DNA (A) und FITCmarkierter L15-PAC-DNA (B) an DAPI-gegengefärbten Metaphase-Chromosomen der Zellinie WMP-1 (Zörnig et al. 1995). Die Hybridisierungssignale der Cosmid- (A) bzw. der PAC-DNA (B) sind mit einem Pfeil (\$) markiert. Die Signale sind in (A) und (B) relativ zur kohybridisierten TRITC-markierten DNA des PAC 473 L8 (9) auf Chromosom 2 in TelomerNähe (qtel) lokalisiert.

\subsection{6 „Cosmid-Rescue“-Analyse}

Der Cosmid-Klon A09170 wurde im folgenden zur Genotypisierung der Insertionsregion und zur Klonierung des Wildtyp-genomischen Anteils der Deletion (Abb. 3.22) weiter molekulargenetisch analysiert. Dazu wurden, da von einem größeren Ausmaß der Deletion ausgegangen wurde, die Endfragmente des in den Lawrist 7Vektor (Abb. 3.27, A) einklonierten „Inserts“ A09170 kloniert, um sie als Sonde in genomischen Southern-Blots einzusetzen. Zusätzlich wurden die genomischen Endfragmente für nachfolgende Experimente, wie z.B. „Cosmid-Walking“ benötigt, um einen Cosmid-Contig zu erstellen, der die Deletion überspannt.

Bei dem hier verwendeten „Cosmid-Rescue“ -Experiment (Abb. 3.27) macht man sich den Umstand zunutze, dass nach restriktionsenzymatischem Verdau mit Sca I ein Fragment mit intaktem Vektoranteil und endständigen „Insert“-Fragmenten entsteht (Abb. 3.27, B), das nach Ligation ein transformierbares und selektierbares Plasmid (Abb. 3.27, D) ergibt. Diese Strategie wurde an der DNA des Cosmids A09170 angewendet, und es konnte ein rund 19 kb großes Plasmid (A09170-SR, Abb. 3.27, D) 
isoliert werden, in dem nach Restriktionskartierung neben dem Vektoranteil $(5,4 \mathrm{~kb})$ ein $4 \mathrm{~kb}$ und ein $10 \mathrm{~kb}$ großes Endfragment identifiziert werden konnten, von denen das 4 kb Fragment mit der Deletions-Sonde DL5-502 (Abb. 3.22, C) hybridisierte (Abb. 3.27, F). Das $4 \mathrm{~kb}$ Fragment wurde isoliert, die Restriktionsenden „blunt-end“ aufgefüllt, das ,blunt-end“ -Fragment in Sma I geschnittenen pBlueScript II SK (-) Vektor kloniert und sequenziert (3.2.7). Sowohl das $4 \mathrm{~kb}$ - als auch das $10 \mathrm{~kb}$-Fragment wurden als Sonde in Southern-Blots an genomischer DNA (3.2.8) eingesetzt. Die Hybridierungs-Sonden wurden im folgenden mit A09170-SR $4 \mathrm{~kb}$ und A09170-SR $10 \mathrm{~kb}$ bezeichnet.

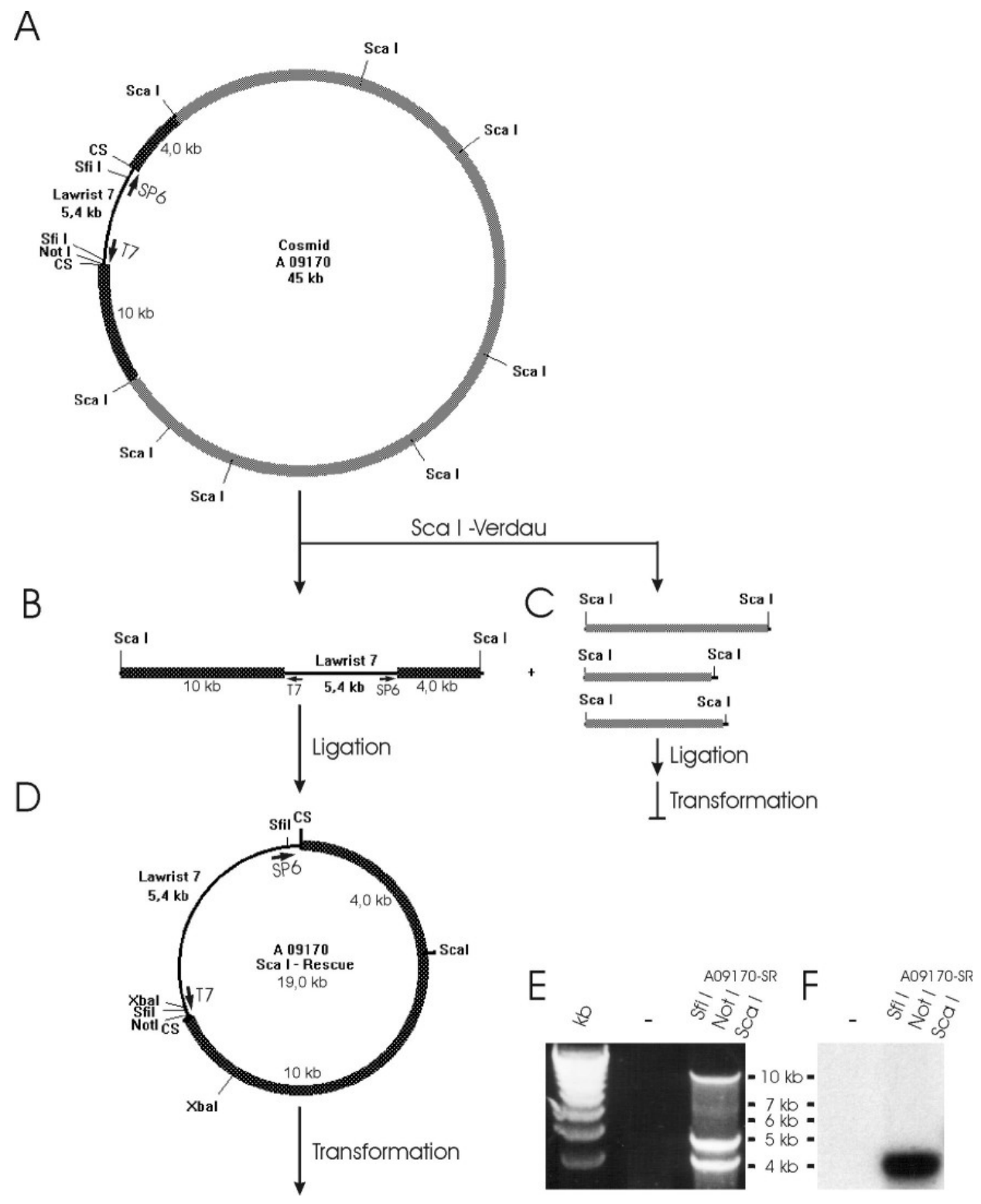

Abb. 3.27 
Abb. 3.27:(S. 111) Schematische Darstellung der „Cosmid-Rescue“ -Strategie (A-D) und Restriktionskartierung des Subklons A09170 Sca I-Rescue (A09170-SR, D, E). In (A) ist die Restriktionskarte des Cosmid-Vektors Lawrist 7 (5,4 kb) gezeigt und das Insert A09170 schematisch mit einer Größe von $40 \mathrm{~kb}$ dargestellt. In das A09170-Insert sind putative Sca I-Schnittstellen eingezeichnet. Der restriktionsenzymatische Verdau mit Sca I liefert die Produkte in (B) und (C), von denen nur das Produkt in (C) nach der Ligation ein transformierbares Plasmid (D) ergab. Die Restriktionskarte in (D) ist für die angegebenen Restriktionsenzyme vollständig. $(C S=$,Cloning Site“, SP6 + T7 = Vektor-Primer $)$. Die endständigen Fragmente in (D) wurden über restriktions-enzymatischen Verdau mit Sfi I / Not I / Sca I (4 kb und $10 \mathrm{~kb}$, E) und Xba I / Not I (1,7 kb) aus dem Klon A09170-SR (D) isoliert und in Southern-Blots verwendet. In $(F)$ ist der Southern-Blot des Gels in (E) mit der Deletions-Sonde DL5-502 gezeigt.

\subsubsection{Sequenzanalyse der Cosmid-Endfragmente}

Zur BLAST-Analyse und zur Generierung von sequenzspezifischen Oligonukleotiden für nachfolgende „Genome-Walking“-Experimente wurde eine Konsensus-Sequenz der neu klonierten Region erstellt. Der Cosmid-Klon A09170 und der Subklon A09170SR $4 \mathrm{~kb}$ wurden mit Vektor-Primern (SP6 und T7) mehrfach von beiden Seiten ansequenziert und der Subklon A09170-SR 4 kb über „Primer-Walking“ durchsequenziert. Die Abb. 3.31 (B) zeigt die Positionen der für die Sequenzierung verwendeten Primer. Aus den erhaltenen Sequenzen wurden mit dem Programm DNASIS ${ }^{\circledR}$ die Konsensus-Sequenz der gesamten Wildtyp-Region und eine Restriktionskarte erzeugt, die schematisch in Abb. 3.31 (C) dargestellt ist. Die Konsensus-Sequenz aus den Sequenzen der Klone A09170-SR 4 kb, DL5-1,2 kb und DL5-2,2 kb hat eine Länge von $6,3 \mathrm{~kb}$. Ein BLAST-Sequenzabgleich dieser Sequenz gegen die Datenbanken des NCBI (www.ncbi.nlm.nih.gov/BLAST/) lokalisierte drei Bereiche hoher Homologie mit einem genomischen PAC-Contig HS 134N8 (Abb. 3.28 und Abb. 3.31, D) auf dem humanen Chromosom 20p12, der syntenen chromosomalen Region zu Maus Chromosom 2 F3-G. Mit Hilfe des „AceBrowser“ (www.sanger.ac.uk/HGP/Chr20/) und den genomischen Datenbanken des Sanger-Zentrums konnte für das humane Chromosom 20 ein Contig humaner genomischer Klone erstellt werden, der partiell in der Abb. 3.28 dargestellt ist. In diesen Klonen wurde vom Sanger-Zentrum das Gen für die humane Phospholipase C beta 1 (PLC-B1) annotiert. Die Transgen-Insertion und die genomische Deletion im Genom der TC-Maus ist über die detektierte SequenzHomologie putativ im Intron 8 des Gens für PLC-ß1 lokalisiert.

Die cDNA-Sequenzinformationen für das PLC-ß1-Gen beim Menschen (Genbank Nr. AJ278314, $3781 \mathrm{bp}$ ) und bei der Maus (Genbank Nr. U85713, $3915 \mathrm{bp}$ ) sind unvollständig, umfassen aber den gesamten Protein-kodierenden Bereich von 3519 bp (1173 Aminosäuren), und zwar beginnend kurz vor dem Startkodon (ATG). Für das PLC-ß1-Gen der Ratte wurden zwei alternativ gespleißte Transkripte von 5,4 kb (Suh et al. 1988b) und 7,2 kb (Bahk et al. 1994) beschrieben und deren cDNA vollständig 
kloniert (PLC-ß1a: Genbank Nr. M20636, 5,2 kb und PLC-ß1b: Genbank Nr. L14323, 7,2 kb). Der „Open Reading Frame“ (ORF) des 7,2 kb-Transkripts kodiert für ein 140 kDa-Protein mit 1173 Aminosäuren. Die Translation des 5,4 kb-Transkripts führt zu einem am C-Terminus um 43 Aminosäuren verlängerten Protein (1216 aa, 150 kDa, siehe auch Abb. 4.2 auf S. 135). Die Exon-Intron-Struktur des humanen PLC-ß1-Gens wurde in der 5'- und 3'-UTR über einen BLAST-Sequenzabgleich der PLC-ß1b-cDNA der Ratte $(7,2 \mathrm{~kb})$ gegen die humanen genomischen Sequenzdatenbanken ermittelt. Das PLC-ß1b-Transkript der Ratte besitzt eine 468 bp lange 5'-UTR, einen offenen Leserahmen von 3519 bp bis zum Stopp-Kodon an Position 3987 der cDNA und eine 3'-UTR mit einer Länge von ca. 3,2 kb. Die Sequenzhomologie zwischen der RattencDNA und der bekannten cDNA-Sequenz des humanen PLC-B1-Gens liegt auf Nukleinsäure-Ebene innerhalb der kodierenden Region bei $89 \%$ und auf AminosäureEbene bei 98 \%. Die Sequenzhomologie zwischen der Ratten- und Maus-cDNA beträgt ebenfalls $89 \%$ auf Nukleinsäure- und $97 \%$ auf Aminosäure-Ebene. 


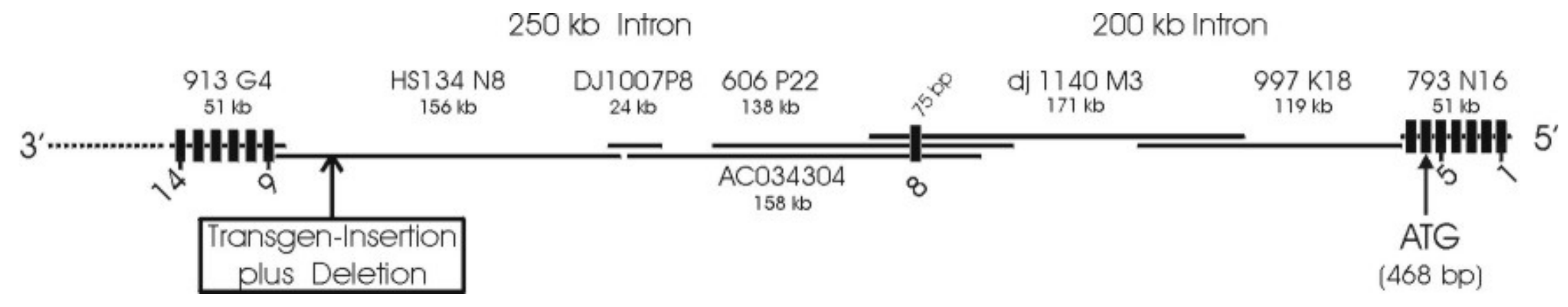

Abb. 3.28:Schematische Darstellung des partiellen DNA-Contigs auf dem humanen Chromosom 20p12. Die Bezeichnungen sowie die Sequenzlängen der überlappenden genomischen Klone sind angegeben. Im 3'-Bereich ist der DNA-Contig unterbrochen dargestellt (----). Die Exone des Gens für die humane Phopholipase C- $\beta 1$ sind als schwarze Boxen dargestellt und in 5'-3'-Richtung durchnummeriert. Die Position des Startkodons (ATG) ist in Exon 6 an Position 468 bp der cDNA-Sequenz eingezeichnnet. Die putative Position der Transgen-Insertion und der Deletion im Genom der TC-Maus ist schematisch im 250 kb großen Intron 8 des humanen Gens für die Phospholipase C beta 1 (PLC-ß1) dargestellt. 


\subsubsection{Southern-Blot Analyse der Cosmid-Region}

Die in Kapitel 3.2.6 durchgeführten Analysen und die durch Restriktionskartierung identifizierte Sca I -Schnittstelle in der Deletion (Abb. 3.22, B) haben gezeigt, dass das 4,0 kb-Endfragment (A09170-SR $4 \mathrm{~kb}$ ) komplett in der deletierten Region liegt und über den bereits klonierten Bereich in 5'-Richtung hinausgeht. Mit dieser erweiterten Deletions-Sonde A09170-SR $4 \mathrm{~kb}$ wurde ein Southern-Blot an restringierter genomischer DNA aller drei Genotypen (+/+, +/- und -/-) durchgeführt und das Ausmaß der Deletion bestimmt. Die Abb. 3.29 (A) zeigt das Hybridisierungsergebnis. Die Sonde A09170-SR $4 \mathrm{~kb}$ detektiert in der Wildtyp- (+/+) und heterozygoten (+/-) Situation bei allen Restriktionen die Fragmente der entsprechenden Hybridisierung mit der Deletions-Sonde DL5-502 (Abb. 3.24). Dieses Fragment ist in der homozygoten (-/-) Situation deletiert. Dort detektiert die Sonde weitere Fragmente, was zeigt, das die Deletion in dieser Region nicht sehr groß ist und von dieser Sonde überspannt wird. Zum Teil detektiert die $4 \mathrm{~kb}$-Sonde neben dem mutierten Fragment auch ein weiteres Wildtyp-Fragment (Hind III / 4,2 kb und Xba I/ $6 \mathrm{~kb}$ ), das in allen drei Genotypen detektierbar ist (Abb. 3.29, A). Die Hybridisierung mit der Sonde A09170-SR $10 \mathrm{~kb}$ zeigt bei allen drei Genotypen ein unverändertes Hybridisierungsmuster (Abb. 3.29, B) und belegt, dass die Region ca. $30 \mathrm{~kb}$ entfernt von der detektierten Insertion genomisch nicht verändert ist. Mit einer Teilsonde aus A09170-SR 4 kb, die mittels PCR generiert wurde (A09170-SR 394) und der Region mit $87 \%$ Homologie zwischen Mensch und Maus entspricht (Abb. 3.31, D und E), konnte das Hybridisierungsmuster in Abb. 3.29 (A) reproduziert werden (Abb. 3.29, C). 

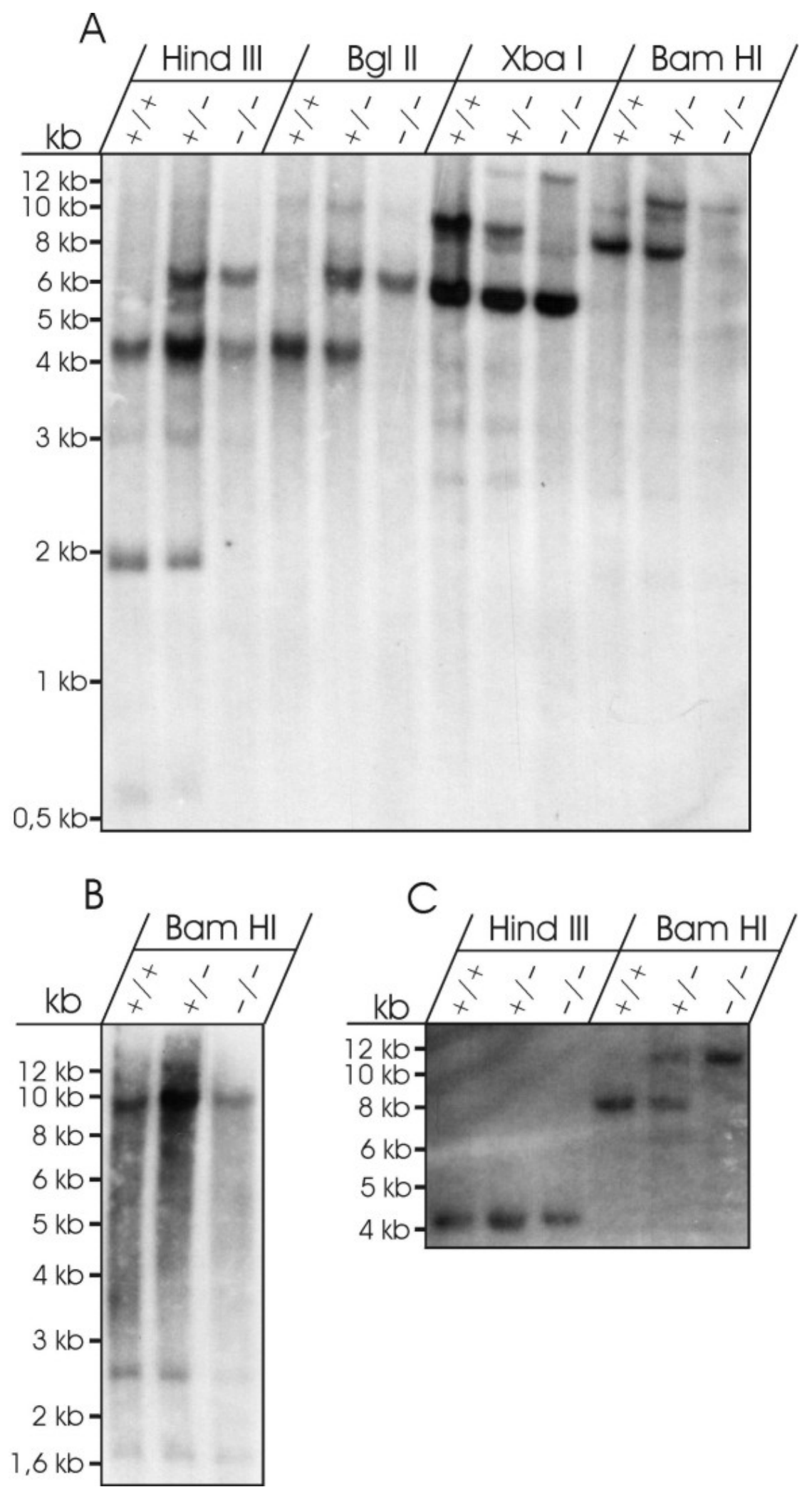

Abb. 3.29: Genomischer Southern-Blot an DNA von Wildtyp (+/+), heterozygoten (+/-) und homozygoten (-/-) TC-Mäusen mit den genomischen Sonden A09170-SR-4 kb (A), A09170-SR-10 kb (B) und A09170-SR-394 bp (C). Die genomische DNA wurde mit den Restriktionsenzymen Hind III, Bgl II, Xba I und Bam HI restringiert ( $k b=k b$-Leiter, +/+ = Wildtyp, +/- = heterozygot, -/- = homozygot) 


\subsubsection{Genomische Klonierung des flankierenden 5'-Bereichs der TC- Insertionsregion über „Genome Walking“-Experiment}

Zur exakten Eingrenzung der Deletion und zur Klärung der Frage, ob die zwischen Mensch und Maus genomisch konservierten Regionen innerhalb dieser Deletion liegen und ihnen eine Bedeutung zukommt, wurde ein weiteres „Genome-Walking“ Experiment an genomischen Adaptor-ligierten DNA-Pools einer homozygoten TCMaus (DL1-DL5) durchgeführt. Die mit der hier verwendeten Primerkombination $\mathrm{A} 09170_{\text {for3 }} / \mathrm{AP}_{\mathrm{GW} 1}$ und $\mathrm{A} 09170_{\text {for } 4} / \mathrm{AP}_{\mathrm{GW} 2}$ (Abb. 3.31, B) erzeugten Amplifikate besitzen eine Größe von 2,0 kb (DL2) und 2,5 kb (DL5) (Abb. 3.30). Die Produkte wurden isoliert, in $p G E M-T$-Vektor kloniert und über Sequenzierung identifiziert. Der Klon DL2-2,0 kb wurde mit $p G E M-T$-Vektor-Primern (SP6 und T7) und mit Hilfe genspezifischer Oligonukleotide sequenziert. In diesem Klon konnte ein transgenes Fragment von 384 bp aus der 5'-flankierenden Region des Tyrosinase-Markergens TYR-SV40 (Abb. 3.31 A, Abb. 1.1 B) identifiziert werden, gefolgt von 1,6 kb Wildtypgenomischer Sequenz. Durch Sequenzvergleich dieser Region mit der KonsensusSequenz der Wildtyp-Sequenz (Abb. 3.31, C) konnte der Bereich der Deletion auf 809 bp eingegrenzt werden (Abb. 3.31).

\begin{tabular}{|c|c|c|c|}
\hline & Enzym & Fragmentgröße & A09170 for4 \\
\hline DL1 & EcoRV & - & 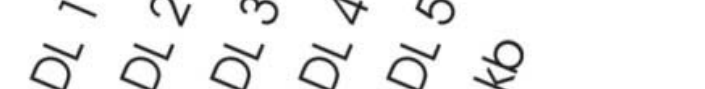 \\
\hline DL2 & Sca I & $2,0 \mathrm{~kb}$ & 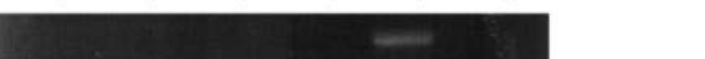 \\
\hline DL3 & Dra I & - & $-2,0 \mathrm{~kb}$ \\
\hline DL4 & Pvu II & - & \\
\hline DL5 & Ssp I & $2,5 \mathrm{~kb}$ & \\
\hline
\end{tabular}

Abb. 3.30:Rechts: Ethidiumbromid gefärbtes 1,2\% Agarosegel der Amplifikate nach der zweiten „,nested"- durchgeführten PCR-Reaktion mit den Primerkombinationen $A 09170_{\text {for } 3} / A P_{G W 1}$ und A09170 for $4_{4} / A P_{G W 2}$ an Adaptor-ligierten DNA-Pools einer homozygoten TC-Maus. Die DNA-Pools DL1-DL5 wurden mit ,, blunt end"- Enzymen generiert und anschließend Adaptorligiert. Die Tabelle links listet die zur Generierung der DNA-Pools verwendeten ,,blunt end“Enzyme und die entsprechenden Fragmentlängen der Amplifikate auf. Neg. = Negativkontrolle, $k b=$ Längenstandard (1 kb DNA-Leiter, Gibco BRL). 


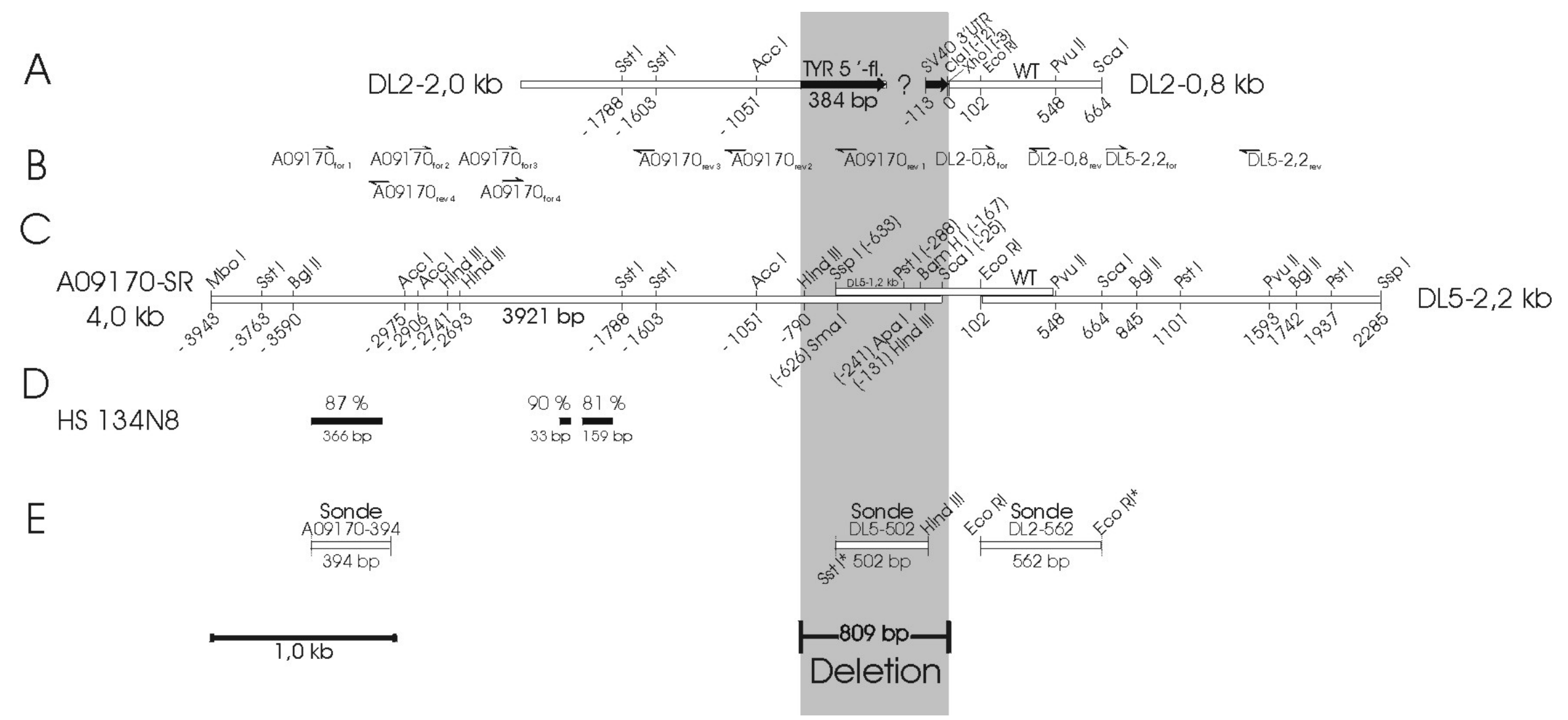

Abb. 3.31:Schematische Darstellung der Restriktionskarte der zur TC-Insertionsregion flankierenden Klone DL2-2,0 kb und DL2-0,8 kb (A) und der Klone A09170-SR 4,0 kb, DL5-1,2 kb und DL5-2,2 kb der entsprechenden Wildtyp-genomischen Region (C). In (A) sind zusätzlich die der Insertion endständigen transgenen Regionen (TYR-5'-fl. und SV40-3' UTR) dargestellt. Die Restriktionskarte ist für die angegebenen Restriktionsenzyme vollständig. Die durch Sequenzvergleich eingegrenzte Deletion von 809 bp ist schattiert unterlegt. In (B) sind die Positionen der verwendeten Primer und in (E) die verwendeten Sonden eingezeichnet. Die Sequenz-Homologie zu dem humanen PAC-Contig HS 134N8 ist schematisch in (D) dargestellt. Die Nukleotid-Positionen der Restriktionsenzyme sind numerisch bezüglich der Insertionsstelle (0) angeben. Mit* markierte Restriktionsenzyme stellen Vektorschnittstellen dar. 


\subsection{Identifizierung, Expressionsanalyse und Klonierung eines SV40-3'UTR Fusionstranskripts}

\subsubsection{Identifizierung und Expressionsanalyse eines Fusionstranskripts mit partieller SV40-3'UTR-Sonde}

Bei der genomischen Integration von Transgenen mit potentieller Spleißdonor- und Akzeptorsequenz können sowohl bei exonischer als auch bei intronischer Insertion Mutationen in Genen erzeugt werden. Diesen Sachverhalt macht man sich bei der Erzeugung von transgenen und mutanten Mäusen mit sogenannten „Gene-Trap“- Vektoren zunutze. Durch die in das Intron integrierte Spleißstelle kommt es nach der Transkription des Gens unter der Kontrolle eines endogenen Promotors und durch den zelleigenen Spleißmechanismus zur Fusion der exonischen Anteile der Vektorsequenz mit abwärts oder aufwärts gelegener exonischer Sequenz des ,getrappten“ Gens. Das auf diese Weise generierte Fusionstranskript lässt sich mit einer geeigneten Sonde aus der Vektorsequenz in einem Northern-Blot detektieren und meist mit der RACE-PCR amplifizieren und klonieren.

Die Konstrukte, die zur Erzeugung der TC-Maus verwendet wurden, besitzen jeweils eine Spleißdonor- und eine Spleißakzeptorstelle flankierend $\mathrm{zu}$ dem $66 \mathrm{bp}$ großen Intron in der SV40-3'UTR (Abb. 1.1 A, B und Abb. 3.33, A) und das TYR-SV40-Kontrukt zusätzlich je eine Stelle flankierend zum Intron A (Abb. 1.1 B). Aus diesem Grund wurde in NorthernBlots an Gesamt-RNA aus dem Gehirn einer Wildtyp- (+/+) und einer homozygoten (-/-) TCMaus auch hier die mögliche Existenz eines Fusionstranskriptes analysiert. Die Abb. 3.32 (A) zeigt, dass mit der ACR-CAT-SV40-DNA als Sonde in Gesamt-RNA aus dem Gehirn einer sechs Monate alten homozygoten TC-Maus ein 1,7 kb großes Transkript detektierbar ist, dass sich in RNA einer Wildtyp-Maus nicht nachweisen lässt. Das aberrante Transkript lässt sich nur mit der partiellen SV40-3'UTR -Teilsonde reproduzieren (Abb. 3.32, D) und nicht mit der partiellen ACR-(B), CAT-(C) oder einer partiellen Tyrosinase-Sonde (E). Die Expressionsanalyse mit der SV40-3'UTR -Teilsonde ergab eine starke Expression des Fusiontranskriptes im gesamten Gehirn, und zwar sowohl im Groß- als auch im Kleinhirn, aber auch in der Milz, der Niere und im Skelettmuskel (Abb. 3.32, F). Durch weitere Hybridisierungen mit der Teilsonde konnte gezeigt werden, dass das 1,7 kb große Transkript auch im Gehirn der heterozygoten TC-Maus (+/-), und zwar mit halber Intensität, nachweisbar exprimiert wird (Abb. 3.32, G), und dass das Fusionstranskript in der Poly $\mathrm{A}^{+}$RNA -Fraktion angereichert ist (Abb. 3.32, H ) und polyadenyliert wird. Daher wurde die Erststrang-cDNA-Synthese für die RACE-PCR mit einem oligo-dT Adaptorprimer (CDSPrimer, Abb. 3.33) durchgeführt. 

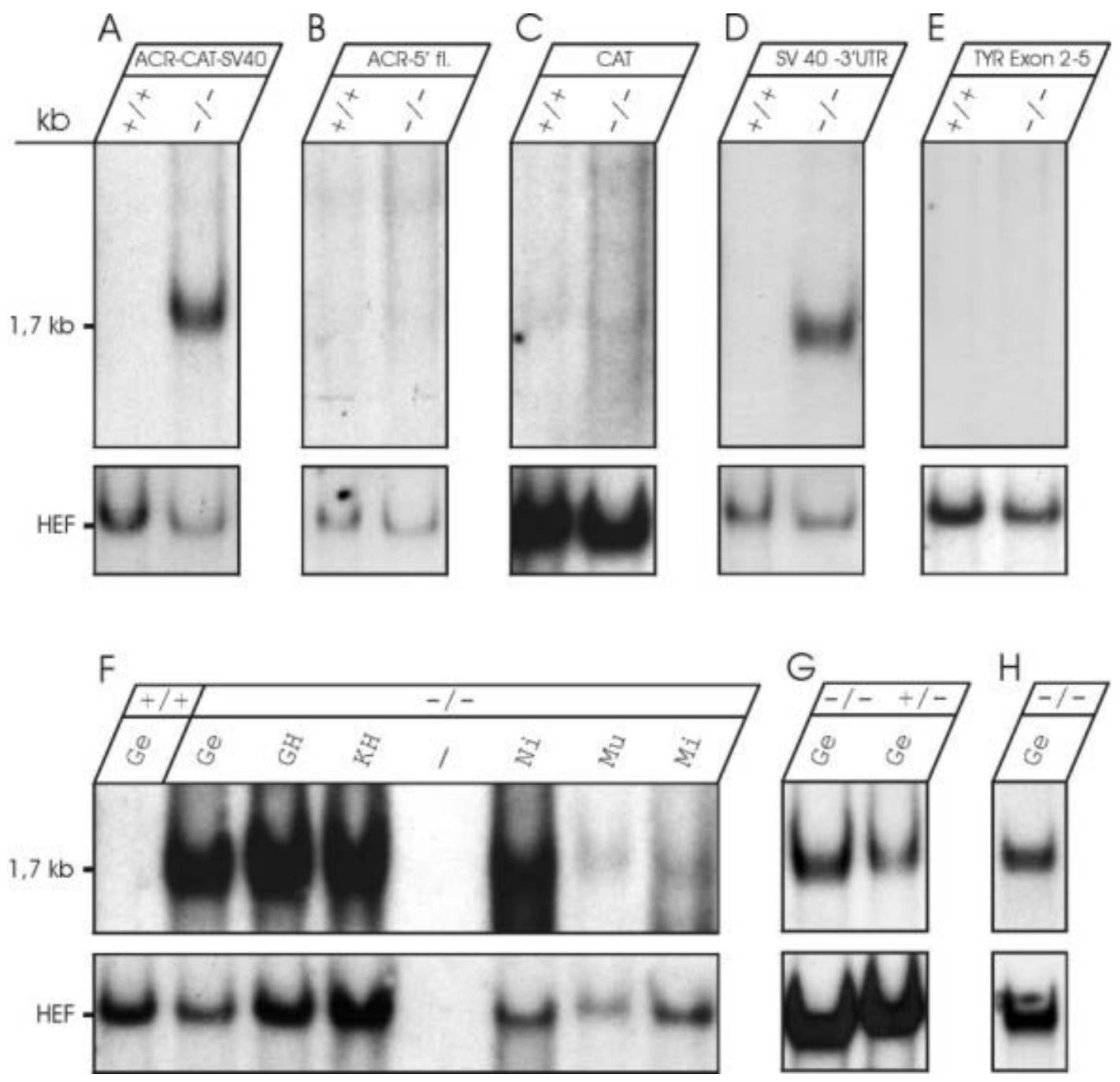

Abb. 3.32:Northern-Blot mit ACR-CAT-SV40-Konstrukt-DNA (A) und Teilsonden ACR-5' fl. (B), CAT (C) und SV40-3'UTR (D) aus diesem Konstrukt an $30 \mu \mathrm{g}$ Gesamt-RNA aus dem Gehirn einer sechs Monate alten Wildtyp-(+/+) und homozygoten (-/-) TC-Maus. In (E) ist die äquivalente Hybridisierung mit einer cDNA-Sonde aus dem Konstrukt TYR-SV40 (Exon 2-5) dargestellt. In (F) ist eine NorthernHybridisierung an $30 \mu \mathrm{g}$ Gesamt-RNA aus Geweben einer homozygoten (-/-) TC-Maus gezeigt. In (G) ist das 1,7 kb Transkript auch im Gehirn der heterozygoten TC-Maus (+/-) detektiert und Abb. (H) zeigt, dass das 1,7 kb große Transkript in $2 \mu \mathrm{g}$ Poly $A^{+}-R N A$ angereichert ist. Die Abb. (F) bis $(H)$ wurden mit der Teilsonde SV40-3'UTR hybridisiert. (Ge=Gehirn, GH=Großhirn, KH=Kleinhirn, $\mathrm{Ni}=$ Niere, $M u=$ Muskel, $M i=$ Milz, HEF=Humaner Elongationsfaktor). 


\subsubsection{RACE-PCR-Analyse des SV40-3'UTR-Fusionstranskripts}

Das $1,7 \mathrm{~kb}$ große Fusionstranskript mit putativem Anteil an cDNA-Information des inserierten und mutierten Gens wurde mit der RACE-PCR-Methode analysiert. Die Entstehung des Fusionstranskripts nach intronischer Insertion der SV40-3' UTR-DNA ist hypothetisch in der Abb. 3.33 (A, B) dargestellt. Die putativ in dem Transkript enthaltene unbekannte cDNA-Information wurde auf 800 bp abgeschätzt. Die Erststrangsynthese wurde mit einem modifizierten oligo-dT Adaptorprimer (CDS-Primer, Abb. 3.33, B) durchgeführt und die cDNA nach der Zweitstrangsynthese an beiden Enden Adaptor-ligiert, so dass sowohl 5'- als auch 3'-RACE an der cDNA durchgeführt werden konnte. Mit der Primerkombination $\mathrm{SV}_{40}$ for 1 und $\mathrm{SV} 40_{\text {for } 1 \mathrm{~N}}$ und dem entsprechenden Adaptorprimer konnte ein 550 bp großes PCR-Produkt amplifiziert, kloniert und sequenziert werden (Abb. 3.33, C), das im SouthernBlot mit der SV40-3'UTR-Sonde hybridisierte (Abb. 3.33, D). Die 5'-RACE-PCR mit der Primerkombination SV40 $0_{\text {rev } 1}$ und SV40 $0_{\text {rev } 1 \mathrm{~N}}$ mit dem entsprechenden Adaptorprimer verlief erfolglos (Abb. 3.33, C). Mit diesem Experiment konnten dennoch die FusionstranskriptHypothese bestätigt und der 3'-Anteil kloniert werden. 


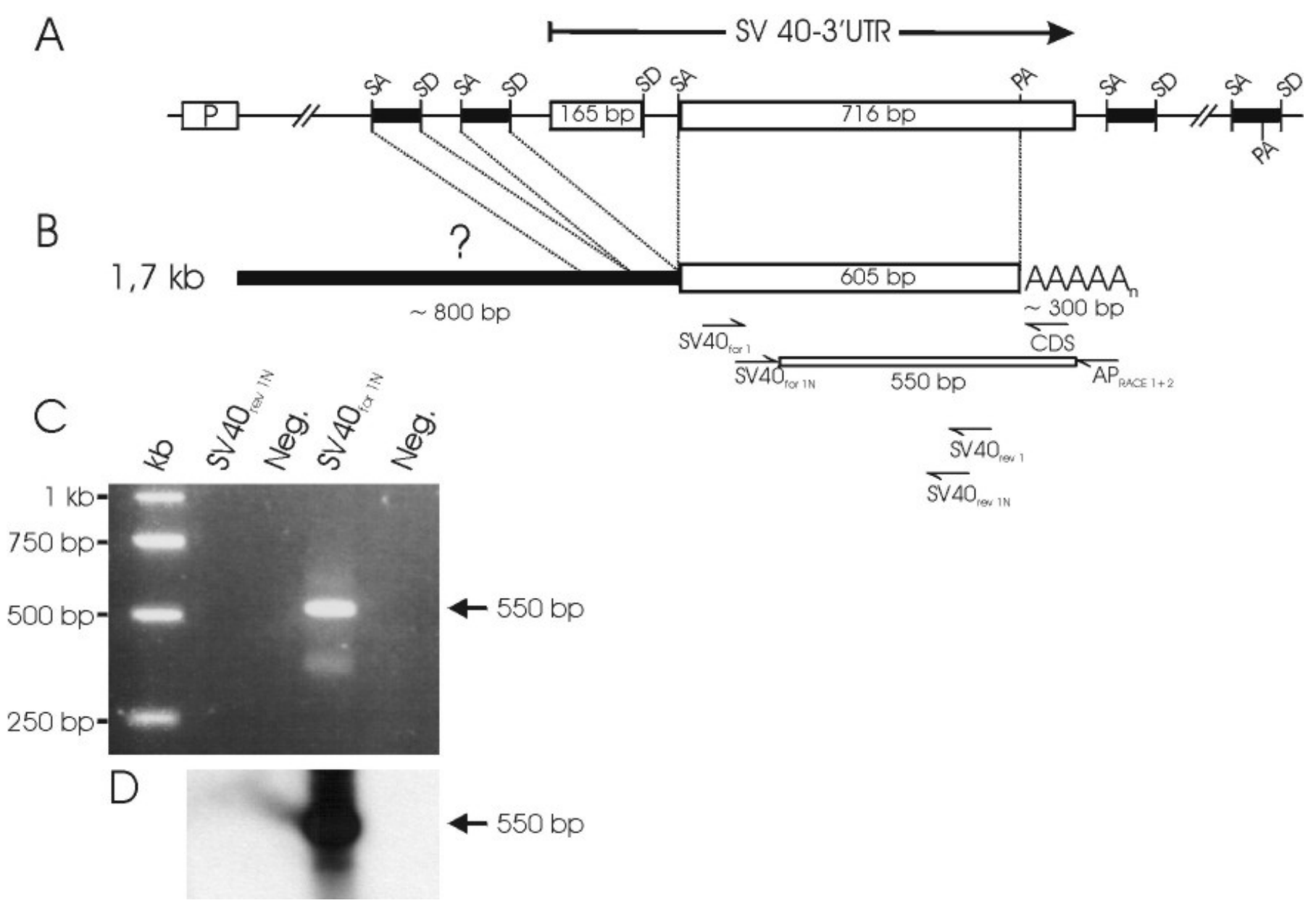

Abb. 3.33: Schematische Darstellung der Hypothese zur ,in vivo “ Generierung des Fusionstranskripts nach intronischer Insertion der SV40-3” UTR-DNA unter der Kontrolle des endogenen Promotors $P(A)$. In (B) ist die hypothetische Struktur des Transkripts mit 605 bp SV40-3'UTR -Sequenz, ca. 300 bp polyadenylierter Region und 800 bp putativ unbekannter mRNA-Information im 5'-Bereich dargestellt. Die Lage der in der 3'- und 5'-RACE-PCR verwendeten Oligonukleotide ist schematisch in (B) eingezeichnet. Die Abbildung in (C) zeigt ein Ethidiumbromid gefärbtes 1,2\% Agarosegel nach gelelektrophoretischer Auftrennung der RACE-PCR -Produkte, das in (D) mit der SV40-3' UTR -Sonde hybridisiert wurde ( $P=$ Promotor, SD=Spleiß-Donor-, SA=Spleiß-Akzeptor, PA=Poly-Adenylierungssignal, $k b=k b$-Leiter, $C D S=$ oligo-dT Adaptorprimer $)$. 


\subsubsection{RT-PCR Analyse des SV40-3'UTR-Fusionstranskripts}

Mit den im Abschnitt 3.2 durchgeführten Experimenten zur Genotypisierung und der in dem Kapitel 3.2.7 beschriebenen Lokalisierung der transgenen Insertion im Intron 8 des Gens für die Phospholipase C beta 1 (Abb. 3.28) ergab sich die Möglichkeit, das Fusionstranskript in 5'-Richtung ausgehend von der SV40-3' UTR Region über eine RT-PCR mit PLC-ß1 genspezifischen Primern zu analysieren. Die Strategie für dieses Experiment ist in der Abb. 3.34 dargestellt. Die cDNA-Informationen für das PLC-ß1b-Transkript der Ratte (7204 bp, Genbank Nr. L14323, Abb. 3.34, A) sind vollständig und erlauben die Identifikation einer 467 bp langen 5'-UTR, einem offenen Leserahmen von 3519 bp (1173 Aminosäuren) und einer 3'-UTR von ungefähr 3,2 kb. Für das PLC-ß1-Transkript der Maus sind 3915 bp Sequenzinformationen (Genbank Nr. U85713), beginnend bei Nukleotidposition 465 kurz vor dem ATG der Ratten cDNA, bekannt. Ein 540 bp großer IMAGE-cDNA-Klon (Genbank Nr. AA509975) zeigt eine $91 \%$ Homologie zu der Ratten-cDNA beginnend an Position 147 und repräsentiert daher einen großen Teil der 5'-UTR der Maus. Ausgehend von dieser cDNAInformation der Maus wurden die sequenzspezifischen Oligonukleotide PLC PL7 $_{14}$ PLC $_{177}$, $\mathrm{PLC}_{1281 \mathrm{rev}}, \mathrm{PLC}_{1245 \text { rev }}$ und $\mathrm{PLC}_{712 \text { rev }}$ generiert (Abb. 3.34, A, B) und $\mathrm{PLC}_{147}$ und PLC 177 zusammen mit den Oligonukleotiden SV40 rev $1 \mathrm{~N}$ und SV40 LTR 1 an SV40 rev 1 ,geprimter“ cDNA aus hippocampaler Gesamt-RNA einer homozygoten TC-Maus in einer RT-PCR eingesetzt. Die Gelelektrophorese der Reaktionsansätze in Abb. 3.34 (D) identifiziert ein $412 \mathrm{bp}$ und ein $460 \mathrm{bp}$ großes PCR-Produkt, die beide mit einer SV40-3'UTR Sonde hybridisieren (E). Die Sequenzierung der PCR-Amplifikate identifizierte das hypothetische Fusionstranskript, bestehend aus 117 bp SV40-3' UTR -Sequenz bis zur SpleißAkzeptorstelle und 343 bp bzw. 295 bp PLC-ß1-cDNA Sequenz der Maus ab Exon 8 (Abb. 3.34 , C). Zusätzlich wurden alternative Spleiß-Produkte identifiziert, die ebenfalls schematisch in der Teilabbildung (C) dargestellt sind. Das 342 bp lange PCR-Produkt, das ausschließlich den PLC-ß1-Anteil des Fusionstranskripts repräsentiert (Abb. 3.34, C), wurde über RT-PCR mit der Primerkombination $\mathrm{PLC}_{177} / \mathrm{PLC}_{712 \text { rev }}$ isoliert, subkloniert und sequenziert und als Sonde in einem Northern-Blot an Gesamt-RNA aus Gehirn einer Wildtyp, heterozygoten und einer homozygoten TC-Maus eingesetzt. Mit dieser Sonde konnte sowohl in der Wildtyp- als auch in der heterozygoten Maus ein 7,2 kb großes PLC-ß1b -Transkript und schwach ein 5,4 kb großes PLC-ß1a -Transkript detektiert werden (Abb. 3.35, A). Bei der heterozygoten und bei der homozygoten Maus konnte mit dieser Teilsonde ein 1,7 kb Transkript detektiert werden, das dem Fusionstranskript mit SV40-3' UTR -Anteil analog ist (Abb. 3.32). Dieses Ergebnis wurde über RT-PCR an $\mathrm{PLC}_{1281 \mathrm{rev}}$ und $\mathrm{SV} 40_{\text {rev } 1}$ doppelt „geprimter“ hippocampaler Gesamt-RNA einer Wildtyp-, homozygoten und heterozygoten TC-Maus mit der Primer-Kombination $\mathrm{PLC}_{177}, \mathrm{PLC}_{1245 \text { rev }}$ und SV40 $\mathrm{STR}_{1}$ reproduziert (Abb. 3.35, B), und auch in dieser PCR konnte ein 827 bp großes alternativ „gespleißtes“ WildtypTranskript identifiziert werden (Abb. 3.34 A). 
A

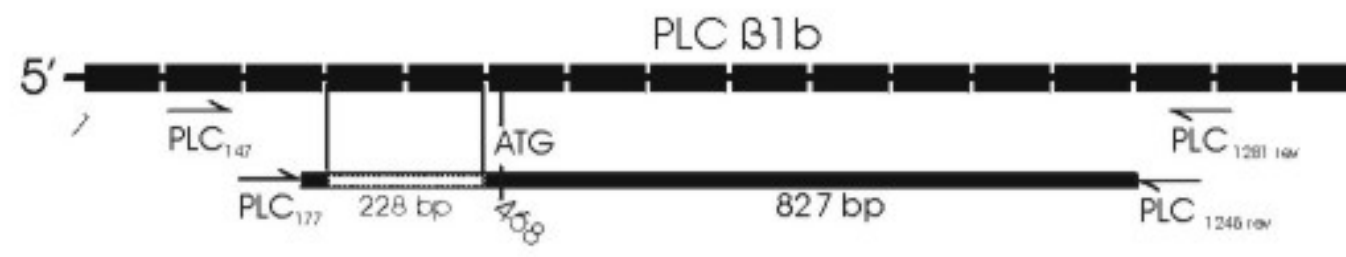

B
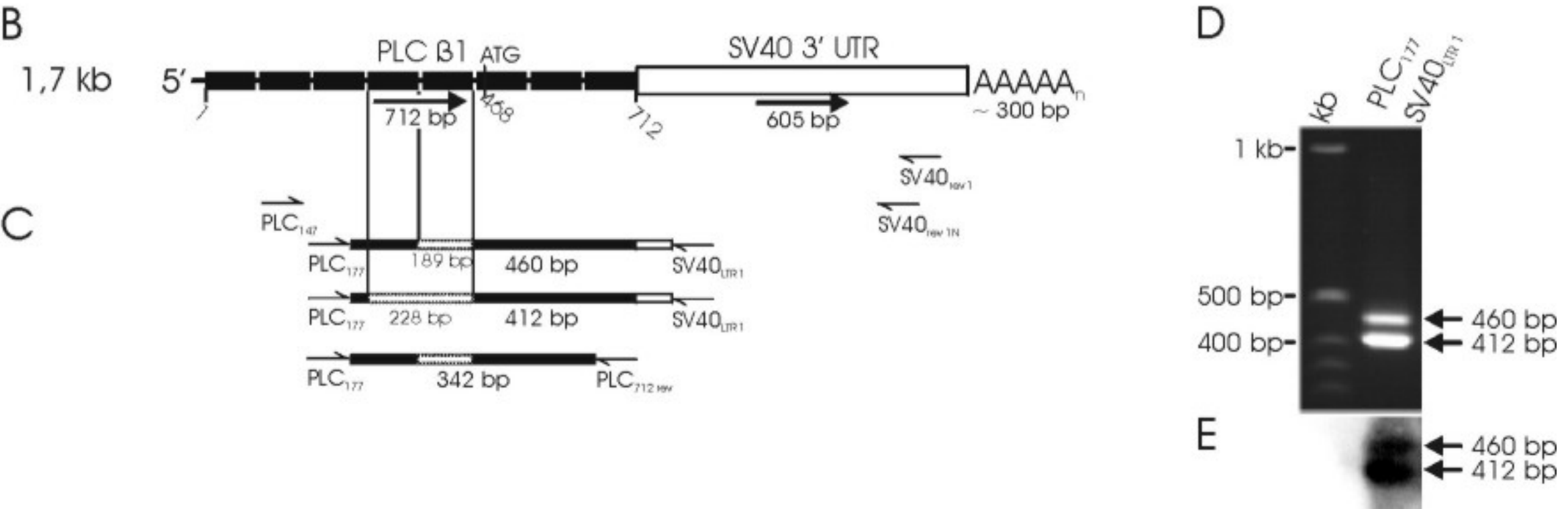

Abb. 3.34:Strategie zur RT-PCR Analyse des SV40-3'UTR-Fusionstranskripts in 5'-Richtung ausgehend von der SV40-3' UTR Region mit PLC-ß1-genspezifischen Primern (A, B). In (A) sind das gesamte Transkript für die Phospholipase C beta 1 b (PLC-ß1b) der Ratte mit dem Translations-Startkodon (ATG) und dem -Stoppsignal (TGA) und das 827 bp große RT-PCR Produkt schematisch dargestellt. In (B) ist die hypothetische Struktur des Fusionstranskripts mit SV40-3' UTR -Anteil gezeigt. Die schwarz gezeichneten Boxen repräsentieren einzelne Exons und sind der genomischen Organisation aus Abb. 3.28. analog. In (C) ist die Struktur der RT-PCRProdukte der Gelelektrophorese in (D) gezeigt. Hell gezeichnete Boxen entsprechen der SV40-3' UTR -Region und gestrichelt gezeichnete Boxen repräsentieren alternativ ,,gespleißte“ Exons. Die Abb. (E) zeigt die Hybridisierung der Produkte in (D) mit radioaktiv markierter SV40 3'-UTR als Sonde. 

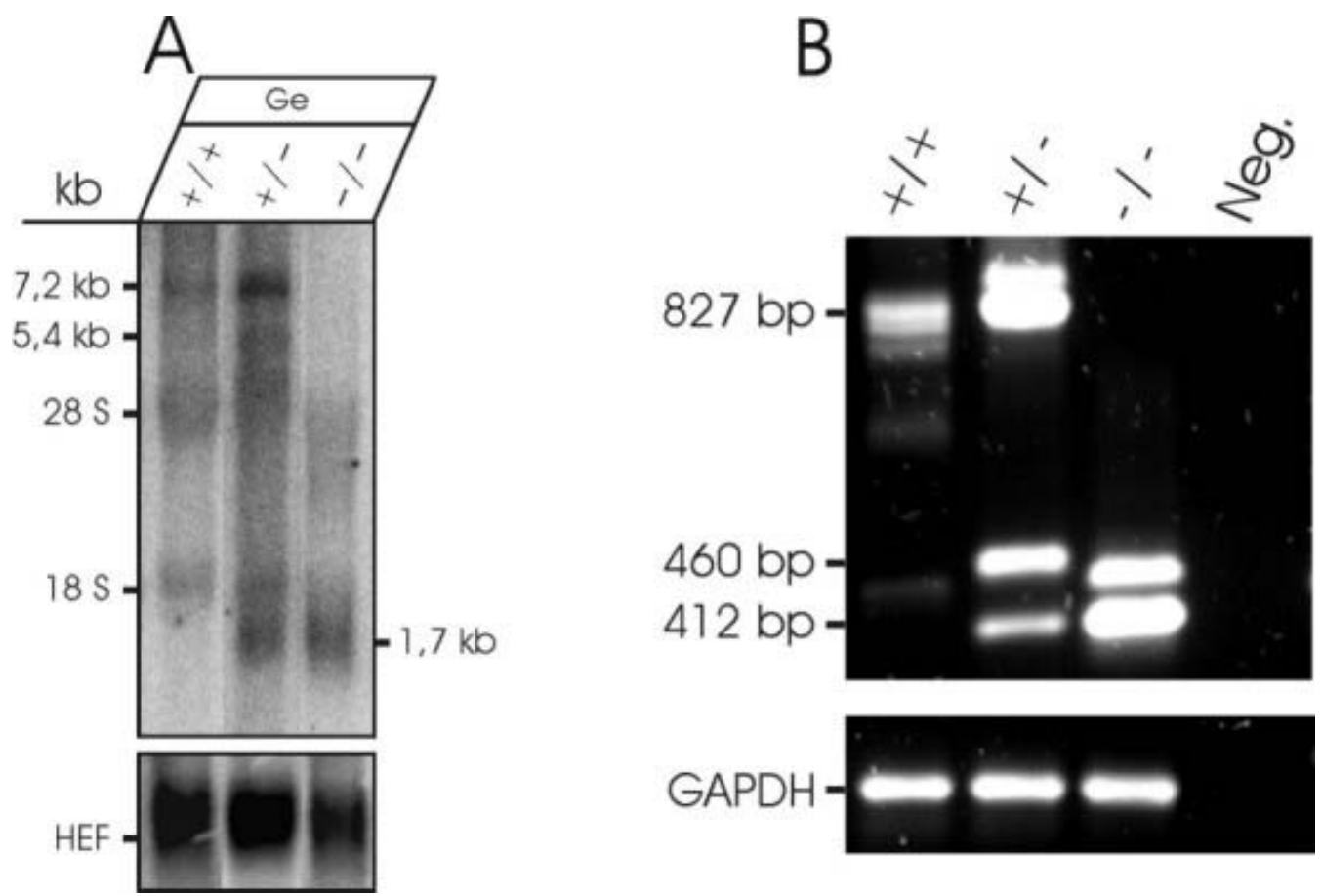

Abb. 3.35:(A) Northern-Blot mit der 342 bp langen Teilsonde aus der Abb. 3.34 (C) an 30 pg GesamtRNA aus dem Gehirn einer Wildtyp- (+/+), heterozygoten (+/-) und homozygoten (-/-) TCMaus. Die Agarose-Gelelektrophorese in (B) identifiziert Wildtyp- und Fusions- RT-PCR Produkte an hippocampaler Gesamt-RNA (Abb. 3.34). (GAPDH=Positiv-Kontrolle).

\subsection{Expressionsanalyse des PLC-ß1 Gens in der TC-Maus}

\subsubsection{Northern-Blot Analyse der PLC-81 Expression in der TC-Maus}

Für die Expressionsanalyse des Phospholipase $C$ beta 1 (PLC- $\beta 1$ ) -Gens und zum Beweis, dass in der homozygoten TC-Maus kein intaktes und funktionelles PLC-ß1Transkript exprimiert ist, wurde ein IMAGE-cDNA Klon (IMAGp998 A151771, RZPD Berlin) aus der 3' UTR des PLC- $\$ 1$ - Gens der Maus (4198-4851 bp) im Northern-Blot an Gesamt-RNA einer Wildtyp- und einer homozygoten TC-Maus eingesetzt. Der Northern-Blot in Abb. 3.36 an $30 \mu$ g intakter Gesamt-RNA (HEF-Hybridisierung) zeigt, dass ein 7,2 kb großes Wildtyp-PLC-ß1b-Transkript stark im Gehirn, und dort explizit im Großhirn, im Kleinhirn und im Hippocampus, aber auch schwach in der Niere exprimiert ist (Abb. 3.36, B). Zusätzlich wird auch hier ein 5,4 kb großes PLC-ß1aTranskript schwach in den erwähnten Organen exprimiert. In Gesamt-RNA aus Testis und der Milz ist in der Wildtyp-Situation kein Transkript detektierbar. In der homozygoten TC-Maus (-/-) ist mit dieser 3'-Sonde in keinem der Gewebe ein PLC-ß1Transkript detektierbar. Im Testis homozygoter TC-Mäuse detektiert diese Sonde 
allerdings reproduzierbar ein Hybridisierungssignal, das mit der ribosomalen $28 \mathrm{~S}$ RNA-Fraktion $(4,4 \mathrm{~kb})$ komigriert, für eine unspezifische Hybridisierung an diese ribosomale RNA aber zu stark ist. Dieses Transkript ist möglicherweise ein weiteres Fusionstranskript, das durch den Akrosin -Promotor des Konstrukts ACR-CAT-SV40 angetrieben wird, und einen Teil der 3'-UTR des PLC-B1-Gens enthält. Dieses Transkript wurde, da es ausschließlich im Testis exprimiert ist und keine Spermatogenese-Defekte nachzuweisen waren, nicht weiter analysiert. Aufgrund des Verlustes an PLC- 31 -Expression in der $\mathrm{TC}^{-/-}$-Maus wurden die Genotypen im folgenden mit PLC$\beta 1_{\mathrm{WT}}^{+/+}\left(\mathrm{WT}^{+/+}\right)$, PLC- $\beta 1_{\mathrm{TC}^{+-}}^{\left.+/ \mathrm{TC}^{+/}\right)}$und PLC- $\beta 1_{\mathrm{TC}^{-/-}}\left(\mathrm{TC}^{-/-}\right)$bezeichnet.
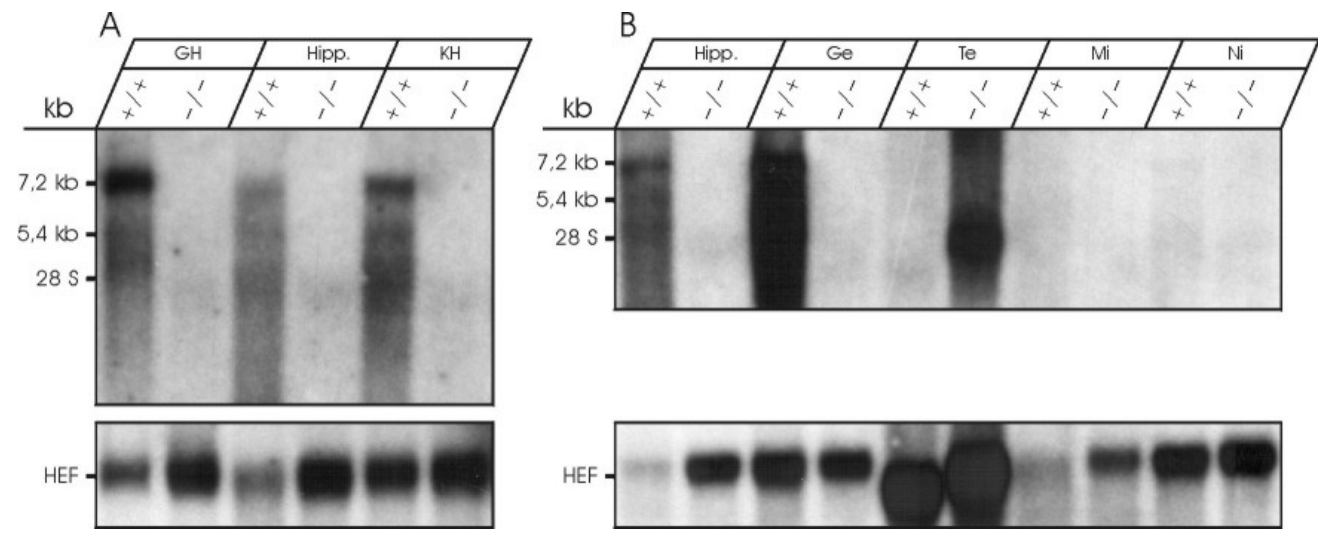

Abb. 3.36:Northern-Blot Analyse von Gesamt-RNA verschiedener Gehirn-Areale (A) und diverser Gewebe (B) einer adulten Wildtyp-(+/+) und homozygoten TC-Maus (-/-). Die Northern-Blots in (A) und (B) wurden mit einer 3'-cDNA-Sonde des PLC-ß1-Gens der Maus (IMAGp998 A151771, RZPD Berlin) hybridisiert und mit der cDNA-Sonde für humanen Elongationsfaktor $(H E F)$ rehybridisiert und die Intaktheit der verwendeten $R N A$ überprüft $(G H=$ Großhirn, Hipp. = Hippocampus, $\mathrm{KH}=$ Kleinhirn, Ge = Gehirn, Te =Testis, $M i=$ Milz, $N i=$ Niere).

\subsubsection{Western-Blot- und immunhistochemische Expressions-Analyse des PLC- B1-Proteins im Hippocampus der TC-Maus und der Wildtyp-Maus}

Ein polyklonaler Antikörper aus Kaninchen, der gegen den Carboxy-terminalen Anteil des PLC $\beta 1$ Proteins der Ratte gerichtet ist (Santa Cruz Biotechnology), wurde in einem Western-Immunoblot an $50 \mu \mathrm{g}$ Protein aus dem Gesamt-Zellysat des Hippocampus einer 12 Monate alten Wildtyp- (PLC- $\beta 1_{\mathrm{WT}}^{+/+}$), heterozygoten $\left(\mathrm{PLC}-\beta 1_{\mathrm{TC}}{ }^{+/-}\right.$) und homozygoten (PLC- $\beta 1_{\mathrm{TC}^{-/}}$) TC-Maus immunhybridisiert (Abb. 3.37 A). Der Antikörper detektiert ein $140 \mathrm{kDa}$ - und schwach ein $150 \mathrm{kDa}$-Protein im Hippocampus-Zellysat der Wildtyp- (PLC- $\beta 1_{\mathrm{WT}}{ }^{+/}$) und der heterozygoten (PLC- $\beta 1_{\mathrm{TC}}{ }^{+/-}$) TC-Maus und zeigt keine unspezifischen Kreuzhybridisierungen mit weiteren Proteinen. In der homozygoten TC-Maus (PLC- $\beta 1_{\mathrm{TC}^{-/}}$) sind beide PLC- 31 -Proteine nicht detektierbar (Abb. 3.37, A). 

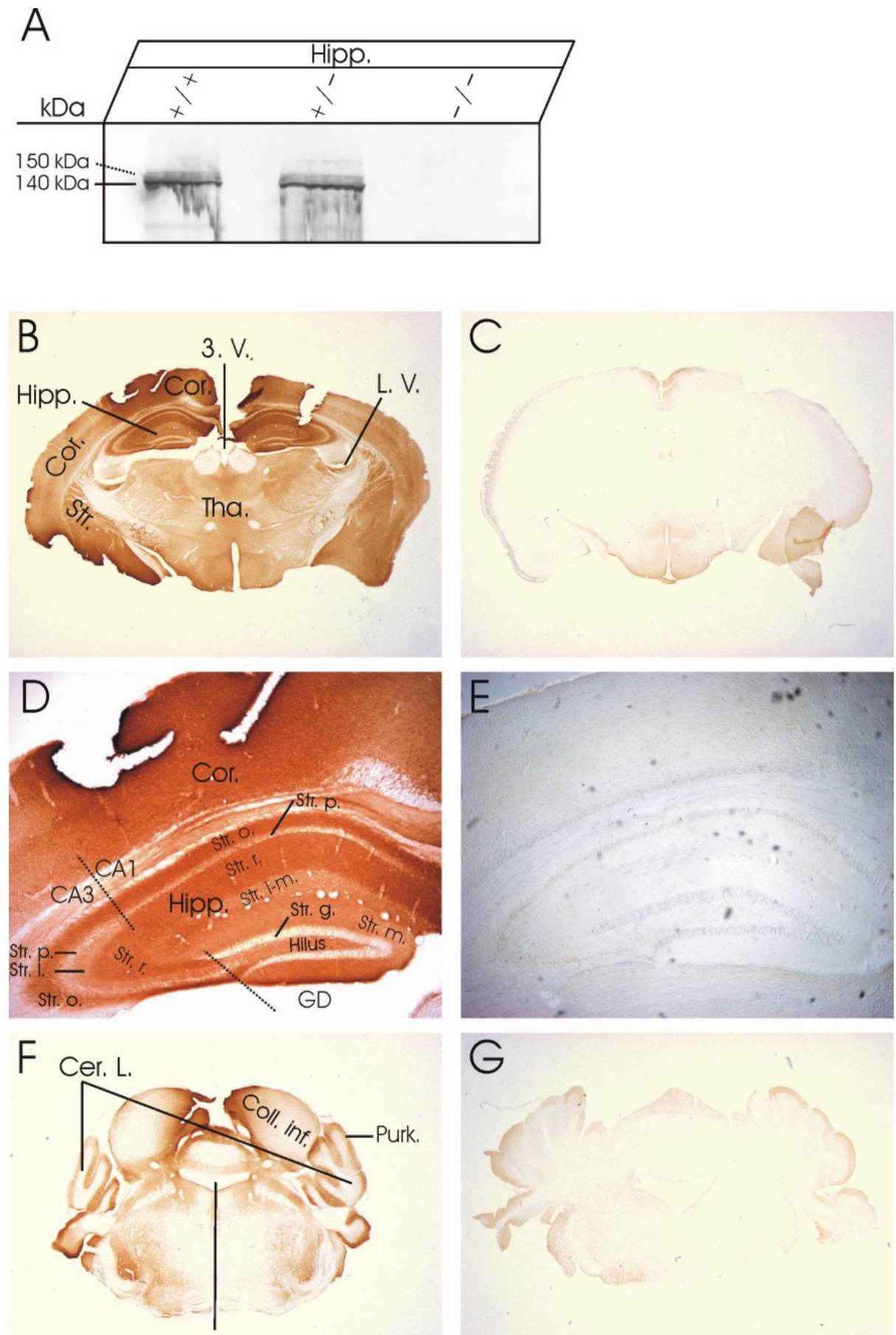

4. V.

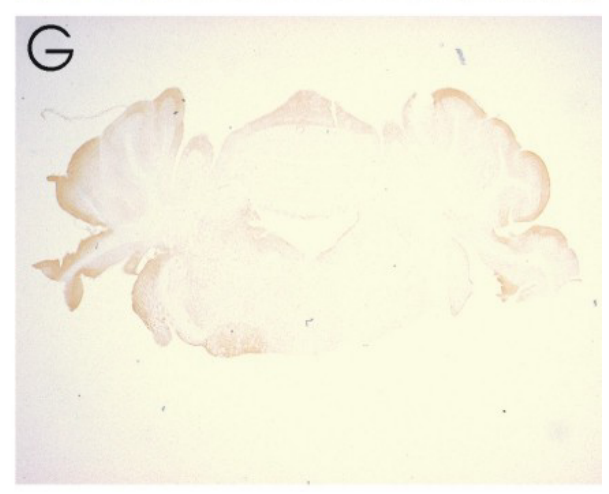

Abb. 3.37:Immunhistologische Analyse mit einem polyklonalen PLC-ß1-Antikörper auf einem WesternBlot mit $50 \mu \mathrm{g}$ Protein aus hippocampalem Zellysat einer 12 Monate alten Wildtyp- (PLC$\beta 1_{W T}^{+++}$), heterozygoten (PLC- $\beta 1_{T C}^{+-}$) und homozygoten (PLC- $\beta 1_{T C}^{-/-}$) TC-Maus (A) und an $40 \mu \mathrm{m}$ Gefrierschnitten des Gehirns einer Wildtyp- $\left(P L C-\beta 1_{T C}^{+/+}, B, D, F\right)$ und einer homozygoten (PLC- $\beta 1_{T C}{ }^{-/}$) TC-Maus $(C, E, G)$. CA1/CA3 = Regionen des Cornu Ammonis, Coll. inf. $=$ Colliculus inferior, Purk.-= Purkinje Zellen, Str.o .= Stratum oriens, Str.r. $=$ Stratum radiatum, Str.p. = Stratum pyramidale, Str.m. = Stratum moleculare, Str.g. = Stratum granulosum, Str. l. = Stratum lucidum, Cer.L = Cerebellare Lobi, Cor. $=$ Cortex, GD $=$ Gyrus dentatus, Hipp. = Hippocampus, Thal. = Thalamus, Str. = Striatum, V. = Ventrikel, L. = Lateral (Vergrößerung D-E: $40 x, B-C, F-G: 8 x$ ). 
In einer Immunhybridisierung an $40 \mu \mathrm{m}$ dicken Gefrierschnitten des Gehirns einer Wildtyp (PLC- $\beta 1_{\mathrm{WT}}^{+/+}$) -Maus konnte die Expression von PLC-ß1-Protein überwiegend im Hippocampus (B, D), sowie zusätzlich stark in einigen corticalen Bereichen (Abb. 3.37, B, D, F), im Striatum (B) und in den Purkinje Zellen des Cerebellums (F), aber auch schwach im Thalamus (B) detektiert werden. In keiner dieser Regionen ist an äquivalenten Gefrierschnitten einer homozygoten TC-Maus (PLC- $\beta 1_{\mathrm{TC}}{ }^{-/}$) eine Immunhybridisierung nachzuweisen (C, E, G). Da das PLC-ß1-Protein besonders prominent im Hippocampus der Maus exprimiert wird, wurde die hippocampale Region ausschnittsvergrößert (Abb. 3.37, D) und die Expression regional analysiert. Es zeigt sich, dass das PLC-ß1-Protein in den Regionen Stratum oriens (Str.o.) und Stratum radiatum (Str.r.) der Region CA3 und CA1 besonders stark exprimiert wird. In der Region Stratum pyramidale (Str.p.) und Stratum granulosum (Str.g.) findet sich keine PLC-ß1-Expression. Im Hilus des Gyrus dentatus (GD) sowie in den Regionen Stratum lucidum (Str.1.), Stratum moleculare (Str. m.) und Stratum lacunosum-moleculare (Str.1-m.) ist nur eine abgeschwächte Expression zu detektieren.

Mit Hilfe einer Immunperoxidase-Elektronenmikroskopie (Brown und Farquhar 1989; Frotscher et al. 1990; Linke et al. 1994) mit dem polyklonalen Antikörper gegen das PLC- $\beta 1$-Protein an $50 \mathrm{~nm}$ dicken Ultradünnschnitten einer PLC- $\beta 1_{\mathrm{WT}}{ }^{+/+}$-Maus konnte das PLC-ß1-Protein nach DAB-Detektion membran-assoziiert, und zwar auf der präund postsynaptischen Seite, im Hilus des Gyrus dentatus (Abb. 3.38 A) und in der CA1Region (Abb. 3.38 B) des Hippocampus detektiert werden. Die Ausschnittvergrößerungen in (C) und (D) zeigen PLC-ß1-positive Membranstücke einer Dendritenaußenmembran in der CA1-Region. 


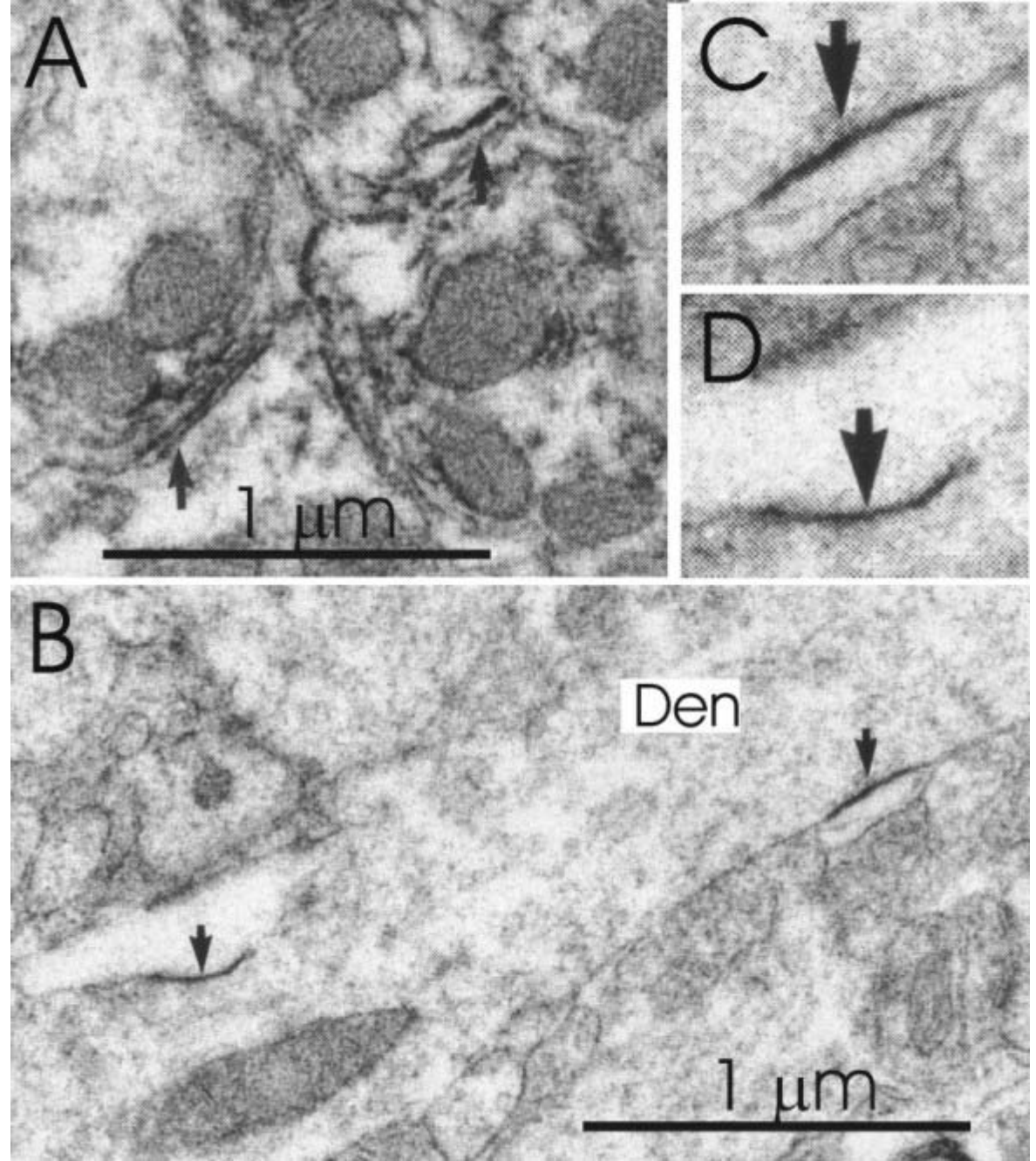

Abb. 3.38:PLC-ß1 immungefärbte elektronenmikroskopische Aufnahmen aus dem Gyrus dentatus (A) und $\operatorname{der} C A 1-$ Region $(B-D)$ einer PLC- $\beta 1_{W T}^{+/+}$-Maus. (\$) = immunpositive Membranen, Den. $=$ Dendrit.

\subsection{Analyse der Proteinkinase C-Aktivität an hippocampalen Synaptosomen der PLC- $\mathbf{~ B 1}_{\mathrm{TC}^{-/-}}$-Maus}

Das PLC-ß1-Enzym katalysiert die Hydrolyse des membranständigen Phospholipids Phosphatidylinositol 4,5-Bisphosphat ( $\left.\mathrm{PIP}_{2}\right)$ unter Bildung der intrazellulären ,second messenger" Diacylglycerol (DAG) und Inositol-1,4,5-Trisphosphat (IP ${ }_{3}$ ). Diacylglycerol ist der physiologische Aktivator der großen Familie der Proteinkinase C Isoenzyme ( $\mathrm{PKC})$, und $\mathrm{IP}_{3}$ induziert die intrazelluläre Ausschüttung von Calcium-Ionen aus internen Speichern im endoplasmatischen Retikulum durch Interaktion mit dem $\mathrm{IP}_{3^{-}}$ Rezeptor. Das PLC-ß1-Enzym wird über einen transmembranen Signaltransduktionsweg aktiviert, der ein extrazelluläres Signal eines Liganden (Transmitter, Hormon, etc.) über einen spezifischen G-Protein gekoppelten Rezeptor in ein intrazelluläres aktiviertes 
G-Protein Signal $\left(\mathrm{G}_{\mathrm{q}} \alpha\right)$ überführt, das das PLC-ß1-Enzym aktiviert. In der Arbeit von Carter et al. (1990) konnte gezeigt werden, dass der physiologische Ligand, der den PLC-B1-Signaltransduktionsweg induziert, durch den Antagonisten Carbachol ersetzt werden kann.

Durch den Verlust des PLC- $\$ 1$-Proteins in der PLC- $\beta 1_{\mathrm{TC}^{-/-}}$-Maus ist in dieser Signaltransduktionskaskade mit „downstream“-Effekten zu rechnen. Daher wurde über einen biochemischen PKC-Assay die Phoshorylierungsaktivität der Proteinkinase $\mathrm{C}$ in hippocampalen Synaptosomen aus drei Monate alten PLC- $\beta 1_{\mathrm{WT}}{ }^{+/+}-$, PLC- $\beta 1_{\mathrm{TC}}{ }^{+/-}$- und PLC- $\beta 1_{\mathrm{TC}}{ }^{-/-}$-Mäusen untersucht. Dazu wurden die synaptosomalen Präparationen mit dem Acetylcholin-Rezeptor-Antagonisten Carbachol $(1 \mathrm{mM})$ stimuliert und anschließend die PKC-Aktivität bestimmt. Die Messwerte wurden mit dem Programm STATISTICA gemittelt, die Standardabweichung für Stichproben berechnet und die Signifikanz der Messwerte über einen t-Test für unabhängige Stichproben ermittelt. Das Ergebnis dieser Analyse ist in der Abb. 3.39 dargestellt und zeigt, dass in der synaptosomalen Präparation aus den Hippocampi von PLC- $\beta 1_{\mathrm{TC}}{ }^{-/-}$-Mäusen keine signifikante PKC-Aktivität durch Carbachol-Stimulation induziert werden kann. In den hippocampalen Synaptosomen der PLC- $\beta 1_{\mathrm{WT}}{ }^{+/+}$und PLC- $\beta 1_{\mathrm{TC}}{ }^{+/-}$-Mäuse sind durch Carbachol signifikante Steigerungen der PKC-Aktivität von $70 \%$ in der PLC- $B 1_{\mathrm{WT}}{ }^{+/+}$Maus $(\mathrm{p}=0,027 ; \mathrm{t}=3,43)$ und $190 \%$ in der PLC- $\beta 1_{\mathrm{TC}}{ }^{+/-}$- Maus $(\mathrm{p}=0,002 ; \mathrm{t}=6,85)$ bezüglich der Mittelwerte zu erzielen.

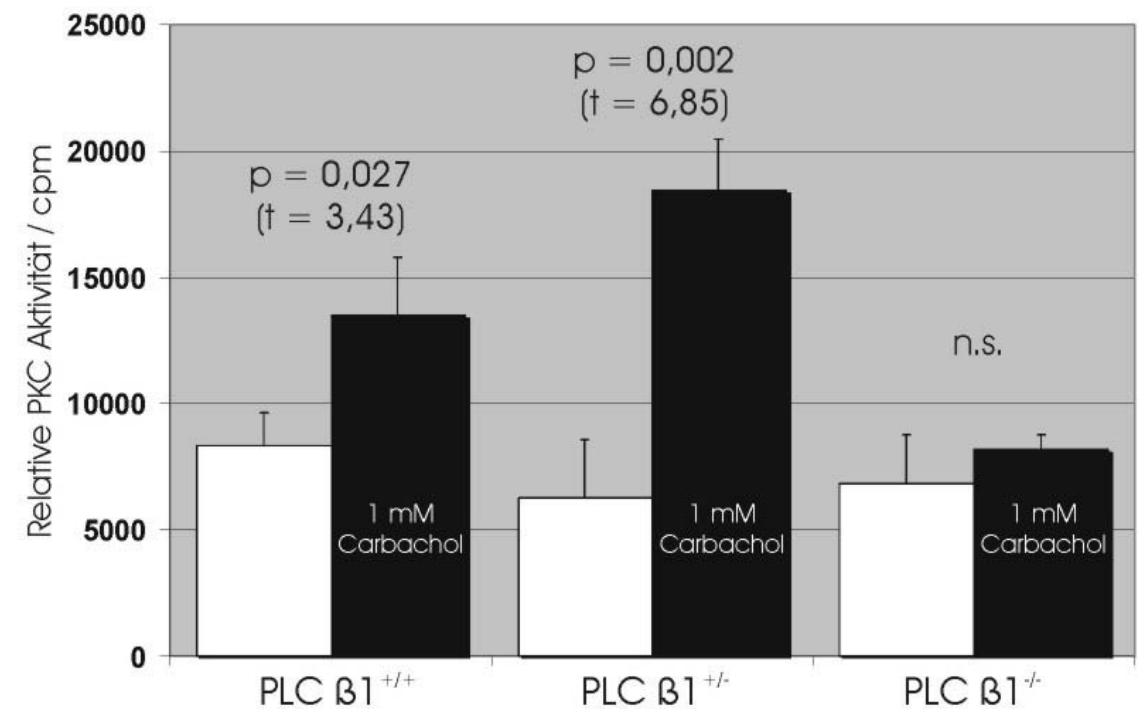

Abb. 3.39: Grafische Darstellung der mit dem PKC-Assay ermittelten PKC-Phosphorylierungsaktivitäten an jeweils $10 \mu \mathrm{g}$ hippocampalen Synaptosomen von PLC- $\beta 1_{W T}{ }^{++}, P L C-\beta 1_{T C}{ }^{+-}$und $P L C-\beta 1_{T C}{ }^{-/-}$ -Mäusen vor und nach Carbachol-Induktion $(1 \mathrm{mM})$. Die gemittelten Werte der jeweiligen Versuchgruppe $(n=3)$ sind zusammen mit der berechneten Standardabweichung als Fehlerbalken dargestellt (cpm = ,counts per minute“). 


\section{Diskussion}

\subsection{Zusammenfassende Darstellung der Ergebnisse}

\subsubsection{Ergebnisse der Phänotyp-Analyse}

1. Entgegen der von Nayernia (1993) durchgeführten Analyse entsprechen die Wurfgrößen und die Genotyp-Verteilungen in den F2- und F3- Generationen den nach den Mendel'schen Vererbungsgesetzen zu erwartenden Wurfzahlen. Eine spezifische embryonale Selektion durch Letalität der $\mathrm{PLC}-\beta 1_{\mathrm{TC}}{ }^{-/-}$Embryonen kann daher ausgeschlossen werden (siehe Abschnitt 3.1.2).

2. Homozygote mutante PLC- $\beta 1_{\mathrm{TC}}{ }^{-/}$-Mäuse zeigen eine ausgeprägte postnatale Wachstumsretardierung, die sich zwischen dem zweiten und dritten postnatalen Tag ausbildet und nach vier Wochen zu einer Letalitätsrate von $73 \%$ führt (siehe Abschnitt 3.1.1).

3. $\mathrm{Ab}$ einem Alter von 6-7 Monaten zeigen PLC- $B 1_{\mathrm{TC}^{-/-}}-$Männchen und -Weibchen nach plötzlicher akustischer und taktiler Stimulation eine ausgeprägte Neigung zu hyperreflektorischem Verhalten. Männliche Tiere sind ab einem Alter von etwa 6-7 Monaten infertil, wobei aber die TestisMorphologie unauffällig ist. (siehe Abschnitt 3.1.3).

4. $\mathrm{Ab}$ einem Alter von 6-9 Monaten zeigen PLC- $B 1_{\mathrm{TC}}{ }^{-/-}$-Männchen und -Weibchen eine stark verminderte motorische Aktivität bezüglich ihrer Lokomotion (Hypokinesie) im „Open-Field“-Experiment. In 4 Wochen alten PLC- $\beta 1_{\mathrm{TC}^{-/-}}$-Männchen ist die Anzahl von „Leaning“-Ereignissen und in 12 Wochen alten PLC- $\beta 1_{\mathrm{TC}}{ }^{-/-}$-Tieren die Anzahl von ,Rearing“-Ereignissen im „Open-Field“-Experiment signifikant reduziert (siehe Abschnitt 3.1.4).

5. PLC- $\beta 1_{\mathrm{TC}}{ }^{-/-}-$Weibchen zeigen unabhängig von ihrem Alter ein gestörtes Brutpflegeverhalten (siehe Abschnitt 3.1.5).

6. Drei Monate alte PLC- $\beta 1_{\mathrm{TC}^{-/-}}$-Mäuse weisen im Radial-Labyrinth eine erhöhte Fehler-Häufigkeit bezüglich ihres räumlichen Lernvermögens auf und zeigen stereotype Verhaltensweisen in Form von sich wiederhohlenden Laufmustern (siehe Abschnitt 3.1.6). 


\subsubsection{Ergebnisse der morphologischen Hippocampus-Analysen}

Die folgende Aufzählung nimmt Bezug auf die in der Abb. 4.1 durchnummerierten Regionen.

1. PLC- $\beta 1_{\mathrm{TC}}^{-/-}$-Mäuse zeigen ab einem Alter von 4 Monaten eine mit der TimmSilbersulfid-Färbetechnik detektierbare ausgeprägte suprapyramidale Moosfaser-Hyperplasie mit einer massiven Vergrößerung der suprapyramidalen Moosfaserprojektion in der CA3-Region des Hippocampus (siehe Abschnitt 3.1.7).

2. PLC- $\beta 1_{\mathrm{TC}^{-/-}}$-Mäuse zeigen ab einem Alter von 4 - 7 Monaten ein mit der Timm-Silbersulfid-Färbetechnik detektierbares Auswachsen (,Sprouting“) von supragranulären Moosfasern auf die Dendritenbäume der Körnerzellen in der inneren Molekularschicht des Gyrus dentatus (siehe Abschnitt 3.1.7)

3. Die Expression des Calcium-Bindungsproteins Calretinin ist im Hippocampus der PLC- $\beta 1_{\mathrm{TC}^{-/}}$-Maus durch axonales Wachstum und Ausbildung von GABAergen- und/oder glutamatergen Synapsen in die Regionen CA1 und CA3 über die normalen Grenzen hinaus ausgedehnt (siehe Abschnitt 3.1.8).

4. Die NMDA-Rezeptordichte ist in 3 Monate-, 9 Monate- und 12 Monate alten PLC- $\beta 1_{\mathrm{TC}}{ }^{-/-}$-Mäusen auf der basal dendritischen Seite der CA1-Region im Stratum oriens gegenüber äquivalenten Kontrolltieren um $35 \%$ vermindert (siehe Abschnitt 3.1.9).

5. Im Subiculum und in der CA1-Region des Hippocampus können bei 8 Monate alten PLC- $ß 1_{\mathrm{TC}^{-/-}}$-Mäusen pyknotische Zellkerne und apoptotische „dark neurons" detektiert werden (siehe Abschnitt 3.1.11).

6. In immunhistochemischen Untersuchungen zur c-fos-Expression kann im Hippocampus von 3 Monate alten PLC- $\beta 1_{\mathrm{TC}^{-/}}$-Mäusen ein Verlust von c-fos immun-reaktiven Neuronen im Hilus des Gyrus dentatus und überwiegend im Stratum oriens der Region CA1 und CA3 detektiert werden (siehe Abschnitt 3.1.10).

Abb. 4.1: (S. 133) Zusammenfassende Darstellung der im Abschnitt 4.1.2 beschriebenen Reorganisationen im Hippocampus der PLC- $\beta 1_{T C}{ }^{-1}$-Maus. Die Rearrangements sind zur Veranschaulichung durch die entsprechenden Nummerierungen hippocampal lokalisiert und beziehen sich auf die im Abschnitt 4.1.2. beschriebene Aufzählung. Die dargestellten Regionen sind: CA1, CA3 = Regionen des Ammonshorns (Cornu ammonis), GD = Gyrus dentatus, Str.m $=$ Stratum moleculare, Str. $g=$ Stratum granulosum, Str. l-m $=$ Stratum lacunosummoleculare, Str. $r=$ Stratum radiatum, Str. $p=$ Stratum pyramidale, Str. $o=$ Stratum oriens, Str. $l=$ Stratum lucidum, $S U B=$ Subiculum. 


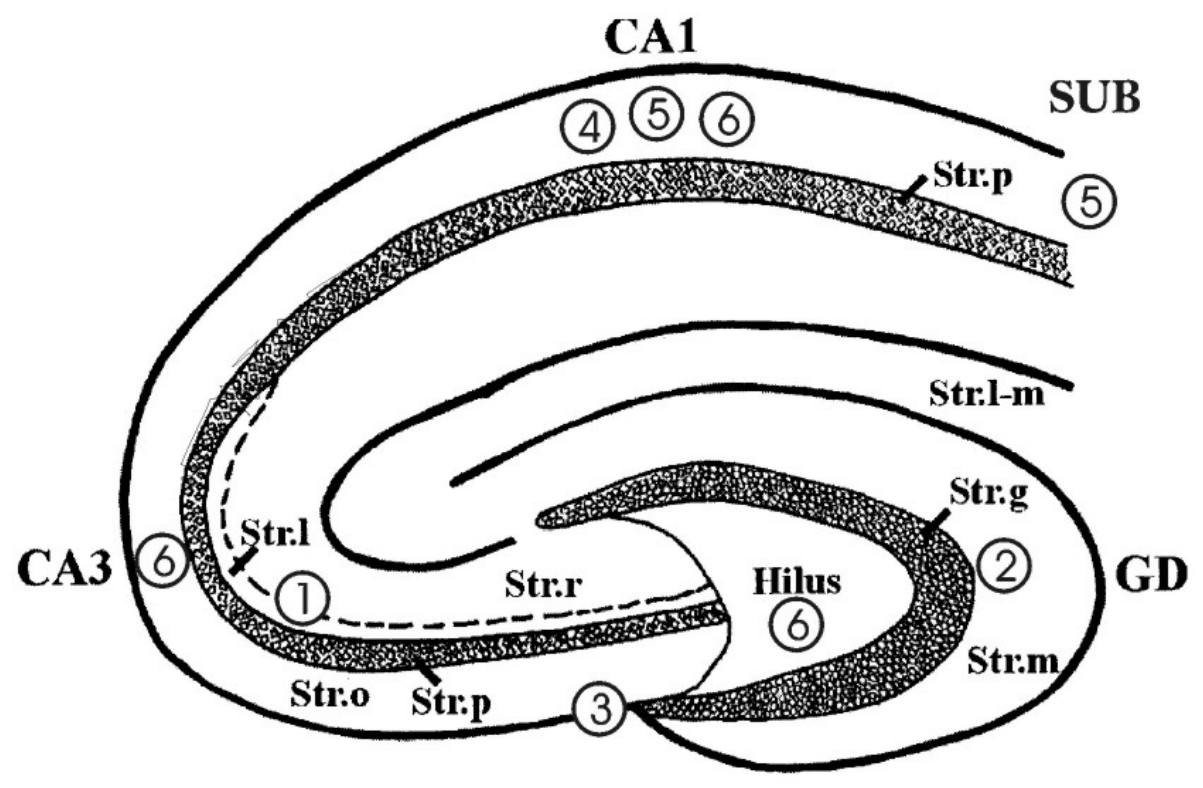

Abb. 4.1

\subsubsection{Ergebnisse der Genotyp-Analyse}

1. Die Transgen-Integration in der TC-Maus im Chromosom 2 in der Region F3$\mathrm{G}$ wurde als intronische Transgen-Insertion in dem Gen für die Phospholipase C-ß1 (PLC-ß1) charakterisiert und die angrenzende genomische Region kloniert (Abschnitte 3.2.1 bis 3.2.9). Der identifizierten Deletion von 809 bp im Genom der TC-Maus kann keine Funktion zugewiesen werden (Abschnitt 3.2.9).

2. Die intronische Transgen-Insertion im PLC-ß1-Gen der Maus führt zu einer in den Abschnitten 3.3.1 bis 3.3.3 dokumentierten Transgen-induzierten SpleißMutation und zu einer vom PLC-ß1-Promotor angetriebenen Expression eines 1,7 kb-Fusionstranskripts. Die RT-PCR-Analyse des Fusions-Transkripts identifizierte nach dem Startkodon (ATG) einen Rest von 244 bp PLC-ß1 kodierenden Bereich, gefolgt von 3'-transkribiertem SV40-3'-UTR-Anteil. Der überwiegende Protein-kodierende Bereich des PLC-ß1-Transkripts erwies sich als nicht exprimiert.

3. Die Expressions-Analyse in den verschiedenen Organen der PLC- $\beta 1_{\mathrm{TC}}{ }^{-/-}$- und der Wildtyp-Maus (PLC- $\beta 1_{\mathrm{WT}}^{+/+}$) konnte den Verlust des PLC-ß1-Transkripts (Abschnitt 3.4.1) und -Proteins (Abschnitt 3.4.2) in der PLC- $\beta 1_{\mathrm{TC}}{ }^{-/-}$-Maus bestätigen. Die Expression des endogenen PLC-ß1-Transkripts entspricht in 
seiner Gewebe-Spezifität der Expression des 1,7 kb-Fusions-Transkripts, ist aber in seiner Intensität deutlich erniedrigt.

4. Aufgrund des Verlustes der PLC-ß1-Expression in der $\mathrm{TC}^{-/-}$-Maus werden die Genotypen in der vorliegenden Arbeit mit PLC- $\beta 1_{\mathrm{WT}}^{+/+}\left(\mathrm{WT}^{+/+}\right)$, PLC- $\beta 1_{\mathrm{TC}}^{+/-}$ $\left(\mathrm{TC}^{+/-}\right)$und PLC- $\beta 1_{\mathrm{TC}^{-/-}}\left(\mathrm{TC}^{-/-}\right)$bezeichnet.

\subsection{Die PLC- $81_{\mathrm{TC}^{-/-}}$-Insertionsmutation in Relation zum existenten PLC-B1 $^{-/-}$-Maus-Modell}

\subsubsection{Gegenüberstellung der molekulargenetischen Ergebnisse}

In der Arbeit von Kim et al. (1997) wurde bereits eine durch homologe Rekombination an embryonalen Stammzellen (ES-Zellen) generierte PLC- $\beta 1^{-/-}$-Mausmutante phänotypisiert. In dem „Knock-out“-Experiment wurde eine PGK-Neomycin-Kassette in das Exon 8 des PLC-ß1-Gens des Maus eingefügt und so der „Open reading frame“ (ORF) des PLC-ß1-Transkripts ab Position 663 (185 bp nach dem Startkodon ATG) unterbrochen und das Protein ab Aminosäureposition 65 verkürzt (siehe Abb. 4.2 A, C). Die Existenz dieses verkürzten Transkripts und des putativen, trunkierten Proteins wurde in dieser Arbeit nicht überprüft. Die molekulare Charakterisierung der TC-Maus (PLC- $\beta 1_{\mathrm{TC}}^{-/}$) identifizierte eine intronische Transgen-Insertion in dem nachfolgenden Intron 8 des PLC-ß1-Gens und eine durch die transgene SV40-3' UTR induzierte Spleiß-Mutation, die zur Expression eines 1,7 kb großen Fusionstranskripts unter der Kontrolle des endogenen PLC-ß1-Promotors und zur Verkürzung des PLC-ß1Transkripts auf 712 bp führt (Abb. 4.2 A). Die Existenz dieses Fusionstranskripts wurde bewiesen und seine Struktur molekular charakterisiert (siehe Abschnitt 3.3). Auch hier besteht die prinzipielle Möglichkeit, dass in der PLC- $\beta 1_{\mathrm{TC}}{ }^{-/-}$-Maus ein Restprotein von 81 Aminosäuren translatiert wird (Abb. 4.2 D), dessen verkürzte PH-Domäne möglicherweise noch an sein Substrat Phosphatidylinositol-4,5-Bisphosphate ( $\left.\mathrm{PIP}_{2}\right)$ binden kann. Die Existenz dieses putativen, trunkierten Proteins wurde in der vorliegenden Arbeit nicht überprüft, da kein Antikörper gegen den amino-terminalen Teil des Proteins existiert. In der Arbeit von Kim et al. (1997) und in der vorliegenden Arbeit wurde mit einem Carboxy-terminal gerichteten Antikörper der vollständige Verlust von funktionellem PLC-ß1-Protein dokumentiert (Abschnitt 3.4.2). In beiden Mutanten sind ein Teil der PH-Domäne, die vier EF-Hand-Domänen, die katalytischen $\mathrm{X}$ - und Y-Domänen, die C2-Domäne und die C-terminale Erweiterung (Abb. 4.2 B, C, D) komplett deletiert, so dass von einem vollständigen Funktionsverlust in den beiden mutanten Linien ausgegangen werden kann. 


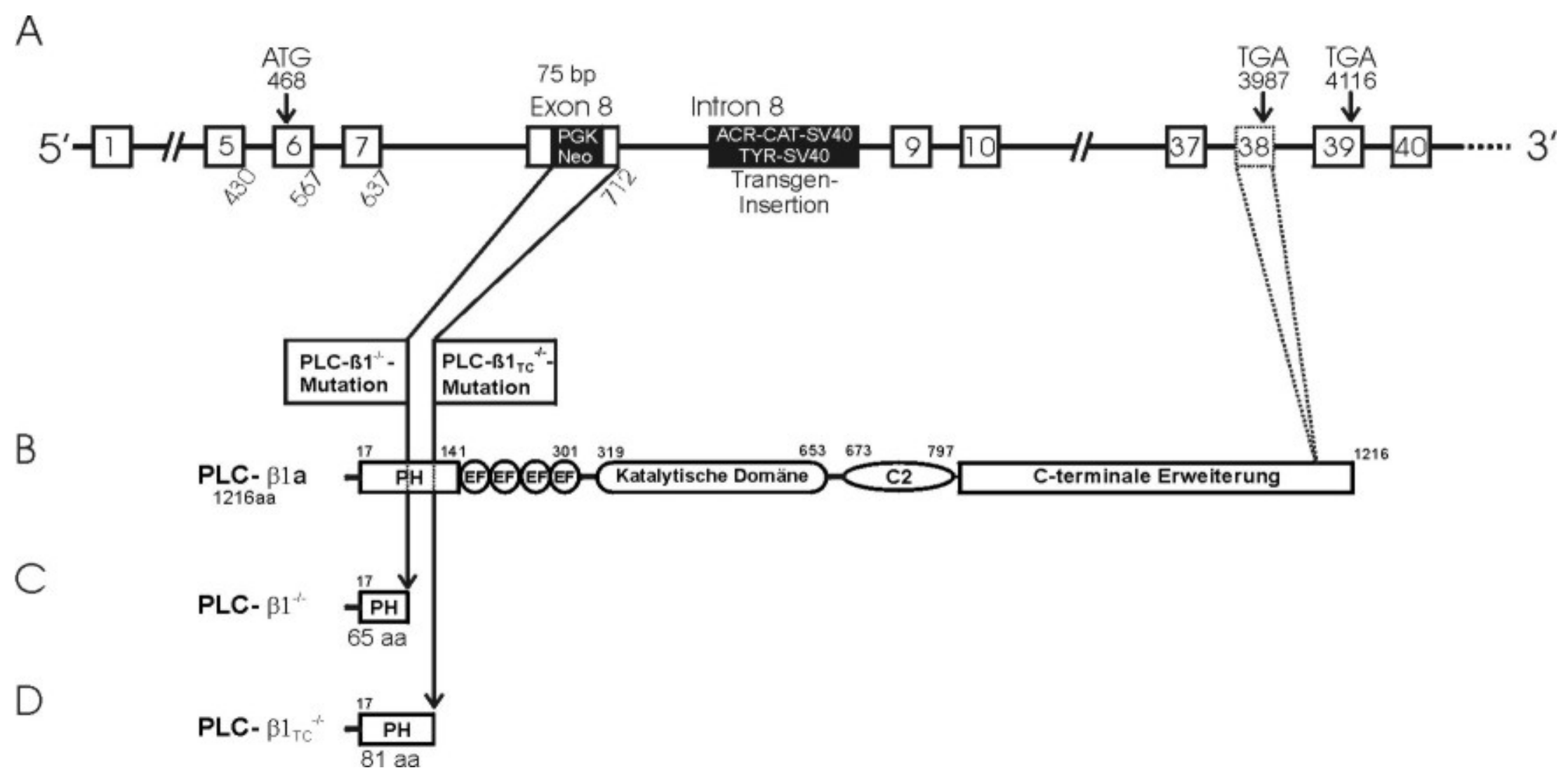

Abb. 4.2: Schematische Darstellung der genomischen Organisation des PLC-ß1-Gens der Maus und vergleichende Lokalisierung der PGK-Neomycin-Insertion (PGK-Neo) in dem Genom der PLC- $\beta 1^{-/}$-Maus (Kim et al. 1997) und der in der vorliegenden Arbeit analysierten Transgen-Insertion (ACR-CAT-SV40 und TYR-SV40) in dem Genom der PLC- $\beta 1_{T C}{ }^{-1}$-Maus. Die Positionen des Startkodons (ATG) und der beiden alternativen Stopp-Kodons (TGA) sind bezüglich ihrer Position in der PLC-ß1-cDNA der Ratte (Genbank-Nr. L14323) angegeben. Die Exone sind als Boxen dargestellt und in 5'-3'-Richtung durchnummeriert. Das alternativ, "herausgespleißte“ Exon 38 der PLC-ß1a-Isoform ist gestrichelt (---) dargestellt (A). Die Teilabbildung (B) zeigt

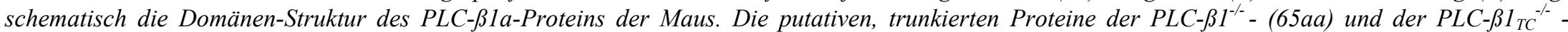
Mutation (81aa) sind in den Teilabbildungen $(C)$ und $(D)$ dargestellt (aa $=$ Aminosäure, $C$ - $=$ Carboxy-, $C 2=C 2$-Domäne, $E F=E F-H a n d$, $P H=$ Pleckstrin-Homologie). 
4.2.2 Zusammenfassende Gegenüberstellung des PLC-1 ${ }^{-/-}$und PLC-B1 ${ }_{\mathrm{TC}}{ }^{-/-}$ Phänotyps

\begin{tabular}{|c|c|c|}
\hline & PLC-B1 $1^{-/-}$ & PLC-B1 ${ }_{\mathrm{TC}}{ }^{-/-}$ \\
\hline $\begin{array}{l}\text { Genotyp } \\
(\text { AA =Aminosäure })\end{array}$ & Kein Protein ab AA 65 & Kein Protein ab AA 81 \\
\hline Postnatale Letalität & $80 \%(3 .-6$. Woche $)$ & $70 \%(1 .-4$. Woche $)$ \\
\hline Wachstumsretardierung & $\mathrm{Ja}$ & $\mathrm{Ja}$ \\
\hline $\begin{array}{l}\text { Hyperreflektorischer } \\
\text { Phänotyp }\end{array}$ & $\begin{array}{l}\text { Nach } 3 \text { Wochen } \\
\text { medikamentös induziertes } \\
\text { hyperreflektorisches } \\
\text { Verhalten }\end{array}$ & $\begin{array}{l}\text { Nach 6-7 Monaten } \\
\text { hyperreflektorisch nach } \\
\text { akustischer Stimulation }\end{array}$ \\
\hline $\begin{array}{l}\text { Hypokinetischer } \\
\text { Phänotyp }\end{array}$ & Keine Angaben & $\begin{array}{l}\text { Nach 6-9 Monaten stark } \\
\text { verminderte Lokomotion } \\
\text { verminderte Anzahl } \\
\text { „Leaning“. } \\
\text { verminderte Anzahl } \\
\text { „Rearing“. }\end{array}$ \\
\hline Lerndefizite & Keine Angaben & erhöhte Fehler-Häufigkeit \\
\hline Brutpflege & Keine Angaben & Bei $q$ gestört \\
\hline Fertilität & Keine Angaben & $\widehat{o} \mathrm{ab}$ 6-7 Monaten infertil \\
\hline Signaltransduktion & $\begin{array}{l}\mathrm{IP}_{3} \text { nach Carbachol- } \\
\text { Stimulation vermindert }\end{array}$ & $\begin{array}{l}\text { PKC-Aktivität nach } \\
\text { Carbachol-Stimulation } \\
\text { vermindert }\end{array}$ \\
\hline Zell-Verlust & $\begin{array}{l}\text { Somatostatin- } \\
\text { immunpositive } \\
\text { Interneurone im Hilus }\end{array}$ & $\begin{array}{l}\text { c-fos-immunpositive } \\
\text { Interneurone im Hilus, } \\
\text { CA3 und CA1 } \\
\text { Pyknotische Zellkerne und } \\
\text { „dark neurons“ in CA1 und } \\
\text { Subiculum }\end{array}$ \\
\hline $\begin{array}{l}\text { Axonale und synaptische } \\
\text { Reorganisationen }\end{array}$ & Keine Angaben & $\begin{array}{l}\text { Supragranuläres } \\
\text { Moosfaser-,,Sprouting“ } \\
\text { Suprapyramidales } \\
\text { Moosfaser-,,Sprouting” } \\
\text { Calretinin-positives } \\
\text { „Sprouting” in CA3 und } \\
\text { CA1 }\end{array}$ \\
\hline
\end{tabular}




\subsubsection{Gegenüberstellung der phänotypischen Ergebnisse}

Heterozygote PLC- $\beta 1^{+/-}$-Mäuse zeigen nach der Arbeit von Kim et al. (1997) keinen Phänotyp. Homozygote PLC- $\beta 1^{-/-}$-Mäuse sind postnatal im Wachstum retardiert und zeigten eine hohe postnatale Sterblichkeitsrate von $80 \%$ bis zur sechsten Lebenswoche, die allerdings erst in der dritten Woche postnatal beginnt. In unserer PLC- $\beta 1_{\mathrm{TC}^{-/-}}$-Maus konnte eine frühe Sterblichkeit schon ab dem zweiten Lebenstag dokumentiert werden, die bereits nach vier Wochen abgeschlossen ist. Dieser Unterschied kann nur über den genetischen Hintergrund gedeutet werden, da beide PLC-ß1-Mutationen auf molekularer Ebene vergleichbar sind (siehe Abschnitt 4.2.1 und Abb. 4.2). In vielen Mutationsanalysen konnte bereits gezeigt werden, dass der genetische Hintergrund durch differentielle Expession von Modulator-Genen einen Phänotyp-modulierenden Effekt ausüben kann (Montagutelli 2000; Beier et al. 1989; Magram und Bishop 1991; Merlino et al. 1991). So konnten in der Arbeit von Beier et al. (1989) an der Mausmutante ple (perinatal lethality), die über eine Transgen-induzierte Insertionsmutation im Chromosom 15 generiert wurde, ebenfalls unterschiedliche Letalitätsraten auf verschiedenen genetischen Hintergründen beschrieben werden. Auf dem genetischen Hintergrund des Auszucht-Stammes CD1 führte die dort beschriebene Mutation bei homozygoten Mäusen zu einem milden Phänotyp mit Wachstumsretardierung und postnataler Letalität bis zur vierten Lebenswoche. Nach Rückkreuzung der Mutation auf den genetischen Hintergrund des Inzucht-Stammes C57Bl/6J verstarben alle homozygoten Tiere bereits postnatal am ersten Lebenstag. Auch in der vorliegenden Arbeit wurde als genetischer Hintergrund ein Auszucht-Stamm (NMRI) verwendet. Dieser Umstand könnte möglicherweise erklären, warum auch hier die frühe Letalitätsrate nicht bei $100 \%$ liegt und die Gewichts-Werte der homozygoten PLC- $\beta 1_{\mathrm{TC}_{\mathrm{C}}}{ }^{-/-}$-Tiere innerhalb der Altersgruppe relativ weit streuen, was durch die Höhe der Standardabweichung in der Abb. 3.1 wiedergegeben wird. Da der Arbeit von Kim et al. (1997) keine Angaben über den verwendeten Maus-Stamm zu entnehmen sind, kann die Natur dieser modulierenden Effekte nicht diskutiert werden. Die in dieser Arbeit beschriebene PLC- $\beta 1_{\mathrm{TC}}{ }^{-/-}$-Mutation wurde bisher nur auf dem NMRI-Hintergrund analysiert. Eine Rückkreuzung der Mutation auf einen Inzucht-Stamm (C57B1/6J oder FVB/N ;Taketo et al. 1991) könnte möglicherweise auch hier zu einer „Verstärkung“ des Phänotyps führen.

Die hohe Letalitätsrate diskutieren Kim et al. (1997) dahingehend, dass die PLC- $\beta 1^{-/-}$Mäuse aufgrund wiederkehrender epileptischer Anfälle versterben. Diese Anfälle wurden als tonisch-klonische- oder klonische Streckungen des gesamten Körpers beschrieben, wie man sie auch nach einer Blockade des inhibitorischen Potentials von 
$\mathrm{GABA}_{\mathrm{A}}$-Rezeptoren mittels Pentylentetrazol findet (Holmes et al. 1999). In der Arbeit von Holmes et al. (1999) sind diese durch Pentylentetrazol-Gabe induzierten Verhaltensauffälligkeiten an Ratten sehr detailliert beschrieben. Dort wird unter anderem auch von akustischen Reaktionen (Schreien), Muskelzuckungen, Kopfschütteln und von einer gesteigerten Bewegungsunruhe der untersuchten Ratten (postnatales Alter: Tag 0-30) berichtet. Desweiteren führten die induzierten epileptischen Anfälle bei keiner dieser Ratten zu einer Letalität. Dieses bei Holmes et al. (1999) beschriebene erweiterte Verhaltens-Repertoire konnte bei den in der vorliegenden Arbeit untersuchten PLC- $\beta 1_{\mathrm{TC}}{ }^{-/-}$-Mäusen nicht beobachtet werden. Es konnte vielmehr gezeigt werden, dass eine Korrelation zwischen der retardierten Gewichtsentwicklung und der Sterblichkeit der PLC- $\beta 1_{\mathrm{TC}^{-/}}$-Mäuse besteht, und dass nur die Mäuse verstarben, die bereits zwei Tage vorher eine Stagnation in der Gewichtsentwicklung und ein unterdurchschnittliches Gewicht aufwiesen. Diese Analysen deuten demnach eher darauf hin, dass die retardierte Gewichtsentwicklung für die frühe postnatale Sterblichkeit ursächlich ist, und dass der genetisch heterogene NMRI - Hintergrund das Ausmaß der Gewichts-Retardierung moduliert (Beier et al. 1989). Allerdings kann auch nicht ausgeschlossen werden, das eine durch die PLC-ß1Verlustmutation induzierte erhöhte Krampfbereitschaft (s.u.) durch den physiologischen Hungerzustand ausgelöst wird.

\subsubsection{Gegenüberstellung der biochemischen Ergebnisse}

Drei Wochen alte PLC- $\beta 1^{-/-}$-Mäuse (Postnatales Alter: Tag 21-26) erwiesen sich in den weiteren Analysen von Kim et al. (1997) tatsächlich als hypersensitiv zu subkonvulsiven Dosen des $\mathrm{GABA}_{\mathrm{A}}$-Antagonisten Pentylentetrazol und des Glutamat-Analogons Kainat. Die Autoren postulieren daher eine Funktion des PLC-ß1-Moleküls in der inhibitorisch wirkenden Signaltransduktion. Es ist bekannt, dass die PLC-ß-Signaltransduktion der Isozyme PLC- $\beta 1$ bis PLC- 34 (siehe Abschnitt 4.5.1) durch agonistische Aktivierung metabotroper Glutamatrezeptoren (mGluR1, mGluR5) mittels ACPD (Johnson et al. 1999), muscarinischer Acetylcholin-Rezeptoren mittels Carbachol (Carter et al. 1990) und serotonerger Rezeptoren vom Typ 2 mittels mCPP (Peroutka 1994) induziert werden kann. Kim et al. (1997) konnten in ihrer Arbeit nur nach Carbachol-Stimulation auf Hippocampusschnitten einer PLC- $\beta 1^{-/-}$-Maus eine Reduktion der Inositol-1,4,5-Trisphosphat- $\left(\mathrm{IP}_{3}\right)$ Konzentration im Vergleich zu einer Wildtyp-Maus detektieren und daher zeigen, dass das PLC-ß1-Protein die Transduktion cholinerger Signale im Hippocampus, im Cortex und im Cerebellum reguliert. Dieses Ergebnis konnte in der vorliegenden Arbeit über die Quantifizierung des „Downstream“-Effektes einer $\mathrm{IP}_{3}$ - und DAG-Reduktion bestätigt werden. Wie im 
Abschnitt 3.5 dokumentiert, konnte gezeigt werden, dass die Proteinkinase C-Aktivität $(\mathrm{PKC})$ in hippocampalen Synaptosomen-Präparationen einer drei Monate alten Wildtyp- und einer entsprechenden PLC- $\beta 1_{\mathrm{TC}}{ }^{+/-}$-Maus über Carbachol-Stimulation gesteigert werden kann (siehe Abb. 3.39), und dass die Induktion der PKC-Aktivität in hippocampalen Synaptosomen einer PLC- $\beta 1_{\mathrm{TC}^{-/-}}$-Maus gleichen Alters unterbleibt. Damit konnte demonstriert werden, dass der PLC-ß1-Funktionsverlust an hippocampalen Synapsen zu intrazellulären „Downstream“-Effekten führt, die über die Aktivität membranständiger Proteinkinasen $\mathrm{C}$ reguliert wird.

Einen Verlust von hippocampaler PKC-Aktivität konnten Ayyagari et al. (1996) und Kolasa et al. (2000) auch nach Denervierung der cholinergen septohippocampalen Fasern zum Hippocampus durch sogenannte Fimbria-Fornix-Läsionen (Crutcher 1987) nachweisen. Der Verlust dieser cholinergen Erregung führte im Hippocampus auch zur Ausbildung chronischer epileptischer Anfälle (Buzsaki et al. 1989a) und zum Verlust der Langzeitpotenzierung (Buzsaki und Gage 1989b). In einer weiteren Arbeit konnte gezeigt werden, dass eine cholinerge Stimulation auf organotypischen Hippocampusschnitten der Ratte das exzitatorische postsynaptische Potential (EPSP) über Aktivierung inhibitorischer Interneurone vermindern kann (Pitler und Alger 1992), so dass die Unterbrechung der cholinergen Signaltransduktion in der PLC- $\beta 1_{\mathrm{TC}^{-/}}$- und PLC- $\beta 1^{-/-}$-Maus (Kim et al. 1997) über eine Abnahme der GABAergen Inhibition zu der Pentylentetrazol- und Kainat-Hypersensitivität der PLC- $\beta 1^{-/-}$- Maus und zu der hyperreflektorischen Problematik in der adulten PLC- $\beta 1_{\mathrm{TC}}{ }^{-/-}$- Maus führen kann (siehe Abschnitt 3.1.3).

\subsubsection{Gegenüberstellung der morphologischen Ergebnisse}

Bei Tieren mit experimentell induzierter Epileptogenese und hyperreflektorischen Anfällen (siehe Abschnitt 1.3), z.B. nach Pilocarpin- (Clifford et al. 1987; Silva und Mello 2000) oder Kainat-Verabreichung (Nadler et al. 1980b; Buckmaster und Dudek 1997), nach subkonvulsiver elektrischer Stimulation afferenter Bahnen des Hippocampus im sogenannten ,elektrogenen“ Tier-Modell (Sutula et al. 1988; Represa et al. 1993), nach cholinerger Denervierung (CD) durch Fimbria/Fornix-Läsionen (Beck et al. 1994), bei einer epileptischen Mausmutante (Stargazer) mit genetischer Ursache (Qiao und Noebels 1993; Letts et al. 1998) und bei der Temporallappen-Epilepsie des Menschen (TLE; de Lanerolle et al. 1989) kommt es $\mathrm{zu}$ charakteristischen neuropathologischen Veränderungen im Hippocampus. Dazu gehören der selektive Verlust von Neuronen im Hilus sowie in der CA3- und CA1-Region (AHS = Ammonshorn-Sklerose; Sloviter 1987; Silva und Mello 2000) und axonale und 
synaptische Reorganisationen (z.B. Moosfaser-,,Sprouting“; Gorter et al. 2001). Diese neuropathologischen Veränderungen führen in ihrer Gesamtheit zu einer chronischen, epileptiformen Aktivität mit wiederkehrenden, zum Teil spontanen Anfällen. Bei der Analyse der PLC- $\$ 1^{-/-}$-Mäuse (Kim et al. 1997) konnte der selektive Verlust Somatostatin-immunreaktiver Interneurone im Hilus des hippocampalen Gyrus dentatus dokumentiert werden. Der selektive Verlust Somatostatin-postiver Interneurone konnte auch in „elektrogenen“ Tier-Modellen“ der Ratte (Sloviter 1987) und in humanem hippocampalem Resektionsmaterial von medikamentös unbehandelbaren TLE-Patienten nachgewiesen werden (de Lanerolle et al. 1989). Der durch Zelltod von inhibitorischen Somatostatin-immunreaktiven Interneuronen manifestierte Verlust hippocampaler Inhibition (Sloviter 1987) wird für die wiederkehrenden epileptiformen Anfälle als ursächlich angesehen (Gorter et al. 2001).

Die Analyse der PLC- $\beta 1_{\mathrm{TC}}{ }^{-/-}$-Maus in der vorliegenden Arbeit hat gezeigt, dass im Hippocampus von 3 Monate alten PLC- $\beta 1_{\mathrm{TC}}{ }^{-/-}$-Mäusen ein Verlust von c-fosimmunreaktiven Neuronen im Stratum oriens und Stratum radiatum der Regionen CA3 und CA1 und im Hilus des Gyrus dentatus vorliegt (siehe Abschnitt 3.1.10). Zur gleichen Zeit findet man bereits eine massive Reduktion der funktionalen NMDARezeptordichte im Stratum oriens der Region CA1 (Abschnitt 3.1.9). In acht Monate alten PLC- $\beta 1_{\mathrm{TC}^{-/-}}$-Mäusen wurden zusätzlich eine große Zahl pyknotischer Zellkerne und „dark neurons“ im Stratum oriens der Region CA1 und im Subiculum detektiert, deren Existenz auf apoptotische- (Ijiri 1989) und neurodegenerative Prozesse (Poirier et al. 2000) in diesen Regionen hinweist (Abschnitt 3.1.11). Poirier et al. (2000) konnte nach Kainat-induzierter Epileptogenese im Hippocampus der Ratte mit einer spezifischen Silberfärbung von „dark neurons“ und mit einem anionischen Fluorochrom (Fluoro-Jade, Schmued und Hopkins 2000) ebenfalls eine große Zahl degenerierter Neurone im Stratum radiatum und Stratum pyramidale der Regionen CA3, CA1 und in der polymorphen Schicht des Hilus detektieren. In diesen Regionen wurden auch in den Pilocarpin- (Mello et al. 1993) und "Kindling"-Epilepsie-Modellen (Cavazos et al. 1994) und im hippocampalen Resektionmaterial von TLE-Patienten (El Bahh et al. 1999) diverse Zellverluste beschrieben. Der in der vorliegenden Arbeit an hippocampalen Schnitten der PLC- $\beta 1_{\mathrm{TC}^{-/}}$-Maus dokumentierte Verlust an zellulärer c-fos-Expression könnte mit dem von Kim et al. (1997) beschriebenen Verlust an Somatostatin-immunreaktiven Intereuronen übereinstimmen. Es gibt Hinweise, dass die c-fos-und die Somatostatin-Expression im Hilus zellulär kolokalisiert sind und in Ratten nach elektrogener Stimulation ("Kindling") koinduziert werden (Woldbye et al. 1996). Die Somatostatin-Expression wird in diesen Zellen unter anderem auch durch den 
Transkriptions-Faktor c-fos am CRE-Element des Somatostatin-Promotors (Montminy et al. 1986) stimuliert. Die hiläre c-fos-Expression ist mit weiteren immunhistologisch unterscheidbaren neuronalen Subpopulationen kolokalisiert (Woldbye et al. 1996). Neuropeptid Y- (NPY) immunpositive inhibitorische Neurone existieren sowohl im Hilus des Gyrus dentatus und in den Regionen CA3, CA1 und im Subiculum (Mitchell et al. 1996) und konnten zumindest im Hilus mit einer c-fos-Expression kolokalisiert werden (Woldbye et al. 1996). NPY-immunreaktive Zellen kommen daher als putativ verlustige Neurone in der CA3- und CA1-Region der PLC- $\beta 1_{\mathrm{TC}^{-/-}}$-Maus in Frage. Eine immunhistologische Untersuchung hippocampaler Schnitte von PLC- $\beta 1_{\mathrm{TC}}{ }^{-/-}$-Mäusen unterschiedlicher Altersstufen mit einem NPY-spezifischen Antikörper zur Lokalisierung NPY-immunreaktiver Interneurone könnte über die zellulären Veränderungen in der Region CA3, CA1 und Hilus Aufschluss geben, konnte aber in der vorliegenden Arbeit nicht mehr durchgeführt werden.

Der postulierte Verlust von Calretinin-immunpositiven Interneuronen im Hilus von PLC- $\beta 1_{\mathrm{TC}}{ }^{-/-}$-Mäusen konnte in der vorliegenden Arbeit nicht bestätigt werden (siehe Abschnitt 3.1.8). Ebenso wie Somatostatin ist Calretinin in der Maus ein immunhistochemisch etablierter Marker für hiläre glutamaterge Mooszellen (Jacobowitz und Winsky 1991; Liu et al. 1996), die in experimentellen EpilepsieModellen nach Kainat-Gabe (Nadler et al. 1980a; Sloviter 1987), PilocarpinVerabreichung (Clifford et al. 1987), elektrischem „Kindling“ (Cavazos und Sutula 1990) und in humanem hippocampalem Resektionsmaterial von TLE-Patienten (Dam 1980; Babb et al. 1984) fehlen. In normalen Ratten konnte Buckmaster et al. (1996) zeigen, dass die Mooszellen im Hilus glutamaterg auf die Dendriten der Körnerzellen in der inneren Molekularschicht projizieren, und dass der Verlust dieser Projektionen aberrantes Moosfaser-,,Sprouting“ auf die „freien“ Dendriten der Körnerzellen induziert. Dieses als supragranuläres Moosfaser-,,Sprouting“ bezeichnete Phänomen wird auch nach Fimbria/Fornix-Läsionen zusammen mit Somatostatin- und Parvalbumin-immunreaktiven Zellverlusten (siehe Abb. 4.3, S. 145) beobachtet und führt auch dort zu einer epileptiformen Aktivität (Mohapel et al. 1997). Inwieweit die glutamatergen Moosfaser-Reorganisationen schließlich ursächlich für die wiederkehrende und spontane epileptiforme Aktivität des Hippocampus in den erwähnten Tiermodellen und bei der humanen TLE sind, wird daher bis heute kontrovers diskutiert (Silva und Mello 2000). Eine Blockade des Pilocarpin- oder Kainat-induzierten Moosfaser-,,Sproutings“ durch Inhibition der Proteinsynthese mittels Cycloheximid (CHX) führte bei Mäusen zum Verlust Calretinin-positiver Zellen und zu epileptischer Aktivität (Longo und Mello 1997; Silva und Mello 2000). Zusätzlich kann auch bei 
einigen Formen humaner Temporallappen-Epilepsie mit entsprechender epileptiformer Aktivität und hippocampalem Zellverlust kein Moosfaser-,,Sprouting“ dokumentiert werden (Spencer und Spencer 1994). In der Arbeit von Gorter et al. (2001) konnte allerdings das supragranuläre Moosfaser-,,Sprouting“ in elektrisch stimulierten (elektrogenen) Ratten mit einer massiven Progression spontaner epileptiformer Anfälle korreliert werden. Auch in der vorliegenden Arbeit konnte das im Abschnitt 3.1.7 dokumentierte supragranuläre Moosfaser-,,Sprouting“ mit hypokinetischem (siehe Abschnitt 3.1.4) und hyperreflektorischem Verhalten (siehe Abschnitt 3.1.3) korreliert werden. Das morphologische Korrelat der schon früher dokumentierten Lerndefizite (siehe Abschnitt 3.1.6), der verminderten Exploration im „Open-Field“-Experiment („Leaning“ und „Rearing“, siehe Abschnitt 3.1.4) und des gestörten BrutpflegeVerhaltens (siehe Abschnitt 3.1.5) muss in den bereits $\mathrm{zu}$ einem früheren Zeitpunkt ausgebildeten morphologischen Veränderungen gesucht werden. Dafür kommen suprapyramidale Moosfaser-Reorganisation (siehe Abschnitt 3.1.7), die Reduktion der NMDA-Rezeptordichte in der hippocampalen Region CA1 (siehe Abschnitt 3.1.9) und der selektive Verlust von c-fos-Expression in den Regionen CA1, CA3 und im Hilus des Gyrus dentatus (siehe Abschnitt 3.1.10) als ursächlich in Frage.

Entgegen der Annahme, dass im Hilus von PLC- $\beta 1_{\mathrm{TC}}{ }^{-/-}$-Mäusen Calretininimmunpostive Mooszellen fehlen sollen, und dass dieser Verlust die aberranten „Sprouting“-Vorgänge induziert (Buckmaster et al. 1996), wurde in der vorliegenden Arbeit in 8 Monate alten PLC- $\beta 1_{\mathrm{TC}}{ }^{-/-}$- Mäusen vielmehr eine Überexpression des Calretinin-Proteins im Hilus und in den Strati granulosum, -oriens und -radiatum der Regionen CA3 und CA1 detektiert (siehe Abschnitt 3.1.8). Die Axone der Mooszellen bilden eine auffällige, aberrante Projektion in das Stratum radiatum der Region CA3 und in das Stratum moleculare des Gyrus dentatus (Abb. 3.10 B) und projizieren dort überwiegend auf asymmetrische, glutamaterge Synapsen (Abb. 3.10 E). Diese Zunahme aberranter exzitatorischer Projektionen auf Pyramiden- und Körnerzellen im Hilus und im Stratum moleculare könnte die in der PLC- $\beta 1_{\mathrm{TC}}{ }^{-/-}$-Maus beobachtete progressive Hyperexzitabilität erklären. Eine Konservierung Calretinin-immunreaktiver Neurone wurde auch im Hippocampus von Ratten nach Fimbria/Fornix-Läsionen (Beck et al. 1994) und bei TLE-Patienten mit Ammonshorn-Sklerose (AHS) beschrieben (Blümcke et al. 1996). Bei TLE-Patienten mit AHS geht die Konservierung auch mit einer Zunahme und Reorganisation des Calretinin-immunreaktiven Neuropils in der Molekularschicht des Gyrus dentatus und im Stratum moleculare-lacunosum und Stratum radiatum der Regionen CA3 und CA1 einher (Blümcke et al. 1996). Die Frage, ob die Ausbildung dieser aberranten Calretinin-positiven Projektionen zeitlich mit dem 
Beginn der Hyperexzitabilität in der PLC- $\beta 1_{\mathrm{TC}}^{-/-}$-Maus korelliert, konnte in der vorliegenden Arbeit nicht weiter untersucht werden.

In den hippocampalen Regionen CA3 und CA1 der PLC- $31_{\mathrm{TC}^{-/-}}$-Maus konnten sowohl asymmetrische, glutamaterge Synapsen (von Mooszell-Axonen) als auch symmetrische, GABAerge Synapsen (von inhibitorischen Interneuronen, Abb. 3.10 F) immunhistologisch nachgewiesen werden. Symmetrische, GABAerge-Synapsen existieren im adulten Hippocampus in allen Strati (Gulyas et al. 1992), während asymmetrische, glutamaterge Synapsen der Mooszellen nur im Gyrus dentatus nachweisbar sind (Buckmaster et al. 1996; Wenzel et al. 1997). Die zelluläre Natur der CalretininÜberexpression in den Regionen CA3 und CA1 konnte in dieser Arbeit nicht eindeutig geklärt werden, da sowohl glutamaterge als auch GABAerge Projektionen für das Calretinin-detektierte axonale „Sprouting“ in Frage kommen. Aberrantes Wachstum von GABAergen inhibitorischen Axonen kann in der frühen postnatalen Entwicklung auch auf organotypischen Hippocampusschnitten nach Blockade der inhibitorischen Aktivität von $\mathrm{GABA}_{\mathrm{A}}$-Rezeptoren mittels Bicucullin $\left(\mathrm{GABA}_{\mathrm{A}}\right.$-Rezeptor-Antagonist; Abb. 4.3) überwiegend im Stratum oriens der Regionen CA3 und CA1 beobachtet werden. Der Verlust der Inhibition führt dort zu einem kompensatorischen Auswachsen inhibitorischer GABAerger Interneurone (Marty und Onteniente 1997). Möglicherweise führt der postulierte Verlust an cholinerger Inhibition in der PLC- $\beta 1_{\mathrm{TC}}{ }^{-/-}$-Maus (siehe Abschnitt 4.2.4) zu vergleichbaren kompensatorischen „Sprouting“-Prozessen inhibitorischer GABAerger Interneurone in der Region CA3 und CA1. Diese Hypothese müsste mit immunhistologischen und elektronenmikroskopischen Methoden in einer postnatalen Entwicklungsstudie geprüft werden, wobei zusätzlich eine Quantifizierung der symmetrischen- und asymmetrischen Synapsen in den jeweiligen Regionen erfolgen sollte. Daher konnte diese Hypothese in der vorliegenden Arbeit nicht weiter untersucht werden

\subsection{Molekulare Mechanismen des axonalen Wachstums und der Synaptogenese in epileptischen Tiermodellen und bei der Temporallappen-Epilepsie des Menschen}

Das in der vorliegenden Arbeit etablierte PLC- $\beta 1_{\mathrm{TC}}^{-/-}$-Mausmodell zeigt im adulten Tier ausgeprägte axonale Reorganisationen, deren zeitliche Entwicklung mit dem Auftreten von hyperexzitatorischen- und hypokinetischen Verhaltensauffälligkeiten korreliert. Die axonalen Reorganisationen betreffen in erster Linie das hippocampale Moosfaser-System. Das Moosfaser-System wurde mit der Timm-SilbersulfidFärbetechnik zur Darstellung zinkhaltiger synaptischer Vesikel (Danscher und Zimmer 
1978) auf Hippocampusschnitten von PLC- $\beta 1_{\mathrm{TC}}{ }^{-/-}$-Mäusen dargestellt. Dabei wurde eine massive Vergrößerung der suprapyramidalen Moosfaserprojektion in der CA3Region des Hippocampus (SP-MF-Hyperplasie) und ein starkes Auswachsen (,Sprouting“) von supragranulären Moosfasern auf die Dendritenbäume der Granularzellen in der inneren Molekularschicht dokumentiert (siehe Abschnitt 3.1.7). Weitere Reorganisationen wurden bei 8 Monate alten PLC- $B 1_{\mathrm{TC}^{-/-}}$-Mäusen im axonalen Calretinin-immunreaktiven Zellsystem gefunden (siehe Abschnitt 3.1.8). Bei dieser morphologischen Veränderung konnte bisher kein Verhaltens-Korrelat und auch keine zeitliche Korrelation nachgewiesen werden.

In der Literatur zu den induzierten Formen axonalen „Sproutings“, und zwar sowohl nach elektrogener- oder Medikamenten-induzierter Exzitation als auch nach afferenten Läsionen wird der durch Exzitation induzierte selektive Zellverlust als die „treibende“ Kraft bei der Epileptogenese angesehen (Sloviter 1987; de Lanerolle et al. 1989; Buckmaster und Dudek 1997; Mohapel et al. 1997; El Bahh et al. 1999; Routbort et al. 1999; Gorter et al. 2001). Für eine Vielzahl von Neuronen konnte eine Sensibilität zu wiederholter exzitatorischer Erregung nachgewiesen werden. Dazu zählen sowohl Körner- und Pyramidenzellen als auch Interneurone des Gyrus dentatus und der Regionen CA3 und CA1 (Nadler 1981; Sloviter 1983; Sloviter 1996). Diese primär exzitatorischen Erregungen können experimentell durch unterschiedliche Strategien herbeigeführt werden (siehe Abb. 4.3) und führen primär zu einem „Status epilepticus“ von begrenzter Dauer, der sich durch akute epileptische Anfälle äußert, die sich nach einiger Zeit normalisieren. Erst nach Tagen oder Wochen kommt es schließlich zur Ausbildung spontaner wiederkehrender epileptischer Anfälle. In den unterschiedlichen Modell-Systemen ist das Auftreten der Hyperexzitabilität und der wiederkehrenden epileptiformen Anfälle meist immer mit einem selektiven inhibitorischen Zellverlust korelliert, wie er auch in der PLC- $\beta 1^{-/-}$-Maus (Kim et al. 1997) und in der hier beschriebenen PLC- $\beta 1_{\mathrm{TC}^{-/}}$-Maus detektiert werden konnte. Dieser spezifische Verlust inhibitorischer Interneurone führt in den meisten Fällen zu einer Verminderung der hippocampalen Inhibition (Sloviter 1987) und zur Potenzierung der Exzitation (siehe Abb. 4.3). Die Literatur zur Notwendigkeit von axonalem „Sprouting“ bei der Generierung von wiederkehrender Hyperexzitabilität ist bis heute kontrovers (Silva und Mello 2000). Es ist bekannt, dass supragranuläres Moosfaser-,,Sprouting“ nur zusammen mit Zellverlust im Hilus oder in der CA3-Region aufritt, und dass diese in ihrer Intensität miteinander korrelieren (Houser et al. 1990; Babb et al. 1991). Eine zwingende Kausalität zwischen dem Auftreten wiederkehrender epileptischer Anfälle und der Notwendigkeit von Moosfaser-,,Sprouting“ konnte bisher allerdings nicht 
bewiesen werden. Aberrantes Moosfaser-,,Sprouting“ ist allein nicht ausreichend für die Ausbildung von Hyperexzitabilität. Zu diesem Ergebnis kamen Clusmann et al. (1992), die an organotypischen Hippocampusschnitten der Ratte zeigen konnten, dass „Kindling“-induziertes Moosfaser-,,Sprouting“ keinen Anstieg des erregenden postsynaptischen Potentials (EPSP) im Hippocampus induziert. Allerdings konnte Gorter et al. (2001) das induzierte supragranuläre Moosfaser-,,Sprouting“ in elektrisch stimulierten Ratten mit einer massiven Progression spontaner epileptiformer Anfälle korrelieren. Eine solche Progression hyperexzitatorischer Verhaltensweisen konnte auch in der vorliegenden Arbeit mit dem Auftreten von supragranulärem Moosfaser„Sprouting“ korreliert werden.

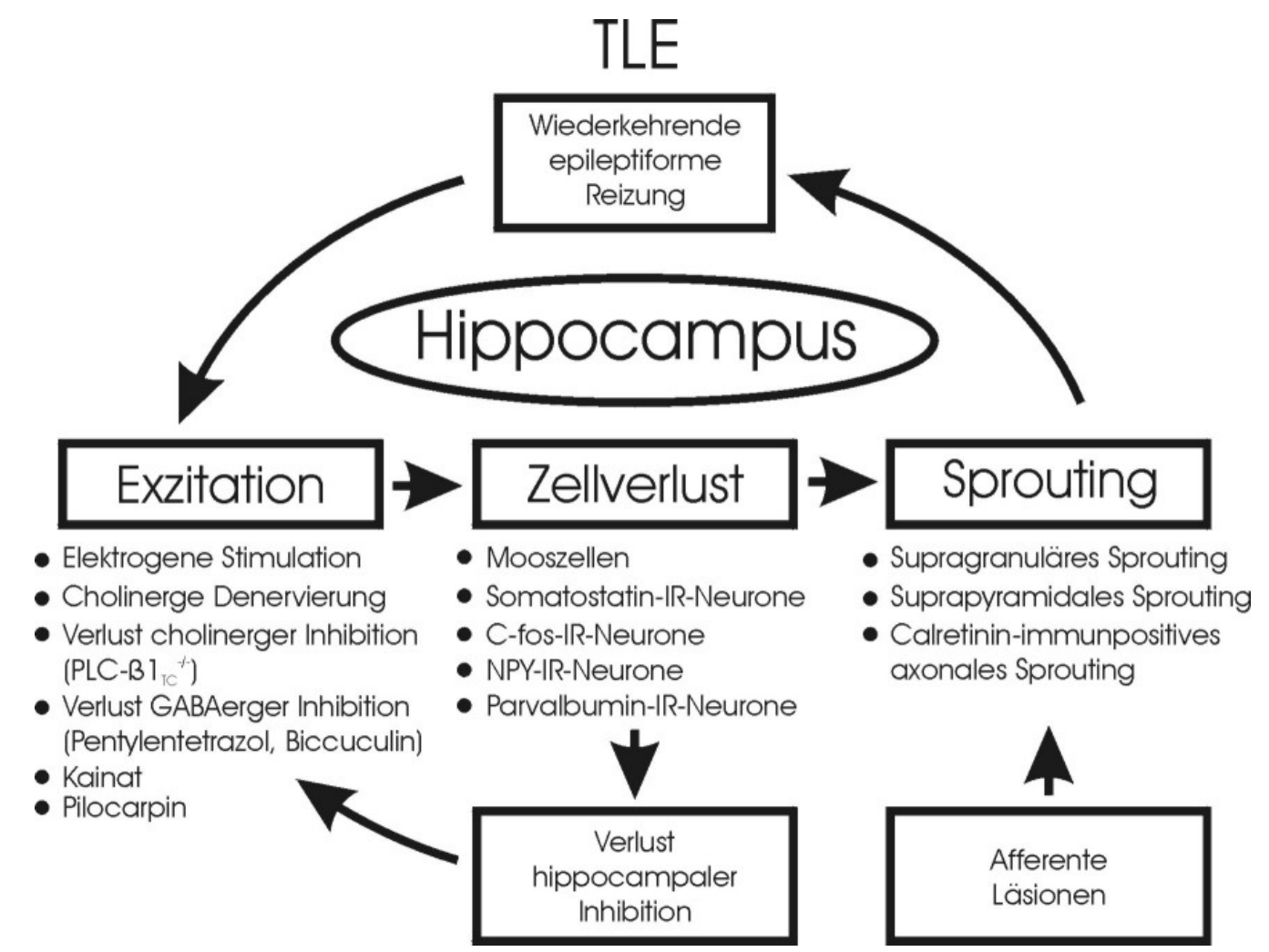

Abb. 4.3: Schematisches Flussdiagramm zur Theorie der Epileptogenese in verschiedenen ModellSystemen der Maus und der Ratte und bei der humanen Temporallappen-Epilepsie (TLE) (IR = Immunreaktiv).

Die präzisen molekularen Mechanismen dieses aberranten axonalen Wachstums und der anschließenden Synaptogenese sind bis heute größtenteils unverstanden, es gibt jedoch Hinweise, dass „Immediate early“-Gene (IEG) (z.B. c-fos, c-jun; Dragunow und Robertson 1987; Simonato et al. 1991; Hosford et al. 1995) und Neurotrophine (z.B FGF-2 und NGF1-B; Fagan et al. 1997; Watson und Milbrandt 1989) als sogenannte „third messenger“ in der intrazellulären Signaltransduktions-Kaskade agieren und 
axonales Wachstum und Synaptogenese induzieren. So konnte Woldbye et al. (1996) zeigen, dass die c-fos-Expression im Stratum granulosum des Gyrus dentatus in Ratten massiv und von kurzer Dauer nach elektrogener Stimulation („Kindling“) induziert wird. Ferner läßt sich, wie in den Arbeiten von Longo und Mello (1997) und Silva und Mello (2000) gezeigt wurde, das Pilocarpin- und Kainat-induzierte Moosfaser„Sprouting“ durch Inhibition der Proteinsynthese mittels Cycloheximid (CHX) blockieren. Untersuchungen haben ergeben, dass Kainat-induzierte epileptische Anfälle durch die direkte Aktivierung von Glutamatrezeptoren der AMPA/Kainat-Klasse und indirekt durch die Ausschüttung exzitatorischer Aminosäuren von Nerven-Terminalien (Ferkany et al. 1984; Ben-Ari 1985) hervorgerufen werden, und dass die c-fosExpression über die Aktivierung von Glutamat-Rezeptoren induziert wird (Murphy et al. 1991; Bading et al. 1993; Lerea und McNamara 1993).

In zahlreichen Arbeiten wurde postuliert, dass einige der potentiellen Zielgene für IEGs für die anhaltende synaptische Reorganisation der Körnerzellen in den experimentellinduzierten Tiermodellen verantwortlich sind. Diese Zielgene kodieren für neurotrophe Faktoren wie z.B. „nerve growth factor“ (NGF), „brain-derived neurotrophic factor“ (BDNF; Ernfors et al. 1991), „ㅁasic fibroblast growth factor“ (bFGF; Bugra et al. 1994; Gall et al. 1994), Rezeptoren für neurotrophe Faktoren (z.B. TrkB und FGFR-1; Bengzon et al. 1993) und axonale Wachstums-assoziierte Proteine, wie z.B. GAP-43 (Bendotti et al. 1993; Meberg et al. 1993). Da neurotrophe Faktoren morphoregulatorische Effekte auf Neuronen des Hippocampus bewirken und unter anderem axonales Wachstum induzieren, könnte die experimentell induzierte Expression dieser Gene eine ursächliche Wirkung auf die morphologischen Rearrangements in den Axonen der Körnerzellen ausüben (Ip et al. 1993; Patel und McNamara 1995; Klein et al. 1999).

In der vorliegenden Arbeit wurde dieser Hypothese folgend die hippocampale Expression des „Immediate early“-Gens c-fos (siehe Abschnitt 3.1.10) und des neurotrophen Faktors GAP-43 in drei- und neun Monate alten PLC- $\beta 1_{\mathrm{TC}^{-/-}}$-Mäusen sowohl auf RNA- als auch auf Protein-Ebene untersucht. In diesen Untersuchungen konnte entgegen der Annahme keine Zunahme der Expression für c-fos (Abb. 3.14) und GAP-43 (nicht dargestellt) dokumentiert werden. Es existiert allerdings die Möglichkeit, dass der Zeitpunkt der putativen, differenziellen c-fos- und GAP-43Expression verfehlt wurde. Für die „Kindling“-induzierte c-fos-Expression im Stratum granulosum des Gyrus dentatus konnte auf Protein-Ebene tatsächlich gezeigt werden, dass diese nur unmittelbar nach der Stimulation für einen kurzen Zeitraum von bis zu zwei Stunden detektierbar ist (Woldbye et al. 1996). Für die neurotrophen Faktoren 
BDNF, NGF und Neurotrophin-3 und für die Tyrosinkinase C-Rezeptoren TrkB und TrkC sowie für GAP-43 wurde nach „Kindling“-induziertem axonalem Wachstum auf mRNA-Ebene eine transiente Expression von 24 Stunden Dauer nach Induktion nachgewiesen (Elmer et al. 1996). GAP-43 Protein wurde in einer Untersuchung von Bendotti et al. (1994) nach Kainat-induzierten epileptischen Anfällen maximal nach 30 Tagen quantifiziert und anschließend nur mit abnehmender Intensität detektiert.

\subsection{Der Hippocampus und die Langzeitpotenzierung}

Bereits in 3 Monate alten PLC- $31_{\mathrm{TC}^{-/-}}$-Mäusen wurde eine signifikante Beeinträchtigung des räumlichen Gedächtnisses gegenüber entsprechenden Wildtyp(PLC- $\beta 1_{\mathrm{WT}}{ }^{+/+}$) und heterozygoten PLC- $\beta 1_{\mathrm{TC}}{ }^{+/-}$-Mäusen dokumentiert (siehe Abschnitt 3.1.6). Es ist bekannt, dass die Hippocampus-Formation eine entscheidende Rolle bei Lern- und Gedächtnisfunktionen in Primaten (Squire 1987; Zola-Morgan et al. 1989; Squire und Zola-Morgan 1991; Rolls 1996; Henke et al. 1997) und in Nicht-Primaten (Tsien et al. 1996b; Steckler et al. 1998) spielt. Nach bilateraler Resektion der medialen temporalen Lobi und der Hippocampi bei Patienten mit medikamentös nicht behandelbarer Temporallappen-Epilepsie (TLE) (Zola-Morgan et al. 1986; Scoville und Milner 2000) wurde eine anhaltende anterograde Amnesie diagnostiziert, die die Bildung neuer Langzeitgedächtnisinhalte bei intaktem Kurzzeit- und Langzeitgedächtnis beeinträchtigt. Dies konnte durch Lernexperimente nach hippocampalen Läsionen bei Mäusen (Cho und Jaffard 1995; Farr et al. 2000) und Ratten (Bannerman et al. 1999) bestätigt werden.

Die Neuronen des im Abschnitt 1.4 dargestellten trisynaptischen, glutamatergen Schaltkreises der Hippocampus-Formation (Abb. 1.3, S. 6) sind für die Speicherung expliziter Gedächtnisinhalte von größter Bedeutung. Es liegen Hinweise vor, dass Neurone im Hippocampus genau jene Plastizität aufweisen, die man für die Bildung dieser expliziten Erinnerungen fordern muss. Eine kurze, hochfrequente Salve von Impulsen, die auf irgendeines der drei hippocampalen Axonbündel (siehe Abb. 1.3) übertragen wird, erhöht die exzitatorischen, postsynaptischen Signale der Hippocampusneurone (Bekkers und Stevens 1990). Diese Verstärkung der postsynaptischen Reaktion kann im Labor ex vivo an hippocampalen Hirngewebeschnitten der Ratte über mehrere Stunden (Bonhoeffer et al. 1989; Huang et al. 1994) und am Tier-Modell in vivo über Tage und sogar Wochen nachgewiesen werden (Bliss und Gardner-Medwin 1973; Bliss und Lomo 1973). Man spricht von Langzeitpotenzierung (LTP = LongTerm Potentiation). Sowohl ionotrope als auch metabotrope Glutamat-Rezeptoren sind an der Ausbildung von Langzeitpotenzierung im Hippocampus beteiligt und 
unentbehrlich. Eine Mausmutante, bei der das Gen für den metabotropen GlutamatRezeptor 1 (mGluR1) über homologe Rekombination ausgeschaltet wurde, zeigt einen Verlust der Langzeitpotenzierung und weist Störungen im assoziativen Lernvermögen auf (Aiba et al. 1994). Die räumlich auf die Pyramidenzellen der hippocampalen CA1Region begrenzte Ausschaltung des Gens für den ionotropen Glutamat-Rezeptor vom NMDA-Typ (NMDAR1) führt bei den Mäusen zu fehlender Langzeitpotenzierung in der Region CA1 und zu gestörtem räumlichen Lernen (Tsien et al. 1996b). Diese Mausmutante ist bezüglich ihrer NMDA-Rezeptordichte in der hippocampalen CA1Region mit der in dieser Arbeit analysierten PLC- $\beta 1_{\mathrm{TC}^{-/}}$-Maus vergleichbar (siehe Abschnitt 3.1.9). Daher kann die bei der PLC- $\beta 1_{\mathrm{TC}}{ }^{-/-}$-Maus dokumentierte Reduktion der NMDA-Rezeptordichte als ursächlich für die Lerndefizite interpretiert werden.

Die Information über die räumliche Aufenthaltsposition scheint in den Pyramidenzellen des Hippocampus in einer räumlichen Karte angelegt zu sein (O'Keefe und Dostrovsky 1971). Dies konnte durch in vivo -Aufzeichungen der neuronalen Aktivität mittels multipler Elektrodenableitungen an „frei beweglichen“ Ratten und Mäusen gezeigt werden. Definierte Pyramidenzellen im Hippocampus „feuerten“ wiederholt genau dann, wenn das Tier sich in einer bestimmten begrenzten Region der Versuchsapparatur aufhielt. Jedem Aufenthaltort konnte auf diese Weise ein spezifisches hippocampales Zellfeld zugeordnet werden (Wilson und McNaughton 1993). Auch an der Ausbildung dieser hippocampalen Felder scheinen Glutamat-Rezeptoren beteiligt zu sein, wie die Arbeiten von McHugh et al. (1996) an der CA1-regionalen NMDAR1-,_Knock-out“Maus zeigen. NMDAR1-defiziente Mäuse weisen dabei eine signifikante Abnahme der räumlichen Spezifität dieser Feuerungsmuster auf. Auch bei den PLC- $\beta 1_{\mathrm{TC}}{ }^{-/-}$-Mäusen muss ein Verlust der hippocampalen Langzeitpotenzierung in der CA1-Region und ein CA1-spezifischer Verlust der räumlichen Aufenthaltsposition postuliert werden. Mehrere in vitro- und in vivo- Experimente haben gezeigt, dass die Expression von „Immediate early“-Genen der fos-Familie (c-fos, FosB, fra-1, fra-2) in neuronalen Zellen durch die Aktivierung von NMDA- Rezeptoren induziert werden kann (Lerea et al. 1992; Bading et al. 1993) und dass deren Expression über die hippocampale Langzeitpotenzierung moduliert wird (Demmer et al. 1993). Möglicherweise induziert der putative Verlust der Langzeitpotenzierung in der Region CA1 aufgrund der reduzierten NMDA-Rezeptordichte den nachgewiesenen Verlust der c-fos-Expression und weiterer Gene der fos-Familie. So konnte bei weiblichen FosB-,,Knock-out“Mäusen ein aberrantes Brutpflege-Verhalten ähnlich dem bei PLC- $\beta 1_{\mathrm{TC}}{ }^{-/-}$-Mäusen (siehe Abschnitt 3.1.5) beschrieben werden (Brown et al. 1996). Eine c-fos-,,Knockout"-Maus zeigt diesen Phänotyp allerdings nicht, weist aber gegenüber Wildtypmäusen 
nach Induktion ein abgeschwächtes axonales Wachstum auf (Watanabe et al. 1996). Diese Überlegungen sprechen daher eher für die Hypothese, dass die kognitiven Lerndefizite in den weiblichen PLC- $\beta 1_{\mathrm{TC}}{ }^{-/-}$-Mäusen für das gestörte BrutpflegeVerhalten ursächlich sind.

\subsection{Die Familie der Phospholipasen C}

\subsubsection{Die Struktur, Funktion und Evolution der Phosphoinositol-spezifischen Phospholipasen $\mathrm{C}$ beim Säuger}

Phosphoinositol-spezifische Phospholipasen C (PI-PLC) bilden eine Familie verwandter Isozyme, die intrazellulär reversibel an Membranen assoziiert vorliegen und die Hydrolyse des Membranbausteins Phosphatidylinositol-4,5-Bisphosphate $\left(\mathrm{PIP}_{2}\right)$ in die beiden „Second-messenger"-Moleküle Inositol-1,4,5-Trisphosphat ( $\left.\mathrm{IP}_{3}\right)$ und Diacylglycerol (DAG) katalysieren. $\mathrm{IP}_{3}$ vermittelt anschließend eine intrazelluläre $\mathrm{Ca}^{2+}$ Ausschüttung aus den Speichern des endoplasmatischen Retikulums (Abb. 4.4 A) und DAG aktiviert zusammen mit $\mathrm{Ca}^{2+}$ membranständig Proteinkinasen $\mathrm{C}$ (PKC) (Abb. 4.4 B). Damit übernehmen die PI-PLC Enzyme eine Schlüsselrolle im Rezeptorvermittelten Signaltransduktionsweg, bei dem ein extrazelluläres Signal eines Transmitters oder Hormons an seinem Rezeptor in ein intrazelluläres Signal transduziert wird und zelluläre Antworten induziert. 


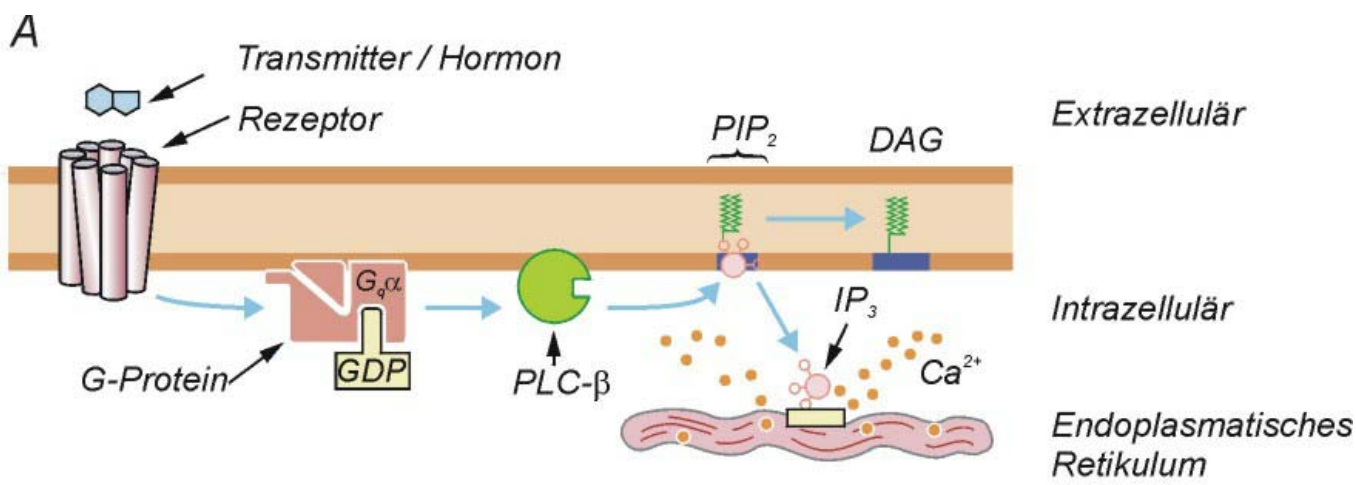

$B$

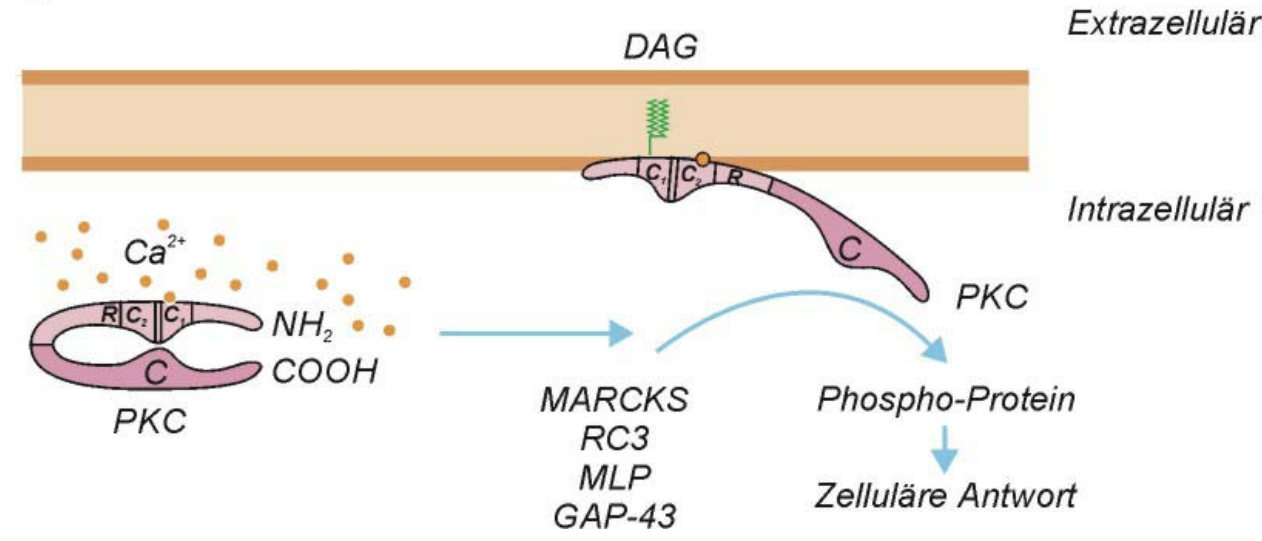

Abb. 4.4: Schematische Darstellung der PLC- $\beta$-vermittelten Signaltransduktion (A) und der DAGinduzierten Aktivierung zytosolischer Protein-Kinasen C (PKC) (B). Das PLC- $\beta$-Isozym wird über einen G-Protein-gekoppelten Rezeptor vom Rhodopsin-Typ (mit 7 TransmembranDomänen) und Freisetzung der $G_{q} \alpha$-Untereinheit aktiviert und katalysiert die Hydrolyse von $\mathrm{PIP}_{2}$ in die beiden intrazellulären ,Second-messenger " -Moleküle $\mathrm{IP}_{3}$ und DAG. $\mathrm{IP}_{3}$ induziert die $\mathrm{Ca}^{2+}$-Freisetzung aus dem endoplasmatischen Retikulum (A). Membranständiges DAG und $\mathrm{Ca}^{2+}$-Ionen rekrutieren zytosolische PKC an die Plasmamembran und induzieren die PKC-katalysierte Phosphorylierung spezifischer Substrat-Moleküle (MARCKS, RC3, MLP, GAP-43) und eine intrazelluläre Antwort. (DAG $=$ Diacylglycerol, $I P_{3}=$ Inositol-1,4,5Trisphosphat, $\mathrm{PIP}_{2}=$ Phosphatidylinositol-4,5-Bisphosphate, $P K C=$ Proteinkinase $C, P L C=$ Phospholipase C).

Die Identifizierung der Phosphoinositol-spezifischen Phospholipasen C (PI-PLC) als Schlüsselenzyme zur $\mathrm{IP}_{3}$ - und DAG-vermittelten Signaltransduktion geht auf Arbeiten von Hokin und Hokin (1953) und Michell (1975) zurück (Überblick in: Berridge und Irvine 1984). Im folgenden wurden diverse PLC-Isozyme isoliert (Rhee et al. 1989) und deren cDNAs vom Rind (Stahl et al. 1988) und Ratte (Suh et al. 1988a; Suh et al. 1988b) kloniert (Überblick in: Rhee und Choi 1992). Zur Zeit sind beim Säuger zehn Phospholipase C -Isozyme beschrieben (Übersichten in: Williams und Katan 1996; Williams 1999; Rebecchi und Pentyala 2000). Auf der Grundlage Ihrer Größe, Struktur und dem Mechanismus ihrer Aktivierung wurden die PI-PLC Isozyme in drei Klassen gruppiert, die mit PLC- $\beta$ 1-4, PLC- $\gamma$ 1-2 und PLC- $\delta$ 1-4 bezeichnet werden (Abb. 4.5). In allen Phospholipase C -Isozymen existiert eine PLC- $\delta$-ähnliche Kern-Struktur (Abb. 
4.5 A-C), die man bereits bei einzelligen Eukaryoten (z.B. Saccharomyces cerevisae; Flick und Thorner 1993) und bei Pflanzen findet (z.B. Dictyostelium discoideum; Drayer und van Haastert 1992), und die in der Evolution als ursprünglich angesehen wird (Rebecchi und Pentyala 2000). Diese Kern-Struktur ist in den PLC- $\beta$ - und PLC- $\gamma$ Isozymen der Parazoa (z.B. dem Süßwasserschwamm Ephydatia fluviatilis; Koyanagi et al. 1998) und bei den Eumetazoa (z.B. Caenorhabditis elegans; Lackner et al. 1999 und Drosophila melanogaster; Shortridge et al. 1991), sowie in den Mammalia modular erweitert (Übersicht in: Rebecchi und Pentyala 2000). Die amino-terminale Region der Kern-Struktur enthält eine Pleckstrin-Homologie Domäne (PH-Domäne, Haslam et al. 1993), die eine Bindungsaffinität zu dem Membranbaustein PIP $_{2}$ besitzt (Lemmon et al. 1995) und das PLC-Molekül an sein Substrat bindet. Über die nachfolgenden vier EFHand-Domänen wird die katalytische Domäne flexibel mit der PH-Domäne und dem Substrat verbunden. Die katalytische Domäne besteht aus zwei hochkonservierten Regionen ( $\mathrm{X}$ und $\mathrm{Y}$ ), die eine hohe Homologie $\mathrm{zu}$ der Triose-Phosphat-Isomerase (TIM) aufweisen, die bereits in der einzigen Phospholipase C bei Prokaryoten (z.B. Bacillus cereus; Kuppe et al. 1989) die Hydrolyse der Sauerstoff-Phosphor-Bindung (OP) zwischen Phosphoinositol und Diacylglycerol (DAG) katalysiert. Diese hochkonservierten Regionen X und Y werden bei den PLC- $\delta$ - und PLC- $\beta$-Isozymen durch eine weniger konservierte Insertion (X/Y-Insertion) getrennt. Diese Insertion enthält Bindungsstellen für regulatorische $\beta \gamma$-Untereinheiten heterotrimerer G-Proteine (Lee et al. 1993; Kuang et al. 1996). Die PLC- $\gamma$-Isozyme weisen in dieser Region eine weitere PH-Domäne auf, die durch zwei SH2-Domänen und eine SH3-Domäne (Z-Insertion) unterbrochen ist, und die zur Regulation der PLC- $\gamma$-Enzymaktivität über membranständige Tyrosinkinasen essentiell sind (Horstman et al. 1999). Die C2-Domäne am

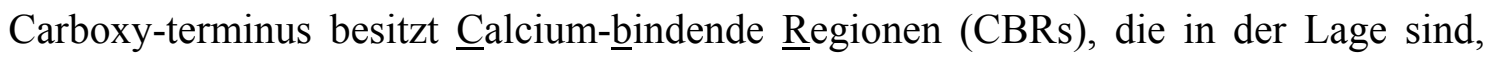
Proteine in Calcium-abhängiger Weise an Lipidmembranen zu binden (Ponting und Parker 1996). Es gibt Hinweise, dass diese CBRs auf diesem Wege auch PLC-Moleküle an der Membran fixieren können (Nalefski und Falke 1996). Nur die PLC- $\beta$-Isozyme besitzen eine C-terminale Erweiterung von etwa 400 Aminosäuren (Abb. 4.5). Für diese Isozyme konnte gezeigt werden, das ihre C-terminale Erweiterung Sequenzen enthält, die für die Aktivierung durch $\alpha-\left(\mathrm{G}_{\mathrm{q}} \alpha\right.$ oder $\left.\mathrm{G}_{11} \alpha\right)$ oder $\beta \gamma$-Untereinheiten Rezeptorgekoppelter heterotrimerer G-Proteine (Abb. 4.4 A; Wu et al. 1993) entscheidend sind. Für diese Region ist weiterhin bekannt, dass auch sie die Bindung an Phospholipide (Jenco et al. 1997; Kim et al. 1996) und eine Lokalisierung im Nukleus (Kim et al. 1996) regulieren kann (Übersicht in: Rebecchi und Pentyala 2000). 


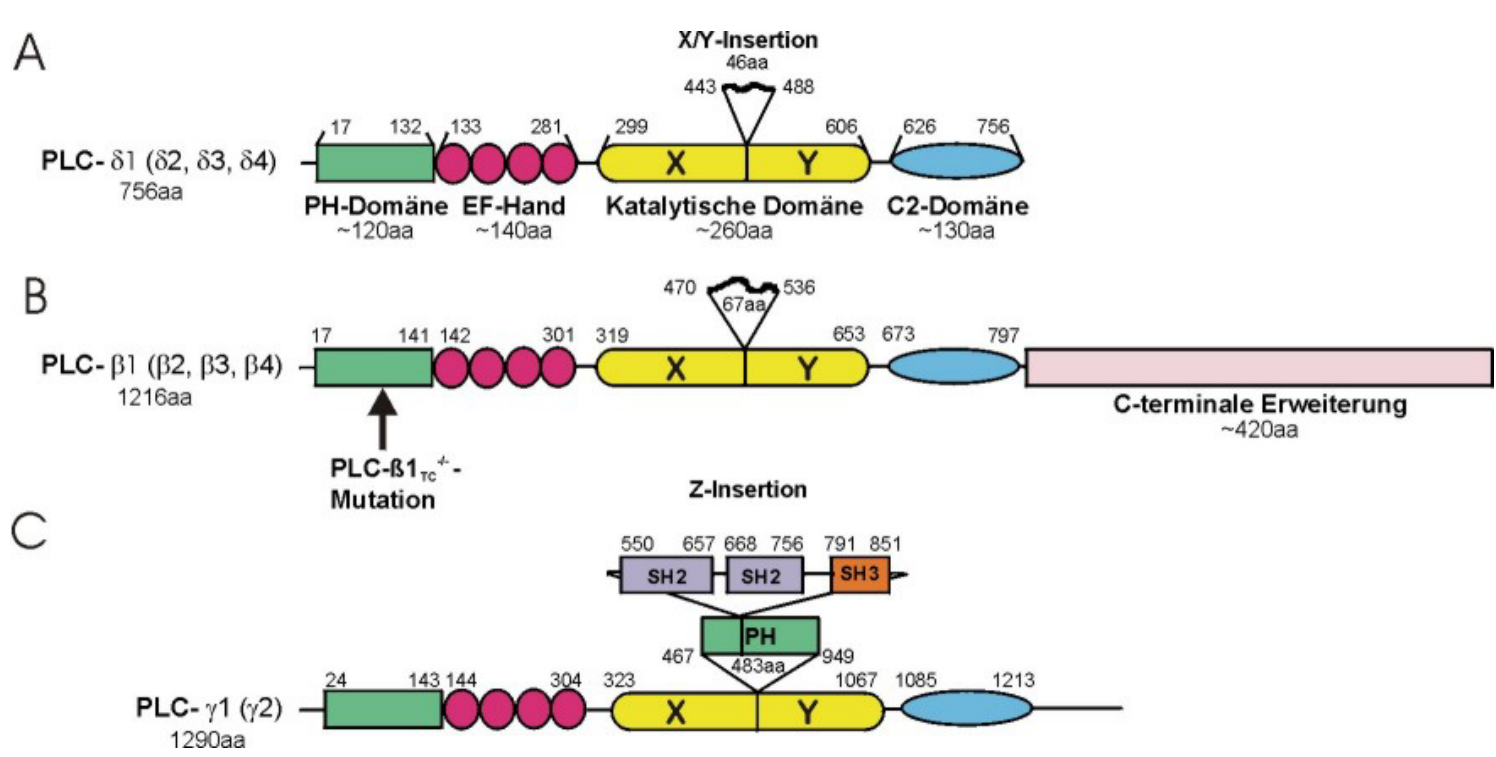

Abb. 4.5: Schematische Darstellung der Domänen-Struktur der Phosphoinositol-spezifischen Phospholipasen C (PI-PLC) beim Säuger. In (A) sind die PLC- $\delta$-Isozyme dargestellt und die Domänen der Kernstruktur benannt, die Homologie zu den PLC- $\beta$ - (B) und PLC- $\gamma$-Isozymen aufweisen. Über die Kernstruktur hinausgehende Domänen sind in (B) und (C) bezeichnet. Die nachgewiesene Mutation im PLC- $\beta 1$-Protein ist durch einen Pfeil $(\uparrow)$ markiert. Die putativen Domänen-Grenzen sind für das jeweils erste Isozym durch Nummerierung der AminosäurePositionen vom N-terminalen Ende ausgehend indiziert ( $a a=$ Aminosäure, $C$ - $=$ Carboxy-, EF-Hand = Domäne aus einer Helix E, einer Schleife und einer Helix F, PLC = Phospholipasen C, PH = Pleckstrin-Homologie, $\mathrm{SH}=$ Src-Homologie ).

\subsubsection{Die Expression der Phospholipase C- $\mathrm{B}$-Isozyme}

In Säugern wurden bisher vier ß-Isoformen und einige Spleiß-Varianten identifiziert. Das PLC-ß1-Protein besitzt von allen vier ß-Isoformen bei den Säugern das breiteste Expression-Spektrum, allerdings mit der stärksten Expression in spezifischen Regionen des Gehirns (Gerfen et al. 1988; Mizuguchi et al. 1991; Rhee et al. 1991; Yamada et al. 1991; Ross et al. 1989; Tanaka und Kondo 1994). Die ersten frühen Studien zur Phospholipase C-ß1-Expression gehen auf die Arbeiten von Suh et al. (1988b) und Homma et al. (1989) zurück, in denen die PLC-ß1-Expression in Poly-A ${ }^{+}$-RNA aus dem Gehirn (Suh et al. 1988b) und aus diversen Organen der Ratte (Homma et al. 1989) besonders stark im Gehirn als 7,2- und 5,4 kb-Transkripte detektiert werden konnte. Nach verlängerter Expositionszeit wurde auch eine schwache Expression beider Transkripte in Poly-A ${ }^{+}$-RNA aus Leber, Niere, Lunge, Skelett-Muskel, Herz, Magen, Milz und Testis nachgewiesen (Homma et al. 1989). In der selben Arbeit wurde auch eine starke Expression in der glialen Zellinie C6Bu-1 der Ratte detektiert. Freeman et al. (1998) konnten in einer groß angelegten RT-PCR-basierten Expressions-Studie an Gesamt-RNA aus 46 verschiedenen Geweben der Maus diese Ergebnissse größtenteils bestätigen und die Expression von PLC-ß1-Transkripten semi-quantitativ 
dokumentieren (siehe www.informatics.jax.org). In dieser Analyse wurde eine starke PLC-ß1-Expression nur im Striatum und im Bulbus olfactorius sowie eine moderate Expression in nahezu allen Regionen des Gehirns (Cortex, Hippocampus, Mittelhirn und Cerebellum) nachgewiesen. Auch hier konnte eine PLC-ß1-RNA-Expression in den Organen Herz, Lunge, Leber, Niere, Testis und Ovar dokumentiert werden. Keine PLC-ß1-Expression war in RNA aus Milz, Pankreas, Haut, Zunge, Thymus und Oberschenkel-Knochen detektierbar. In RNA-in-situ-Hybridisierungs-Studien mit ${ }^{35} \mathrm{~S}$ markierten Isoform-spezifischen cDNA-Proben der PLC- $\beta$-Isozyme (PLC-ß1-ß34) konnten Tanaka und Kondo (1994) sowie Watanabe et al. (1998) an Gehirnschnitten der Maus die regionale PLC-ß1-Expression im Gehirn konkretisieren und zeigen, dass im Gehirn der Maus eine Isoform-spezifische Expression in deutlich voneinander abgrenzbaren Arealen des Gehirns existiert. Im adulten Gehirn sind die PLC-ß1- und die PLC-ß4 -Isoformen weitaus am prominentesten exprimiert, wobei die ExpressionAreale deutlich voneinander abgegrenzt sind. PLC-ß1-mRNA-Expression wird stark in der Pyramiden- und Körnerzellschicht des Hippocampus, in den Schichten II-IV des cerebralen Cortex, im Bulbus olfactorius, in der Amygdala, im Caudate putamen (Striatum) und in den lateralen Septum-Kernen detektiert. In den Purkinje-, Körner- und Molekularschicht-Neuronen des Cerebellums ist hingegen nur eine schwache Expression dokumentiert. In diesen Regionen des Cerebellums ist die PLC-ß34Expression dominant. Zusätzlich findet man PLC-ß4-Expression auch abgeschwächt im Bulbus olfactorius, in den medialen Septum-Kernen und im Thalamus, also in den Regionen fehlender PLC-ß1-Expression. PLC-ß3-mRNA ist spezifisch und ausschließlich in der Purkinje-Zellschicht des Cerebellums exprimiert, während PLC-ß2-mRNA nur nach verlängerter Exposition schwach im Corpus callosum, in der Fimbria und in der Medulla zu detektieren war.

Im Western-Blot sind mit polyklonalen und monoklonalen Antikörpern gegen das Phospholipase-ß1-Protein im Gehirn der Ratte und des Rindes (Ryu et al. 1986; Ryu et al. 1987a; Ryu et al. 1987b) immunhistologisch zwei unterscheidbare Polypeptide mit einer Größe von $140 \mathrm{kDa}$ und $150 \mathrm{kDa}$ zu detektieren (Suh et al. 1988c; Bahk et al. 1994). Bahk et al. (1994) konnte weiterhin zeigen, dass die 7,2 kb- und 5,4 kb-PLC-ß1Transkripte in der Ratte durch alternatives Spleißen eines einzigen PLC-ß1-Gens gebildet werden. Durch Vergleich beider cDNA-Sequenzen wurde in dem 7,2 kbTranskript (PLC-ß1b) eine 118 bp große Insertion am 3'-Ende der cDNA und eine 1738 bp große Verlängerung der 3'-UTR identifiziert, die im Fall der PLC-ß1b-cDNA (7,2 kb) zu einer Verkürzung des „Open reading frame“(ORF) um 43 Aminosäuren und zum $140 \mathrm{kDa}$ großen PLC-ß1b-Protein führt (siehe auch Abb. 4.2 auf S. 135). Das 
5,4 kb-Transkript und das daraus synthetisierte $150 \mathrm{kDa}$-Protein wird jetzt in der Literatur mit PLC-ß1a bezeichnet (Bahk et al. 1998). In immunhistochemischen Untersuchungen an Gehirnschnitten der Ratte wurden die Ergebnisse der Expressionstudie von Watanabe et al. (1998) und Freeman et al. (1998) auf ProteinEbene bestätigt. Auch Gerfen et al. (1988) konnte die stärkste PLC-ß1-Immunreaktivität in den Neuronen des Striatums, in den Regionen Stratum oriens und Stratum radiatum des Hippocampus (im Neuropil der Pyramiden- und Körnerzellen) und im Neuropil des Cortex sowie schwach in einigen Regionen des Thalamus lokalisieren. Im Cerebellum der Maus konnte Martelli et al. (1996) eine spezifische Expression von PLC-ß1-Protein ebenfalls nur in den Purkinje-Zellen und schwach in der Molekularschicht dokumentieren. In der vorliegenden Arbeit konnte diese Gewebe- und Gehirnspezifische PLC-ß1-Expression auf RNA- (Abschnitt 3.4.1) und Protein-Ebene (Abschnitt 3.4.2) bestätigt werden.

\subsubsection{Subzelluläre Lokalisation des PLC-ß1-Proteins}

Nach der Homogenisierung von Geweben oder kultivierten Zellen in schwach ionischen Puffern und Fraktionierung der Zellbestandteile in eine nukleäre-, zytosolische- und partikuläre Zellmembran-Fraktion konnten die Phospholipase C-ß-Isozyme (PLC-ß1PLC-B4) zwar überwiegend in der Zellmembran-Fraktion aber auch in der nukleären Fraktion detektiert werden, während die PLC- $\delta$-und PLC- $\gamma$-Isozyme hauptsächlich in der zytosolischen Fraktion nachweisbar waren (Katan und Parker 1987; Lee et al. 1987; Ryu et al. 1987a; Jhon et al. 1993; Lee et al. 1993; Kim et al. 1996). Für das PLC-ß1 Isozym konnte Divecha et al. (1993) in der Leber der Ratte zeigen, dass allerdings nur $5 \%$ des gesamten PLC- $\$ 1$ Proteins nukleär lokalisiert sind. Auch hier fanden sich keine nukleär lokalierten $\delta$ - und $\gamma$-PLC-Isoformen. In Swiss 3T3-Zellen konnten Divecha et al. (1991) und Martelli et al. (1992) das PLC-ß1 -Protein fast ausschließlich im Nukleus lokalisieren, während Martelli et al. (2000) in Western-Blots an subzellulären Fraktionen aus NIH 3T3-Zellen zeigen konnten, dass sämtliche PLC-ß-Isozyme etwa gleichverteilt in den nukleären und in den zytosolischen Fraktionen vorliegen. Kim et al. (1996) konnten durch in-vitro Mutagenese konservierter Lysin- und Arginin-Cluster in der C-terminalen Erweiterung des PLC- $\beta 1$-Proteins und Deletion des gesamten C-terminalen Bereichs nach Expression in CV-1-, Rat-2- und Swiss 3T3-Zellen zeigen, dass das Kernlokalisierungs-Signal innerhalb von zwei konservierten Regionen innerhalb der C-terminalen Erweiterung lokalisiert ist. Obwohl die putativen Kernlokalisierungs-Signale sowohl in dem $140 \mathrm{kDa}$ großen PLC-ß1b-Protein als auch in dem $150 \mathrm{kDa}$ großen PLC-ß1a-Protein der Ratte enthalten sind, konnte Bahk et al. (1998) mit Subtyp-spezifischen Antikörpern in Lokalisierungs-Experimenten an der 
glialen Zellinie C6Bu-1 der Ratte zeigen, dass das 140 kDa große PLC-ß1b-Protein des alternativ gespleißten 7,2 kb PLC-ß1b-Transkripts präferentiell im Nukleus und das $150 \mathrm{kDa}$ große PLC-ß1a-Protein des PLC-ß1a-Transkripts $(5,4 \mathrm{~kb})$ überwiegend im Zytosol lokalisiert sind. In der vorliegenden Arbeit wurde in den getesteten Organe der Maus auf RNA-Ebene überwiegend das PLC-ß1b-Transkript (7,2 kb, Abschnitt 3.4.1) und mit dem verwendeten PLC- $\beta 1$-Antikörper das entsprechende $140 \mathrm{kDa}$-Protein (PLC-ß1b) im Hippocampus der Maus detektiert (Abb. 3.37 A, Abschnitt 3.4.2). In immunhistochemischen Untersuchungen mit dem PLC-ß1 -Antikörper an Hirnschnitten der Maus konnte dieses PLC-ß1b -Protein überwiegend in den zellarmen Schichten des Hippocampus detektiert werden (Abb. 3.37 B). Dieses Ergebnis würde gegen eine überwiegende Lokalisierung des PLC- $\beta 1 \mathrm{~b}$-Proteins im Nukleus von Neuronen sprechen. Die subzelluläre Lokalisation im Gehirn der Maus bedarf allerdings weiterer experimenteller Überprüfung, beispielsweise mit der Immun-Elektronenmikroskopie. In den immun-elektronenmikroskopischen Aufnahmen der Abb. 3.38 im Abschnitt 3.4.2 konnte diese Frage nicht abschließend beantwortet werden. Dort konnte nur die membran-assoziierte Lokalisierung der PLC-ß1-Proteine gezeigt werden.

Die Aktivierung der Zellmembran-gebundenen PLC-ß1- Isozyme über $\alpha-\left(G_{q} \alpha\right.$ oder $\left.\mathrm{G}_{11} \alpha\right)$ und $\beta \gamma$-Untereinheiten Rezeptor-gekoppelter G-Proteine wurde in vielen Arbeiten detailliert untersucht und ist bereits gut verstanden (Rebecchi und Pentyala 2000). Die Aktivität der nukleären PLC-ß-Isozyme wird unabhängig von den Zellmembranlokalisierten B-Isoformen auf noch unbekanntem Weg reguliert (Kim et al. 1996). Es wurde allerdings ein autonomer, nukleärer Phosphatidylinositol-Signalweg postuliert (Mazzoni et al. 1992; Marmiroli et al. 1994). Als gesichert gilt, dass die PLC-ßIsozyme auch im Nukleus die Phosphatidylinositol-Hydrolyse $\left(\mathrm{PIP}_{2}\right)$ in $\mathrm{IP}_{3}$ und Diacylglycerol (DAG) katalysieren, dabei den zytosolischen Phosphatidylinositol-Pool unverändert lassen (Marmiroli et al. 1994) und das Zellwachstum und die Zelldifferenzierung regulieren (Divecha et al. 1993; Marmiroli et al. 1994; York und Majerus 1994). Als gesichert gilt auch, dass es nach intranukleärer DAG-Freisetzung durch PIP $_{2}$-Hydrolyse zu einer Translokation von PKC an die Kern-Membran kommt (Divecha et al. 1991; Banfic et al. 1993; Neri et al. 1998). Fields et al. (1990) gelang es, nach PDGF - Stimulation (latelet-derived growth factor) von NIH / 3T3-Fibroblasten zu zeigen, dass die Translokation von PKC an die Kern-Membran auch zu dessen Aktivierung und zur PKC-katalysierten Phosphorylierung von Laminen (Typ A, B und C) der Kernlamina führt. In den Arbeiten von Tokui et al. (1991) und Irvine und Divecha (1992) wurden auch die DNA-Polymerase- $\beta$ und die Topoisomerase II als intranukleäres Substrat der PKC identifiziert. Ebenso gelang Marmiroli et al. (1994) der 
experimentelle Nachweis, dass Interleukin $1 \alpha$ die nukleäre PhosphatidylinositolHydrolyse über Aktivierung von nukleärem PLC-ß-Protein in der SaOS-2-Zellinie (humane Osteosarcoma-Zellinie) induziert. Eine der am besten untersuchten Signaltransduktions-Kaskaden an der Kernmembran ist die IGF-1 induzierte Aktivierung des nukleären PLC-ß1-Proteins in Swiss 3T3-Zellen, die zu einem Anstieg der nukleären Diacylglycerol-Konzentration (DAG) führt (Cocco et al. 1989) und eine Aktivierung der Proteinkinase-C- $\alpha$ (PKC- $\alpha$ ) (Divecha et al. 1991; Martelli et al. 1992) und die Stimulation der DNA-Synthese zur Folge hat (Manzoli et al. 1997). Der Mechanismus der nukleären PLC-ß1-Aktivierung ist noch nicht aufgeklärt (Rebecchi und Pentyala 2000). Allerdings konnten Martelli et al. (2000) kürzlich zeigen, dass das PLC-ß1b Protein nach Insulin-Induktion in NIH 3T3-Zellen durch eine nukleär tranlozierte MAPKinase (Mitogen-aktivierte Protein-Kinase, ERK1 oder ERK2) an Serin-Resten phosphoryliert wird und die PLC- $\beta 1 \mathrm{~b}$ katalysierte Phosphatidylinositol-Hydrolyse induziert. Möglicherweise sind bei der PLC- $\beta 1_{\mathrm{TC}}^{-/-}$-Maus bisher nicht untersuchte Effekte der PLC-ß1-Mutation auf die nukleäre Signaltransduktion von Wachstumsfaktoren (z.B. IGF-I; Cocco et al. 1989) für die beobachtete Gewichtsretardierung und die postnatale Letalität verantwortlich (siehe Abschnitt 3.1.1).

\subsection{Mögliche „Downstream“ - Effekte der PLC-ß1 ${ }_{\mathrm{TC}^{-/-}}$-Mutation}

Im Abschnitt 4.5.2 wurde die in diversen Arbeiten dokumentierte Hippocampusspezifische PLC-ß1-Expression sowohl auf RNA- (Tanaka und Kondo 1994; Watanabe et al. 1998) als auch auf Protein-Ebene (Gerfen et al. 1988) diskutiert und die PLC-ßIsoform-spezifische Expression (PLC-ß1-ß4) in deutlich voneinander abgrenzbaren Arealen des Gehirns dokumentiert. Die zitierten Arbeiten zeigen auch, dass im Hippocampus das PLC-ß1-Protein die einzige ß-Isoform darstellt, und dass der Funktions-Verlust im Hippocampus der PLC- $\beta 1_{\mathrm{TC}}{ }^{-/-}$-Maus dementsprechend zu einem vollständigen Verlust der PLC- 31 -induzierten PIP $_{2}$-Hydrolyse und Bildung von DAG und $\mathrm{IP}_{3}$ führen muss (siehe $\mathrm{Abb} .4 .4$ und Abschnitt 4.5.1). $\mathrm{Da} \mathrm{IP}_{3}$ eine intrazelluläre $\mathrm{Ca}^{2+}$-Ausschüttung aus den Speichern des endoplasmatischen Retikulums vermittelt (Abb. $4.4 \mathrm{~A}$ ) und DAG zusammen mit $\mathrm{Ca}^{2+}$ membranständig Proteinkinasen $\mathrm{C}$ (PKC) aktiviert (Abb. 4.4 B), ist in der mutanten PLC- $\beta 1_{\mathrm{TC}^{-/}}$-Maus mit „downstream“Effekten bezüglich des intrazellulären Calcium-Haushalts und bezüglich der Aktivität von Proteinkinasen C zu rechnen. In vitro- (Carter et al. 1990; Lee et al. 1998) und in vivo-Experimente (Kim et al. 1997) haben gezeigt, dass die PLC-ß1-katalysierte PIP2- 
Hydrolyse über eine G-Protein gekoppelte Signaltransduktion mit dem cholinergen Agonisten Carbachol induziert werden kann.

Mit dem im Abschnitt 3.5 dokumentierten Ergebnis konnte gezeigt werden, dass der PLC- $\beta 1$-Funktionsverlust in den PLC- $\beta 1_{\mathrm{TC}}{ }^{-/-}$-Mäusen tatsächlich $\mathrm{zu}$ einer intrazellulären Verminderung der Carbachol-induzierten PKC-Aktivität führt. Aufgrund dieses Befundes und der diskutierten Expressiondaten kann im Hippocampus der PLC- $\beta 1_{\mathrm{TC}}{ }^{-/-}$-Maus von einem nahezu vollständigen Verlust der PLC- $\beta 1$-gekoppelten cholinergen Signaltransduktion ausgegangen werden.

Es ist bekannt, dass Fimbria-Fornix-Läsionen zu einer Denervierung der cholinergen, septohippocampalen Fasern zum Hippocampus ( $C D=$ cholinerge Denervierung) und zu einem kompensatorischen Einwachsen, noradrenerger sympathischer Fasern führen (HSI = Hippocampal sympathetic ingrowth; Crutcher 1987). Beide Vorgänge lassen sich durch experimentell gezielt gesetzte Läsionen getrennt voneinander untersuchen (Ayyagari et al. 1996). In der Arbeit von Ayyagari et al. (1996) führt die isolierte cholinerge Denervierung (CD) des Hippocampus bei Ratten $\mathrm{zu}$ einer signifikanten Verminderung der PKC-Aktivität in hippocampalen Extrakten. In früheren Arbeiten dieser Arbeitsgruppe konnte nach isolierter cholinerger Denervierung (CD) in hippocampalen Extrakten bereits eine Verminderung der Carbachol-stimulierten $\mathrm{PIP}_{2}-$ Hydrolyse nachgewiesen werden (Connor und Harrell 1989; Harrell et al. 1992). Die cholinerge Denervierung geht mit kompensatorischen Veränderungen in der hippocampalen Verteilung der muscarinischen Acetycholin-Rezeptoren (mAChR) einher (Harrell et al. 1994; Kolasa et al. 1995). Die Anzahl der M1-AcetylcholinRezeptoren ist im cholininerg denervierten Hippocampus von Ratten signifikant erhöht, während die Anzahl der M2-Acetylcholin-Rezeptoren signifikant vermindert ist. Aufgrund der Ergebnisse bezüglich der reduzierten Carbachol-stimulierten PIP $_{2}$ Hydrolyse und der daraus resultierenden Verminderung der hippocampalen PKCAktivität kann in dem denervierten Ratten-Modell auch von einem Verlust der cholinergen Signaltransduktion ausgegangen werden. Dieser Verlust der cholinergen Signaltransduktion führt bei den Ratten auch zur Ausbildung chronischer epileptischer Anfälle, zu axonalen Reorganisationen im Hippocampus (Buzsaki et al. 1989a) sowie zum Verlust der Langzeitpotenzierung (Buzsaki und Gage 1989b). Diese Verluste und axonalen Reorganisationen weisen Ähnlichkeiten mit den in der PLC- $\beta 1_{\mathrm{TC}}{ }^{-/-}$-Maus beschriebenen Veränderungen auf.

Der Verlust der PLC- $\beta 1$-gekoppelten cholinergen Signaltransduktion in der PLC- $\beta 1_{\mathrm{TC}}{ }^{-/-}$ und PLC- $\beta 1^{-/-}$-Maus (Kim et al. 1997) und in der cholinerg denervierten Ratte könnte $\mathrm{zu}$ einem Verlust von cholinerger Inhibition und zur Ausbildung von epileptiformer 
Exzitation führen, die dem Schema in Abb. 4.3 folgend möglicherweise sekundär zu inhibitorischen Zellverlusten und zu den beobachteten axonalen Reorganisationen führt. Irreversible Zellverluste nach gesteigerter hippocampaler Exzitation oder fehlender Inhibition wurden in vielen Arbeiten beschrieben (Sloviter 1983; Sloviter 1987). Als Ursache für diese „elektrogen“ induzierten Zellverluste wird die Ausschüttung exzitatorischer Neurotransmitter in neurotoxischen Konzentrationen verantwortlich gemacht (siehe Abb. 4.6 und Sloviter und Dempster 1985). Die Existenz einer cholinergen Inhibition im Hippocampus der Ratte konnte in einer Arbeit von Pitler und Alger (1992) bestätigt werden. Dort führte eine cholinerge Stimulation auf organotypischen Hippocampusschnitten der Ratte über eine Aktivierung inhibitorischer Interneurone $\mathrm{zu}$ einer Verminderung des exzitatorischen, postsynaptischen Potentials (EPSP). Die Unterbrechung der cholinergen Signaltransduktion in der PLC- $\beta 1_{\mathrm{TC}}{ }^{-/-}$- und PLC- $\beta 1^{-/-}$-Maus könnte über eine Abnahme der GABAergen Inhibition zu der Pentylentetrazol- und Kainat-Hypersensitivität der PLC-B1 $1^{-/-}$- Maus (Kim et al. 1997) und $\mathrm{zu}$ der hyperreflektorischen Problematik in der adulten PLC- $\beta 1_{\mathrm{TC}}{ }^{-/-}-$Maus führen (siehe Abschnitt 3.1.3).

Protein-Kinasen C (PKCs) gehören zur Familie der Serin/Threonin-Protein-Kinasen, die nach Aktivierung in membranassoziierter Form spezifische Zielproteine an Serin- und Threoninresten phosphorylieren und eine Rolle in der transmembranen SignalTransduktion ausüben (siehe Abb. 4.4 sowie Mellor und Parker 1998; Toker 1998). Aus der großen Familie der Protein-Kinasen C (PKC) von derzeit zwölf beschriebenen Isozymen (Mellor und Parker 1998; Toker 1998) werden neun durch den Lipid-,,Second messenger“" Diacylglycerol (DAG) in Calcium-abhängiger- (PKC- $\left.\alpha,-\beta_{\mathrm{I}},-\beta_{\mathrm{II}},-\gamma\right)$ oder in Calcium-unabhängiger Weise (PKC- $\left.\delta,-\theta,-\eta,-\varepsilon,-\varepsilon^{\prime}\right)$ aktiviert. Alle DAG-aktivierten PKCs werden im Gehirn und mit spezifischem Expressionmuster im Hippocampus der Maus (Bowers et al. 1995) und der Ratte (Naik et al. 2000) exprimiert, und die PKC$\gamma$-Isoform ist als die im Hippocampus prominenteste PKC-Isoform beschrieben (Nishizuka 1988; Wetsel et al. 1992). Die PKC-induzierte Substrat-Phosphorylierung ist in einem breiten Spektrum neuronaler Prozesse involviert. Dazu zählen unter anderem neuronale Differenzierungs-, Wachstums- und Regenerationsprozesse (CambrayDeakin et al. 1990; Campenot et al. 1994; Parrow et al. 1995), NeurotransmitterAusschüttung (Robinson 1991) und Glutamat-Neurotoxizität (Favaron et al. 1990; Felipo et al. 1993). Ferner sind PKCs auch in die Kontrolle der Zell-Proliferation (Isakov et al. 1992) und -Apoptose (Villalba 1998), in Lernvorgänge (SunayashikiKusuzaki et al. 1993; Abeliovich et al. 1993a) und in die Regulation der hippocampalen Langzeitpotenzierung (LTP; Abschnitt 4.4; Abeliovich et al. 1993b) involviert. 
Letzteres konnte in den Arbeiten von Abeliovich et al. (1993a; 1993b) anhand der Analyse von PKC- $\gamma-$,Knock-out"“-Mäusen bewiesen werden. Im Gehirn existieren vier Haupt-Substrate der PKC-induzierten Phosphorylierung: GAP-43 (Neuromodulin), RC3 (Neurogranin), MARCKS und MLP (MARCKS-like-Protein).

Der nachgewiesene Verlust hippocampaler PKC-Aktivität in der PLC- $\beta 1_{\mathrm{TC}}{ }^{-/-}$-Maus könnte die Phosphorylierung dieser spezifischen PKC-Substrate unterbinden und deren Inhibition oder Aktivierung zur Folge haben. In der Tat ist für einige PKC-Substrate eine neuromodulatorische Wirkung dokumentiert. Für das MARCKS-Protein wurde in der Arbeit von McNamara und Lenox (1998b) gezeigt, das es in den Körnerzellen und in den Moosfasern stark exprimiert ist und der Funktions-Verlust in heterozygoten „Knock-out"-Mäusen zu vermindertem axonalem Wachstum der infrapyramidalen Moosfaser-Projektion (siehe Abschnitt 3.1.7 und Abb. 3.7) und zu Defiziten im räumlichen Lernen führt (McNamara et al. 1998a). Aktives MARCKS-Protein katalysiert die Verknüpfung von Aktin-Filamenten und reguliert möglicherweise die Plastizität des Membran-Zytoskeletts bei axonalen Wachstumsprozessen (Aderem 1992a; Aderem 1992b). Dementsprechend ist das MARCKS-Protein stark in nervalen Geweben, während der Gehirn-Entwicklung (McNamara und Lenox 1997; McNamara und Lenox 1998b) und in axonalen Wachstums-Kegeln (McNamara et al. 1998a) exprimiert. Das MARCKS-Protein wird durch PKC-katalysierte Phosphorylierung inaktiviert (siehe Abb. 4.6). Damit einhergehend ist eine Translokation des katalytisch aktiven Proteins von der Plasmamembran in das Zytosol (McNamara et al. 1998a). Der Verlust von PKC-Aktivität in den PLC- $\beta 1_{\mathrm{TC}}{ }^{-/-}$-Mäusen könnte demnach auch zu einer Zunahme der MARCKS-Aktivität führen und axonale Wachstumsprozesse induzieren. Erst kürzlich konnten McNamara et al. (2000) zeigen, dass die Expression von MARCKS-Protein während axonaler Regenerations-Prozesse erhöht ist.

Für GAP-43-Protein ist dokumentiert, dass es während der Entwicklung des Nervensystems der Vertebraten in den axonalen Wachtums-Kegeln hochexprimiert ist, und dass die GAP-43-Expression während axonaler Regenerations-Prozesse erneut induziert wird (Benowitz und Routtenberg 1997). Desweiteren konnte durch Überexpression von GAP-43 in transgenen Mäusen axonales Wachstum und SynapsenBildung im hippocampalen Moosfasersystem induziert werden (Aigner et al. 1995a). In GAP-43-,,Knock-out"-Mäusen ist die ,axonale Pfadfindung“ gestört, so dass homozygote Tiere bereits kurz nach der Geburt versterben (Strittmatter et al. 1995), und in neuronaler Zellkultur führt die Blockierung der GAP-43-Translation durch „Antisense“-Oligonukleotid-Zugabe zu einer Beeinträchtigung des NeuritenWachstums (Aigner und Caroni 1995b). Allerdings wird GAP-43 durch DAG-aktivierte 
Protein-Kinasen C nach dessen Phosphorylierung aktiviert (Aigner et al. 1995a), so dass bei verminderter PKC-Aktivität eine Reduktion von axonalem Wachstum zu erwarten wäre (siehe Abb. 4.6). Der in der vorliegenden Arbeit verwendete PKC-,,Assay“ der Firma Gibco BRL detektiert allerdings nur die PKC-Aktivität der Calcium-abhängigen Protein-Kinasen $\mathrm{C}(\alpha, \beta$ und $\gamma)$. Es ist bekannt das GAP-43 auch von Calciumunabhängigen PKC-Isoformen phosphoryliert und aktiviert wird (Toker 1998). Möglicherweise kommt es durch den Verlust der PKC-Aktivität auch zu kompensatorischen Effekten und zur Überexpression anderer PKC-Isoformen.

In einer Arbeit von Ambalavanar et al. (1993) konnte ferner gezeigt werden, dass die PKC- $\gamma$-Isoform und das c-fos-Protein in neuronalen Zellen des Vorderhirns und des Striatums koexprimiert sind und $\mathrm{PKC}-\gamma$ die c-fos-Expression induzieren kann. Für diese Hypothese sprechen auch in-vitro-Untersuchungen an HC11-Epithelzellen der Maus (Uberall et al. 1994). Auch über diese Aktivierungs-Kaskade (siehe Abb. 4.6) könnte der Verlust der hippocampalen c-fos-Expression (siehe Abschnitt 3.1.10) nach PLC-ß1Funktions-Verlust und Verminderung der PKC- $\gamma$-Aktivität erklärt werden.

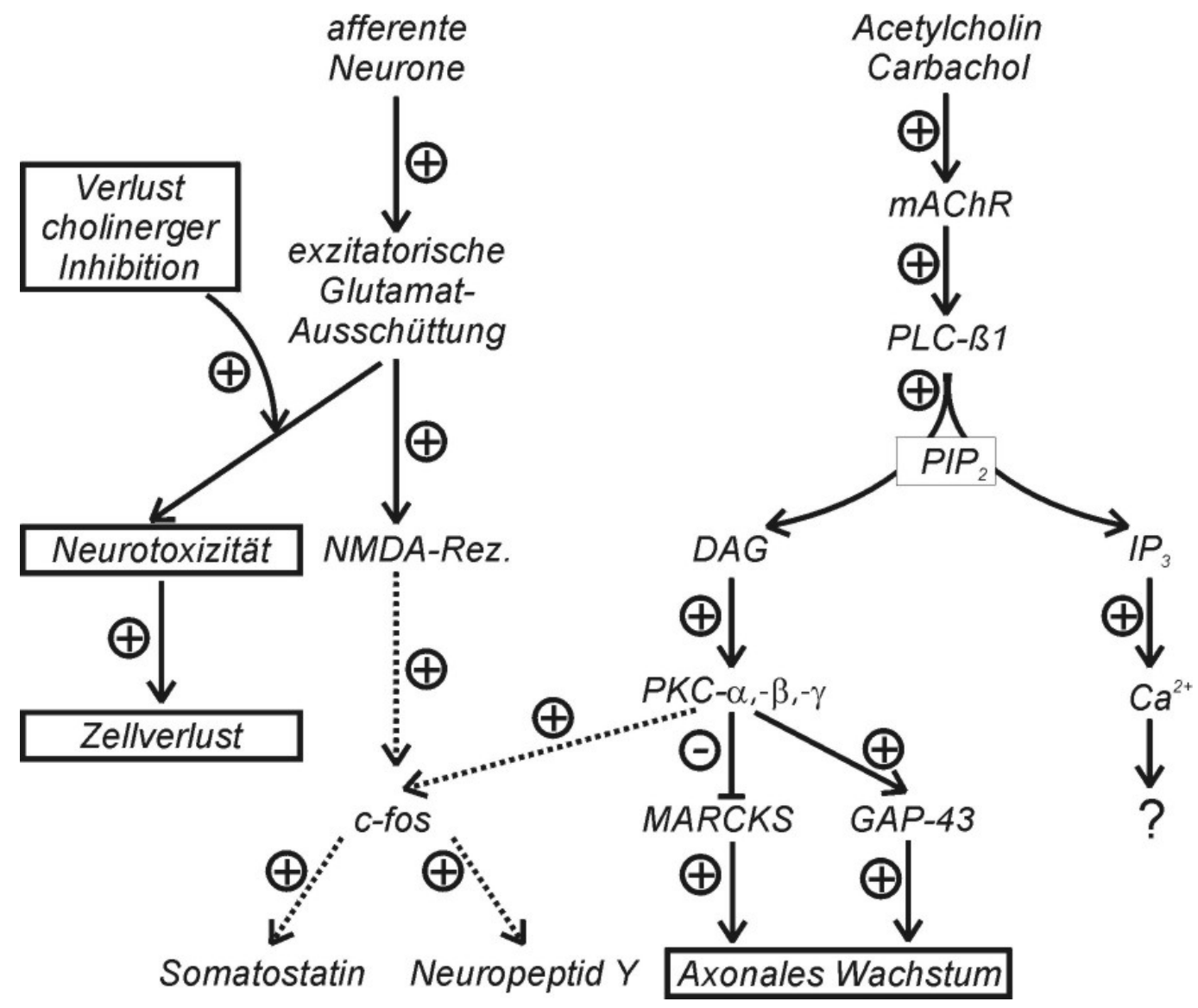

Abb. 4.6 
Abb. 4.6: (S. 160) Schematische Darstellung der PLC-ß1-Signaltransduktionskaskade und diskutierter „,downstream“-Effekte (rechts) sowie des Modells der neurotoxisch wirksamen GlutamatAusschüttung nach Verlust der cholinergen Inhibition (links). Auf Protein-Ebene über Phosphorylierung, Hydrolyse oder Transmitter-Interaktion regulierte Effekte sind mit durchgezogener Linie (-) dargestellt. Regulatorische Effekte auf die Genexpression sind mit gestrichelter Linie (----) wiedergegeben. Positiv- (+) und negativ-regulatorische (-) Effekte sind entsprechend dargestellt.

\subsection{Offene Fragen und weiterführende Experimente}

Die Problematik der postnatalen Gewichtsretardierung und Letalität der PLC- $\beta 1_{\mathrm{TC}}{ }^{-/-}$ -Mäuse wurde in der vorliegenden Arbeit bisher nicht analysiert. Zum einen kommen dafür ernährungsphysiologische Erklärungsansätze (verminderte Nahrungsaufnahme oder -verwertung) und zum anderen Effekte der Mutation auf die Signaltransduktion von Wachstumsfaktoren (z.B. IGF-I und IGF-II; Cocco et al. 1989) in Frage. Für IGF-Iund IGF-II-Wachstumsfaktoren konnten Effekte auf die Zellproliferation und Zelldifferenzierung beschrieben werden (Jones und Clemmons 1995). Für weitere Experimente wäre es zunächst erforderlich, die PLC-ß1-Mutation auf einen Inzuchtstamm (zB. C57B1/J6) rückzukreuzen, um bezüglich der Wachstumsretardierung und Letalität einen einheitlichen Phänotyp zu erhalten. Da es Hinweise gibt, dass das PLC-ß1-Protein in der IGF-Signaltransduktionskaskade „downstream“ zu IGF-I angeordnet ist (Cocco et al. 1989) wäre die Quantifizierung der nukleären PIP $_{2}$ Hydrolyse an IGF-stimulierten Fibroblasten-Kulturen der PLC- $\beta 1_{\mathrm{TC}^{-/-}}-$, PLC- $\beta 1_{\mathrm{TC}}{ }^{+/-}$ und PLC- $\beta 1_{\mathrm{WT}}{ }^{+/+}$-Maus ein geeigneter experimenteller Ansatz, um die Effekte auf die IGF-Signaltransduktionskaskade zu untersuchen.

In der vorliegenden Arbeit und in der von Kim et al. (1997) beschriebenen Studie wurde gezeigt, dass die PLC-ß1-Signaltransduktion im Hippocampus maßgeblich über cholinerge Rezeptoren aktiviert wird, und dass die Effekte des PLC-ß1-Funktionsverlustes in diesen Mausmodellen denen einer cholinergen Denervierung vergleichbar sind. Diese Hypothese bedarf der experimentellen Überprüfung durch eine rezeptorautoradiografische Quantifizierung cholinerger Rezeptoren (M1-, M2- und M3-AChR) und/oder einer Acetylcholinesterase-Färbung (Geneser 1987).

Um die Hypothese der PLC- $\beta 1_{\mathrm{TC}^{-/-}}$-induzierten hippocampalen, cholinergen Denervierung zu untermauern, wäre die vergleichende Phänotyp-Analyse nach Verabreichung des erregenden Cholinergikums Pilocarpin ein interessanter Ansatz. Bei PLC- $\beta 1_{\mathrm{TC}^{-}}{ }^{-/}$-Mäusen mit putativ unterbrochener cholinerger Signaltransduktion wären nach Verabreichung konvulsiver Dosen des Acetylcholin-Agonisten Pilocarpin mildere Effekte im Vergleich zu Wildtyp- Mäusen (PLC- $\beta 1_{\mathrm{WT}}^{+/+}$) zu erwarten. 
Die zelluläre Natur der verlustigen c-fos- Expression in den hippocampalen Regionen der 3 Monate alten PLC- $\beta 1_{\mathrm{TC}^{-/-}}$-Mäuse müsste über immunhistochemische Untersuchungen mit Antikörpern gegen Somatostatin, Parvalbumin und Neuropeptid Y überprüft werden. Ferner müssten die Hinweise auf apoptotische Vorgänge im Subikulum und in der CA1-Region mit entsprechend sensitiven Apoptose-Tests (z.B Dark neuron- und Fluoro-Jade Färbung; Poirier et al. 2000) untersucht werden.

In weiterführenden Calretinin-immunhistochemischen Entwicklungsstudien wäre die Frage $\mathrm{zu}$ untersuchen, ob das über Calretinin-Immunhistochemie detektierte axonale „Sprouting“ ein entsprechendes phänotypisches Korrelat besitzt und zeitlich mit dem Auftreten der Hyperreflexie korelliert.

In gleicher Weise wie Protein-Kinasen C die in Abschnitt 4.6 diskutierten „downstream“-Effekte der PLC-ß1-vermittelten Signaltransduktion vermitteln können, könnte möglicherweise eine in der PLC- $\beta 1_{\mathrm{TC}}{ }^{-/-}$-Maus intrazellulär verminderte Calcium-Ionen-Konzentration (siehe Abb. 4.6) die neuronale Aktivität und -Plastizität von metabotropen Rezeptoren (Henzi und MacDermott 1992; Berridge 1993) modulieren und Zelltod-induzierende Exzitation (siehe Abb. 4.3), axonale Reorganisationen und Hyperexzitabilität zur Folge haben. Für diese Hypothese sprechen im besonderen Maße die Arbeiten von Qiao und Noebels (1993), die in der Mausmutante „stargazer“ mit einer mutanten $\gamma$-Untereinheit eines Calcium-Kanals (Cacng2; Letts et al. 1998) Zellverlust, aberrantes Moosfaser-,,Sprouting“ und epileptiforme Anfälle dokumentieren konnten. Eine mögliche Reduktion intrazellulärer Calcium-IonenAusschüttung könnte nach Carbachol-Stimulation auf organotypischen Hippocampusschnitten von PLC- $\beta 1_{\mathrm{TC}^{-/-}}$- und Wildtyp-Mäusen über eine Calcium-Quantifizierung mit dem Fluoreszenz-Farbstoff Fura-2 (Kudo et al. 1991) detektiert werden.

Sowohl im PLC- $\beta 1^{-/}$- (Kim et al. 1997) als auch bei dem in der vorliegenden Arbeit analysierten PLC- $\beta 1_{\mathrm{TC}}{ }^{-/-}$-Mausmodell besteht die Möglichkeit, dass ein trunkiertes Protein von 65 bzw. 81 Aminosäuren mit einem Teil der Pleckstrin-Homologie-Domäne exprimiert wird (Abb. 4.2, S. 135). Es kann nicht ausgeschlossen werden, dass diese Proteine über ihre trunkierten PH-Domänen mit PIP $_{2}$ interagieren, diese blockieren oder andere aberrante Funktionen ausüben (,gain of function“"), die bei der PLC- $\beta 1_{\mathrm{TC}}{ }^{-/-} \mathrm{zu}$ Apoptose, Zelltod und aberrantem axonalen Wachstum führen. Auch diese Hypothese bedarf der experimentellen Überprüfung durch die Phänotyp-Analyse eines transgenen Mausmodells, in dem das PLC-ß1-SV40-Fusionstranskript unter der Kontrolle des endogenen PLC-ß1-Promotors exprimiert wird. 
Das in der vorliegenden Arbeit etablierte Mausmodell mit genetisch bedingtem selektivem Zellverlust, aberrantem axonalem Wachstum und begleitender Hyperexzitabilität ist in besonderer Weise geeignet, die molekularen Mechanismen aufzuklären, die zum aberranten Moosfaserwachstum und zu synaptischen Reorganisationen führen. Die Isolierung und Charakterisierung differentiell exprimierter unbekannter Gene könnte mit der „PCR-Select-cDNA-Subtraction“Methode an RNA aus Hippocampus-Präparationen von PLC- $\beta 1_{\mathrm{TC}^{-/}}$-Mäusen zu verschiedenen Zeitpunkten der postnatalen Entwicklung oder aus PLC- $\beta 1_{\mathrm{TC}}{ }^{-/-}$-Mäusen und aus PLC- $\beta 1_{\mathrm{WT}}{ }^{+/+}$-Mäusen zu diskreten Zeitpunkten der postnatalen Entwicklung erfolgen. Die „PCR-Select-cDNA-Subtraction“-Methode eignet sich dafür im besonderen Maße, da sie hochsensitiv ist und nur geringe Mengen hippocampaler Poly$\mathrm{A}^{+}$-RNA benötigt (Diatchenko et al. 1996). 


\section{Zusammenfassung}

Im Rahmen der vorliegenden Arbeit konnte gezeigt werden, dass es innerhalb der postnatalen Entwicklung der homozygoten PLC- $\beta 1_{\mathrm{TC}}{ }^{-/-}$-Maus mit Insertionsmutation zu charakteristischen und zeitlich markanten Veränderungen in der Entwicklung des Phänotyps kommt. Die zeitliche Entwicklung des Phänotyps bezüglich Wachstumsretardierung, postnataler Letalität, gestörter Brutpflege, Infertilität, Hypokinesie und Hyperreflexie wurde detailliert analysiert und beschrieben (siehe Abschnitt 3.1). Es konnte gezeigt werden, dass die Wachstumretardierung für die postnatale Sterblichkeit ursächlich ist und ihr Auftreten zeitlich ab dem dritten postnatalen Tag miteinander korreliert. Sowohl die Wachstumsretardierung als auch die postnatale Sterblichkeit sind bis zum Ende der vierten Lebenswoche abgeschlossen. Die postnatale Sterblichkeit betrug in der quantitativen Analyse $73 \%$. Bereits in 3 Monate alten homozygoten PLC- $\beta 1_{\mathrm{TC}^{-/-}}$-Mäusen konnte eine signifikante Beeinträchtigung des räumlichen Lernvermögens nachgewiesen werden. Ferner zeigten bereits zwei Monate alte homozygote PLC- $\beta 1_{\mathrm{TC}}{ }^{-/-}$-Weibchen eine massive Störung des Brutpflegeverhaltens mit dem Effekt, dass alle Nachkommen unabhängig von ihrem Genotyp versterben. Ab einem Alter von 6-7 Monaten kommt es bei homozygoten PLC- $\beta 1_{\mathrm{TC}}{ }^{-/-}$-Mäusen zur Ausbildung von hyperreflektorischem Verhalten nach akustischer und taktiler Stimulation, zur Manifestation von hypokinetischem Verhalten und zur Entwicklung einer männlichen Infertilität bei nachweislich intakter Testis-Morphologie.

Mit neuroanatomischen und rezeptorautoradiografischen Methoden gelang es zu zeigen, dass für die Verhaltensauffälligkeiten jeweils ein morphologisches Korrelat im Hippocampus der PLC- $\beta 1_{\mathrm{TC}}{ }^{-/-}$-Maus existiert (siehe Abschnitte 3.1.7 bis 3.1.11). Die Ausbildung des hyperreflektorischen und hypokinetischen Phänotyps korelliert zeitlich und morphologisch mit der Ausbildung und Detektion von axonalen Reorganisationen im hippocampalen Moosfasersystem der PLC- $\beta 1_{\mathrm{TC}}{ }^{-/-}$-Mäuse. Diese Reorganisationen konnten mit der Timm-Silbersulfid-Färbetechnik in der suprapyramidalen und in der supragranulären Moosfaser-Projektion nachgewiesen werden. Ferner wurde nur im Hippocampus von 9 Monate alten PLC- $\beta 1_{\mathrm{TC}^{-/}}$-Mäusen ein Auswachsen von Calretininimmunreaktiven Axonen dokumentiert, dessen Ausbildung aber bisher nicht mit aberrantem Verhalten korreliert werden konnte. Bereits in drei Monate alten PLC- $\beta 1_{\mathrm{TC}}{ }^{-/-}$ -Mäusen wurde eine Reduktion der NMDA-Rezeptordichte im Stratum oriens der hippocampalen Region CA1 detektiert, die möglicherweise das morphologische Korrelat für die beschriebenen Lerndefizite der PLC- $\beta 1_{\mathrm{TC}}{ }^{-/-}$-Mäuse darstellt. Schließlich 
konnte im Hippocampus von drei Monate alten PLC- $\beta 1_{\mathrm{TC}}{ }^{-/-}$-Mäusen ein zellulärer Verlust an c-fos -Expression im Hilus sowie in der CA3- und CA1-Region detektiert werden, der auf inhibitorische Zellverluste in diesen Regionen hinweist. Hinweise auf Zellverluste und neurodegenerative Prozesse wurden auch in acht Monate alten PLC- $\beta 1_{\mathrm{TC}^{-/-}}$-Mäusen in den hippocampalen Regionen Subiculum und CA1 durch Detektion von pyknotischen Zellkernen und ,dark neurons“ gefunden.

Mit zytogenetischen und molekulargenetischen Methoden konnte die TransgenIntegration in der PLC- $\beta 1_{\mathrm{TC}^{-/-}}$-Maus im Chromosom 2 in der Region F3-G als intronische Insertion in dem Gen für die Phospholipase C-ß1 (PLC-ß1) charakterisiert werden. Die angrenzende genomische Region der Insertion wurde kloniert, und im Genom der PLC- $\beta 1_{\mathrm{TC}}{ }^{-/-}$-Maus konnte eine Deletion von 809 bp identifiziert werden, der aber keine Funktion zugewiesen werden kann (siehe Abschnitt 3.2). Es konnte jedoch gezeigt werden, dass die intronische Transgen-Insertion im PLC-ß1-Gen der Maus zu einer Transgen-induzierten Spleiß-Mutation und $\mathrm{zu}$ einer vom PLC-ß1-Promotor angetriebenen Expression eines 1,7 kb-Fusionstranskripts (PLC-ß1-SV40) führt (siehe Abschnitt 3.3). Die RT-PCR-Analyse des Fusions-Transkripts identifizierte einen Rest von 244 bp nach dem Translations-Startkodon, der für ein putatives, trunkiertes Protein von 81 Aminosäuren kodiert. Durch Expressions-Analysen in den verschiedenen Organen der PLC- $\beta 1_{\mathrm{TC}^{-/-}}$-Maus konnte der Verlust des PLC-ß1-Transkripts und -Proteins bestätigt werden, so dass in der PLC- $\beta 1_{\mathrm{TC}}{ }^{-/-}$-Maus mit Insertionsmutation von einem vollständigen PLC-ß1-Funktionsverlust ausgegangen werden kann (siehe Abschnitt 3.4). Dieser Funktionsverlust konnte abschließend durch einen Verlust hippocampaler PKC-Aktivität in PLC- $\beta 1_{\mathrm{TC}}{ }^{-/-}$-Mäusen bestätigt werden (siehe Abschnitt 3.5). 


\section{Literatur}

Abeliovich, A., C. Chen, Y. Goda, A. J. Silva, C. F. Stevens und S. Tonegawa (1993b). Modified hippocampal long-term potentiation in PKC gamma-mutant mice. Cell 75 (7): 1253-62.

Abeliovich, A., R. Paylor, C. Chen, J. J. Kim, J. M. Wehner und S. Tonegawa (1993a). PKC gamma mutant mice exhibit mild deficits in spatial and contextual learning. Cell 75 (7): 1263-71.

Aderem, A. (1992a). Signal transduction and the actin cytoskeleton: the roles of MARCKS and profilin. Trends Biochem Sci 17 (10): 438-43.

Aderem, A. (1992b). The MARCKS brothers: a family of protein kinase C substrates. Cell 71 (5): 713-6.

Aiba, A., C. Chen, K. Herrup, C. Rosenmund, C. F. Stevens und S. Tonegawa (1994). Reduced hippocampal long-term potentiation and context-specific deficit in associative learning in mGluR1 mutant mice. Cell 79 (2): 365-75.

Aigner, L., S. Arber, J. P. Kapfhammer, T. Laux, C. Schneider, F. Botteri, H. R. Brenner und P. Caroni (1995a). Overexpression of the neural growth-associated protein GAP-43 induces nerve sprouting in the adult nervous system of transgenic mice. Cell $\mathbf{8 3}$ (2): $269-78$.

Aigner, L. und P. Caroni (1995b). Absence of persistent spreading, branching, and adhesion in GAP-43- depleted growth cones. J Cell Biol 128 (4): 647-60.

Amaral, D. G. (1978). A Golgi study of cell types in the hilar region of the hippocampus in the rat. J Comp Neurol 182 (4): 851-914.

Ambalavanar, R., E. A. Van der Zee, J. J. Bolhuis, B. J. McCabe und G. Horn (1993). Co-expression of Fos immunoreactivity in protein kinase (PKC gamma)- positive neurones: quantitative analysis of a brain region involved in learning. Brain Res $\mathbf{6 0 6}$ (2): $315-8$.

Ausubel, F. M. (1995). Current protocols in molecular biology. New York, Wiley \& Sons Inc.

Ayyagari, P. V., L. E. Harrell, D. S. Parsons und K. Kolasa (1996). Sympathetic sprouting reverses decreases in membrane-associated activity of protein kinase $\mathrm{C}$ 
following septohippocampal denervation of the rat hippocampus. Brain Res 708 (1-2): 205-8.

Babb, T. L., W. J. Brown, J. Pretorius, C. Davenport, J. P. Lieb und P. H. Crandall (1984). Temporal lobe volumetric cell densities in temporal lobe epilepsy. Epilepsia 25 (6): $729-40$.

Babb, T. L., W. R. Kupfer, J. K. Pretorius, P. H. Crandall und M. F. Levesque (1991). Synaptic reorganization by mossy fibers in human epileptic fascia dentata. Neuroscience 42 (2): 351-63.

Bading, H., D. D. Ginty und M. E. Greenberg (1993). Regulation of gene expression in hippocampal neurons by distinct calcium signaling pathways. Science 260 (5105): 1816.

Bahk, Y. Y., Y. H. Lee, T. G. Lee, J. Seo, S. H. Ryu und P. G. Suh (1994). Two forms of phospholipase C-beta 1 generated by alternative splicing. J Biol Chem 269 (11): 8240-5.

Bahk, Y. Y., H. Song, S. H. Baek, B. Y. Park, H. Kim, S. H. Ryu und P. G. Suh (1998). Localization of two forms of phospholipase C-beta1, a and b, in C6Bu-1 cells. Biochim Biophys Acta 1389 (1): 76-80.

Banfic, H., M. Zizak, N. Divecha und R. F. Irvine (1993). Nuclear diacylglycerol is increased during cell proliferation in vivo. Biochem $J 290$ (Pt 3): 633-6.

Bannerman, D. M., B. K. Yee, M. A. Good, M. J. Heupel, S. D. Iversen und J. N. Rawlins (1999). Double dissociation of function within the hippocampus: a comparison of dorsal, ventral, and complete hippocampal cytotoxic lesions. Behav Neurosci 113 (6): 1170-88.

Beck, K. D., F. Hefti und H. R. Widmer (1994). Deafferentation removes calretinin immunopositive terminals, but does not induce degeneration of calbindin D-28k and parvalbumin expressing neurons in the hippocampus of adult rats. $J$ Neurosci Res 39 (3): 298-304.

Beermann, F., S. Ruppert, E. Hummler, F. X. Bosch, G. Muller, U. Ruther und G. Schutz (1990). Rescue of the albino phenotype by introduction of a functional tyrosinase gene into mice. Embo $J 9$ (9): 2819-26.

Beermann, F., S. Ruppert, E. Hummler und G. Schutz (1991). Tyrosinase as a marker for transgenic mice. Nucleic Acids Res 19 (4): 958. 
Beier, D. R., C. C. Morton, A. Leder, R. Wallace und P. Leder (1989). Perinatal lethality (ple): a mutation caused by integration of a transgene into distal mouse chromosome 15. Genomics 4 (4): 498-504.

Bekkers, J. M. und C. F. Stevens (1990). Presynaptic mechanism for long-term potentiation in the hippocampus. Nature 346 (6286): 724-9.

Ben-Ari, Y. (1985). Limbic seizure and brain damage produced by kainic acid: mechanisms and relevance to human temporal lobe epilepsy. Neuroscience 14 (2): 375403.

Bendotti, C., M. Pende und R. Samanin (1994). Expression of GAP-43 in the granule cells of rat hippocampus after seizure-induced sprouting of mossy fibres: in situ hybridization and immunocytochemical studies. Eur J Neurosci 6 (4): 509-15.

Bendotti, C., A. Vezzani, G. Tarizzo und R. Samanin (1993). Increased expression of GAP-43, somatostatin and neuropeptide Y mRNA in the hippocampus during development of hippocampal kindling in rats. Eur J Neurosci 5 (10): 1312-20.

Bengzon, J., Z. Kokaia, P. Ernfors, M. Kokaia, G. Leanza, O. G. Nilsson, H. Persson und O. Lindvall (1993). Regulation of neurotrophin and trkA, $\operatorname{trkB}$ and trkC tyrosine kinase receptor messenger RNA expression in kindling. Neuroscience 53 (2): 433-46.

Benowitz, L. I. und A. Routtenberg (1997). GAP-43: an intrinsic determinant of neuronal development and plasticity. Trends Neurosci 20 (2): 84-91.

Berridge, M. J. (1993). Inositol trisphosphate and calcium signalling. Nature 361 (6410): 315-25.

Berridge, M. J. und R. F. Irvine (1984). Inositol trisphosphate, a novel second messenger in cellular signal transduction. Nature 312 (5992): 315-21.

Bialek, P., C. T. Chan und S. P. Yee (2000). Characterization of a novel insertional mouse mutation, kkt: A closely linked modifier of Pax1. Dev Biol 218 (2): 354-66.

Birnboim, H. C. (1983). A rapid alkaline extraction method for the isolation of plasmid DNA. Methods Enzymol 100 : 243-55.

Birnboim, H. C. und J. Doly (1979). A rapid alkaline extraction procedure for screening recombinant plasmid DNA. Nucleic Acids Res 7 (6): 1513-23.

Bliss, T. V. und A. R. Gardner-Medwin (1973). Long-lasting potentiation of synaptic transmission in the dentate area of the unanaestetized rabbit following stimulation of the perforant path. $J$ Physiol 232 (2): 357-74. 
Bliss, T. V. und T. Lomo (1973). Long-lasting potentiation of synaptic transmission in the dentate area of the anaesthetized rabbit following stimulation of the perforant path. $J$ Physiol 232 (2): 331-56.

Blümcke, I., H. Beck, R. Nitsch, C. Eickhoff, B. Scheffler, M. R. Celio, J. Schramm, C. E. Elger, H. K. Wolf und O. D. Wiestler (1996). Preservation of calretininimmunoreactive neurons in the hippocampus of epilepsy patients with Ammon's horn sclerosis. J Neuropathol Exp Neurol 55 (3): 329-41.

Bonhoeffer, T., V. Staiger und A. Aertsen (1989). Synaptic plasticity in rat hippocampal slice cultures: local "Hebbian" conjunction of pre- and postsynaptic stimulation leads to distributed synaptic enhancement. Proc Natl Acad Sci U S A 86 (20): 8113-7.

Bowers, B. J., S. C. Christensen, J. R. Pauley, R. Paylor, L. Yuva, S. E. Dunbar und J. M. Wehner (1995). Protein and molecular characterization of hippocampal protein kinase C in C57BL/6 and DBA/2 mice. J Neurochem 64 (6): 2737-46.

Bradford, M. M. (1976). A rapid and sensitive method for the quantitation of microgram quantities of protein utilizing the principle of protein-dye binding. Anal Biochem 72 : 248-54.

Broadie, K. (1998). Forward and reverse genetic approaches to synaptogenesis. Curr Opin Neurobiol 8 (1): 128-38.

Brown, J. R., H. Ye, R. T. Bronson, P. Dikkes und M. E. Greenberg (1996). A defect in nurturing in mice lacking the immediate early gene fosB. Cell 86 (2): 297-309.

Brown, W. J. und M. G. Farquhar (1989). Immunoperoxidase methods for the localization of antigens in cultured cells and tissue sections by electron microscopy. Methods Cell Biol 31 : 553-69.

Buckmaster, P. S. und F. E. Dudek (1997). Neuron loss, granule cell axon reorganization, and functional changes in the dentate gyrus of epileptic kainate-treated rats. J Comp Neurol 385 (3): 385-404.

Buckmaster, P. S., H. J. Wenzel, D. D. Kunkel und P. A. Schwartzkroin (1996). Axon arbors and synaptic connections of hippocampal mossy cells in the rat in vivo. J Comp Neurol 366 (2): 271-92.

Bugra, K., H. Pollard, G. Charton, J. Moreau, Y. Ben-Ari und M. Khrestchatisky (1994). aFGF, bFGF and flg mRNAs show distinct patterns of induction in the hippocampus following kainate-induced seizures. Eur J Neurosci 6 (1): 58-66. 
Buzsaki, G. und F. H. Gage (1989b). Absence of long-term potentiation in the subcortically deafferented dentate gyrus. Brain Res 484 (1-2): 94-101.

Buzsaki, G., G. L. Ponomareff, F. Bayardo, R. Ruiz und F. H. Gage (1989a). Neuronal activity in the subcortically denervated hippocampus: a chronic model for epilepsy. Neuroscience 28 (3): 527-38.

Cajal, S. R. y. (1911). Histologie du Systeme Nerveux de l' homme et des Vertebrates. Tome II. Paris, Maloine.

Cajal, S. R. y. (1995). Histology of the Nervous System. Übersetzung von: N. Swanson und L.W. Swanson. New York, Oxford University Press.

Cambray-Deakin, M. A., J. Adu und R. D. Burgoyne (1990). Neuritogenesis in cerebellar granule cells in vitro: a role for protein kinase C. Brain Res Dev Brain Res $\mathbf{5 3}$ (1): 40-6.

Cammarota, M., G. Paratcha, M. Levi de Stein, R. Bernabeu, I. Izquierdo und J. H. Medina (1997). B-50/GAP-43 phosphorylation and PKC activity are increased in rat hippocampal synaptosomal membranes after an inhibitory avoidance training. Neurochem Res 22 (4): 499-505.

Campenot, R. B., D. D. Draker und D. L. Senger (1994). Evidence that protein kinase C activities involved in regulating neurite growth are localized to distal neurites. $J$ Neurochem 63 (3): 868-78.

Carter, H. R., M. A. Wallace und J. N. Fain (1990). Purification and characterization of PLC-beta $\mathrm{m}$, a muscarinic cholinergic regulated phospholipase $\mathrm{C}$ from rabbit brain membrane. Biochim Biophys Acta 1054 (1): 119-28.

Cavazos, J. E., I. Das und T. P. Sutula (1994). Neuronal loss induced in limbic pathways by kindling: evidence for induction of hippocampal sclerosis by repeated brief seizures. J Neurosci 14 (5 Pt 2): 3106-21.

Cavazos, J. E. und T. P. Sutula (1990). Progressive neuronal loss induced by kindling: a possible mechanism for mossy fiber synaptic reorganization and hippocampal sclerosis. Brain Res 527 (1): 1-6.

Cecconi, F. und B. I. Meyer (2000). Gene trap: a way to identify novel genes and unravel their biological function. FEBS Lett 480 (1): 63-71.

Chenchik, A., L. Diachenko, F. Moqadam, V. Tarabykin, S. Lukyanov und P. D. Siebert (1996). Full-length cDNA cloning and determination of mRNA 5' and 3 ' ends by amplification of adaptor-ligated cDNA. Biotechniques 21 (3): 526-34. 
Chien, A., D. B. Edgar und J. M. Trela (1976). Deoxyribonucleic acid polymerase from the extreme thermophile Thermus aquaticus. J Bacteriol 127 (3): 1550-7.

Cho, Y. H. und R. Jaffard (1995). Spatial location learning in mice with ibotenate lesions of entorhinal cortex or subiculum. Neurobiol Learn Mem 64 (3): 285-90.

Chomczynski, P. und N. Sacchi (1987). Single-step method of RNA isolation by acid guanidinium thiocyanate- phenol-chloroform extraction. Anal Biochem 162 (1): 156-9.

Clark, J. M. (1988). Novel non-templated nucleotide addition reactions catalyzed by procaryotic and eucaryotic DNA polymerases. Nucleic Acids Res 16 (20): 9677-86.

Clifford, D. B., J. W. Olney, A. Maniotis, R. C. Collins und C. F. Zorumski (1987). The functional anatomy and pathology of lithium-pilocarpine and high- dose pilocarpine seizures. Neuroscience 23 (3): 953-68.

Clusmann, H., J. Stabel, D. N. Stephens und U. Heinemann (1992). Alterations in medial perforant path and mossy fiber induced field potentials in amygdala and betacarboline (FG 7142) kindled rats. Neurosci Lett 146 (1): 65-8.

Cocco, L., A. M. Martelli, R. S. Gilmour, A. Ognibene, F. A. Manzoli und R. F. Irvine (1989). Changes in nuclear inositol phospholipids induced in intact cells by insulin-like growth factor I. Biochem Biophys Res Commun 159 (2): 720-5.

Connor, D. J. und L. E. Harrell (1989). Chronic septal lesions cause upregulation of cholinergic but not noradrenergic hippocampal phosphoinositide hydrolysis. Brain Res 488 (1-2): 387-9.

Costa, G. L. und M. P. Weiner (1994). Polishing with T4 or Pfu polymerase increases the efficiency of cloning of PCR fragments. Nucleic Acids Res 22 (12): 2423.

Crusio, W. E. und H. Schwegler (1987). Hippocampal mossy fiber distribution covaries with open-field habituation in the mouse. Behav Brain Res 26 (2-3): 153-8.

Crutcher, K. A. (1987). Sympathetic sprouting in the central nervous system: a model for studies of axonal growth in the mature mammalian brain. Brain Res 434 (2): 203-33.

Dam, A. M. (1980). Epilepsy and neuron loss in the hippocampus. Epilepsia 21 (6): 617-29.

Danscher, G. und J. Zimmer (1978). An improved Timm sulphide silver method for light and electron microscopic localization of heavy metals in biological tissues. Histochemistry 55 (1): 27-40. 
de Lanerolle, N. C., J. H. Kim, R. J. Robbins und D. D. Spencer (1989). Hippocampal interneuron loss and plasticity in human temporal lobe epilepsy. Brain Res 495 (2): $387-$ 95.

De Robertis, E., A. Pellegrino de Iraldi, G. Rodriguez de Lorez de Arnaiz und C. J. Gomez (1961). On the isolation of nerve endings and synaptic vesicles. J. Biophys. Biochem. Cytol. 9 : 229-235.

Deller, T. (1998). The anatomical organization of the rat fascia dentata: new aspects of laminar organization as revealed by anterograde tracing with Phaseolus vulgarisLuecoagglutinin (PHAL). Anat Embryol (Berl) 197 (2): 89-103.

Demmer, J., M. Dragunow, P. A. Lawlor, S. E. Mason, J. D. Leah, W. C. Abraham und W. P. Tate (1993). Differential expression of immediate early genes after hippocampal long- term potentiation in awake rats. Brain Res Mol Brain Res 17 (3-4): 279-86.

Denhardt, D. T. (1966). A membrane-filter technique for the detection of complementary DNA. Biochem Biophys Res Commun 23 (5): 641-6.

Diatchenko, L., Y. F. Lau, A. P. Campbell, A. Chenchik, F. Moqadam, B. Huang, S. Lukyanov, K. Lukyanov, N. Gurskaya, E. D. Sverdlov und P. D. Siebert (1996). Suppression subtractive hybridization: a method for generating differentially regulated or tissue-specific cDNA probes and libraries. Proc Natl Acad Sci U S A 93 (12): 602530 .

Divecha, N., H. Banfic und R. F. Irvine (1991). The polyphosphoinositide cycle exists in the nuclei of Swiss 3T3 cells under the control of a receptor (for IGF-I) in the plasma membrane, and stimulation of the cycle increases nuclear diacylglycerol and apparently induces translocation of protein kinase C to the nucleus. Embo J 10 (11): 3207-14.

Divecha, N., H. Banfic und R. F. Irvine (1993). Inositides and the nucleus and inositides in the nucleus. Cell 74 (3): 405-7.

Divecha, N., S. G. Rhee, A. J. Letcher und R. F. Irvine (1993). Phosphoinositide signalling enzymes in rat liver nuclei: phosphoinositidase $\mathrm{C}$ isoform beta 1 is specifically, but not predominantly, located in the nucleus. Biochem J 289 (Pt 3): 617-20.

Don, R. H., P. T. Cox, B. J. Wainwright, K. Baker und J. S. Mattick (1991). 'Touchdown' PCR to circumvent spurious priming during gene amplification. Nucleic Acids Res 19 (14): 4008.

Dragunow, M. und H. A. Robertson (1987). Kindling stimulation induces c-fos protein(s) in granule cells of the rat dentate gyrus. Nature 329 (6138): 441-2. 
Drayer, A. L. und P. J. van Haastert (1992). Molecular cloning and expression of a phosphoinositide-specific phospholipase C of Dictyostelium discoideum. J Biol Chem 267 (26): 18387-92.

Duvernoy, H. M. (1988). The human hippocampus. An atlas of applied anatomie. München, Bergmann.

El Bahh, B., V. Lespinet, D. Lurton, M. Coussemacq, G. Le Gal La Salle und A. Rougier (1999). Correlations between granule cell dispersion, mossy fiber sprouting, and hippocampal cell loss in temporal lobe epilepsy. Epilepsia 40 (10): 1393-401.

Elmer, E., M. Kokaia, Z. Kokaia, I. Ferencz und O. Lindvall (1996). Delayed kindling development after rapidly recurring seizures: relation to mossy fiber sprouting and neurotrophin, GAP-43 and dynorphin gene expression. Brain Res 712 (1): 19-34.

Epstein, D. J., M. Vekemans und P. Gros (1991). Splotch (Sp2H), a mutation affecting development of the mouse neural tube, shows a deletion within the paired homeodomain of Pax-3. Cell 67 (4): 767-74.

Erdel, M., M. Hubalek, A. Lingenhel, K. Kofler, H. C. Duba und G. Utermann (1999). Counting the repetitive kringle-IV repeats in the gene encoding human apolipoprotein(a) by fibre-FISH. Nat Genet 21 (4): 357-8.

Ernfors, P., J. Bengzon, Z. Kokaia, H. Persson und O. Lindvall (1991). Increased levels of messenger RNAs for neurotrophic factors in the brain during kindling epileptogenesis. Neuron 7 (1): 165-76.

Fagan, A. M., S. T. Suhr, C. A. Lucidi-Phillipi, D. A. Peterson, D. M. Holtzman und F. H. Gage (1997). Endogenous FGF-2 is important for cholinergic sprouting in the denervated hippocampus. J Neurosci 17 (7): 2499-511.

Farr, S. A., W. A. Banks, M. E. La Scola, J. F. Flood und J. E. Morley (2000). Permanent and temporary inactivation of the hippocampus impairs T-maze footshock avoidance acquisition and retention. Brain Res 872 (1-2): 242-9.

Favaron, M., H. Manev, R. Siman, M. Bertolino, A. M. Szekely, G. DeErausquin, A. Guidotti und E. Costa (1990). Down-regulation of protein kinase C protects cerebellar granule neurons in primary culture from glutamate-induced neuronal death. Proc Natl Acad Sci U S A 87 (5): 1983-7.

Feinberg, A. P. und B. Vogelstein (1983). A technique for radiolabeling DNA restriction endonuclease fragments to high specific activity. Anal Biochem 132 (1): 6-13. 
Felipo, V., M. D. Minana und S. Grisolia (1993). Inhibitors of protein kinase C prevent the toxicity of glutamate in primary neuronal cultures. Brain Res 604 (1-2): 192-6.

Ferkany, J. W., R. Zaczek und J. T. Coyle (1984). The mechanism of kainic acid neurotoxicity [letter]. Nature 308 (5959): 561-2.

Fidlerova, H., G. Senger, M. Kost, P. Sanseau und D. Sheer (1994). Two simple procedures for releasing chromatin from routinely fixed cells for fluorescence in situ hybridization. Cytogenet Cell Genet 65 (3): 203-5.

Fields, A. P., G. Tyler, A. S. Kraft und W. S. May (1990). Role of nuclear protein kinase $\mathrm{C}$ in the mitogenic response to platelet- derived growth factor. J Cell Sci 96 (Pt 1): 107-14.

Flick, J. S. und J. Thorner (1993). Genetic and biochemical characterization of a phosphatidylinositol- specific phospholipase $\mathrm{C}$ in Saccharomyces cerevisiae. Mol Cell Biol 13 (9): 5861-76.

Franklin, K. B. J. und G. Paxinos (1997). The mouse brain in stereotaxic coordinates. San Diego, California, Academic Press Inc.

Freeman, T. C., A. K. Dixon, E. A. Campbell, T. M. Tait, P. J. Richardson, K. M. Rice, G. L. Maslen, A. D. Metcalfe, C. H. Streuli und D. R. Bentley (1998). Expression mapping of mouse genes. MGI Direct Data Submission : MGI:1205470.

Frohman, M. A., M. K. Dush und G. R. Martin (1988). Rapid production of full-length cDNAs from rare transcripts: amplification using a single gene-specific oligonucleotide primer. Proc Natl Acad Sci U S A 85 (23): 8998-9002.

Frotscher, M., B. Heimrich und H. Schwegler (1990). Plasticity of identified neurons in slice cultures of hippocampus: a combined Golgi/electron microscopic and immunocytochemical study. Prog Brain Res 83 : 323-39.

Gall, C. M., R. Berschauer und P. J. Isackson (1994). Seizures increase basic fibroblast growth factor mRNA in adult rat forebrain neurons and glia. Brain Res Mol Brain Res 21 (3-4): 190-205.

Geneser, F. A. (1987). Distribution of acetylcholinesterase in the hippocampal region of the rabbit: II. Subiculum and hippocampus. J Comp Neurol 262 (1): 90-104.

Gerfen, C. R., W. C. Choi, P. G. Suh und S. G. Rhee (1988). Phospholipase C I and II brain isozymes: immunohistochemical localization in neuronal systems in rat brain. Proc Natl Acad Sci U S A 85 (9): 3208-12. 
Gershoni, J. M. und G. E. Palade (1982). Electrophoretic transfer of proteins from sodium dodecyl sulfate- polyacrylamide gels to a positively charged membrane filter. Anal Biochem 124 (2): 396-405.

Gispen, W. H., P. Schotman und E. R. d. Kloet (1972). Brain RNA and hypophysectomy; a topographical study. Neuroendocrinology 9 (5): 285-96.

Gordon, J. W., G. A. Scangos, D. J. Plotkin, J. A. Barbosa und F. H. Ruddle (1980). Genetic transformation of mouse embryos by microinjection of purified DNA. Proc Natl Acad Sci U S A 77 (12): 7380-4.

Gorter, J. A., E. A. Van Vliet, E. Aronica und F. H. Da Silva (2001). Progression of spontaneous seizures after status epilepticus is associated with mossy fibre sprouting and extensive bilateral loss of hilar parvalbumin and somatostatin-immunoreactive neurons. Eur J Neurosci 13 (4): 657-669.

Gray, E. G. und V. P. Whittaker (1962). The isolation of nerve endings from brain: An electron-microscopic study of cell fragments derived by homogenization and centrifugation. J. Anat. (Lond.) 96 : 79-87.

Gubler, U. und B. J. Hoffman (1983). A simple and very efficient method for generating cDNA libraries. Gene 25 (2-3): 263-9.

Gulyas, A. I., R. Miettinen, D. M. Jacobowitz und T. F. Freund (1992). Calretinin is present in non-pyramidal cells of the rat hippocampus--I. A new type of neuron specifically associated with the mossy fibre system. Neuroscience 48 (1): 1-27.

Guthrie, K. M., A. G. Woods, T. Nguyen und C. M. Gall (1997). Astroglial ciliary neurotrophic factor mRNA expression is increased in fields of axonal sprouting in deafferented hippocampus. J Comp Neurol 386 (1): 137-48.

Hanes, J., J. Freudenstein, G. Rapp und K. H. Scheit (1992). Construction of a plasmid containing the complete coding region of human elongation factor 2. Biol Chem Hoppe Seyler 373 (4): 201-4.

Harrell, L. E., V. Ayyagari, D. S. Parsons, D. J. Connor und A. Peagler (1992). Hippocampal phosphoinositide turnover is altered by hippocampal sympathetic ingrowth and cholinergic denervation. Pharmacol Biochem Behav 42 (2): 277-84.

Harrell, L. E., V. Ayyagari, A. Peagler und D. S. Parsons (1994). Hippocampal sympathetic ingrowth and cholinergic denervation alter hippocampal muscarinic cholinergic receptors. Hippocampus 4 (2): 199-203. 
Haslam, R. J., H. B. Koide und B. A. Hemmings (1993). Pleckstrin domain homology. Nature 363 (6427): 309-10.

Hecker, K. H. und K. H. Roux (1996). High and low annealing temperatures increase both specificity and yield in touchdown and stepdown PCR. Biotechniques 20 (3): 47885 .

Henke, K., A. Buck, B. Weber und H. G. Wieser (1997). Human hippocampus establishes associations in memory. Hippocampus 7 (3): 249-56.

Henzi, V. und A. B. MacDermott (1992). Characteristics and function of $\mathrm{Ca}(2+)$ - and inositol 1,4,5- trisphosphate-releasable stores of Ca2+ in neurons. Neuroscience 46 (2): $251-73$.

Herkenham, M. und L. Sokoloff (1984). Quantitative receptor autoradiography: tissue defatting eliminates differential self-absorption of tritium radiation in gray and white matter of brain. Brain Res 321 (2): 363-8.

Hill, R. E., J. Favor, B. L. Hogan, C. C. Ton, G. F. Saunders, I. M. Hanson, J. Prosser, T. Jordan, N. D. Hastie und V. van Heyningen (1991). Mouse small eye results from mutations in a paired-like homeobox- containing gene. Nature 354 (6354): 522-5.

Hodge, R. (1994). Preparation of RNA gel blots. Methods Mol Biol 28 : 49-54.

Hokin, M. R. und L. E. Hokin (1953). Enzyme secretion and the incorporation of 32P into phopholipids of pancreas slices. J Biol Chem 203 : 967-977.

Holmes, G. L., M. Sarkisian, Y. Ben-Ari und N. Chevassus-Au-Louis (1999). Mossy fiber sprouting after recurrent seizures during early development in rats. J Comp Neurol 404 (4): 537-53.

Homma, Y., T. Takenawa, Y. Emori, H. Sorimachi und K. Suzuki (1989). Tissue- and cell type-specific expression of mRNAs for four types of inositol phospholipid-specific phospholipase C. Biochem Biophys Res Commun 164 (1): 406-12.

Horstman, D. A., A. Chattopadhyay und G. Carpenter (1999). The influence of deletion mutations on phospholipase C-gamma 1 activity. Arch Biochem Biophys 361 (1): 14955 .

Hosford, D. A., M. Simonato, Z. Cao, N. Garcia-Cairasco, J. M. Silver, L. Butler, C. Shin und J. O. McNamara (1995). Differences in the anatomic distribution of immediate-early gene expression in amygdala and angular bundle kindling development. J Neurosci 15 (3 Pt 2): 2513-23. 
Houser, C. R., J. E. Miyashiro, B. E. Swartz, G. O. Walsh, J. R. Rich und A. V. Delgado-Escueta (1990). Altered patterns of dynorphin immunoreactivity suggest mossy fiber reorganization in human hippocampal epilepsy. J Neurosci 10 (1): 267-82.

Hu, G. (1993). DNA polymerase-catalyzed addition of nontemplated extra nucleotides to the 3' end of a DNA fragment. DNA Cell Biol 12 (8): 763-70.

Huang, Y. Y., X. C. Li und E. R. Kandel (1994). cAMP contributes to mossy fiber LTP by initiating both a covalently mediated early phase and macromolecular synthesisdependent late phase. Cell 79 (1): 69-79.

Ijiri, K. (1989). Cell death (apoptosis) in mouse intestine after continuous irradiation with gamma rays and with beta rays from tritiated water. Radiat Res 118 (1): 180-91.

Ip, N. Y., Y. Li, G. D. Yancopoulos und R. M. Lindsay (1993). Cultured hippocampal neurons show responses to BDNF, NT-3, and NT-4, but not NGF. J Neurosci 13 (8): 3394-405.

Irvine, R. F. und N. Divecha (1992). Phospholipids in the nucleus--metabolism and possible functions. Semin Cell Biol 3 (4): 225-35.

Isakov, N., M. I. Mally und A. Altman (1992). Mitogen-induced human T cell proliferation is associated with increased expression of selected PKC genes. Mol Immunol 29 (7-8): 927-33.

Itakura, K., J. J. Rossi und R. B. Wallace (1984). Synthesis and use of synthetic oligonucleotides. Annu Rev Biochem 53 : 323-56.

Jacobowitz, D. M. und L. Winsky (1991). Immunocytochemical localization of calretinin in the forebrain of the rat. J Comp Neurol 304 (2): 198-218.

Jaenisch, R. (1976). Germ line integration and Mendelian transmission of the exogenous Moloney leukemia virus. Proc Natl Acad Sci U S A 73 (4): 1260-4.

Jain, R., R. H. Gomer und J. J. Murtagh, Jr. (1992). Increasing specificity from the PCR-RACE technique. Biotechniques 12 (1): 58-9.

Jenco, J. M., K. P. Becker und A. J. Morris (1997). Membrane-binding properties of phospholipase C-beta1 and phospholipaseC- beta2: role of the C-terminus and effects of polyphosphoinositides, G- proteins and Ca2+. Biochem J 327 (Pt 2): 431-7.

Jhon, D. Y., H. H. Lee, D. Park, C. W. Lee, K. H. Lee, O. J. Yoo und S. G. Rhee (1993). Cloning, sequencing, purification, and Gq-dependent activation of phospholipase C-beta 3. J Biol Chem 268 (9): 6654-61. 
Johnson, G. D. und G. M. Nogueira Araujo (1981). A simple method of reducing the fading of immunofluorescence during microscopy. J Immunol Methods 43 (3): 349-50.

Johnson, M. P., M. Chamberlain und G. M. Kelly (1999). Phosphoinositide hydrolysis in vivo with group I metabotropic glutamate receptor agonists. Brain Res 821 (2): 53945 .

Jones, J. I. und D. R. Clemmons (1995). Insulin-like growth factors and their binding proteins: biological actions. Endocr Rev 16 (1): 3-34.

Katan, M. und P. J. Parker (1987). Purification of phosphoinositide-specific phospholipase C from a particulate fraction of bovine brain. Eur J Biochem 168 (2): 413-8.

Kim, C. G., D. Park und S. G. Rhee (1996). The role of carboxyl-terminal basic amino acids in Gqalpha-dependent activation, particulate association, and nuclear localization of phospholipase C-beta1. J Biol Chem 271 (35): 21187-92.

Kim, D., K. S. Jun, S. B. Lee, N. G. Kang, D. S. Min, Y. H. Kim, S. H. Ryu, P. G. Suh und H. S. Shin (1997). Phospholipase C isozymes selectively couple to specific neurotransmitter receptors. Nature 389 (6648): 290-3.

Klein, R. L., R. K. McNamara, M. A. King, R. H. Lenox, N. Muzyczka und E. M. Meyer (1999). Generation of aberrant sprouting in the adult rat brain by GAP-43 somatic gene transfer. Brain Res 832 (1-2): 136-44.

Kolasa, K., L. E. Harrell und D. S. Parsons (1995). The effect of hippocampal sympathetic ingrowth and cholinergic denervation on hippocampal M2 cholinergic receptors. Brain Res 684 (2): 201-5.

Kolasa, K., D. S. Parsons und L. E. Harrell (2000). Effect of phospholipase C and protein kinase $\mathrm{C}$ following cholinergic denervation and hippocampal sympathetic ingrowth in rat hippocampus. Neuroscience 99 (1): 25-31.

Koyanagi, M., K. Ono, H. Suga, N. Iwabe und T. Miyata (1998). Phospholipase C cDNAs from sponge and hydra: antiquity of genes involved in the inositol phospholipid signaling pathway. FEBS Lett 439 (1-2): 66-70.

Kristjansson, G. I., H. Zwiers, A. B. Oestreicher und W. H. Gispen (1982). Evidence that the synaptic phosphoprotein B-50 is localized exclusively in nerve tissue. $J$ Neurochem 39 (2): 371-8.

Kuang, Y., Y. Wu, A. Smrcka, H. Jiang und D. Wu (1996). Identification of a phospholipase C beta2 region that interacts with Gbeta-gamma. Proc Natl Acad Sci US A 93 (7): 2964-8. 
Kudo, Y., T. Nakamura und E. Ito (1991). A 'macro' image analysis of fura-2 fluorescence to visualize the distribution of functional glutamate receptor subtypes in hippocampal slices. Neurosci Res 12 (3): 412-20.

Kuppe, A., L. M. Evans, D. A. McMillen und O. H. Griffith (1989). Phosphatidylinositol-specific phospholipase $\mathrm{C}$ of Bacillus cereus: cloning, sequencing, and relationship to other phospholipases. J Bacteriol 171 (11): 6077-83.

Lackner, M. R., S. J. Nurrish und J. M. Kaplan (1999). Facilitation of synaptic transmission by EGL-30 Gqalpha and EGL-8 PLCbeta: DAG binding to UNC-13 is required to stimulate acetylcholine release. Neuron 24 (2): 335-46.

Laemmli, U. K. (1970). Cleavage of structural proteins during the assembly of the head of bacteriophage T4. Nature 227 (259): 680-5.

Laird, P. W., A. Zijderveld, K. Linders, M. A. Rudnicki, R. Jaenisch und A. Berns (1991). Simplified mammalian DNA isolation procedure. Nucleic Acids Res 19 (15): 4293.

Laurberg, S. und J. Zimmer (1981). Lesion-induced sprouting of hippocampal mossy fiber collaterals to the fascia dentata in developing and adult rats. $J$ Comp Neurol 200 (3): 433-59.

Lee, C. H., I. C. Shin, J. S. Kang, H. C. Koh, J. H. Ha und C. K. Min (1998). Differential coupling of $\mathrm{G}$ alpha $\mathrm{q}$ family of G-protein to muscarinic M1 receptor and neurokinin-2 receptor. Arch Pharm Res 21 (4): 423-8.

Lee, C. W., D. J. Park, K. H. Lee, C. G. Kim und S. G. Rhee (1993). Purification, molecular cloning, and sequencing of phospholipase C-beta 4. J Biol Chem 268 (28): 21318-27.

Lee, K. Y., S. H. Ryu, P. G. Suh, W. C. Choi und S. G. Rhee (1987). Phospholipase C associated with particulate fractions of bovine brain. Proc Natl Acad Sci U S A 84 (16): 5540-4.

Lee, S. B., S. H. Shin, J. R. Hepler, A. G. Gilman und S. G. Rhee (1993). Activation of phospholipase C-beta 2 mutants by $\mathrm{G}$ protein alpha $\mathrm{q}$ and beta gamma subunits. $J$ Biol Chem 268 (34): 25952-7.

Lemmon, M. A., K. M. Ferguson, R. O'Brien, P. B. Sigler und J. Schlessinger (1995). Specific and high-affinity binding of inositol phosphates to an isolated pleckstrin homology domain. Proc Natl Acad Sci U S A 92 (23): 10472-6. 
Lerea, L. S., L. S. Butler und J. O. McNamara (1992). NMDA and non-NMDA receptor-mediated increase of c-fos mRNA in dentate gyrus neurons involves calcium influx via different routes. J Neurosci 12 (8): 2973-81.

Lerea, L. S. und J. O. McNamara (1993). Ionotropic glutamate receptor subtypes activate $\mathrm{c}$-fos transcription by distinct calcium-requiring intracellular signaling pathways. Neuron 10 (1): 31-41.

Lesche, R., A. Peetz, F. van der Hoeven und U. Ruther (1997). Ft1, a novel gene related to ubiquitin-conjugating enzymes, is deleted in the Fused toes mouse mutation. Mamm Genome 8 (12): 879-83.

Letts, V. A., R. Felix, G. H. Biddlecome, J. Arikkath, C. L. Mahaffey, A. Valenzuela, F. S. Bartlett, 2nd, Y. Mori, K. P. Campbell und W. N. Frankel (1998). The mouse stargazer gene encodes a neuronal Ca2+-channel gamma subunit. Nat Genet 19 (4): 340-7.

Lichter, P., T. Cremer, J. Borden, L. Manuelidis und D. C. Ward (1988). Delineation of individual human chromosomes in metaphase and interphase cells by in situ suppression hybridization using recombinant DNA libraries. Hum Genet 80 (3): 224-34.

Lin, M. S., D. E. Comings und O. S. Alfi (1977). Optical Studies of the interaction of 4'6'-diamidino-2-phenylindole with DNA and metaphase chromosomes. Chromosoma 60 (1): $15-25$.

Linke, R., H. Schwegler und M. Boldyreva (1994). Cholinergic and GABAergic septohippocampal projection neurons in mice: a retrograde tracing study combined with double immunocytochemistry for choline acetyltransferase and parvalbumin. Brain Res 653 (1-2): 73-80.

Liu, Y., N. Fujise und T. Kosaka (1996). Distribution of calretinin immunoreactivity in the mouse dentate gyrus. I. General description. Exp Brain Res 108 (3): 389-403.

Loh, E. Y., J. F. Elliott, S. Cwirla, L. L. Lanier und M. M. Davis (1989). Polymerase chain reaction with single-sided specificity: analysis of $\mathrm{T}$ cell receptor delta chain. Science 243 (4888): 217-20.

Lonart, G. und T. C. Sudhof (1998). Region-specific phosphorylation of rabphilin in mossy fiber nerve terminals of the hippocampus. J Neurosci 18 (2): 634-40.

Longo, B. M. und L. E. Mello (1997). Blockade of pilocarpine- or kainate-induced mossy fiber sprouting by cycloheximide does not prevent subsequent epileptogenesis in rats. Neurosci Lett 226 (3): 163-6. 
Lorente de Nó, R. (1934). Studies on the structure of the cerebral cortex. II. Continuation of the study of the ammonic system. J Psychol Neurol 46 : 113-177.

Luckow, B. und G. Schütz (1987). CAT constructions with multiple unique restriction sites for the functional analysis of eukaryotic promoters and regulatory elements. Nucleic Acids Res 15 (13): 5490.

Magnus-Ellenbroek, B. und U. Havemann-Reinecke (1993). Morphine-induced hyperactivity in rats-a rebound effect? Naunyn Schmiedebergs Arch Pharmacol 347 (6): 635 42 .

Magram, J. und J. M. Bishop (1991). Dominant male sterility in mice caused by insertion of a transgene. Proc Natl Acad Sci U S A 88 (22): 10327-31.

Malva, J. O., A. P. Carvalho und C. M. Carvalho (1994). Modulation of dopamine and noradrenaline release and of intracellular $\mathrm{Ca} 2+$ concentration by presynaptic glutamate receptors in hippocampus. Br J Pharmacol 113 (4): 1439-47.

Manzoli, L., A. M. Billi, S. Rubbini, A. Bavelloni, I. Faenza, R. S. Gilmour, S. G. Rhee und L. Cocco (1997). Essential role for nuclear phospholipase C betal in insulin-like growth factor I-induced mitogenesis. Cancer Res 57 (11): 2137-9.

Marchi, M. und M. Raiteri (1989). Interaction acetylcholine-glutamate in rat hippocampus: involvement of two subtypes of M-2 muscarinic receptors. J Pharmacol Exp Ther 248 (3): 1255-60.

Mark, W. H., K. Signorelli, M. Blum, L. Kwee und E. Lacy (1992). Genomic structure of the locus associated with an insertional mutation in line 4 transgenic mice. Genomics 13 (1): 159-66.

Marmiroli, S., A. Ognibene, A. Bavelloni, C. Cinti, L. Cocco und N. M. Maraldi (1994). Interleukin 1 alpha stimulates nuclear phospholipase $\mathrm{C}$ in human osteosarcoma SaOS-2 cells. J Biol Chem 269 (1): 13-6.

Martelli, A. M., A. M. Billi, L. Manzoli, I. Faenza, M. Aluigi, M. Falconi, A. De Pol, R. S. Gilmour und L. Cocco (2000). Insulin selectively stimulates nuclear phosphoinositide-specific phospholipase C (PI-PLC) betal activity through a mitogen-activated protein (MAP) kinase-dependent serine phosphorylation. FEBS Lett 486 (3): 230-6.

Martelli, A. M., R. S. Gilmour, V. Bertagnolo, L. M. Neri, L. Manzoli und L. Cocco (1992). Nuclear localization and signalling activity of phosphoinositidase C beta in Swiss 3 T3 cells. Nature 358 (6383): 242-5. 
Martelli, A. M., S. Lach, V. Grill, R. S. Gilmour, L. Cocco, P. Narducci und R. Bareggi (1996). Expression and immunohistochemical localization of eight phospholipase $\mathrm{C}$ isoforms in adult male mouse cerebellar cortex. Acta Histochem 98 (2): 131-41.

Marty, S. und B. Onteniente (1997). The expression pattern of somatostatin and calretinin by postnatal hippocampal interneurons is regulated by activity-dependent and - independent determinants. Neuroscience 80 (1): 79-88.

Mazzoni, M., V. Bertagnolo, L. M. Neri, C. Carini, M. Marchisio, D. Milani, F. A. Manzoli und S. Capitani (1992). Discrete subcellular localization of phosphoinositidase C beta, gamma and delta in PC12 rat pheochromocytoma cells. Biochem Biophys Res Commun 187 (1): 114-20.

McHugh, T. J., K. I. Blum, J. Z. Tsien, S. Tonegawa und M. A. Wilson (1996). Impaired hippocampal representation of space in CA1-specific NMDAR1 knockout mice. Cell 87 (7): 1339-49.

McNamara, R. K., Y. Jiang, W. J. Streit und R. H. Lenox (2000). Facial motor neuron regeneration induces a unique spatial and temporal pattern of myristoylated alanine-rich C kinase substrate expression. Neuroscience 97 (3): 581-9.

McNamara, R. K. und R. H. Lenox (1997). Comparative distribution of myristoylated alanine-rich $\mathrm{C}$ kinase substrate (MARCKS) and F1/GAP-43 gene expression in the adult rat brain. $J$ Comp Neurol 379 (1): 48-71.

McNamara, R. K. und R. H. Lenox (1998b). Distribution of the protein kinase C substrates MARCKS and MRP in the postnatal developing rat brain. J Comp Neurol 397 (3): 337-56.

McNamara, R. K., D. J. Stumpo, L. M. Morel, M. H. Lewis, E. K. Wakeland, P. J. Blackshear und R. H. Lenox (1998a). Effect of reduced myristoylated alanine-rich C kinase substrate expression on hippocampal mossy fiber development and spatial learning in mutant mice: transgenic rescue and interactions with gene background. Proc Natl Acad Sci U S A 95 (24): 14517-22.

Meberg, P. J., C. M. Gall und A. Routtenberg (1993). Induction of F1/GAP-43 gene expression in hippocampal granule cells after seizures [corrected] [published erratum appears in Brain Res Mol Brain Res 1993 Jul;19(1-2):179]. Brain Res Mol Brain Res 17 (3-4): 295-9.

Meisler, M. H. (1992). Insertional mutation of 'classical' and novel genes in transgenic mice. Trends Genet 8 (10): 341-4. 
Mello, L. E., E. A. Cavalheiro, A. M. Tan, W. R. Kupfer, J. K. Pretorius, T. L. Babb und D. M. Finch (1993). Circuit mechanisms of seizures in the pilocarpine model of chronic epilepsy: cell loss and mossy fiber sprouting. Epilepsia 34 (6): 985-95.

Mellor, H. und P. J. Parker (1998). The extended protein kinase C superfamily. Biochem $J 332$ (Pt 2): 281-92.

Merlino, G. T., C. Stahle, C. Jhappan, R. Linton, K. A. Mahon und M. C. Willingham (1991). Inactivation of a sperm motility gene by insertion of an epidermal growth factor receptor transgene whose product is overexpressed and compartmentalized during spermatogenesis. Genes Dev 5 (8): 1395-406.

Michell, R. H. (1975). Inositol phospholipids and cell surface receptor function. Biochim Biophys Acta 415 (1): 81-47.

Mitchell, J., M. Gatherer, N. Best, L. Sundstrom und H. V. Wheal (1996). Hippocampal NPY neurons project to the fascia dentata in organotypic cultures. Hippocampus 6 (2): 173-82.

Mjaatvedt, C. H., H. Yamamura, A. A. Capehart, D. Turner und R. R. Markwald (1998). The Cspg2 gene, disrupted in the hdf mutant, is required for right cardiac chamber and endocardial cushion formation. Dev Biol 202 (1): 56-66.

Mohapel, P., L. L. Armitage, D. K. Hannesson und M. E. Corcoran (1997). The effects of fimbria/fornix transections on perforant path kindling and mossy fiber sprouting. Brain Res 778 (1): 186-93.

Montagutelli, X. (2000). Effect of the genetic background on the phenotype of mouse mutations. J Am Soc Nephrol 11 Suppl 16 : S101-5.

Montminy, M. R., K. A. Sevarino, J. A. Wagner, G. Mandel und R. H. Goodman (1986). Identification of a cyclic-AMP-responsive element within the rat somatostatin gene. Proc Natl Acad Sci U S A 83 (18): 6682-6.

Morris, R. (1984). Developments of a water-maze procedure for studying spatial learning in the rat. J Neurosci Methods 11 (1): 47-60.

Murphy, T. H., P. F. Worley und J. M. Baraban (1991). L-type voltage-sensitive calcium channels mediate synaptic activation of immediate early genes. Neuron 7 (4): 625-35.

Nadler, J. V. (1981). Minireview. Kainic acid as a tool for the study of temporal lobe epilepsy. Life Sci 29 (20): 2031-42. 
Nadler, J. V., B. W. Perry und C. W. Cotman (1980b). Selective reinnervation of hippocampal area CA1 and the fascia dentata after destruction of CA3-CA4 afferents with kainic acid. Brain Res 182 (1): 1-9.

Nadler, J. V., B. W. Perry, C. Gentry und C. W. Cotman (1980a). Degeneration of hippocampal CA3 pyramidal cells induced by intraventricular kainic acid. J Comp Neurol 192 (2): 333-59.

Naik, M. U., E. Benedikz, I. Hernandez, J. Libien, J. Hrabe, M. Valsamis, D. DowEdwards, M. Osman und T. C. Sacktor (2000). Distribution of protein kinase Mzeta and the complete protein kinase C isoform family in rat brain. J Comp Neurol 426 (2): 243 58.

Nalefski, E. A. und J. J. Falke (1996). The C2 domain calcium-binding motif: structural and functional diversity. Protein Sci 5 (12): 2375-90.

Nayernia, K. (1993). Untersuchungen zur Transkriptions- und Translationskontrolle des Keimzell-spezifischen Gens für Proakrosin mit Hilfe transgener Mäuse. Dissertation, Universität Göttingen: 172 Seiten.

Nayernia, K., S. Nieter, H. Kremling, H. Oberwinkler und W. Engel (1994). Functional and molecular characterization of the transcriptional regulatory region of the proacrosin gene. J Biol Chem 269 (51): 32181-6.

Neri, L. M., P. Borgatti, S. Capitani und A. M. Martelli (1998). Nuclear diacylglycerol produced by phosphoinositide-specific phospholipase $\mathrm{C}$ is responsible for nuclear translocation of protein kinase C-alpha. J Biol Chem 273 (45): 29738-44.

Nishizuka, Y. (1988). The molecular heterogeneity of protein kinase C and its implications for cellular regulation. Nature 334 (6184): 661-5.

Norrander, J., T. Kempe und J. Messing (1983). Construction of improved M13 vectors using oligodeoxynucleotide- directed mutagenesis. Gene 26 (1): 101-6.

Ohara, O., R. L. Dorit und W. Gilbert (1989). One-sided polymerase chain reaction: the amplification of cDNA. Proc Natl Acad Sci U S A 86 (15): 5673-7.

Okayama, H. und P. Berg (1982). High-efficiency cloning of full-length cDNA. Mol Cell Biol 2 (2): 161-70.

Okazaki, M. M., D. A. Evenson und J. V. Nadler (1995). Hippocampal mossy fiber sprouting and synapse formation after status epilepticus in rats: visualization after retrograde transport of biocytin. J Comp Neurol 352 (4): 515-34. 
O'Keefe, J. und J. Dostrovsky (1971). The hippocampus as a spatial map. Preliminary evidence from unit activity in the freely-moving rat. Brain Res 34 (1): 171-5.

Parrow, V., S. Fagerstrom, G. Meyerson, E. Nanberg und S. Pahlman (1995). Protein kinase C-alpha and -epsilon are enriched in growth cones of differentiating SH-SY5Y human neuroblastoma cells. J Neurosci Res 41 (6): 782-91.

Patel, M. N. und J. O. McNamara (1995). Selective enhancement of axonal branching of cultured dentate gyrus neurons by neurotrophic factors. Neuroscience 69 (3): 763-70.

Peroutka, S. J. (1994). 5-Hydroxytryptamine receptors in vertebrates and invertebrates: why are there so many? Neurochem Int 25 (6): 533-6.

Peruzzi, D., G. Calabrese, I. Faenza, L. Manzoli, A. Matteucci, F. Gianfrancesco, A. M. Billi, L. Stuppia, G. Palka und L. Cocco (2000). Identification and chromosomal localisation by fluorescence in situ hybridisation of human gene of phosphoinositidespecific phospholipase C beta(1). Biochim Biophys Acta 1484 (2-3): 175-82.

Pinkel, D., J. Landegent, C. Collins, J. Fuscoe, R. Segraves, J. Lucas und J. Gray (1988). Fluorescence in situ hybridization with human chromosome-specific libraries: detection of trisomy 21 and translocations of chromosome 4. Proc Natl Acad Sci U S A 85 (23): 9138-42.

Pitler, T. A. und B. E. Alger (1992). Cholinergic excitation of GABAergic interneurons in the rat hippocampal slice. J Physiol 450 : 127-42.

Poirier, J. L., R. Capek und Y. De Koninck (2000). Differential progression of Dark Neuron and Fluoro-Jade labelling in the rat hippocampus following pilocarpine-induced status epilepticus. Neuroscience 97 (1): 59-68.

Ponting, C. P. und P. J. Parker (1996). Extending the C2 domain family: C2s in PKCs delta, epsilon, eta, theta, phospholipases, GAPs, and perforin. Protein Sci 5 (1): 162-6.

Qiao, X. und J. L. Noebels (1993). Developmental analysis of hippocampal mossy fiber outgrowth in a mutant mouse with inherited spike-wave seizures. $J$ Neurosci 13 (11): 4622-35.

Quintiliani, L., P. Iudicone, M. Guglielmetti und A. Buzzonetti (1984). Immunoenzymatic determination of immunoglobulins secreted by human peripheral blood lymphocytes in pokeweed mitogen and lipo- polysaccharide stimulated cultures. Boll Ist Sieroter Milan 63 (3): 188-95.

Rapp, G., J. Klaudiny, G. Hagendorff, M. R. Luck und K. H. Scheit (1989). Complete sequence of the coding region of human elongation factor 2 (EF- 2) by enzymatic 
amplification of cDNA from human ovarian granulosa cells. Biol Chem Hoppe Seyler 370 (10): 1071-5.

Rebecchi, M. J. und S. N. Pentyala (2000). Structure, function, and control of phosphoinositide-specific phospholipase C. Physiol Rev 80 (4): 1291-335.

Represa, A., I. Jorquera, G. Le Gal La Salle und Y. Ben-Ari (1993). Epilepsy induced collateral sprouting of hippocampal mossy fibers: does it induce the development of ectopic synapses with granule cell dendrites? Hippocampus 3 (3): 257-68.

Rhee, S. G. und K. D. Choi (1992). Multiple forms of phospholipase C isozymes and their activation mechanisms. Adv Second Messenger Phosphoprotein Res 26 : 35-61.

Rhee, S. G., P. G. Suh, S. H. Ryu und S. Y. Lee (1989). Studies of inositol phospholipid-specific phospholipase C. Science 244 (4904): 546-50.

Rigby, P. W., M. Dieckmann, C. Rhodes und P. Berg (1977). Labeling deoxyribonucleic acid to high specific activity in vitro by nick translation with DNA polymerase I. J Mol Biol 113 (1): 237-51.

Rijkers, T., A. Peetz und U. Ruther (1994). Insertional mutagenesis in transgenic mice. Transgenic Res 3 (4): 203-15.

Robinson, P. J. (1991). The role of protein kinase C and its neuronal substrates dephosphin, B- 50, and MARCKS in neurotransmitter release. Mol Neurobiol 5 (2-4): 87-130.

Rolls, E. T. (1996). A theory of hippocampal function in memory. Hippocampus 6 (6): 601-20.

Ross, C. A., M. W. MacCumber, C. E. Glatt und S. H. Snyder (1989). Brain phospholipase $\mathrm{C}$ isozymes: differential mRNA localizations by in situ hybridization. Proc Natl Acad Sci U S A 86 (8): 2923-7.

Routbort, M. J., S. B. Bausch und J. O. McNamara (1999). Seizures, cell death, and mossy fiber sprouting in kainic acid-treated organotypic hippocampal cultures. Neuroscience 94 (3): 755-65.

Ryu, S. H., K. S. Cho, K. Y. Lee, P. G. Suh und S. G. Rhee (1986). Two forms of phosphatidylinositol-specific phospholipase $\mathrm{C}$ from bovine brain. Biochem Biophys Res Commun 141 (1): 137-44.

Ryu, S. H., K. S. Cho, K. Y. Lee, P. G. Suh und S. G. Rhee (1987b). Purification and characterization of two immunologically distinct phosphoinositide-specific phospholipases C from bovine brain. J Biol Chem 262 (26): 12511-8. 
Ryu, S. H., P. G. Suh, K. S. Cho, K. Y. Lee und S. G. Rhee (1987a). Bovine brain cytosol contains three immunologically distinct forms of inositolphospholipid-specific phospholipase C. Proc Natl Acad Sci U S A 84 (19): 6649-53.

Saiki, R. K., D. H. Gelfand, S. Stoffel, S. J. Scharf, R. Higuchi, G. T. Horn, K. B. Mullis und H. A. Erlich (1988). Primer-directed enzymatic amplification of DNA with a thermostable DNA polymerase. Science 239 (4839): 487-91.

Sambrook, J., E. F. Fritsch und T. Maniatis (1989). Molecular cloning: A Laboratory manual. New York, Cold Spring Harbor.

Sanger, F., S. Nicklen und A. R. Coulson (1977). DNA sequencing with chainterminating inhibitors. Proc Natl Acad Sci U S A 74 (12): 5463-7.

Schmued, L. C. und K. J. Hopkins (2000). Fluoro-Jade: novel fluorochromes for detecting toxicant-induced neuronal degeneration. Toxicol Pathol 28 (1): 91-9.

Schwegler, H. und W. E. Crusio (1995). Correlations between radial-maze learning and structural variations of septum and hippocampus in rodents. Behav Brain Res 67 (1): $29-41$.

Schwegler, H., W. E. Crusio und I. Brust (1990). Hippocampal mossy fibers and radialmaze learning in the mouse: a correlation with spatial working memory but not with non-spatial reference memory. Neuroscience 34 (2): 293-8.

Scoville, W. B. und B. Milner (2000). Loss of recent memory after bilateral hippocampal lesions. 1957. J Neuropsychiatry Clin Neurosci 12 (1): 103-13.

Seipp, S. und W. Buselmaier (1994). Isolation of glyceraldehyde 3-phosphate dehydrogenase (Gapdh) cDNA from the distal half of mouse chromosome 16: further indication of a link between Alzheimer's disease and glycolysis. Neurosci Lett 182 (1): 91-4.

Senger, G., T. A. Jones, H. Fidlerova, P. Sanseau, J. Trowsdale, M. Duff und D. Sheer (1994). Released chromatin: linearized DNA for high resolution fluorescence in situ hybridization. Hum Mol Genet 3 (8): 1275-80.

Shortridge, R. D., J. Yoon, C. R. Lending, B. T. Bloomquist, M. H. Perdew und W. L. Pak (1991). A Drosophila phospholipase C gene that is expressed in the central nervous system. J Biol Chem 266 (19): 12474-80.

Siebert, P. D., A. Chenchik, D. E. Kellogg, K. A. Lukyanov und S. A. Lukyanov (1995). An improved PCR method for walking in uncloned genomic DNA. Nucleic Acids Res 23 (6): 1087-8. 
Silva, J. G. und L. E. Mello (2000). The role of mossy cell death and activation of protein synthesis in the sprouting of dentate mossy fibers: evidence from calretinin and neo- timm staining in pilocarpine-epileptic mice. Epilepsia 41 (Suppl 6): S18-23.

Simonato, M., D. A. Hosford, D. M. Labiner, C. Shin, H. H. Mansbach und J. O. McNamara (1991). Differential expression of immediate early genes in the hippocampus in the kindling model of epilepsy. Brain Res Mol Brain Res 11 (2): 115-24.

Singh, G., D. M. Supp, C. Schreiner, J. McNeish, H. J. Merker, N. G. Copeland, N. A. Jenkins, S. S. Potter und W. Scott (1991). legless insertional mutation: morphological, molecular, and genetic characterization. Genes Dev 5 (12A): 2245-55.

Sloviter, R. S. (1983). "Epileptic" brain damage in rats induced by sustained electrical stimulation of the perforant path. I. Acute electrophysiological and light microscopic studies. Brain Res Bull 10 (5): 675-97.

Sloviter, R. S. (1987). Decreased hippocampal inhibition and a selective loss of interneurons in experimental epilepsy. Science 235 (4784): 73-6.

Sloviter, R. S. (1996). Hippocampal pathology and pathophysiology in temporal lobe epilepsy. Neurologia 11 Suppl $4: 29-32$.

Sloviter, R. S. und D. W. Dempster (1985). "Epileptic" brain damage is replicated qualitatively in the rat hippocampus by central injection of glutamate or aspartate but not by GABA or acetylcholine. Brain Res Bull 15 (1): 39-60.

Southern, E. M. (1975). Detection of specific sequences among DNA fragments separated by gel electrophoresis. J Mol Biol 98 (3): 503-17.

Spencer, D. D. und S. S. Spencer (1994). Hippocampal resections and the use of human tissue in defining temporal lobe epilepsy syndromes. Hippocampus 4 (3): 243-9.

Squire, L. R. (1987). The organization and neural substrates of human memory. Int $J$ Neurol 22 : 218-22.

Squire, L. R. und S. Zola-Morgan (1991). The medial temporal lobe memory system. Science 253 (5026): 1380-6.

Stahl, M. L., C. R. Ferenz, K. L. Kelleher, R. W. Kriz und J. L. Knopf (1988). Sequence similarity of phospholipase $\mathrm{C}$ with the non-catalytic region of src. Nature 332 (6161): 269-72.

Steckler, T., W. H. Drinkenburg, A. Sahgal und J. P. Aggleton (1998). Recognition memory in rats--II. Neuroanatomical substrates. Prog Neurobiol 54 (3): 313-32. 
Strittmatter, S. M., C. Fankhauser, P. L. Huang, H. Mashimo und M. C. Fishman (1995). Neuronal pathfinding is abnormal in mice lacking the neuronal growth cone protein GAP-43. Cell 80 (3): 445-52.

Suh, P. G., S. H. Ryu, W. C. Choi, K. Y. Lee und S. G. Rhee (1988c). Monoclonal antibodies to three phospholipase C isozymes from bovine brain. J Biol Chem 263 (28): 14497-504.

Suh, P. G., S. H. Ryu, K. H. Moon, H. W. Suh und S. G. Rhee (1988a). Inositol phospholipid-specific phospholipase $\mathrm{C}$ : complete cDNA and protein sequences and sequence homology to tyrosine kinase-related oncogene products. Proc Natl Acad Sci U $S A 85$ (15): 5419-23.

Suh, P. G., S. H. Ryu, K. H. Moon, H. W. Suh und S. G. Rhee (1988b). Cloning and sequence of multiple forms of phospholipase C. Cell 54 (2): 161-9.

Sunayashiki-Kusuzaki, K., D. S. Lester, B. G. Schreurs und D. L. Alkon (1993). Associative learning potentiates protein kinase $\mathrm{C}$ activation in synaptosomes of the rabbit hippocampus. Proc Natl Acad Sci U S A 90 (9): 4286-9.

Sutula, T., G. Cascino, J. Cavazos, I. Parada und L. Ramirez (1989). Mossy fiber synaptic reorganization in the epileptic human temporal lobe. Ann Neurol 26 (3): 321-30.

Sutula, T., X. X. He, J. Cavazos und G. Scott (1988). Synaptic reorganization in the hippocampus induced by abnormal functional activity. Science 239 (4844): 1147-50.

Swanson, L. W., P. E. Sawchenko und W. M. Cowan (1981). Evidence for collateral projections by neurons in Ammon's horn, the dentate gyrus, and the subiculum: a multiple retrograde labeling study in the rat. J Neurosci 1 (5): 548-59.

Taguchi, T., J. Y. Zhou, M. Feder, S. Litwin, A. J. Klein-Szanto und J. R. Testa (1996). Detection of aneuploidy in interphase nuclei from non-small cell lung carcinomas by fluorescence in situ hybridization using chromosome- specific repetitive DNA probes. Cancer Genet Cytogenet 89 (2): 120-5.

Takahashi, J. S., L. H. Pinto und M. H. Vitaterna (1994). Forward and reverse genetic approaches to behavior in the mouse. Science 264 (5166): 1724-33.

Taketo, M., A. C. Schroeder, L. E. Mobraaten, K. B. Gunning, G. Hanten, R. R. Fox, T. H. Roderick, C. L. Stewart, F. Lilly und C. T. Hansen (1991). FVB/N: an inbred mouse strain preferable for transgenic analyses. Proc Natl Acad Sci U S A 88 (6): 2065-9. 
Tanabe, H., Y. Nakagawa, D. Minegishi, K. Hashimoto, N. Tanaka, M. Oshimura, T. Sofuni und H. Mizusawa (2000). Human monochromosome hybrid cell panel characterized by FISH in the JCRB/HSRRB [In Process Citation]. Chromosome Res 8 (4): 319-34.

Tanaka, O. und H. Kondo (1994). Localization of mRNAs for three novel members (beta 3, beta 4 and gamma 2) of phospholipase $\mathrm{C}$ family in mature rat brain. Neurosci Lett 182 (1): 17-20.

Thein, S. L., J. R. Lynch, D. J. Weatherall und R. B. Wallace (1986). Direct detection of haemoglobin E with synthetic oligonucleotides [letter]. Lancet 1 (8472): 93.

Timm, F. (1958). Zur Histochemie der Schwermetalle, Das Sulfid-Silberverfahren. Dtsch. Z. ges. gerichtl. Med. 46 : 706-711.

Toker, A. (1998). Signaling through protein kinase C. Front Biosci 3 : D1134-47.

Tokui, T., M. Inagaki, K. Nishizawa, R. Yatani, M. Kusagawa, K. Ajiro, Y. Nishimoto, T. Date und A. Matsukage (1991). Inactivation of DNA polymerase beta by in vitro phosphorylation with protein kinase C. J Biol Chem 266 (17): 10820-4.

Towbin, H., T. Staehelin und J. Gordon (1979). Electrophoretic transfer of proteins from polyacrylamide gels to nitrocellulose sheets: procedure and some applications. Proc Natl Acad Sci U S A 76 (9): 4350-4.

Travis, G. H., M. B. Brennan, P. E. Danielson, C. A. Kozak und J. G. Sutcliffe (1989). Identification of a photoreceptor-specific mRNA encoded by the gene responsible for retinal degeneration slow (rds). Nature 338 (6210): 70-3.

Tsien, J. Z., D. F. Chen, D. Gerber, C. Tom, E. H. Mercer, D. J. Anderson, M. Mayford, E. R. Kandel und S. Tonegawa (1996a). Subregion- and cell type-restricted gene knockout in mouse brain. Cell 87 (7): 1317-26.

Tsien, J. Z., P. T. Huerta und S. Tonegawa (1996b). The essential role of hippocampal CA1 NMDA receptor-dependent synaptic plasticity in spatial memory. Cell 87 (7): 1327-38.

Uberall, F., S. Kampfer, W. Doppler und H. H. Grunicke (1994). Activation of c-fos expression by transforming Ha-ras in HC11 mouse mammary epithelial cells is PKCdependent and mediated by the serum response element. Cell Signal 6 (3): 285-97.

Uhrig, S., S. Schuffenhauer, C. Fauth, A. Wirtz, C. Daumer-Haas, C. Apacik, M. Cohen, J. Muller-Navia, T. Cremer, J. Murken und M. R. Speicher (1999). MultiplexFISH for pre- and postnatal diagnostic applications. Am J Hum Genet 65 (2): 448-62. 
Villalba, M. (1998). A possible role for PKC delta in cerebellar granule cells apoptosis. Neuroreport 9 (10): 2381-5.

Vogelstein, B. und D. Gillespie (1979). Preparative and analytical purification of DNA from agarose. Proc Natl Acad Sci U S A 76 (2): 615-9.

Wang, X., E. A. Bornslaeger, O. Haub, C. Tomihara-Newberger, N. Lonberg, M. B. Dinulos, C. M. Disteche, N. Copeland, D. J. Gilbert, N. A. Jenkins und E. Lacy (1996). A candidate gene for the amnionless gastrulation stage mouse mutation encodes a TRAF-related protein. Dev Biol 177 (1): 274-90.

Watanabe, M., M. Nakamura, K. Sato, M. Kano, M. I. Simon und Y. Inoue (1998). Patterns of expression for the mRNA corresponding to the four isoforms of phospholipase Cbeta in mouse brain. Eur J Neurosci 10 (6): 2016-25.

Watanabe, Y., R. S. Johnson, L. S. Butler, D. K. Binder, B. M. Spiegelman, V. E. Papaioannou und J. O. McNamara (1996). Null mutation of c-fos impairs structural and functional plasticities in the kindling model of epilepsy. J Neurosci 16 (12): 3827-36.

Watson, M. A. und J. Milbrandt (1989). The NGFI-B gene, a transcriptionally inducible member of the steroid receptor gene superfamily: genomic structure and expression in rat brain after seizure induction. Mol Cell Biol 9 (10): 4213-9.

Wells, D. und J. D. Delhanty (2000). Comprehensive chromosomal analysis of human preimplantation embryos using whole genome amplification and single cell comparative genomic hybridization. Mol Hum Reprod 6 (11): 1055-1062.

Wenzel, H. J., P. S. Buckmaster, N. L. Anderson, M. E. Wenzel und P. A. Schwartzkroin (1997). Ultrastructural localization of neurotransmitter immunoreactivity in mossy cell axons and their synaptic targets in the rat dentate gyrus. Hippocampus 7 (5): 559-70.

Wetsel, W. C., W. A. Khan, I. Merchenthaler, H. Rivera, A. E. Halpern, H. M. Phung, A. Negro-Vilar und Y. A. Hannun (1992). Tissue and cellular distribution of the extended family of protein kinase C isoenzymes. J Cell Biol 117 (1): 121-33.

Williams, R. L. (1999). Mammalian phosphoinositide-specific phospholipase C. Biochim Biophys Acta 1441 (2-3): 255-67.

Williams, R. L. und M. Katan (1996). Structural views of phosphoinositide-specific phospholipase C: signalling the way ahead. Structure 4 (12): 1387-94.

Wilson, M. A. und B. L. McNaughton (1993). Dynamics of the hippocampal ensemble code for space. Science 261 (5124): 1055-8. 
Woldbye, D. P., M. H. Greisen, T. G. Bolwig, P. J. Larsen und J. D. Mikkelsen (1996). Prolonged induction of c-fos in neuropeptide Y- and somatostatin- immunoreactive neurons of the rat dentate gyrus after electroconvulsive stimulation. Brain Res $\mathbf{7 2 0}$ (12): 111-9.

Woychik, R. P. und K. Alagramam (1998). Insertional mutagenesis in transgenic mice generated by the pronuclear microinjection procedure. Int J Dev Biol 42 (7): 1009-17.

Wu, D., H. Jiang, A. Katz und M. I. Simon (1993). Identification of critical regions on phospholipase C-beta 1 required for activation by G-proteins. J Biol Chem 268 (5): 3704-9.

Yasuda, I., A. Kishimoto, S. Tanaka, M. Tominaga, A. Sakurai und Y. Nishizuka (1990). A synthetic peptide substrate for selective assay of protein kinase C. Biochem Biophys Res Commun 166 (3): 1220-7.

York, J. D. und P. W. Majerus (1994). Nuclear phosphatidylinositols decrease during Sphase of the cell cycle in HeLa cells. J Biol Chem 269 (11): 7847-50.

Zimmermann, S., G. Steding, J. M. Emmen, A. O. Brinkmann, K. Nayernia, A. F. Holstein, W. Engel und I. M. Adham (1999). Targeted disruption of the Insl3 gene causes bilateral cryptorchidism. Mol Endocrinol 13 (5): 681-91.

Zola-Morgan, S., L. R. Squire und D. G. Amaral (1986). Human amnesia and the medial temporal region: enduring memory impairment following a bilateral lesion limited to field CA1 of the hippocampus. J Neurosci 6 (10): 2950-67.

Zola-Morgan, S., L. R. Squire und D. G. Amaral (1989). Lesions of the hippocampal formation but not lesions of the fornix or the mammillary nuclei produce long-lasting memory impairment in monkeys. J Neurosci 9 (3): 898-913.

Zörnig, M., C. Klett, H. Lovec, H. Hameister, H. Winking, S. Adolph und T. Moroy (1995). Establishment of permanent wild-mouse cell lines with readily identifiable marker chromosomes. Cytogenet Cell Genet 71 (1): 37-40. 


\section{Anhang}

\section{Danksagung}

Mein herzlicher Dank gilt Herrn Prof. Dr. Wolfgang Engel für die Überlassung des interessanten Themas und für seine stetige und konstruktive Diskussionsbereitschaft, die wesentlich zum Gelingen dieser Arbeit beigetragen hat. Ohne seine fachliche und finanzielle Unterstützung wäre eine integrative Darstellung von Phänotyp, Morphologie und Genotyp der TC-Maus nicht möglich gewesen.

Ebenfalls möchte ich Herrn Dr. Peter Burfeind danken, der durch seine umfangreiche und gewissenhafte Beratung bei der Planung und Auswertung der Experimente entscheidend mitgewirkt hat.

Herrn Prof. Dr. Ulrich Grossbach danke ich für die Übernahme des Korreferats.

Bei allen Mitarbeiterinnen und Mitarbeitern des Instituts für Humangenetik möchte ich mich für die freundliche und kooperative Atmosphäre bedanken.

Weiterhin bedanke ich mich bei Herrn Prof. Dr. Herbert Schwegler für die angenehme Zusammenarbeit und für die Beratung bezüglich neuroanatomischer Fragestellungen.

Den Tierpflegerinnen und Tierpflegern im institutseigenen Tierstall danke ich für die Verrichtung der Arbeiten, die notwendigerweise für eine so umfangreiche Zucht von „Springmäusen“ unerläßlich ist.

Ganz besonders bedanke ich mich bei meinen Eltern für deren moralische und fördernde Unterstützung während meiner gesamten Ausbildungszeit.

Besonderer Dank gilt Andrea Schneider, die mit Verständnis und Humor eine harmonische Atmosphäre erzeugt hat und den „Fellgesichtern“ Tassilo, Cameo und Kimba für unerwartete und belustigende Ablenkungen. 


\section{Lebenslauf}

Persönliche Daten:

Staatsangehörigkeit:

\section{Ausbildung:}

September 1971 - Juni 1976

August 1976 - Juni 1985

August 1985 - Januar 1988

Februar 1988 - September 1988

August 1989 - August 1991

August 1991 - August 1995

16. Oktober 1992

10. Februar 1993

März 1995 - Januar 1996

13. Juni 1996

ab August 1996
Detlef Böhm

geboren am 2. Mai 1965 in Heinebach

als Sohn von Manfred und Margarete Böhm, geb.

Bohnsack

deutsch

Besuch der Grund- und Mittelpunktschule in Adelebsen

Besuch des Otto-Hahn-Gymnasiums in Göttingen

Ausbildung zum Biologie-Laboranten am Institut für Humangenetik in Göttingen

Berufstätigkeit als Biologie-Laborant bei Dr. med. $\mathrm{K}$. Wiedekind in Göttingen

Beginn des Studiums der Chemie an der GeorgAugust Universität zu Göttingen

Studium der Biologie und Chemie für gymnasiales Lehramt an der Georg-August Universität zu Göttingen

Zwischenprüfung in Zoologie und Botanik

Zwischenprüfung in Physikalischer Chemie

Experimentelle Arbeiten zur Staatsexamensarbeit am Institut für Humangenetik in Göttingen unter der Leitung von Prof. Dr. W. Engel mit dem Thema: „Untersuchungen zur Regulation der Expression des keimzellspezifischen Gens für Transitionsprotein 2 beim Säuger“

Erste Staatsprüfung für das Lehramt an Gymnasien in den Fächern Botanik, Zoologie und Physikalische Chemie

Beginn der experimentellen Arbeiten zur vorliegenden Dissertation unter der Leitung von Prof. Dr. W. Engel als wissenschaftlicher Angestellter am Institut für Humangenetik in Göttingen 